\title{
IUCN
}

\section{Guidelines for privately protected areas}

Brent A. Mitchell, Sue Stolton, Juan Bezaury-Creel, Heather C. Bingham,

Tracey L. Cumming, Nigel Dudley, James A. Fitzsimons, Delphine Malleret-King,

Kent H. Redford and Pedro Solano

Craig Groves, Series Editor

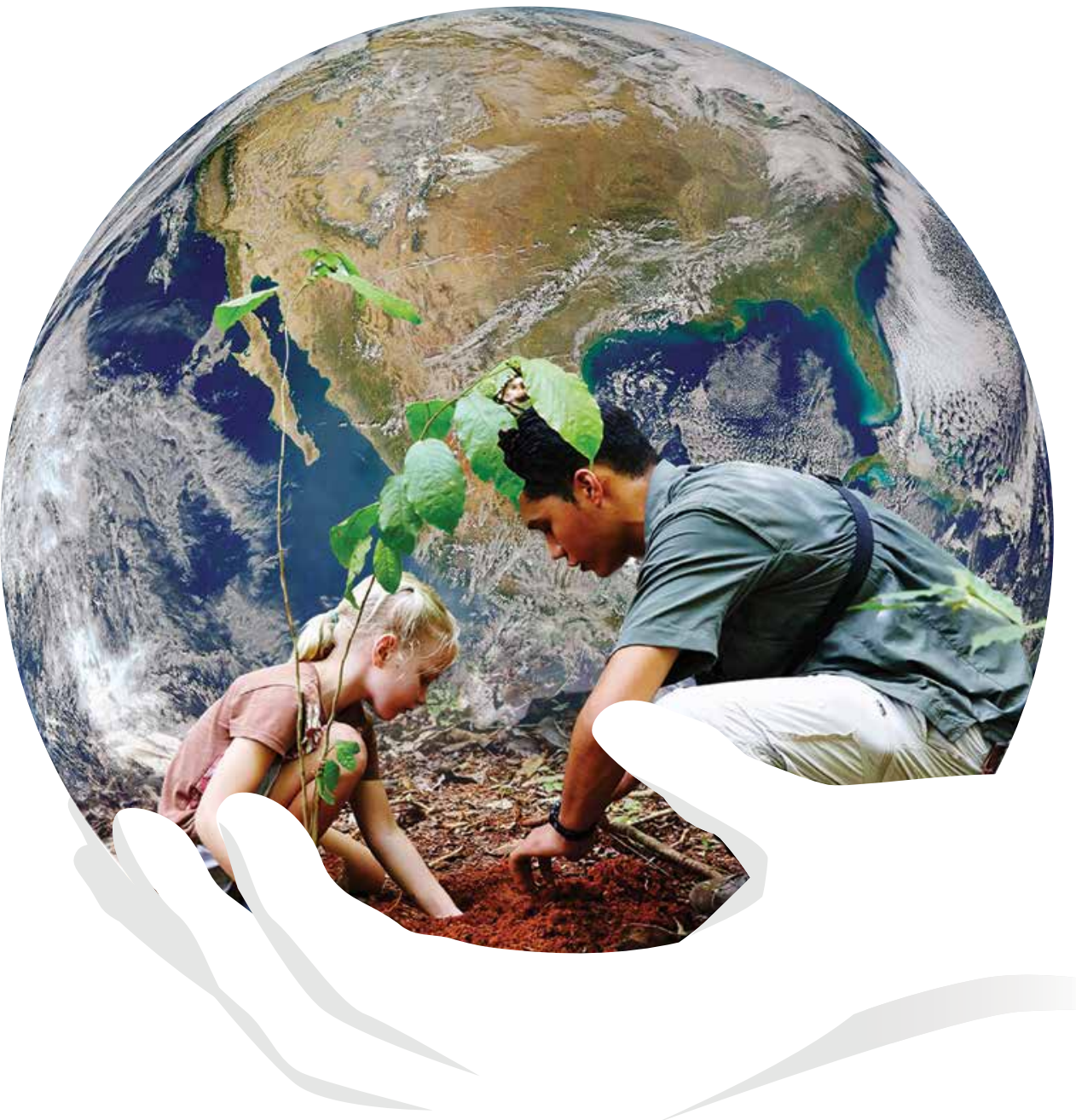

Best Practice Protected Area Guidelines Series No. 29

구을 


\section{IUCN WCPA'S BEST PRACTICE PROTECTED AREA GUIDELINES SERIES}

IUCN-WCPA's Best Practice Protected Area Guidelines are the world's authoritative resource for protected area managers. Involving collaboration among specialist practitioners dedicated to supporting better implementation of ideas in the field, the Guidelines distil learning and advice drawn from across IUCN. Applied in the field, they build institutional and individual capacity to manage protected area systems effectively, equitably and sustainably, and to cope with the myriad of challenges faced in practice. The Guidelines also assist national governments, protected area agencies, non-governmental organisations, communities and private sector partners in meeting their commitments and goals, and especially the Convention on Biological Diversity's Programme of Work on Protected Areas.

A full set of guidelines is available at: www.iucn.org/pa_guidelines

Complementary resources are available at: www.cbd.int/protected/tools/

Contribute to developing capacity for a Protected Planet at: www.protectedplanet.net/

\section{IUCN PROTECTED AREA DEFINITION, MANAGEMENT CATEGORIES AND GOVERNANCE TYPES}

IUCN defines a protected area as:

A clearly defined geographical space, recognised, dedicated and managed, through legal or other effective means, to achieve the long-term conservation of nature with associated ecosystem services and cultural values.

The definition is expanded by six management categories (one with a sub-division), summarized below.

la Strict nature reserve: Strictly protected for biodiversity and also possibly geological/ geomorphological features, where human visitation, use and impacts are controlled and limited to ensure protection of the conservation values.

Ib Wilderness area: Usually large unmodified or slightly modified areas, retaining their natural character and influence, without permanent or significant human habitation, protected and managed to preserve their natural condition.

II National park: Large natural or near-natural areas protecting large-scale ecological processes with characteristic species and ecosystems, which also have environmentally and culturally compatible spiritual, scientific, educational, recreational and visitor opportunities.

III Natural monument or feature: Areas set aside to protect a specific natural monument, which can be a landform, sea mount, marine cavern, geological feature such as a cave, or a living feature such as an ancient grove.

IV Habitat/species management area: Areas to protect particular species or habitats, where management reflects this priority. Many will need regular, active interventions to meet the needs of particular species or habitats, but this is not a requirement of the category.

V Protected landscape or seascape: Where the interaction of people and nature over time has produced a distinct character with significant ecological, biological, cultural and scenic value: and where safeguarding the integrity of this interaction is vital to protecting and sustaining the area and its associated nature conservation and other values.

VI Protected areas with sustainable use of natural resources: Areas which conserve ecosystems, together with associated cultural values and traditional natural resource management systems. Generally large, mainly in a natural condition, with a proportion under sustainable natural resource management and where low-level non-industrial natural resource use compatible with nature conservation is seen as one of the main aims.

The category should be based around the primary management objective(s), which should apply to at least three-quarters of the protected area - the 75 per cent rule.

The management categories are applied with a typology of governance types - a description of who holds authority and responsibility for the protected area. IUCN defines four governance types.

Type A. Governance by government: Federal or national ministry/agency in charge; sub-national ministry or agency in charge (e.g. at regional, provincial, municipal level); government-delegated management (e.g. to NGO).

Type B. Shared governance: Trans-boundary governance (formal and informal arrangements between two or more countries); collaborative governance (through various ways in which diverse actors and institutions work together); joint governance (pluralist board or other multi-party governing body).

Type C. Private governance: Conserved areas established and run by individual landowners; non-profit organisations (e.g. NGOs, universities) and for-profit organisations (e.g. corporate landowners).

Type D. Governance by Indigenous peoples and local communities: Indigenous peoples' conserved areas and territories - established and run by Indigenous peoples; community conserved areas - established and run by local communities.

For more information on the IUCN definition, categories and governance types see Dudley (2008). Guidelines for applyingprotected area management categories, which can be downloaded at: www.iucn.org/pa_categories 


\section{Guidelines for privately protected areas}

The Specialist Group on Privately Protected Areas and Nature Stewardship dedicates this volume to our greatly missed colleague Elisa Corcuera 


\section{IUCN}

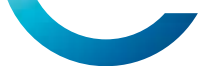

\section{International Union for Conservation of Nature (IUCN)}

IUCN helps the world find pragmatic solutions to our most pressing environment and development challenges. IUCN works on biodiversity, climate change, energy, human livelihoods and greening the world economy by supporting scientific research, managing field projects all over the world, and bringing governments, non-governmental organisations, the United Nations and companies together to develop policy, laws and best practice. IUCN is the world's oldest and largest global environmental organisation, with more than 1,300 members from government and non-governmental organisations and more than 13,000 volunteer experts volunteer experts. IUCN's work is supported by around 900 staff in more than 50 countries and hundreds of partners in public, non-governmental organisations and private sectors around the world.

www.iucn.org

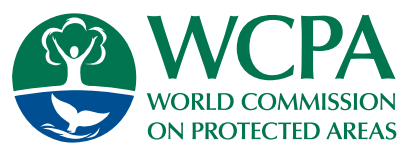

IUCN World Commission on Protected Areas (WCPA)

IUCN's World Commission on Protected Areas is the world's premier network of protected area expertise. It is administered by IUCN's Programme on Protected Areas and has over 2,500 members, spanning 140 countries. WCPA helps governments and others plan protected areas and integrate them into all sectors by providing strategic advice to policymakers; by strengthening capacity and investment in protected areas; and by convening the diverse constituency of protected area stakeholders to address challenging issues. For more than 60 years, IUCN and WCPA have been at the forefront of global action on protected areas. The Best Practice Guidelines series is one of the Commission's flagship products, providing timely guidance on all aspects of protected area planning, management and assessment.

www.iucn.org/wcpa

\section{PRIVATELY \\ PROTECTED AREAS \\ PRIVATE MEANS - PUBLIC BENEFIT}

\section{Specialist Group on Privately Protected Areas and Nature Stewardship}

A Specialist Group of IUCN's World Commission on Protected Areas, the group aims to improve understanding and recognition of the role of private approaches to nature conservation, and enhance the effectiveness of privately protected and conserved areas through information gathering and sharing at the global level.

\section{privateconservation.net}

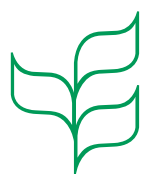

Convention on

Biological Diversity

\section{Convention on Biological Diversity (CBD)}

Opened for signature at the Earth Summit in Rio de Janeiro in 1992, and entered into force in December 1993, the Convention on Biological Diversity is an international treaty for the conservation of biodiversity, the sustainable use of the components of biodiversity and the equitable sharing of the benefits derived from the use of genetic resources. With 196 Parties so far, the Convention has near universal participation among countries.

\section{www.cbd.int}

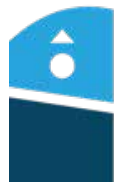

Fundación

Mar Adentro

\section{Fundación Mar Adentro}

Fundación Mar Adentro is a private non-profit Chilean foundation dedicated to the development of multidisciplinary programmes that integrate art and nature for educational purposes to explore biodiversity conservation strategies based on scientific research of natural life in Chile, raise awareness, and encourage a change with respect to the value that is placed upon natural and cultural heritage.

www.fundacionmaradentro.cl 


\section{Equilibrium RESEARCH}

\section{Equilibrium Research}

Equilibrium Research offers practical solutions to conservation challenges, from concept, to implementation and evaluation of impact. With partners ranging from local communities to UN agencies across the world, Equilibrium explores and develops approaches to natural resource management that balance the needs of nature and people. The founders, Nigel Dudley and Sue Stolton, see biodiversity conservation as an ethical necessity, which can also support human wellbeing.

www.equilibriumresearch.com

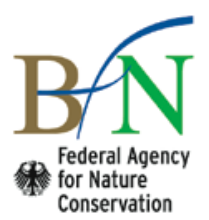

Bundesamt für Naturschutz (BfN)

The German Federal Agency for Nature Conservation (Bundesamt für Naturschutz BfN) is the German government's scientific authority with responsibility for national and international nature conservation. BfN is one of the government's departmental research agencies and reports to the German Environment Ministry (BMUB). The Agency provides the German Environment Ministry with professional and scientific assistance in all nature conservation and landscape management issues and in international cooperation activities. BfN furthers its objectives by carrying out related scientific research and is also in charge of a number of funding programmes. BfN additionally performs important enforcement work under international agreements on species conservation and nature conservation, the Antarctic Treaty and the German Genetic Engineering Act.

www.bfn.de/en
TURNER

ENDANGERED

SPECIES

FUND

\section{The Turner Endangered Species Fund (TESF)}

TESF was launched in 1997 and is dedicated to conserving biological diversity by ensuring the persistence of imperiled species and their habitats with an emphasis on private land. Our activities range from single species conservation actions to restoration of ecological communities and functional ecosystems. We are unique in our efforts to bring the role of private lands to the forefront of ecological conservation. We aim to use the best science to effectively conserve biodiversity and disseminate reliable scientific and policy information. We are determined to establish a new level of effectiveness for private-public efforts to redress the extinction crisis.

tesf.org

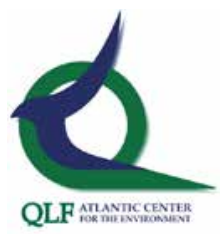

\section{QLF Atlantic Center for the Environment}

QLF exists to promote global leadership development, to support the rural communities and environment of eastern Canada and New England, and to create models for stewardship of natural resources and cultural heritage that can be shared worldwide. The Quebec-Labrador Foundation is registered as a 501(c)3 nonprofit organisation in the United States and a charitable organization in Canada. From headquarters in Massachusetts, QLF Atlantic Center for the Environment manages the Specialist Group on Privately Protected Areas and Nature Stewardship under the auspices of IUCN's World Commission on Protected Areas.

www.qlf.org 



\section{Guidelines for privately protected areas}

Brent A. Mitchell, Sue Stolton, Juan Bezaury-Creel, Heather C. Bingham,

Tracey L. Cumming, Nigel Dudley, James A. Fitzsimons, Delphine Malleret-King, Kent H. Redford and Pedro Solano

Craig Groves, Series Editor 
The designation of geographical entities in this book, and the presentation of the material, do not imply the expression of any opinion whatsoever on the part of IUCN or other participating organisations concerning the legal status of any country, territory or area, or of its authorities, or concerning the delimitation of its frontiers or boundaries.

The views expressed in these guidelines do not necessarily reflect those of IUCN or other participating organisations.

This publication has been made possible in part by funding from Bundesamt für Naturschutz (BfN) and the Turner Endangered Species Fund.

Published by:

Copyright:

Citation:

ISBN:

DOI:

Cover photo:

Back cover photo

Layout by:

Printed by:

Available from:

\section{IUCN, Gland, Switzerland}

(C) 2018 IUCN, International Union for Conservation of Nature and Natural Resources

Reproduction of this publication for educational or other non-commercial purposes is authorised without prior written permission from the copyright holder provided the source is fully acknowledged.

Reproduction of this publication for resale or other commercial purposes is prohibited without prior written permission of the copyright holder.

Mitchell, B.A., Stolton, S., Bezaury-Creel, J., Bingham, H.C., Cumming, T.L., Dudley, N., Fitzsimons, J.A., Malleret-King, D., Redford, K.H. and Solano, P. (2018). Guidelines for privately protected areas. Best Practice Protected Area Guidelines Series No. 29. Gland, Switzerland: IUCN. xii + 100pp.

978-2-8317-1944-3 (PDF)

978-2-8317-1945-0 (print version)

doi.org/10.2305/IUCN.CH.2018.PAG.29.en

(C) Lapa Rios, Osa Peninsula, Costa Rica

Nature Conservancy of Canada conservation volunteers planting marram grass (Ammophila breviligulata) @ Mike Dembeck

Miller Design

Druckerei Weidner GmbH, Carl-Hopp-Str. 15, D-18069 Rostock, Germany

International Union for Conservation of Nature (IUCN)

Global Protected Areas Programme

Rue Mauverney 28

1196 Gland

Switzerland

Tel +41229990000

Fax +41229990002

wcpa@iucn.org

www.iucn.org/resources/publications

The text of this book is printed on paper made from wood fibre from well-managed forests certified in accordance with the rules of the Forest Stewardship Council (FSC). 


\section{Contents}

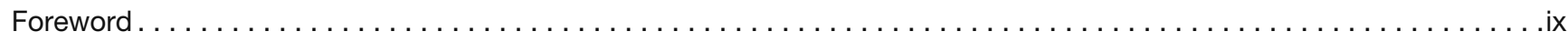

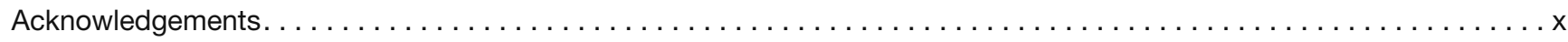

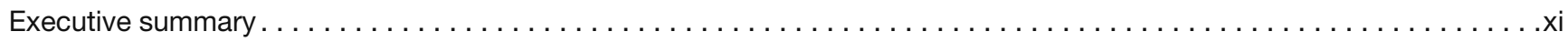

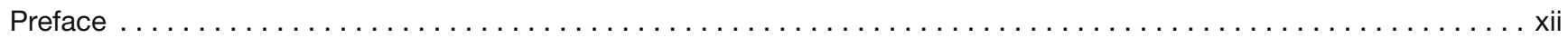

Part A What is a privately protected area? ...........................

Part B Best practices. . . . . . . . . . . . . . . . . . . . . . . . . . . . . .

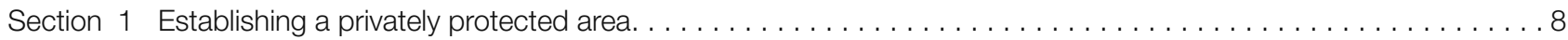

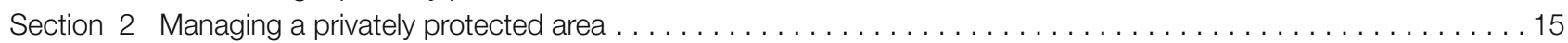

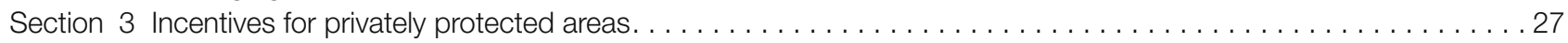

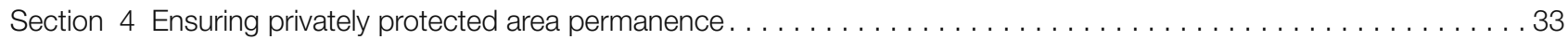

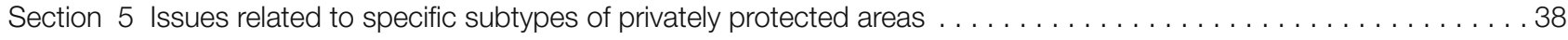

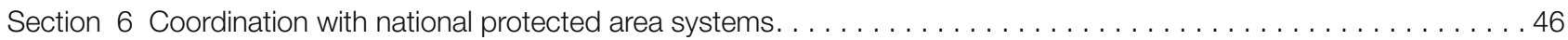

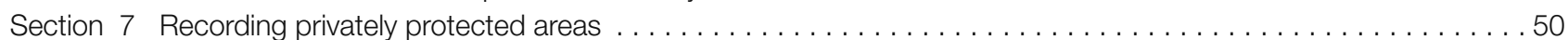

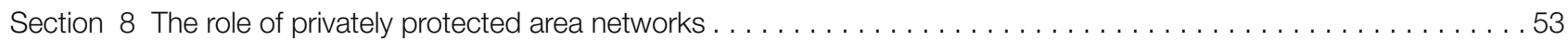

Part C Looking forward: Opportunities for realising the potential of PPAs. . . . . . . . . . . . . . . .

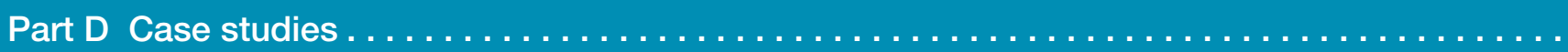

1 Australia's National Reserve System of public, private and indigenous protected areas . . . . . . . . . . . . . 62

2 Brazil's Private Natural Heritage Reserves: Private initiative as public policy . . . . . . . . . . . . . . . . 64

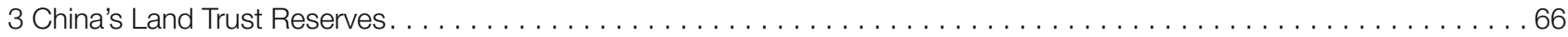

4 PPAs and tourism: A site-based example from Lapa Rios, Costa Rica $\ldots \ldots \ldots \ldots \ldots \ldots . \ldots \ldots$

5 The National Natural Heritage: Contributing to private engagement in nature conservation in Germany. . . . . . . . . 70

6 A successful wildlife conservancy management model: Lewa Wildlife Conservancy, Kenya . . . . . . . . . . . . . . . 72

7 Private land conservation in New Zealand as a social movement $\ldots \ldots \ldots \ldots \ldots \ldots \ldots \ldots \ldots \ldots$

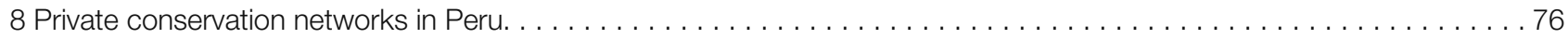

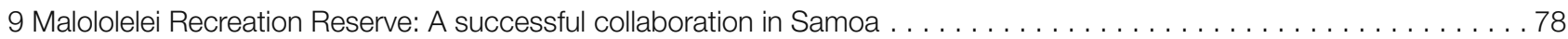

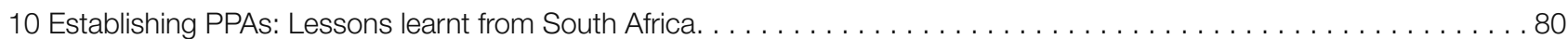

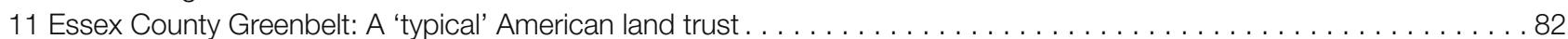

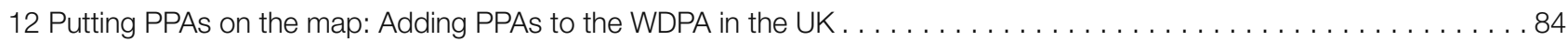

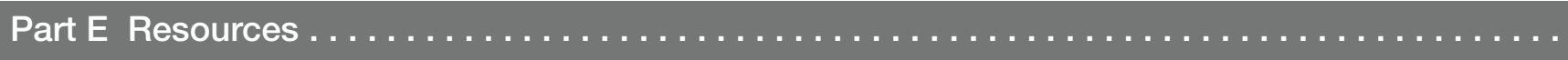

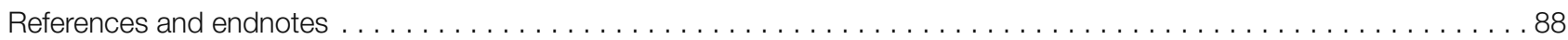

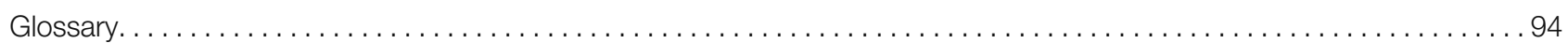

Appendix 1 PPAs and other effective area-based conservation measures $\ldots \ldots \ldots \ldots \ldots \ldots \ldots \ldots \ldots \ldots \ldots$

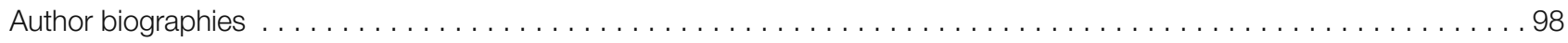

\section{Boxes}

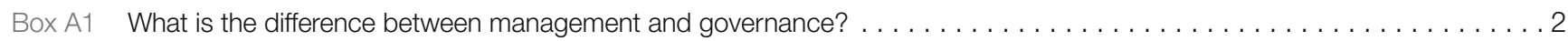

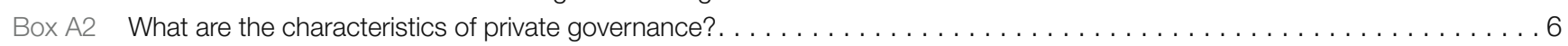

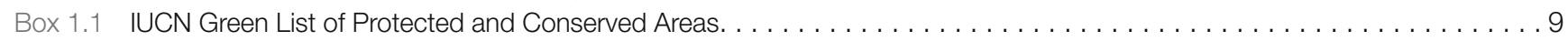

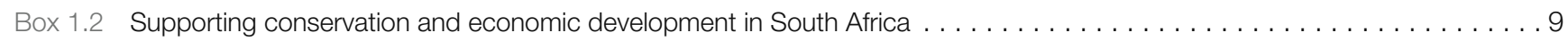

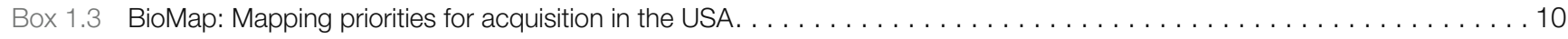

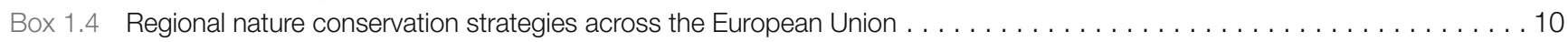

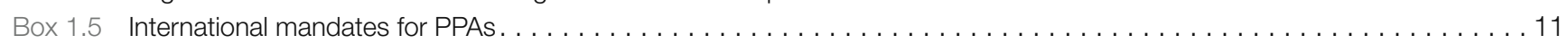

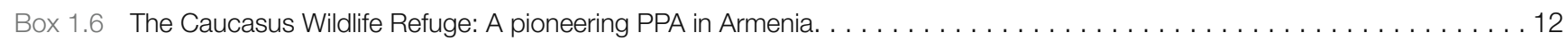

Box 1.7 Chumbe Island Coral Park in Zanzibar, Tanzania, the first marine PPA in the world $\ldots \ldots \ldots \ldots \ldots$

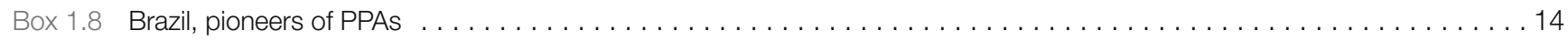

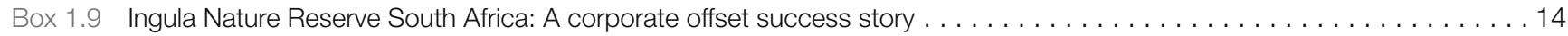

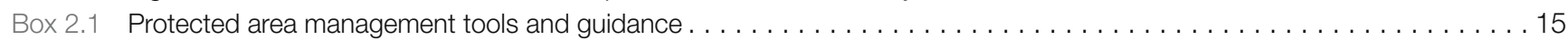


Box 2.2 Management best practice and legislative requirements within the context of South Africa's PPAs . . . . . . . . . . 16

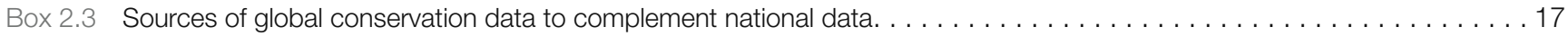

Box 2.4 Traditional Ecological Knowledge and Bush Heritage Australia $\ldots \ldots \ldots \ldots \ldots \ldots \ldots \ldots \ldots \ldots$

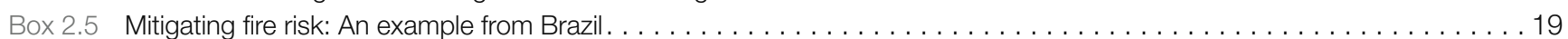

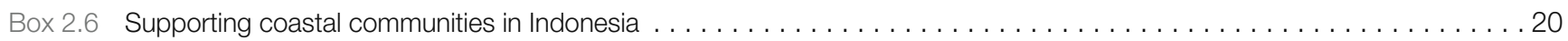

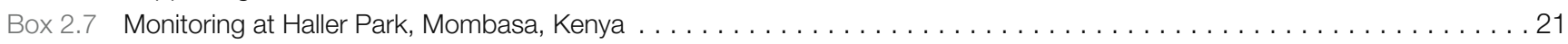

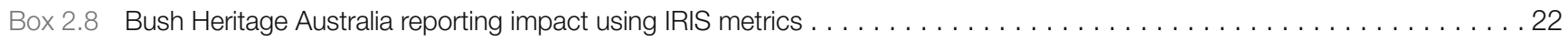

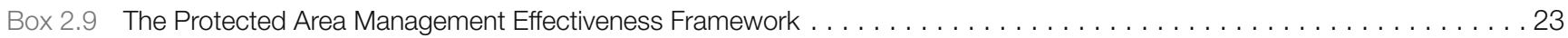

Box 2.10 Lessons learnt from working with volunteers: Namibia, Brazil and Canada $\ldots \ldots \ldots \ldots \ldots \ldots \ldots$

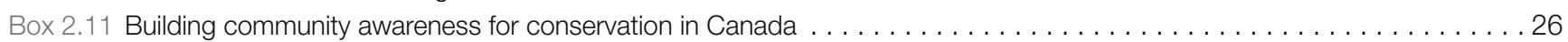

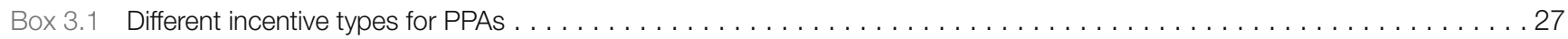

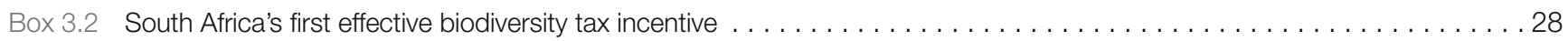

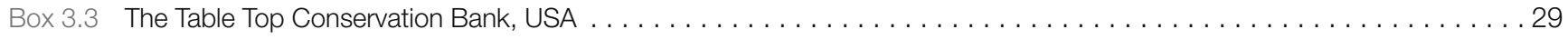

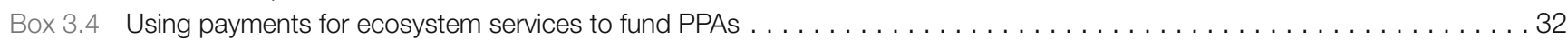

Box 4.1 'Purchase-protect-resale': A conservation strategy of The Nature Conservancy. . . . . . . . . . . . . . . . . . . . 37

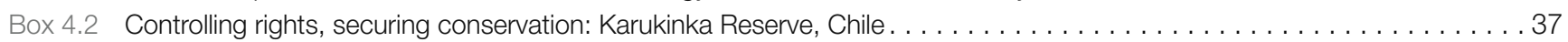

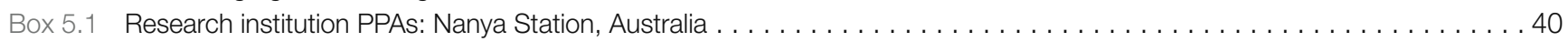

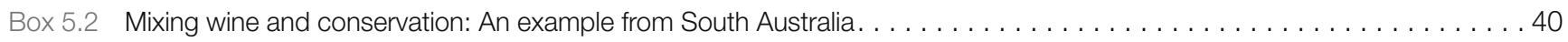

Box 5.3 Recreating habitat after sand and gravel extraction: Attenborough Nature Reserve, UK . . . . . . . . . . . 41

Box 5.4 Creating long-term financial security for managing the Borana Conservancy, Kenya . . . . . . . . . . . . . . . 43

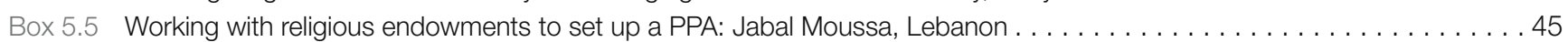

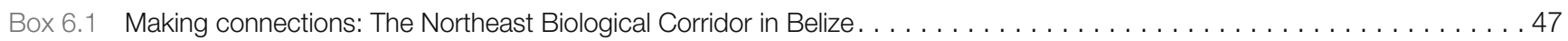

Box 6.2 Collaboration across protected area governance types to save the Orinoco crocodile in Colombia . . . . . . . . . . . . . 49

Box 7.1 World Database on Protected Areas and Global Database on Protected Area Management Effectiveness . . . . . . . . . 50

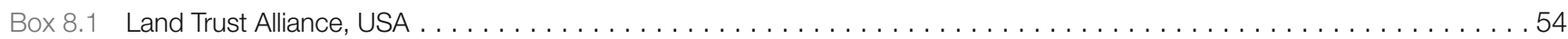

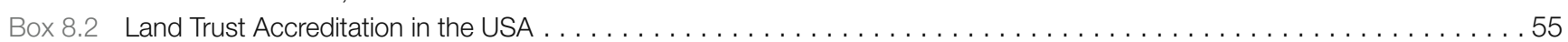

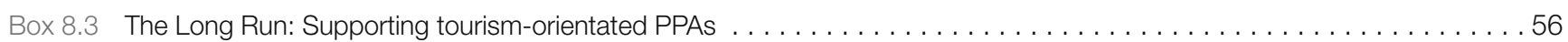

Box 8.4 The NamibRand Nature Reserve, Namibia: A landholders' association . . . . . . . . . . . . . . . . . . . . 58

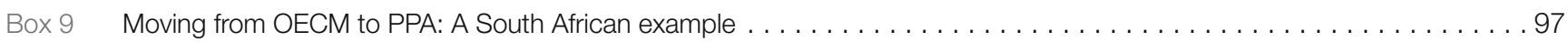

\section{Tables}

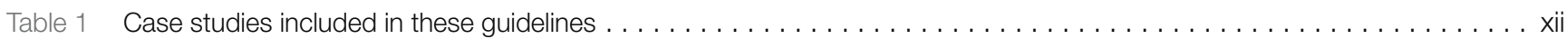

Table 2 'The IUCN protected area matrix': A classification system for protected areas comprising both

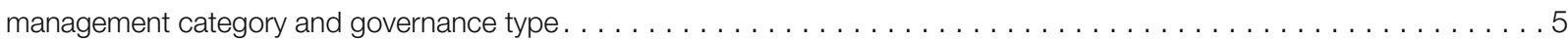

Table 3 Summary of criteria that distinguish PPAs from other PAs under different governance types $\ldots \ldots \ldots \ldots \ldots \ldots \ldots$

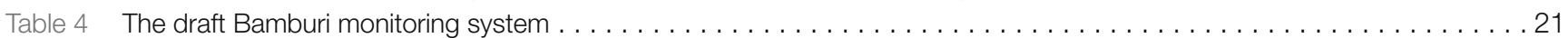

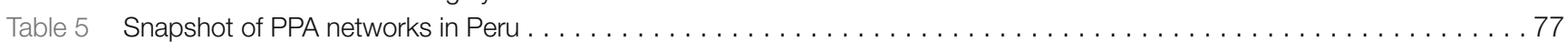

\section{Figures}

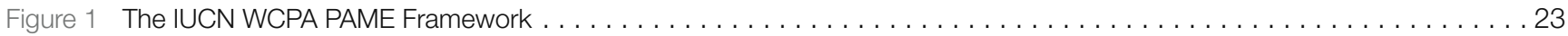

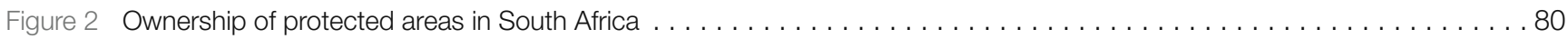

Figure 3 Hierarchy of biodiversity stewardship agreements. Biodiversity stewardship represents South Africa's detailed institutional structure and practical implementation framework that allows for the establishment of PPAs. 


\section{Foreword}

IUCN defines a protected area as: A clearly defined geographical space, recognised, dedicated and managed, through legal or other effective means, to achieve the longterm conservation of nature with associated ecosystem services and cultural values. The Convention on Biological Diversity also emphasises that protected areas are managed and regulated to achieve specific conservation objectives.

Protected areas can include a range of governance and management regimes. Governance types include governance by government, private governance, governance by indigenous peoples and local communities and various forms of shared governance. There is already much general guidance available on managing protected areas but these guidelines focus specifically on the particular areas which meet the IUCN definition but are under private governance and management. These can be properties owned and managed by individuals who hold title to a property, NGOs or other institutions or even companies, including commercial private sector operations which hold management rights under tenure or a long-term lease. As with other protected areas, it is expected that privately protected areas (PPAs) will be maintained as permanent conservation areas, even if ownership changes. Their defining characteristic is that they are established under private governance.

Currently, only 28 countries report PPAs to the World Database on Protected Areas, although PPAs occur in many other countries. The identification and recognition of PPAs has great potential to complement and supplement national protected area networks, contributing to a mosaic of land, wetland and coastal areas that enhance connectivity and biodiversity conservation. PPAs are already a familiar part of the conservation estate in the USA, Australia and parts of Latin America, Europe and Africa, and are now emerging as a new conservation model in other countries.

These guidelines, prepared by the Privately Protected Areas and Nature Stewardship Specialist Group of the IUCN World Commission on Protected Areas, offer a range of best practices for establishing PPAs and securing effective longterm conservation on private properties. They offer specific guidance applicable to areas under private governance and

\section{Katheew Mackinnow}

Dr. Kathy MacKinnon

Chair, IUCN/World Commission on Protected Areas management, including appropriate legal and institutional arrangements and useful insights into funding mechanisms.

Private landholders may have very diverse reasons for wishing to establish a PPA, ranging from a personal or organisational interest in wildlife conservation to commercial tourism operations. For an area in private ownership to be designated or declared to be a PPA, it must meet the IUCN definition of a protected area, or equivalent criteria under national laws, including intent to achieve the conservation of nature in the long term. Achieving this degree of permanence usually requires a specific undertaking, contract, articles of association, covenant, registered servitude in favour of nature conservation over the title to the property, memorandum of understanding, or other instrument that is binding on current and future successors in title in the long term.

It is worth noting that the guidelines use the term privately protected area, rather than private protected area, to stress that these areas provide many public benefits despite the fact that they are established and managed by private entities on private lands. In some cases, national legislation will recognise and support these private voluntary efforts to biodiversity conservation through tax incentives, land use grants or other financial contributions. In other cases, there is an option to introduce new mechanisms for the recognition of these areas and to maintain and enhance their effectiveness.

These guidelines discuss different options and instruments for establishing and managing PPAs, drawing on a diversity of PPAs from around the world. It is hoped that practitioners will draw on and contribute further to these best practices, enriching the suite of examples and inspiring new application of the principles and guidance.

As countries enhance their efforts to meet the Aichi Targets and consider the post-2020 agenda and obligations under the Convention on Biological Diversity, it is clear that the establishment and recognition of PPAs offers great opportunities for engaging more stakeholders in conservation efforts and expanding the conservation estate to protect and manage areas of important biodiversity that lie beyond the boundaries of state-governed and managed protected areas.

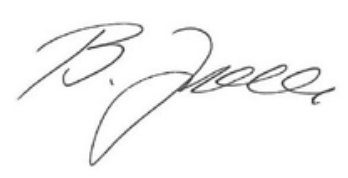

Prof. Dr. Beate Jessel

President of the Federal Agency for Nature Conservation, Germany 


\section{Acknowledgments}

Participants in the framing workshop at the International Academy for Nature Conservation of the German Federal Agency for Nature Conservation, Vilm, Germany, June 2017: Juan Bezaury Creel (The Nature Conservancy, Mexico); Nandipha Bhengu (Department of Environmental Affairs, South Africa); Heather Bingham (UN Environment World Conservation Monitoring Centre, UK); Carlos Chacón (Forever Costa Rica Association); Tracey Cumming (UNDP BIOFIN, South Africa); Tilmann Disselhoff (European Land Conservation Network, Germany); Nigel Dudley (Equilibrium Research, UK); Nicole Ellena (MVMT, Chile); André Ferretti (Fundação Grupo Boticário, Brazil); James Fitzsimons (The Nature Conservancy, Australia); Ralf Grunewald (BfN International Academy for Nature Conservation, Germany); Mike Jebson (Queen Elizabeth II National Trust, New Zealand); Laura Johnson (International Land Conservation Network, USA); Delphine Malleret King (The Long Run, UK); Lisa McLaughlin (Nature Conservancy of Canada); Brent Mitchell (QLF Atlantic Center for the Environment, USA); Kiragu Mwangi (BirdLife, UK); Miquel Rafa (Fundació Catalunya-La Pedrera, Spain); Oswaldo Sabido (Belize Association of Privately Protected Areas); Pedro Solano (Peruvian Society for Environmental Law); Gisela Stolpe (BfN International Academy for Nature Conservation, Germany); Sue Stolton (Equilibrium Research, UK); John Waithaka (IUCN World Commission on Protected Areas, Kenya).

Participants in the PPA session at the International Land Conservation Network Conference, Santiago, Chile, January 2018 run by Brent Mitchell and James Fitzsimons: Mark Anderson (The Nature Conservancy, USA); Alan Bannister (Parque Tantauco, Chile); Jessica Brown (New England Biolabs Foundation, USA); Beatriz Bustos (Fundación Mar Adentro, Chile); Kristijan Čivić (Eurosite, Netherlands); Mike Daniels (John Muir Trust, Scotland); Michael Dowling (Land Trust Alliance, USA); Anton Gazenbeek (European Commission, Belgium); Lance Gloss (Brown University, USA); Jennifer Gooden (Oxford University, UK); Ana GonzálezRojas (Huilo Huilo Biological Reserve, Chile); Roberta Guagliardi (Private Reserves Program of Rio de Janeiro, Brazil); Tim Hughes (South Endeavour Trust, Australia); Olivia Humphreys (Parque Tantauco, Chile); Madeline Hurtado (Fundación Mar Adentro, Chile); Ruben Khachatryan (Foundation for the Preservation of Wildlife and Cultural Assets, Armenia); Catherine Kenrick (Parque Andino Juncal, Chile); Judy LaBelle (Glynwood, Inc., USA); Rosa Madera (Empatthy, Chile); Victoria Marles (Trust for Nature, Australia); Rodrigo Mata (Huilo Huilo Biological Reserve, Chile); Lisa McLaughlin (Nature Conservancy of Canada); Carlos Mendoza (Fundación Mar Adentro, Chile); Florencia Morales (Red Argentina de Reservas Naturales Privadas); Flávio Ojidos (National Confederation of Natural Heritage Private Reserves, Brazil); Miquel Rafa (Fundació Catalunya-La Pedrera, Spain); Loring Schwartz (Friends of Spannocchia, USA); Henrique Seixas Barros (Consultant, Brazil); Marion Leticia B. Silva (Fundação Grupo Boticário, Brazil); Jin Tong (The Nature Conservancy, China); Agus Utomu (BirdLife Indonesia); Grace Weatherall (QLF Atlantic Center for the Environment, USA); Geoff Wescott (Deakin University, Australia) and Mike Williams (Nature Conservation Trust of NSW, Australia)

People who commented on draft 2: Thora Amend, Germany; Rafael Antelo, Colombia; Hari Balasubramanian, Canada; María Paula Bertolini, Argentina; Renata Bomfim, Brazil; Alejandra Carminati, Argentina; Melissa Carmody, Chile; Subir Mario Chowfin, India; Benjamin Cooke, Australia; Kalilou Dama, Mali; Pierre Doumet, Lebanon; Kate Fitzherbert, Australia; Anton Gazenbeek, Belgium; Jennifer Gooden, USA/UK; John Gordon, UK; Yogani Govender, Puerto Rico, USA; Ben Guillon, USA; Mat Hardy, Australia; George Holmes, UK; Harry Jonas, UK/Indonesia; Daniel Marnewick, South Africa; Rossana Merizalde, USA; Lisa McLaughlin, Canada; Beto Mesquita, Brazil; Flávio Ojidos, Brazil; Nils Odendaal, Namibia; Jessica Owley, USA; Juan Pacheco, Chile; Ceclia Riebl, Australia; Sibylle Riedmiller, Tanzania; Juan Carlos Sandino, Colombia; Carolina Sans, Uruguay; Karina Schiaffino, Argentina; Michael Schuett, USA; Edji Seyoum, Canada; Anna Spenceley, South Africa; Candice Stevens, South Africa; Stan Stevens, USA; Philip Tabas, USA; Christophe Tourenq, Australia; Francis Vorhies, USA/France; Paul Walker, Belize; Maria Cristina Weyland Vieira, Brazil; Dale Wright, South Africa; Noelia Zafra-Calvo, Spain.

Case study authors: Australia: James Fitzsimons, The Nature Conservancy, Deakin University, Australia. Brazil: Renata Bomfim, RPPN Eluz, Beto Mesquita, independent consultant, Flávio Ojidos, National Confederation of Natural Heritage Private Reserves (CNRPPN) and Maria Cristina Weyland Viera, Association of RPPN and Other Private Reserves Minas Gerais. China: Jin Tong, The Nature Conservancy China Program. Costa Rica: Delphine Malleret King, The Long Run and Karen Lewis, Lapa Rios. Germany: Gisela Stolpe BfN Vilm, Karin Reiter, BfN Bonn and Tilmann Disselhoff, NABU. Kenya: Tuqa Jirmo, Lewa Wildlife Conservancy. New Zealand: Mike Jebson, Queen Elizabeth II National Trust. Peru: Christel Scheske and Bruno Monteferri, Sociedad Peruana de Derecho Ambiental with contributions from José Vargas, Martín Vasquez, Fernando Arévalo and Karina Pinasco. Samoa: Moeumu Uili, Ministry of Natural Resources and Environment. South Africa: Candice Stevens, BirdLife South Africa. UK: Sue Stolton, IUCN NC UK. USA: Brent Mitchell, Chair, IUCN-WCPA Specialist Group on Privately Protected Areas and Nature Stewardship and Ed Becker, Essex County Greenbelt Association.

Peer reviewers: Geoff Wescott and Andrew Knight and IUCN WCPA (Sarina van der Ploeg; Trevor Sandwith; Kathy MacKinnon; Craig Groves). 


\section{Executive summary}

These guidelines address the establishment and management of privately protected areas (PPAs) and are aimed at practitioners and policy makers who are or may be involved with PPAs.

A PPA is a protected area, as defined by IUCN, under private governance. This can include governance by individuals and groups of individuals; non-governmental organisations; corporations, including commercial companies and small companies established to manage groups of PPAs; forprofit owners such as ecotourism companies; research entities such as universities and field stations; or religious entities. Not all private conservation initiatives can meet the definition of a protected area nor should become PPAs. The best practices are grouped under 34 principles, which are summarised below. Each best practice contains descriptive text and examples including many short boxed examples and photos. Given the array of individuals and organisations involved in private governance, each section clearly identifies the main audience for the principles and best practices. A further 12 longer case studies from around the world provide details of the best practices being applied.

\section{Principles}

\section{Section 1: Establishing a privately protected area}

1.1: A PPA must meet the definition of a protected area

1.2: PPA owners and managers should articulate clear conservation objectives from the outset

1.3: PPAs are best developed within a clear, supportive institutional framework that empowers governance and management

1.4: PPAs can be established through a variety of mechanisms

1.5: All PPAs should be established with a long-term strategy and sustainable financing

\section{Section 2: Managing a privately protected area}

2.1: Current and potential PPA landholders should have a clear understanding of what is happening in and around the PPA before developing management activities

2.2: Management systems should focus on the achievement of defined PPA objectives

2.3: The full costs and benefits of the PPA should be understood as the basis for management

2.4: Management should be adaptive

2.5: Building a team should help develop PPA management capacity

2.6: Information about PPA management should be communicated widely

Section 3: Incentives for privately protected areas

3.1: PPA incentives should be carefully designed, communicated and implemented to ensure effectiveness
3.2: Incentives should be designed to encourage both PPA establishment as well as long-term governance and management

3.3: Identify and avoid perverse incentives

3.4: Recognition and support are powerful incentives for PPAs

3.5: Direct management and technical support are an incentive for PPA management, supporting long-term commitment

3.6: Marketing assistance is an effective incentive to PPAs that have income-generating potential

3.7: Financial incentives are important for the establishment and management of PPAs

Section 4: Ensuring privately protected area permanence

4.1: PPA governance should embody the long-term intent to achieve conservation

4.2: Many different private conservation instruments can contribute to PPA permanence

Section 5: Issues related to specific subtypes of privately protected areas

5.1: Specific subtypes of PPAs may require tailored forms of recognition, support and encouragement

5.2: Corporate PPAs offer specific benefits to companies and vice versa

5.3: PPAs managed by extractive industries must demonstrate contributions to biodiversity conservation

5.4: PPAs set up as for-profit companies/enterprises should ensure they achieve their specified conservation outcomes

5.5: Religious entities can contribute to conservation through developing PPAs on their own land

Section 6: Coordination with national protected area systems

6.1: Conservation benefits when PPAs are coordinated with other types of protected area as part of a national system of protected areas

6.2: PPAs can complement other protected area governance types to develop effective national protected area systems

Section 7: Recording privately protected areas

7.1: PPAs should be recorded in the World Database on Protected Areas

Section 8: The role of privately protected area networks

8.1: Networks can be effective mechanisms to represent the interests and concerns of landholders

8.2: Networks can provide support structures for PPA landholders

8.3: Networks can have a role in the monitoring and verification of PPAs

8.4: Networks can play an important role in promoting PPA products

8.5: PPA networks should match structures and governance to their mission and objectives

8.6: PPA networks, like any organisation, should find ways to support and sustain their activities 


\section{Preface}

These guidelines address planning and management of privately protected areas (or PPAs). A privately protected area is a protected area, as defined by IUCN (i.e. A clearly defined geographical space, recognised, dedicated and managed, through legal or other effective means, to achieve the long-term conservation of nature with associated ecosystem services and cultural values), under private governance. This can include governance by individuals and groups of individuals; non-governmental organisations; corporations, including existing commercial companies and small companies established to manage groups of PPAs; for-profit owners such as ecotourism companies; research entities such as universities and field stations; or religious entities. Not all private conservation initiatives can or should become PPAs.

The guidance is aimed principally at practitioners and policy makers, who are or may be involved with PPAs, including:

- $\quad$ Owners of all types, including:

a Individuals and groups of individuals;

a Non-governmental organisations (NGOs);

a. Corporations, both commercial companies and sometimes corporations set up by groups of private owners to manage groups of PPAs;

a For-profit owners;

a Research entities (e.g. universities, field stations);

o Religious entities;

- Government officials (management agencies and legislative and policy authorities);

- $\quad$ Associated interest groups (e.g. conservation NGOs);

- Focal points of international agreements (such as the Convention on Biological Diversity).
Guidance is given on all aspects of PPA establishment, management and reporting, and information is provided on principles and best practices, with examples drawn from many different parts of the world. After an introduction (Part A), Part B focuses on the major issues impacting PPAs, which are elaborated through a series of best practices organised according to encompassing principles. A vision for the future of PPAs and links to global conservation targets are outlined in Part C. Finally, the principles and best practices described in part B are further explored in a set of case studies (Part D) which illustrate real-life experiences (see Table 1).

The aim of these guidelines is to shape the application of IUCN policy and principles towards enhanced effectiveness and conservation outcomes, focused on PPA managers and administrators. Some guidance will be more appropriate for the senior administrators of protected area agencies who establish the regulatory or legal conditions for PPAs, and other aspects will be of more use to site managers. In Part $\mathrm{B}$, the main target audience for each section is highlighted at the start of the section. Not all the guidance will necessarily apply in all social, political and economic contexts. However, learning from best practices around the world and considering how these can be incorporated at site or national level may improve the likelihood of success in private conservation and suggest how conditions might be improved to favour PPAs and thus capitalise on the opportunities they present. As part of a long-running series of best practice guidance on protected areas from IUCN, these guidelines, for the most part, do not repeat guidance that is universal to protected areas or is covered in other volumes of this series ${ }^{1}$.

Table 1: Case studies included in these guidelines

\begin{tabular}{|c|c|c|c|c|c|c|c|c|}
\hline \multirow[t]{2}{*}{ Case study } & \multicolumn{8}{|c|}{ Sub-sections in part B of the guidelines } \\
\hline & $\begin{array}{l}\text { Establishing } \\
\text { a PPA }\end{array}$ & $\begin{array}{c}\text { Managing } \\
\text { a PPA }\end{array}$ & $\begin{array}{l}\text { Incentivising } \\
\text { PPAs }\end{array}$ & $\begin{array}{c}\text { Ensuring } \\
\text { permanence }\end{array}$ & $\begin{array}{c}\text { Specific } \\
\text { subtypes } \\
\text { of PPA }\end{array}$ & $\begin{array}{l}\text { Coordinating } \\
\text { with National } \\
\text { PA Systems }\end{array}$ & $\begin{array}{c}\text { PPA } \\
\text { recording }\end{array}$ & $\begin{array}{c}\text { PPA } \\
\text { networks }\end{array}$ \\
\hline 1. Australia & & & & & & & & \\
\hline 2. Brazil & & & & & & & & \\
\hline 3. China & & & & & & & & \\
\hline 4. Costa Rica & & & & & & & & \\
\hline 5. Germany & & & & & & & & \\
\hline 6. Kenya & & & & & & & & \\
\hline 7. New Zealand & & & & & & & & \\
\hline 8. Peru & & & & & & & & \\
\hline 9. Samoa & & & & & & & & \\
\hline 10. South Africa & & & & & & & & \\
\hline 11. USA & & & & & & & & \\
\hline 12. UK & & & & & & & & \\
\hline
\end{tabular}




\section{Understanding protected areas}

IUCN has spent several decades wrestling with the question of what defines a 'protected area'. In 2008, consensus was reached on a revised definition (Dudley, 2008): "A clearly

defined geographical space, recognised, dedicated and managed, through legal or other effective means, to achieve the long-term conservation of nature with associated ecosystem services and cultural values." This definition states clearly that nature conservation is the primary function of protected areas, further emphasised by an associated principle: "For IUCN, only those areas where the main objective is conserving nature can be considered protected areas; this can include many areas with other goals as well, at the same level, but in the case of conflict, nature conservation will be the priority." Although application by countries is voluntary, its use has been supported by the IUCN membership through resolution (WCC-2012-Res-040-EN: Endorsement and uniform application of protected area management guidelines) and decisions of the Convention on Biological Diversity (CBD) (e.g. Decision VII/28 on "the value of a single international classification system for protected areas...").

Data on protected areas are collated globally by the United Nations Environment World Conservation Monitoring Centre (UNEP-WCMC), which manages the World Database on Protected Areas (WDPA) together with IUCN (UNEPWCMC, 2017).

Protected areas as defined by IUCN are grouped into four types of governance based on the underlying tenurial rights and thereby the rights of people to assert decision-

\section{Box A1 \\ What is the difference between management and governance?}

In the context of protected areas, management refers to what is being done in pursuit of given objectives (i.e. the means and actions to achieve such objectives); governance refers to who decides what these objectives are, what to do to pursue them, and with what means. Examples of governance decisions can include:

- The establishment of a protected area;

- The long-term goal (vision) of the protected area;

- Main management objective;

- How objectives will relate to local livelihoods and development;

- Sanctioning a management plan and/or system;

- Deciding who will implement management;

- Ensuring human and financial resources to pursue management are in place;

- Establishing how the rule of law and broader international legislation (including human and indigenous peoples' rights) are to be respected and enforced (Borrini-Feyerabend et al., 2013). making power over an area and its resources (see Table 2). These four types span governance by government, shared governance, governance by private entities, and governance by indigenous peoples and local communities. In certain cases, where tenurial rights are unclear and overlapping as a result of history, contested rights or lack of official recognition of these rights, governance may be conducted de facto by particular local actors, although the underlying legal or customary governance rights may be de jure (BorriniFeyerabend et al., 2013).

The best practices discussed in these guidelines focus on the 'private governance' type of governance and situations where shared governance arrangements include an element of private governance (Borrini-Feyerabend et al., 2013). To provide more understanding and appreciation of this governance type of protected areas, the IUCN WCPA PPA Specialist group developed an IUCN WCPA Technical Report, The Futures of Privately Protected Areas (Stolton et al., 2014). Its definition of a PPA was confirmed in an IUCN Resolution (see Box 1.5): "a privately protected area is a protected area, as defined by IUCN, under private governance (i.e. individuals and groups of individuals; non-governmental organizations (NGOs); corporations both existing commercial companies and sometimes corporations set up by groups of private owners to manage groups of PPAs; for-profit owners; research entities (e.g. universities, field stations) or religious entities)" or put more simply: land or sea managed for conservation under private governance is only a PPA if it is a protected area as defined by IUCN and is managed under private governance.

IUCN assigns one or more of six management categories to protected areas, based on their objectives. These management categories range from the strictest protection to those that allow multiple uses of the area. Private governance can apply to any of the six IUCN Protected Area Management Categories. Table 2 helps visualise the matrix of protected area categories and governance types as defined by IUCN.

In practice, not all areas fit neatly into the boxes and there are many instances of shared governance arrangements that involve private governance in combination with other governance types, depending on the legal and institutional context for conservation in any country. Distinctions are not always clear-cut or permanent. Some PPAs pass voluntarily into government hands; this recently happened to a huge PPA in Chile. ${ }^{2}$ Other PPAs will be subject to state policies that influence management. Furthermore, it is not always clear when a group of private landholders come together to form a protected area whether it counts as a PPA or a local community protected area. Shared governance can also be complicated and lack clarity about decision-making power across different stakeholders. Larger protected areas sometimes have multiple governance types within them. For example, the 4,408 hectare (ha) Tallgrass Prairie National Preserve ${ }^{3}$ was established in 1996 in the Flint Hills of the State of Kansas, USA, as part of the US National Park System. The National Park Service co-manages the property with The Nature Conservancy, an NGO, a pattern 


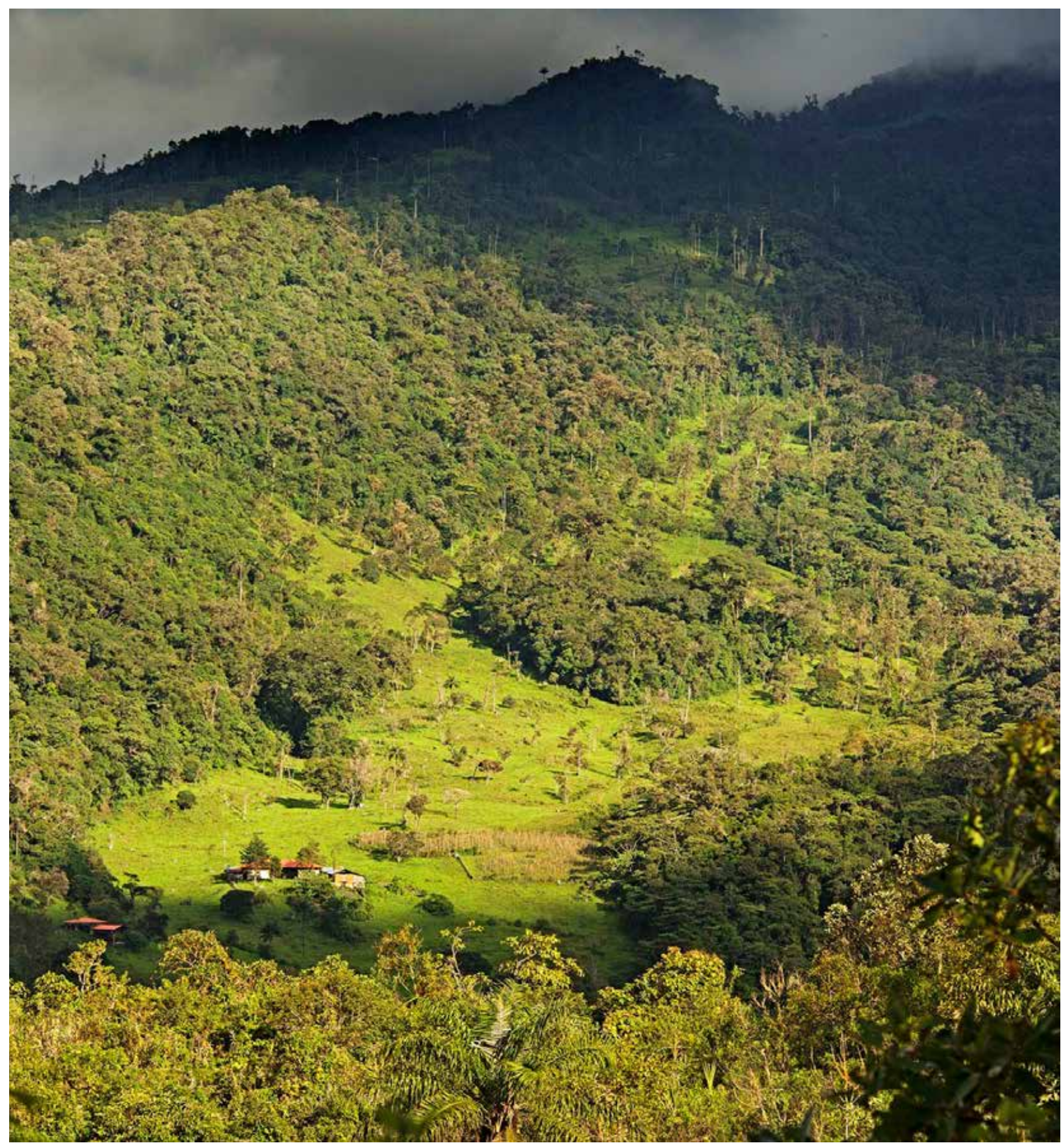

Bosque Berlin PPA in Amazonas, Peru, habitat of the endemic and critically endangered Yellow-Tailed Woolly Monkey (Lagothrix flavicauda). Conservamos por Naturaleza created a crowdfunding campaign to raise US $\$ 10,000$ to help the owner buy adjacent land to increase landscape connectivity $\odot$ Walter $\mathrm{H}$. Wust.

very common throughout the world. However, at the Tallgrass Preserve almost all of the land is owned by the private partner, the reverse of the ownership pattern in most shared governance arrangements. Tallgrass Prairie tilts strongly towards being a PPA. Similarly, there are many examples in which a site demonstrates characteristics of both a PPA and an Indigenous and Community Conserved Area (ICCA), depending on the tenure rights and governance approach of the latter. In some countries, for example, Peru, legislation makes no distinction between private and indigenous protected areas. Table 3 summarises some of the distinctions discussed above.

\section{What is not a PPA?}

The governance type of PPAs is not meant to include all private conservation efforts but rather to distinguish those that fit the IUCN definition of a protected area. There are many types of private initiatives that may contribute to conservation but will not qualify as a PPA as defined above (e.g. Fitzsimons, 2015; Mitchell et al., 2018). Types of privately conserved land/water which may be on the borderline include, for example, some wildlife ranches in South Africa and Namibia, where intensive game ranching is closely associated with commercial agricultural practices and involves 


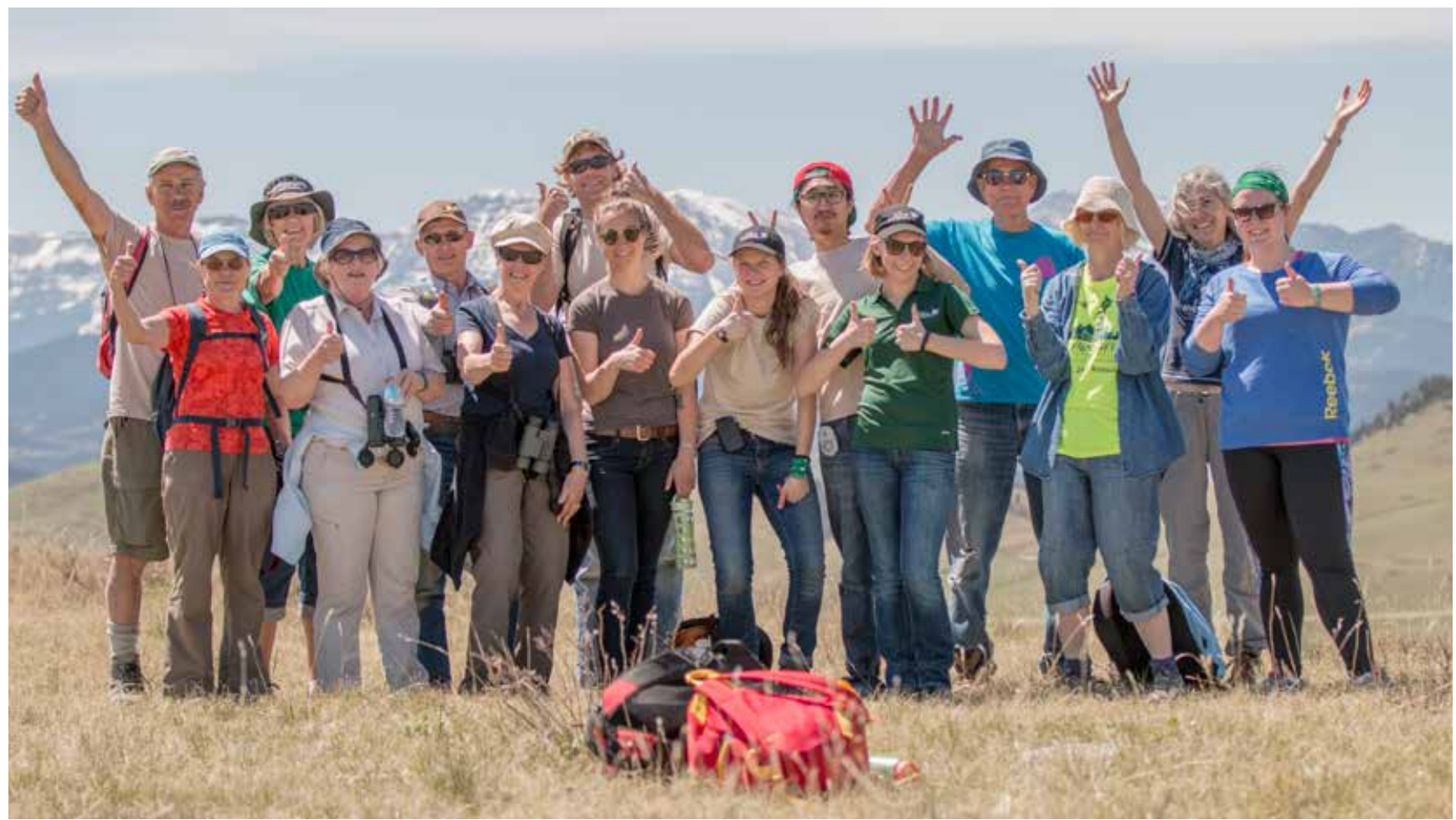

Some of the Nature Conservancy of Canada's many conservation volunteers at the Waldron Conservation Project, Alberta @ NCC

internal fenced camps, feedlots and removal of predators. Where nature conservation is not the primary aim, such areas would not be considered as PPAs. Similarly, responsible forestry operations on private land may retain key habitats, protect against poaching and support endangered species, but would not generally be considered PPAs if conservation is not the primary aim (see Part B, Section 1).

\section{Why are PPAs important?}

To date, the large majority of recorded protected areas have been created on state-owned lands and waters. Despite these efforts, several ecoregions are poorly represented in the global protected areas network. Many of the world's most important places for biodiversity (and geodiversity) remain outside formal protected areas (Dinerstein et al., 2017) and occur on private, communal or indigenous peoples' land. To cite one example, Important Bird and Biodiversity Areas cover over 14 million ha, constituting 11.6 per cent of South Africa's land surface. More than 60 per cent of this land surface is not formally protected and mostly occurs on privately owned land (Marnewick et al., 2015).
There are already many thousands of PPAs around the world (Bingham et al., 2017), with more being established. But until recently, PPAs have remained a largely hidden resource; they are ignored by some governments, omitted from international conservation reporting mechanisms and left out of regional conservation strategies (Stolton et al., 2014). The recognition of existing private conservation efforts, and the establishment of new PPAs, can often fill important gaps in national protected area systems in terms of geographic coverage, ecological representation and protection of endangered habitats and species. Purchase or donation of land and water by individuals can often increase the speed of response to conservation challenges as compared with lengthy government processes of protected area designation (Pasquini et al., 2011). They also bring a wide range of stakeholders into the conservation endeavour, enabling private citizens to contribute directly to conservation efforts through a bottom-up process and private entities to contribute to the public good. 
Table 2: 'The IUCN protected area matrix': A classification system for protected areas comprising both management category and governance type (Dudley, 2008)

\begin{tabular}{|c|c|c|c|c|c|c|c|c|c|c|c|}
\hline \multirow{2}{*}{$\begin{array}{l}\text { Governance types } \\
\text { Protected } \\
\text { area } \\
\text { categories }\end{array}$} & \multicolumn{3}{|c|}{$\begin{array}{l}\text { A. Governance by } \\
\text { government }\end{array}$} & \multicolumn{3}{|c|}{$\begin{array}{l}\text { B. Shared } \\
\text { governance }\end{array}$} & \multicolumn{3}{|c|}{ C. Private governance } & \multicolumn{2}{|c|}{$\begin{array}{l}\text { D. Governance by } \\
\text { indigenous peoples and } \\
\text { local communities }\end{array}$} \\
\hline & 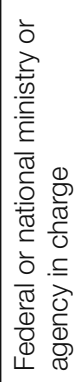 & 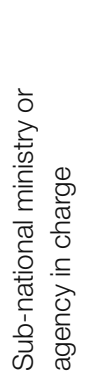 & 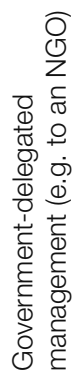 & 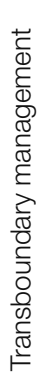 & 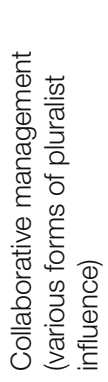 & 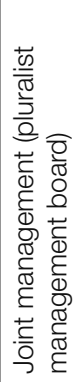 & 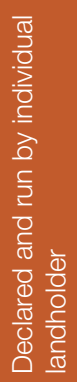 & 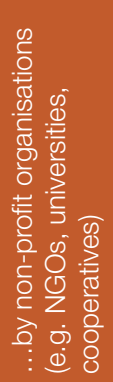 & 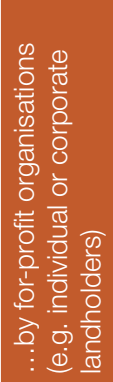 & 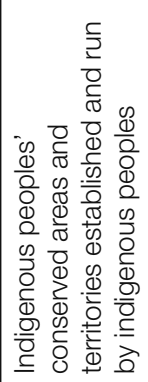 & 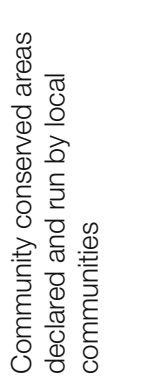 \\
\hline \multicolumn{12}{|l|}{$\begin{array}{l}\text { la. Strict Nature } \\
\text { Reserve }\end{array}$} \\
\hline \multicolumn{12}{|l|}{ Ib. Wilderness Area } \\
\hline \multicolumn{12}{|l|}{ II. National Park } \\
\hline \multicolumn{12}{|l|}{ III. Natural Monument } \\
\hline \multicolumn{12}{|l|}{$\begin{array}{l}\text { IV. Habitat/Species } \\
\text { Management }\end{array}$} \\
\hline \multicolumn{12}{|l|}{$\begin{array}{l}\text { V. Protected } \\
\text { Landscape/Seascape }\end{array}$} \\
\hline $\begin{array}{l}\text { VI. Managed Resource } \\
\text { Protected Area }\end{array}$ & & & & & & & & & & & \\
\hline
\end{tabular}

Table 3: Summary of criteria that distinguish PPAs from other PAs under different governance types (adapted from Stolton et al., 2014)

\begin{tabular}{|c|c|}
\hline PPA criterion & Sub-criteria \\
\hline Protected area & $\begin{array}{l}\text { - Area is legally designated and managed in accordance with the IUCN protected area definition and associated } \\
\text { principles. } \\
\text { OR } \\
\text { - Area is managed in accordance with the IUCN protected area definition and associated principles, and, though } \\
\text { not legally designated, is recognised as a PPA. }\end{array}$ \\
\hline $\begin{array}{l}\text { Private entities } \\
\text { involved }\end{array}$ & - Individual or a group of individuals, NGO, corporation, for-profit owner, research entity or religious entity. \\
\hline Governance & $\begin{array}{l}\text { - Area is dedicated primarily to the purpose of nature conservation. } \\
\text { AND } \\
\text { - PPA landholders are aware of any rights of use which are not in their control and efforts should be made to ensure } \\
\text { that such use does not impact the overall conservation objectives. }\end{array}$ \\
\hline Permanence & 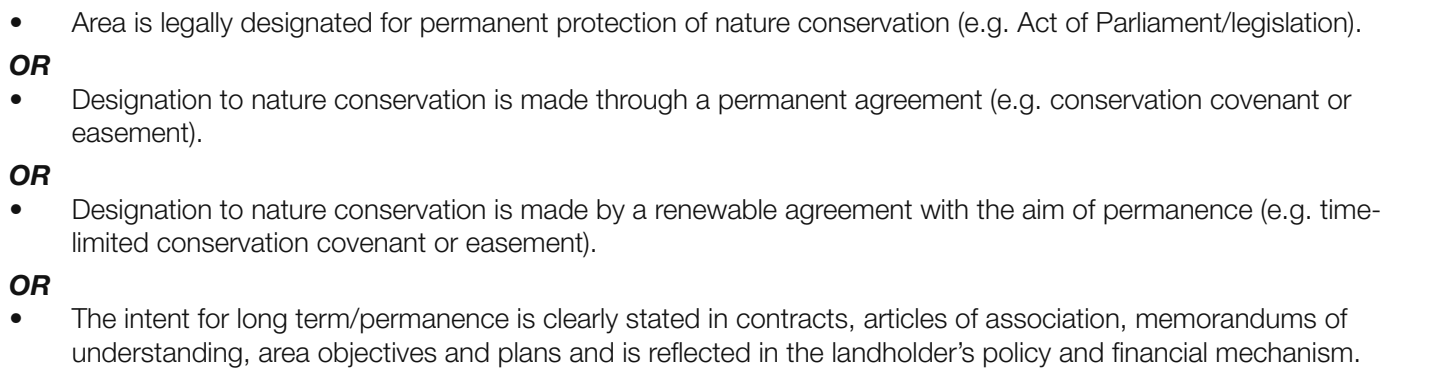 \\
\hline
\end{tabular}




\section{Box A2 \\ What are the characteristics of private governance?}

Private governance of nature emerges under land and sea tenure systems which accord rights over a property to private landholders (see glossary regarding use of this term for all types of land and sea tenure systems). These rights may be through, for example, land title or long-term lease. The landholder has rights to the exclusive occupation and use of the area, to assign or cede these rights to others through leasehold or other agreements, and to sell or alienate the property to successors in title. The landholders may therefore be:

- An individual or individuals who hold a title or lease to a property;

- A legally-constituted organisation, which owns the property/lease, including non-governmental organisations, community property owners' associations, trusts and foundations;

- A company or corporation, which owns the property/ lease in terms of the laws under which companies are established in the jurisdiction, including not-for-profit companies, commercial or for-profit companies.

These landholders may in turn lease or delegate governance or management responsibilities to others, including the private actors described above. Landholders usually have the right to determine the land-use including for nature conservation purposes. This can include establishing the area as a PPA as defined by IUCN and/or in terms of the relevant legislation in the jurisdiction, which may allow for the designation of the area as a PPA or as a land-use planning zone restricted to nature conservation. Conversely, the rights of landholders may be constrained by prevailing land-use planning laws that regulate the kinds of activities that may be conducted on private property.

Accountability for the area and for the activities that take place in the area, and impacts on neighbouring properties, are the responsibility of the landholders. The conduct of nature conservation activities is generally assumed to be in the hands of landholders, although official recognition of this land-use and associated costs and benefits may be subject to specific nature conservation or heritage conservation legislation.

For an area in private ownership to be designated or declared to be a PPA, it must meet the requirements for a protected area as defined by IUCN or in the equivalent applicable laws, including the statement of intent to achieve the conservation of nature in the long term. Achieving this degree of permanence usually requires an instrument that

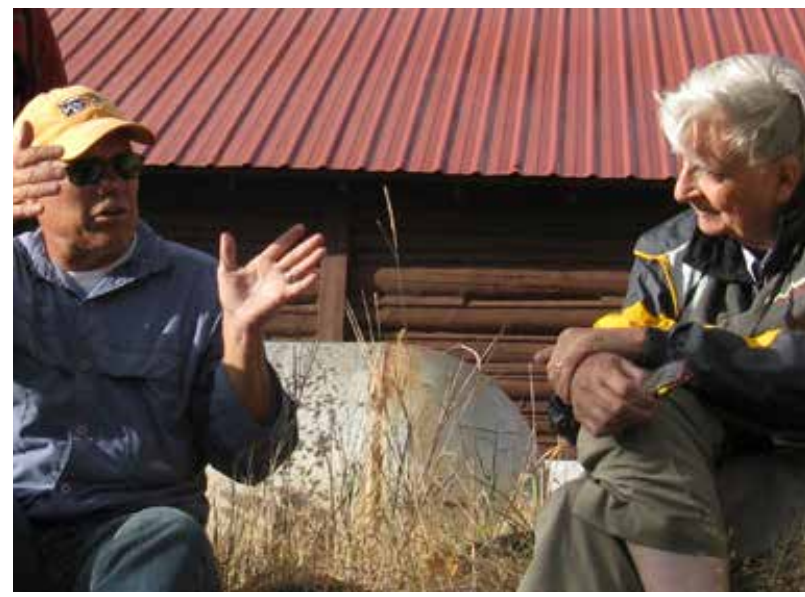

Mike Phillips and E.O. Wilson discussing imperilled species conservation projects at the Flying $D$ Ranch, a 46,000 ha private conservation property in southwestern Montana, USA, owned by R.E. (Ted) Turner.

(C) Turner Endangered Species Fund

is binding on current and future successors in title in the long term. This can take the form of a specific statement of intent, undertaking, contract, articles of association covenant, registered servitude in favour of nature conservation over the title to the property, memorandum of understanding or other similar instrument (see Table 3). The many options for establishing permanence are more fully discussed in Part B Section 4, and several diverse instruments for establishing PPAs, both through voluntary declaration or with the support of relevant legislation are detailed in the Part D Case Studies.

In turn, the landholders of the property and hence signatories to the founding statement of intent, may organise themselves in such a manner as to exercise their responsibilities. This may take the form of a board, committee or other governance body, with a particular composition, powers and duties, and which in turn, may assign, engage, contract, delegate or commission the day-to-day management of the area to be undertaken by a management team of volunteers or employees, or another contracted management agency. The governance responsibility should not be confused with the responsibility to undertake day-to-day management. In practice, however, confusion often prevails, since the management agency may be the public face of the PPA, and especially when governance and management are undertaken by the same entity or persons. In these situations, it is necessary to understand who holds the ultimate legal and moral responsibility for the PPA, this being a factor of the specific private governance arrangements (Borrini-Feyerabend et al., 2013).

Author: Trevor Sandwith, IUCN 


\section{Section 1: Establishing a privately protected area}

\section{Who should read this section? \\ Anyone who is engaged in the establishment or management of a PPA, whether as landholder or government authority with a mandate for helping establish PPAs. Although not all the best practices below will be applicable to every type and size of PPA, the examples draw from experiences around the world to provide guidance on some of the most important elements of PPA establishment.}

An important part of developing best practices around the establishment of PPAs is to understand the diversity of reasons motivating people to set up PPAs. Establishing a PPA is in some ways similar to establishing other types of protected areas, but there are key differences. PPAs can be, and are often, set up unilaterally by a single individual; others may involve large groups of people (e.g. company workers or religious orders). PPAs can also be established by organisations (e.g. NGOs) often with very large numbers of voluntary members. Examples of PPAs that have been established by different groups are found throughout these guidelines.

Landholders have a range of motivations for developing PPAs. While these can be in response to external incentives and drivers (see Section 3), experience and research (e.g. Farmer et al., 2011; Leménager et al., 2014; Selinske et al., 2015; Farmer et al., 2016) indicate that for many individuals the most powerful motivations are personal and intrinsic, ranging from altruism to spiritual or religious beliefs, and are often complicated. Mechanisms for the recognition and establishment of PPAs vary depending on a country's legal and regulatory frameworks (or lack of them) (Mitchell 2005). PPAs are established voluntarily and this section describes some of the common conditions and drivers that often accompany establishing a PPA.

\section{Principle 1.1: A PPA must meet the definition of a protected area}

To be recognised internationally by IUCN and listed on the WDPA (see Section 7), a PPA must meet IUCN's definition of a protected area (see Part A), that is, the primary objective must be nature conservation. Areas that do not meet the definition are not protected areas, and in this regard private areas are no different to government areas. Areas that do not meet the protected area definition but that make effective and permanent contributions to conservation may qualify as other effective area-based conservation measures (OECMs), as introduced in the CBD's Aichi Biodiversity Target 11 (Jonas et al., 2014, 2018; Mitchell et al., 2018) (see Appendix 1).
Best Practice 1.1.1: PPAs should be officially
recognised by a credible entity

Recognition often comes from government (see Case Study 1 from Australia and 7 from New Zealand and Best Practice 1.2.1), and this is highly desirable, if the area is to be reported through official channels into the World Database on Protected Areas (see Section 7). It is not the only option, as PPA owners sometimes choose not to engage with state processes that are specifically designed to recognise PPAs (Clements et al., 2018). Independent recognition can also sometimes be given by international organisations such as IUCN (e.g. see Case Study 12 from the UK and Best Practice 7.1.8) or regional/national/local PPA networks (see Section 8). Any recognition entity should be independent of the landholder, that is to say, recognition should not be selfgranted. Exceptions may be made in the case of lands held fee-simple by conservation NGOs, provided they have some form of accreditation of their mission and function. Having multiple parties to a PPA agreement can heighten security of protection.

Best Practice 1.1.2: Independent third-party recognition can operate alongside official, governmental recognition of PPAs

IUCN and WCMC are establishing a system for improving recording of PPAs in the WDPA, in parallel to the current government-centred processes and using independent experts (see Section 7 for more detail and Case Study 4 from Costa Rica). Similar systems can be established the national level (Bingham et al., 2017).

\section{Best Practice 1.1.3: Accreditation programmes can provide additional recognition of a PPA}

Recognition is not always the same as accreditation. Recognition may certify that minimum legal requirements are met. Accreditation goes further, evaluating management and governance in a more detailed way with periodic assessments. A third-party accreditation usually certifies 
the compliance of an area, business or product to specific performance standards (see also Best Practice 2.4.3). Third party accreditation ensures transparency and provides assurance that enables the public, authorities and other stakeholders (including government) to trust that stated objectives are met. Systems that may be relevant for PPAs include: the recognition of Global Ecosphere Retreats (see Box 8.3), IUCN's Green List of Protected and Conserved Areas (see Box 1.1) and The Land Trust Alliance Standards and Practices (see Box 8.2).

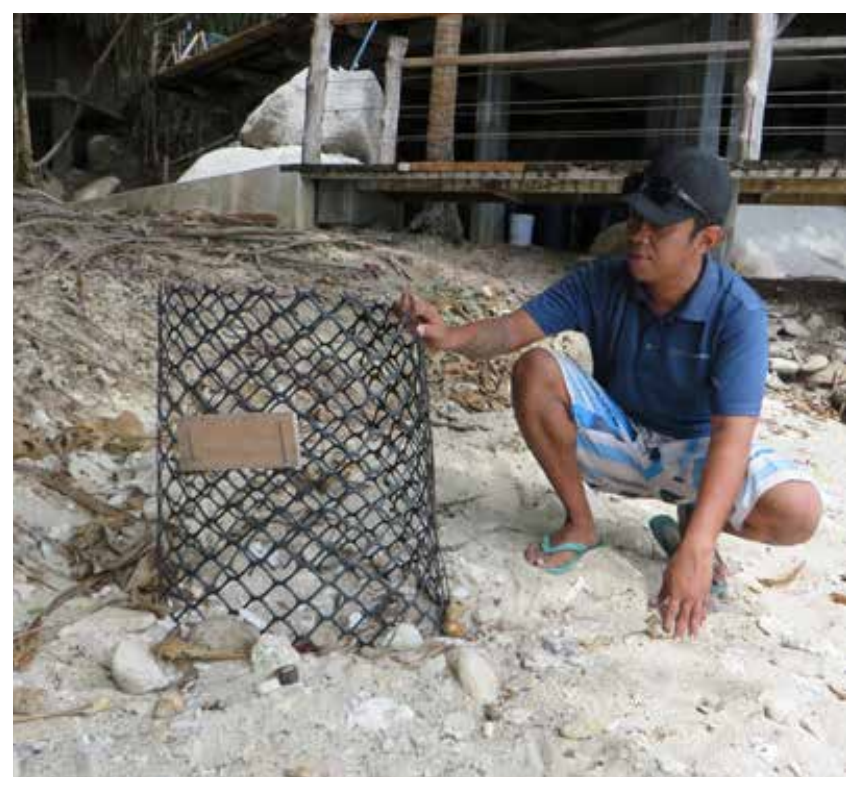

Creating turtle nests on one of the Long Run member sites @ C Nikoi Island, Indonesia

\section{Box 1.1 \\ IUCN Green List of Protected and Conserved Areas}

The IUCN Green List of Protected and Conserved Areas Programme ${ }^{4}$ aims to encourage, achieve and promote effective, equitable and successful protected and conserved areas to deliver conservation outcomes. The Green List Standard, approved by the IUCN Council in November 2017, is organised into four components reflecting successful nature conservation in protected and conserved areas. The baseline components are:

- Good governance;

- Sound design and planning;

- Effective management;

- Successful conservation outcomes.

A User Manual (IUCN WCPA, 2016) describes how the IUCN Green List Standard developed, the supporting programme, how protected areas are evaluated against the Standard through a set of adapted indicators and how observance of the rules and procedures of the User Manual is verified. An example of how the Green List has been applied in PPAs is provided in Case Study 6 from Kenya.

\section{Principle 1.2: PPA owners and managers should articulate clear conservation objectives from the outset}

PPAs may be established for a variety of reasons and it is important for PPA owners (and holders of easements or covenants) to articulate conservation objectives clearly at the initiation of the project (Best Practice 2.2.1). For example, conservation NGOs such as land trusts may target specific areas that are particularly important for biodiversity or other conservation values. Conversely, landholders may choose to protect his or her property based on personal sympathies, irrespective of its priority in national strategy. In other cases, conservationists may mobilise to acquire and protect parcels of land under threat of land use conversion. However, all should be able to demonstrate their intended role in conserving nature on that land irrespective of other land uses (see Principle 1.1 and Box 1.2).

\section{Box 1.2 \\ Supporting conservation and economic development in South Africa}

South Africa's biodiversity stewardship sites provide for a range of economic and commercial activities dependent on the level of protection and land use restriction prescribed. The Business Case for Biodiversity Stewardship (SANBI, 2015) makes a strong argument to use the establishment of PPAs, through biodiversity stewardship, for stimulating rural growth/sustainability using the wildlife economy. As a result, PPAs in South Africa often underpin vital and economically sustainable activities, whilst being clearly set up and managed for conservation.

The Sneeuberg Protected Environment ${ }^{5}$ in the grasslands of north-eastern Free State was declared with nature conservation as its primary objective but with livestock farming as the primary land use. While PPAs in South Africa require a management plan encompassing issues like grassland management and habitat rehabilitation, these management objectives still allow landowners to undertake economic activities on the land if they are compatible with its PPA status. The management plan for Sneeuberg, for example, incorporates both environmental management for grasslands and wetlands as well as the continuation of commercial food production. Additionally, it has inspired the economic development of local tourism based on bird watching. This PPA model facilitates effective nature conservation whilst providing livelihoods, wildlife-based economic development, food security and involvement with the agricultural sector which is a large contributor to South Africa's gross domestic product.

Author: Daniel Marnewick, BirdLife South Africa 
Best Practice 1.2.1: Where possible, when establishing PPAs and developing management objectives, link them to national or sub-national priorities for nature conservation

Most countries have National Biodiversity Strategy and Action Plans $^{6}$ (NBSAP) and other planning instruments, which usually include some prioritisation for establishing new protected areas, e.g. identifying ecosystems that are under-represented in protected areas. When available, such priorities should be used to help target establishment of PPAs, particularly in the case of conservation NGOs purchasing land for conservation or prioritising covenant/easement establishment. Governments can help facilitate this process. In Mexico, for example, formal recognition of a PPA requires the existence of a management plan demonstrating the area's biological significance in the context of the National System of Protected Areas and the participation of all stakeholders (Hora et al., 2018). In the USA, government agencies provide strategic mapping to organisations setting up and managing PPAs, many of which adopt priorities in alignment with government-identified strategies (see Box 1.3). Similar guidance is available in South Africa (see Case Study 10). In Australia, government funding for purchase of PPAs is linked to priority bioregions (see Case Study 1). This is also how the European Union's Natura 2000 Network operates (see Box 1.4).

\section{Box 1.3 \\ BioMap: Mapping priorities for acquisition in the State of Massachusetts, USA}

The Commonwealth of Massachusetts, USA, and The Nature Conservancy conducted extensive mapping exercises to identify:

- Habitats for rare, vulnerable or uncommon species;

- Priority natural communities;

- High-quality wetland, vernal pool aquatic, and coastal habitats;

- Intact forest ecosystems;

- The largest landscape blocks in each of eight ecoregions and adjacent uplands that buffer wetland, aquatic and coastal habitats.

The exercise identified over a million hectares of important biodiversity areas across the state. Since 2010 the BioMap has set priorities for the state's conservation land acquisition grants and, as a result, most land trusts have aligned their strategies with the BioMap when setting priorities for new PPAs (Commonwealth of Massachusetts and The Nature Conservancy, 2010)

Author: Brent Mitchell, QLF

\section{Box 1.4 Regional nature conservation strategies across the European Union}

The European Union's Natura 2000 Network identifies priorities for conservation at a continental level, defining habitats and species of European importance and setting targets for achieving favourable conservation status for them. These are then implemented nationally and regionally, with local work programmes, priorities (Prioritised Action Frameworks) and funding. All the large NGOs in Europe which buy, own and manage land for conservation use these lists, targets and distribution maps to fine-tune their own work programmes for PPAs. The LIFE programme run by the European Commission provides up to 75 per cent co-financing for conservation NGOs, and other private bodies, such as farmer or forester associations or private commercial companies (providing they give the right guarantees and evidence of having access to scientific management expertise), to buy land with habitats/species of European importance to set up PPAs (Tasos et al., 2014)

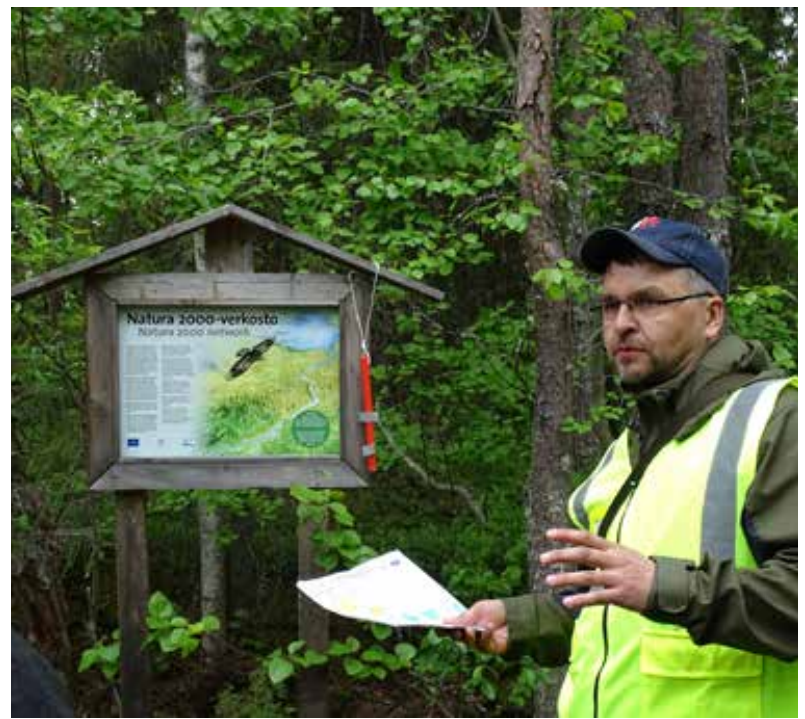

Kätkävaara Nature Trail, Finland @ Sue Stolton

Best Practice 1.2.2: Where national priorities do not exist, or are incomplete, internationally recognised conservation prioritisation exercises can help inform PPA establishment

Internationally recognised prioritisation processes can help inform PPA establishment in the absence of national priorities. For example, Key Biodiversity Areas (KBAs) are sites contributing significantly to the global persistence of biodiversity (IUCN, 2016a). Sites qualify as global KBAs if they meet one or more of 11 criteria, clustered into five categories: threatened biodiversity, geographically restricted biodiversity, ecological integrity, biological processes and irreplaceability. The KBA criteria can be applied to species and ecosystems in terrestrial, inland water and marine environments and can help identify priority sites for PPA establishment. The KBA partnership is made up of several leading conservation 
organisations including IUCN, and the World Database of $\mathrm{KBAs}^{7}$ provides information on location (see Box 2.3). Important Bird and Biodiversity Areas (IBBAs) are based on a similar concept and have been developed and applied for over 30 years. ${ }^{8}$

Best Practice 1.2.3: While governments should encourage PPA establishment in areas targeted by national or sub-national priority setting, they should not preclude PPA establishment in areas currently considered of lower priority

The world is undergoing rapid change, the results of which are not fully understood. Much of the conservation planning that has taken place may be overtaken by the impacts of climate change, rapid invasions by alien species or simply by a species not previously recorded in an area unexpectedly moving in. Having as wide an area protected as possible may well be essential for future conservation success, and adaptive management, and contribute to connectivity and the overall conservation estate. Individuals or entities setting up PPAs may choose to prioritise land purchases in places where land prices are relatively cheap (as in Chile, where there are few PPAs in the high priority, high-cost Mediterranean areas, but more in the lower-priority, lower-cost Patagonian regions). Alternatively, they may choose places where there are higher potential economic returns as is the case for the game reserves in certain parts of South Africa. Data on human and social factors (e.g. landholder willingness-to-participate) can be as important for identifying PPAs as conservation priorities (Knight et al., 2010, 2011), as is information on the types of support mechanisms available (Pence et al., 2003; Wilson et al., 2007).

\section{Principle 1.3: PPAs are best developed within a clear, supportive institutional framework that empowers governance and management}

PPA establishment is easiest where national/regional societal conditions and institutional and legal frameworks are conducive (see Case Study 10 from South Africa and Boxes 1.2, 1.3 and 1.4). These include not only legislation specific to the establishment of PPAs, but also extension support for ongoing management, carefully targeted financial incentives (see Section 3), some form of auditing, and social learning institutions.

\section{Box 1.5 International mandates for PPAs}

Paragraph 2 of decision XII/19 of the 2014 Conference of Parties of the CBD (UNEP/CBD/COP/DEC/XII/19 17 October 2014): "Recognises the contribution of private protected areas, in addition to public and indigenous and local community conserved areas, in the conservation of biodiversity, and encourages the private sector to continue its efforts to protect and sustainably manage ecosystems for the conservation of biodiversity."

Building on this, a resolution from IUCN's 2016 World Conservation Congress (WHC2016-036 "Supporting privately protected areas") encourages IUCN State Members to:

a) adopt policies that recognise, encourage, and monitor privately protected areas as a key contribution to national and international conservation targets, and also to implement mechanisms to integrate privately protected areas into national, provincial and local protected area systems;

b) create or promote legal and financial incentives, including through legal reform as appropriate, for the maintenance and strengthening of privately protected areas, particularly in countries where restrictions and/ or ambiguity in national legislation exist; and

c) work alongside civil society organisations to establish in the public agenda the importance of the voluntary conservation of private land, based on the concept of subsidiarity of the private, non-governmental sector in national conservation policies (IUCN, 2016b).

Best Practice 1.3.1: International recognition for PPAs can help provide support for PPA establishment and recognition

Both the CBD and IUCN have supported the further development of PPAs in recent decisions (see Box 1.5). Other international conventions (e.g. Ramsar, ${ }^{9}$ World Heritage ${ }^{10}$ and UNESCO's Man and the Biosphere Programme) ${ }^{11}$ can provide much needed international recognition to pioneering PPAs.

\section{Best Practice 1.3.2: Individual PPAs can become} exemplars for further PPA development in countries

Sometimes what is needed is one pioneering person or organisation to set up a PPA in a country to start a whole movement. (See for example Boxes 1.6, 1.7, 1.8 and 5.5 and Case Studies 3 from China, 4 from Costa Rica, 6 from Kenya and 9 from Samoa). In Peru, Chaparrí Ecological Reserve ${ }^{12}$ was established in 2001. An innovation at the time, the creation of the reserve inspired the government to develop suitable regulation and for landholders to create new PPAs (Solano \& Wust, 2005). 


\section{Box 1.6 \\ The Caucasus Wildlife Refuge: A pioneering PPA in Armenia}

In 2010, the Foundation for the Preservation of Wildlife and Cultural Assets ${ }^{13}$ (FPWC) in Armenia set up the Caucasus Wildlife Refuge ${ }^{14}$ (CWR). Currently protecting 20,000 ha ranging from semi-desert to alpine meadows, CWR provides a safe haven for a number of endangered and rare animals of the Southern Caucasus and Eastern Europe. The land for the refuge is leased by FPWC from the communities of Ararat and Vayots Dzor regions. The lease runs over 25 years, although in some cases communities have donated land for conservation in perpetuity. Currently the CWR is the only project of this type in the entire South Caucasus. It has been set up to be a model PPA project, where local community involvement, education, ecotourism and nature conservation are interconnected. The overall objective of CWR is to contribute to efficient biodiversity protection in Armenia by improving the protection of flora and fauna in the reserve's previously unsustainably managed buffer zones and wildlife migration corridors.

The success of the model is already apparent. FPWC maintains a permanently-staffed ranger station with six rangers employed from the community. Rangers patrol the area continuously to prevent any illegal activity and to monitor animals. Data is then entered into a database which serves to create a GIS map of the area offering a detailed insight into the range of species, sensitive habitats and important wildlife corridors. While in 2010, wildlife in the area was virtually non-existent, mainly due to illegal hunting, camera traps located all over CWR now show significant numbers of rare and Red Listed animals, including bezoar goats (Capra aegagrus), brown bears (Ursus arctos), Armenian viper (Vipera raddei) and bearded vultures (Gypaetus barbatus), as well as common species like the Caucasian lynx (Lynx dinniki), martens, badgers, grey wolves, foxes and hares. In the summer of 2013, camera traps recorded a male Caucasian leopard (Panthera pardus saxicolor) in the PPA. The success of CWR is allowing FPWC to plan an expansion of PPAs into important conservation areas in the southern edges of Armenia (Röttger et al., 2016).

\section{Author: Vicky Mkrtchyan, FPWC}

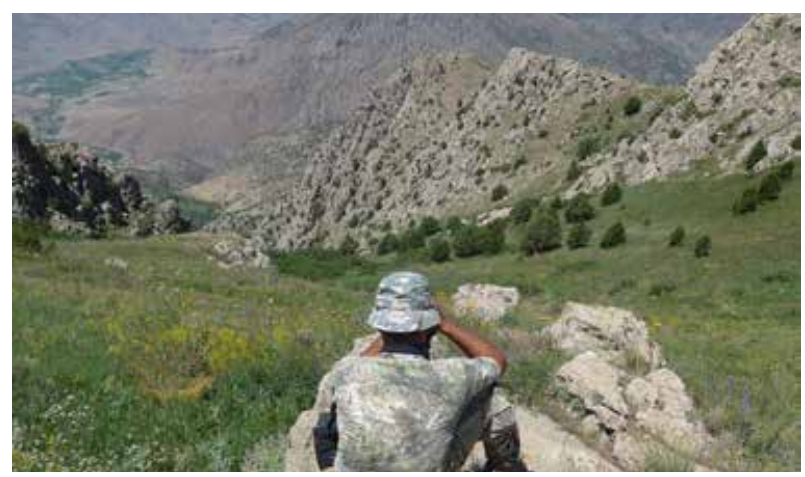

The Caucasus Wildlife Refuge @ Sue Stolton

\section{Principle 1.4: PPAs can be established through a variety of mechanisms}

Approaches to establishment of PPAs (Lausche, 2011) include:

1. An individual landholder voluntarily agrees/sets up a formal protected area, retaining title and exercising management responsibilities according to the designated conservation objectives and protected area category (see Case Studies 6 from Kenya and 10 from South Africa).

2. An individual landholder voluntarily surrenders to the government certain legal rights to use the private property in order to preserve certain conservation values, while retaining title and rights to other compatible non-conservation uses (such as maintaining a residence). Sometimes certain rights to a particular property are surrendered in exchange for rights to develop adjacent or other property, or other incentives such as a reduction in property taxes to compensate for the theoretical loss in value of other production potential. Mechanisms for this approach include the negative easement (called a conservation easement in some jurisdictions), servitudes, covenants running with the land (i.e. the restriction encumbers the property, not the landholder, and therefore remains in place, even if land ownership changes) and management agreements (see Case Study 1 from Australia, Case Study 2 from Brazil and Case Study 7 from New Zealand).

3. An NGO, research or religious organisation receives charitable contributions or raises funds privately or publicly to purchase, lease or manage donated land for protection and conservation (see Case Study 3 from China and Case Study 5 from Germany).

4. An NGO, research, religious organisation or for-profit organisation purchases or donates land/water and then sells this holding on to another private landholder after placing a protective agreement on the title (e.g. a revolving fund or covenants) (see Case Study 4 from Costa Rica).

5. A for-profit corporation purchases and directly manages an area for conservation to generate profit from conservation-compatible activities such as tourism (see Case Study 8 from Peru).

6. A for-profit corporation sets aside, donates or directly manages an area for conservation to build good public relations, or as a concession or offset for other activities. Motivations may include interest in gaining 'green' certification for an associated development project or making an investment for the future (see Case Study 9 from Samoa).

7. A for-profit corporation, NGO or research organisation, by contractual agreement with governments and/or local communities, creates a marine or lake no-take area based on a so-called Marine Conservation Agreement (MCA), and directly manages this area for conservation, research or to generate profit from compatible activities such as tourism (see Box 1.7 and TNC \& Cl, 2012).

These mechanisms should not be viewed or implemented in isolation. Rather, best practice is to find 'optimal mechanism mixes' that maximise conservation benefit for minimal effort 
or expense (Young et al., 1996). In addition, establishment agreements may not be enough to protect the area in the long term and additional mechanisms may be needed for long-term stewardship to ensure the area meets the definition of a PPA.

Best Practice 1.4.1: Mechanisms for setting up PPAs should not undermine other legitimate rights to land or resources

It is important that PPA landholders (or prospective landholders) undertake due diligence to ensure that purchasing areas for the purpose of establishing a PPA does not undermine legal or customary rights. Relying on information held by states or land registries is often insufficient and further research and enquiries are usually necessary. It is the responsibility of the prospective landholders to understand potential traditional access rights of local communities and apply the principles of Free Prior and Informed Consent (FAO, 2017) when engaging with communities and their rights. It is also important to understand whether different access rights to specific resources, spiritual sites or access routes are challenged by the PPA and ensure that the PPA owners work in consultation with the communities in planning conservation interventions that might restrict these. Where appropriate landholders should respect the UN Declaration on the Rights of Indigenous Peoples (UN, 2007) and be aware of IUCN policies which can help ensure best practice including: WCC 2016 Resolution 30 "Recognising and respecting the territories and areas conserved by indigenous peoples and local communities (ICCAs) overlapped by protected areas", ${ }^{15}$ WCC 2008 Resolution 38 "Recognition and conservation of sacred natural sites in protected areas"16 and WCC 2012 Recommendation 147 "Sacred Natural Sites Support for custodian protocols and customary laws in the face of global threats and challenges"17.

\section{Best Practice 1.4.2: Private governance is often established through land ownership but other mechanisms are possible}

PPAs can be established on leased land, provided these are intended to be long-term and renewable (see Case Study 3 from China and Box 1.7). Leases can pass between multiple owners but the conservation objective should remain. For example, in Tanzania, the Grumeti Reserve was created by the government in 1994 primarily in order to protect the path of the annual wildebeest migration. In 2002, the Grumeti Community and Wildlife Conservation Fund, a not-for-profit organisation, was granted the right to manage and conserve the 140,000 ha area. Four years later, the safari company, Singita ${ }^{18}$, took over the management of the property, at the request of the concessionaire. The conservation management of the area has remained constant throughout.

\section{Box 1.7 \\ Chumbe Island Coral Park in Zanzibar, Tanzania, the first marine PPA in the world}

Based on an investment proposal for a marine and terrestrial PPA presented by Chumbe Island Coral Park Limited (CHICOP), ${ }^{19}$ the Government of Zanzibar Commission for Land and Environment in 1993 leased an area of 2.44 ha for building an ecolodge on the uninhabited island of Chumbe to the company for a renewable period of 33 years. Between 1991 and 1994, $\mathrm{CHICOP}$ had successfully negotiated with the semiautonomous government of Zanzibar, Tanzania for the western coral reef and forest of the Island to be gazetted as an MPA, with management of the MPA entrusted to $\mathrm{CHICOP}$. The company was specifically established for the purpose of developing and managing the MPA in a financially sustainable way, utilising ecotourism to generate revenue for all MPA operational costs and associated conservation, research, education and awareness building activities. Through this, Chumbe became the first managed marine park in Tanzania, the first privately managed MPA in the world, and, to date, is a rare example of a financially self-sustainable MPA globally. The company objectives are not-for-profit, implementing conservation and education initiatives over more than 20 years under the framework of three management plans that were developed with stakeholder participation (19952005, 2006-2016 and 2017-2027). Ecotourism business operations follow commercial principles for maximising revenue and promoting cost-effectiveness to ensure a sustainable revenue stream for MPA activities, exemplifying a successful business-oriented approach to sustainable and effective MPA management.

Author: Sibylle Riedmiller, Chumbe Island Coral Park Ltd. Also see Dodds (2012) for more information

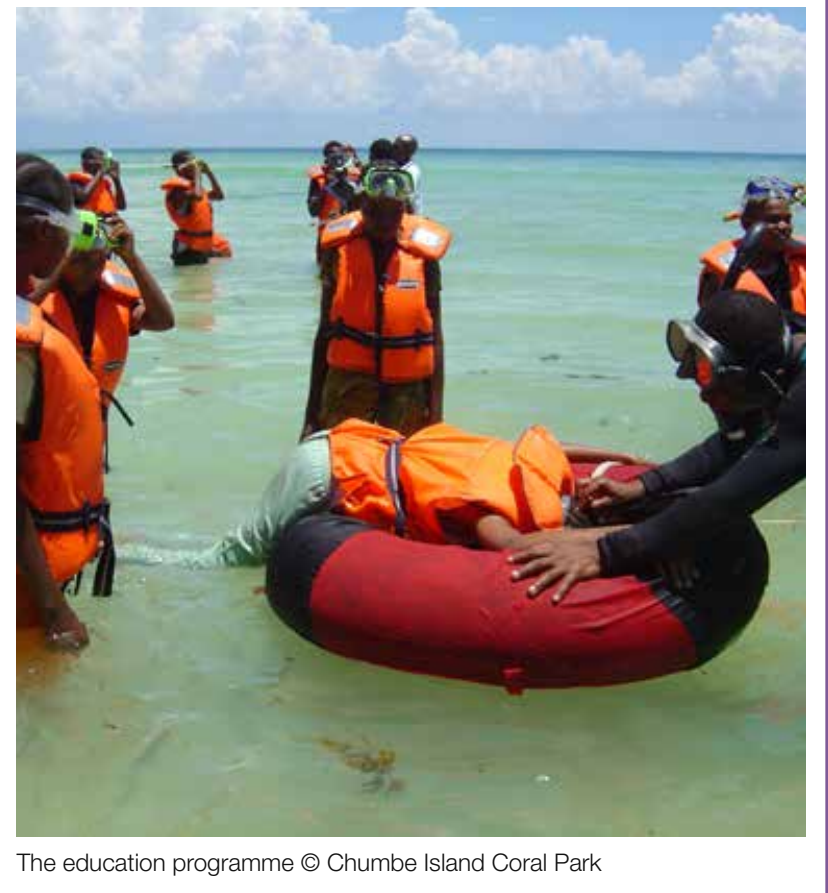




\section{Principle 1.5: All PPAs should be established with a long-term strategy and sustainable financing}

PPAs should be established with an expectation of long-term conservation outcomes; key elements of this are likely to include conservation planning, sufficient long-term financial support for management and generational succession.

Best Practice 1.5.1: Mechanisms for establishing PPAs should ensure protection in the long term

When establishing a PPA, it is essential that the conservation status of the land/water is secured for the long term (see Section 4), even where no legal instruments exist. It is therefore important to consider issues of intergenerational stewardship (Best Practice 1.5.2). Current generations dictate the conservation decisions of future generations through establishing PPAs, or creating 'perpetual' conservation easements (Thompson, 2004). Because conditions, preferences and knowledge change over time, such 'intergenerational conservancies' can become problematic unless successor landowners continue a conservation ethic and/or society is willing to uphold legal protections.

\section{Best Practice 1.5.2: Establishing a PPA should} anticipate changes in ownership of the property and establish rules for succession

PPAs are likely to be subject to changes in ownership governance over time. Contingency planning for such changes should be made during the PPA set-up phase (Best Practice 4.1.4 and Case Study 4 from Costa Rica). For example, if an NGO land trust or individual landholder were to create a PPA they might make an arrangement with a partner conservation NGO to assume responsibility for the property should the initial $\mathrm{NGO/landholder} \mathrm{no} \mathrm{longer} \mathrm{be} \mathrm{able} \mathrm{to} \mathrm{maintain} \mathrm{its} \mathrm{properties.}$ In some cases, government departments may also act as a default owner or manager. Conservation covenants can also be placed in land deeds/registries, ensuring any agreement is tied to the land, not the owners (see Box 1.8).

Where the declaration of a covenant or easement is via a government, statutory authority or NGO then resourcing for ongoing engagement with the current and any future landholders should be factored into future planning and budgeting. For example, in Brazil, Caiman Ecological Refuge ${ }^{20}$ is seeking to establish a partnership with an NGO to secure the management of the Private Reserve in the long term, mitigating potential changes of business priorities in the future.

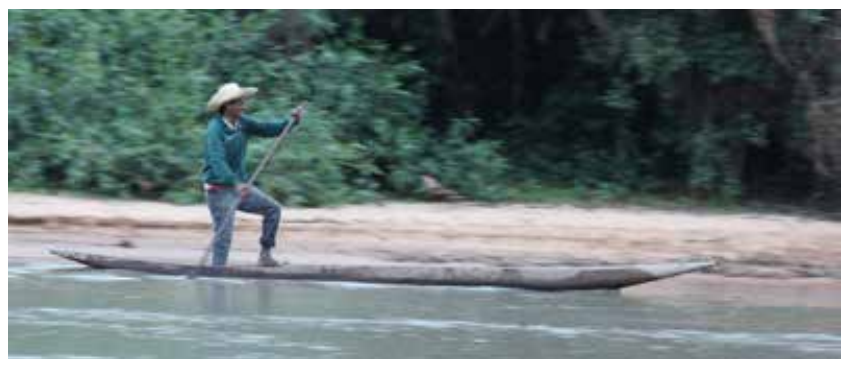

The last resident of RPPN Sesc Pantanal @ Brent A. Mitchell

Best Practice 1.5.3: PPAs created as biodiversity offsets should follow the IUCN policy on biodiversity offsets

Biodiversity offsets can contribute to positive conservation outcomes (see Box 1.9), such as the establishment of PPAs or restoration of biodiversity values on PPAs. However, IUCN's Policy on Biodiversity Offsets (WCC 2016 Res 059)21 also states that "biodiversity offsets are only appropriate for projects which have rigorously applied the mitigation hierarchy (avoid, minimise, restore/rehabilitate and offset)".

\section{Box 1.8 \\ Brazil, pioneers of PPAs}

Brazil was a pioneer nation in Latin America in creating private reserves, as the Forest Code of 1934 provided for the establishment of PPAs, called 'Forest Protectors'. These areas remained private property and were considered legally untouchable. With the reform of the Forest Code in 1965, the Forest Protectors category was eliminated, but the new law retained the option of declaring any portion of private land as a perpetual conservation area (Art. $6^{\circ}$, Federal Law $\left.n^{\circ} 4771 / 1965\right)$. This required signing an agreement with the authorities and recording it with the land deed. This new option, however, only became truly operational 25 years later with the official approval of this decree and the creation of the modern concept of Private Natural Heritage Reserves (RPPN in Portuguese) (Mesquita \& Vieira, 2004). See Case Study 2 on Brazil for more details.

Author: Maria Cristina Viera Weyland and members of the CRPPN, RPPN Association

\section{Box 1.9 \\ Ingula Nature Reserve South Africa: A corporate offset success story}

An environmental offset was required as part of the approval for the Ingula Pumped Storage Scheme development in South Africa (Maphisa et al., 2017). For this purpose, the Ingula Nature Reserve ${ }^{22}$ (a corporatelyowned PPA) surrounding the water utility was declared in 2018 with the primary objective of nature conservation. It is an example of how an industrial undertaking together with a suitable offset in the form of a PPA can successfully integrate conservation and development for mutual benefit.

Author: Daniel Marnewick, BirdLife South Africa 


\title{
Section 2: Managing a privately protected area
}

\author{
Who should read this section? \\ Anyone who is managing a PPA, whether a private landholder, NGO, etc. Although \\ not all the best practices below will be applicable to every type and size of PPA the \\ examples drawn from experiences around the world provide guidance on some of the \\ most important elements of PPA management.
}

Having a management system in place is an important step in ensuring effective nature conservation in PPAs. Ideally, a management system should consider all aspects of protected area management, from identifying objectives to monitoring and adaptation. The extent to which it is practical to implement the different best practices in this section will depend on the size and needs and conditions in individual PPAs.

There is already extensive information available on best practices for protected area management, much of it applicable to PPAs (see Box 2.1). This section provides examples of how these practices have been implemented by PPAs around the world.

\section{Box 2.1 \\ Protected area management tools and guidance}

Much has already been written and many methods developed to aid the planning and management of biodiversity for conservation. More information on overall best practices for a range of protected area management issues is provided by WCPA ${ }^{23}$ and through the extensive online volume on Protected Area Governance and Management (Worboys et al., 2015). IUCN's Programme on

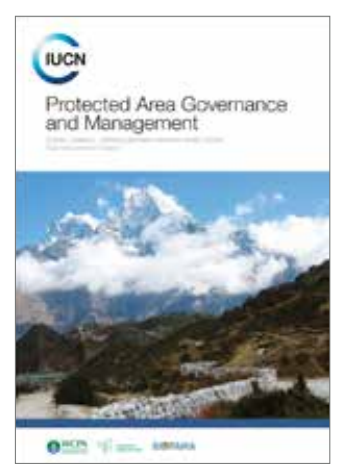
African Protected Areas \& Conservation (PAPACO) is developing a series of MOOCs ${ }^{24}$ (Massive Open Online Course) on conservation and protected areas, with another initiative being planned by the Zoological Society of London and National Geographic. The courses are meant for an unlimited number of participants and give anyone with an Internet connection access to knowledge on protected area management.

\section{Principle 2.1: Current and potential PPA landholders should have a clear understanding of what is happening in and around the PPA before developing management activities}

Where possible it is important to gather geographic, hydrological, social, ecological, geoheritage, cultural and legislative/political information on the PPA and its surroundings before planning any management activities. This step in planning is often referred to as a situation analysis (CMP, 2013). Individual owners may have knowledge on the area they are establishing as a PPA going back for generations. In other cases, NGOs/for-profit organisations may be purchasing/leasing a piece of land with more limited information available. The best practices below note some important information sources (see also Box 2.3). Most areas should also be able to access local information from conservation agencies, organisations and researchers. Partnerships (Best Practice 2.5.4) are important sources of information, and all partners should have a shared understanding of the area.

Best Practice 2.1.1: Management can be directed by legislation and/or from learning and sharing practices with similar properties

Management should build on what is already available. This may mean ensuring that actions follow government legislation, as in countries like Mexico (Hora et al., 2018), Brazil (see Case Study 2) and South Africa (see Case Study 10) where most PPAs are managed under the same legislative system as government-managed protected areas (see Box 2.2), or adapting management plans from properties with similar objectives. Given that many PPAs are relatively small, connectivity with neighbouring areas is particularly important. Spending time on finding out the context of the site (in terms of nature conservation and from a social, cultural and economic perspective) and surroundings can save resources when developing a management system. Where many protected areas are situated together within one landscape, one overall management plan may be better than plans for 
individual areas (see Box 2.4) and can be a more efficient use of time, funds and capacity. For example, the Avalon Marshes in Somerset, UK are becoming a mosaic of protected areas owned by government agencies and conservation NGOs, as commercial farming and peat production become less viable. Activities have developed in cooperation across the landscape and management actions are jointly planned (Avalon Marshes Landscape Partnership, 2011).

\section{Box 2.2 \\ Management best practice and legislative requirements within the context of South Africa's PPAs}

South Africa's "National Environmental Management: Protected Areas Act, 2003"25 requires all protected areas, including PPAs, to have a management plan drafted and submitted to the relevant conservation authority as well as having a management authority designated. The Norms and Standards for the Management of Protected Areas in South Africa (National Gazette No. 41224, 2017) and the Regulations for the Proper Administration of Nature Reserves, both developed in terms of South Africa's Protected Areas Act, include requirements for an assessment of the management of protected areas declared on privately-owned land. The Regulations require the designated management authority to monitor and report annually on the status of the implementation of the reserve's management plan, while the Norms and Standards require annual reports on progress towards meeting and maintaining the norms and standards. The reporting requirements of the latter are met through the completion of a management effectiveness assessment using a South African-specific version of the Management Effectiveness Tracking Tool (METT) (Best Practice 2.4.2). METT assessments are particularly useful as a means of identifying and prioritising management activities to address deficiencies and improve the effectiveness of protected area management. Assessments are completed quickly and easily. Ideally, they are completed by the protected area's managers, as well as their staff and other stakeholders, as a form of self-assessment. The assessments are best at comparing one site over time rather than creating a comparison between sites, as the repeat assessments provide trends in effectiveness over time and aid in the adaptive management of protected areas (Cowan et al., 2010).

Author: Greg Martindale, Conservation Outcomes
Best Practice 2.1.2: Incorporate conservation values and biodiversity status and trends into a management plan/system

When developing management systems it is important to get information for species, habitat status and trends. A baseline study helps to determine what should be monitored and assessed, and therefore how biodiversity status and trends can be understood. Few protected areas, whatever their governance regime, have comprehensive baselines for biodiversity, but having some knowledge of status and trends is vital for identifying specific management actions. As a first step, PPAs can compile and assess relevant existing data and develop, for example, basic maps of habitats, species occurrence and connectivity with other natural or semi-natural habitats. Particular attention should be paid to species or ecosystems of regional, national or global importance. Box 2.3 provides some global sources of information, but more local, regional resources will also be available.

Best Practice 2.1.3: Incorporate indigenous, local and traditional people and their knowledge, including, where appropriate, Traditional Ecological Knowledge into management

Working with and learning from others can save considerable time and effort, and help build local alliances, when developing management activities for a PPA. For example, during the rapid ecological assessments (Sayre et al., 2000) conducted by the Fundación Vida Silvestre in Argentina to develop a new agreement for a private reserve, interviews were conducted with personnel working in the area, neighbouring residents and other stakeholders. Sharing knowledge works two ways: local people learn more about the presence of wildlife species while sharing their perception of conservation problems, threats, etc., whilst the technicians who carry out the survey, or the owners of the property, learn of new information or issues which could impact site management. In some places, Traditional Ecological Knowledge can make an essential contribution to management (see Box 2.4).

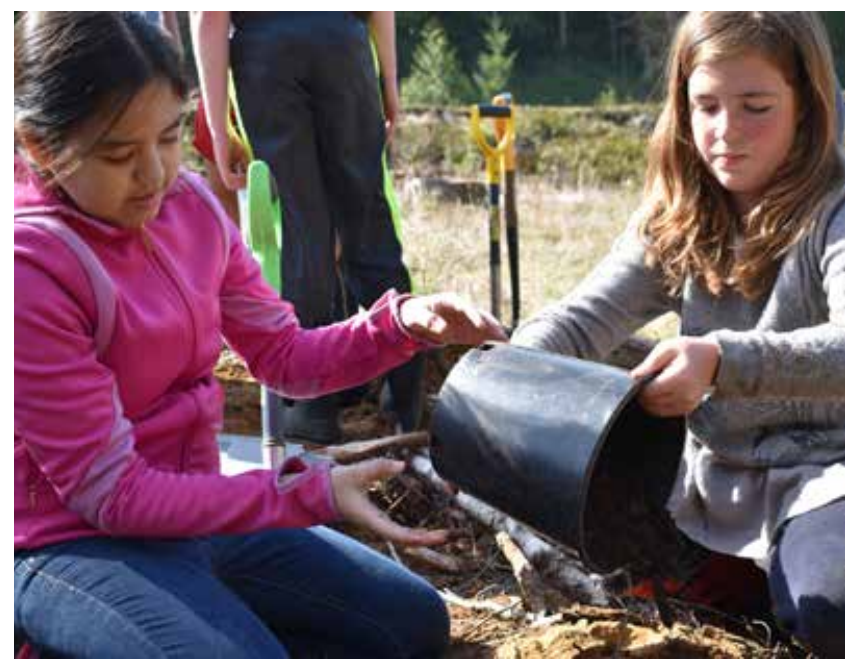

Guided by elders and knowledge holders, school children, students and local volunteers have helped the Galiano Conservancy (see Box 2.11) in Canada restore a native plant forage forest (c) Galiano Conservancy Association 


\section{Box 2.3}

\section{Sources of global conservation data to complement national data}

Protected Planet ${ }^{26}$ is the most complete source of spatial and management information on protected areas globally.

\section{The Global Biodiversity Information Facility (GBIF) ${ }^{27}$} contains data about all types of life on Earth. It is the world's largest biodiversity database with records of over 1.7 million species, ranging from bacteria to blue whales. Databases can be sorted by publisher, country, species, etc.

The IUCN Red List of Threatened Species ${ }^{28}$ is the most comprehensive global evaluation of the conservation status of plant and animal species. As well as global databases, National Red Lists ${ }^{29}$ have been developed in many countries.

\section{World Database of Key Biodiversity Areas ${ }^{30}$ is}

managed by BirdLife International on behalf of the Key Biodiversity Areas (KBA) Partnership. It hosts data on global and regional KBAs, including Important Bird and Biodiversity Areas, Alliance for Zero Extinction sites, KBAs identified through hotspot ecosystem profiles supported by the Critical Ecosystem Partnership Fund, and a small number of other KBAs. This database is updated as KBAs are revised and new KBAs are identified.

Google Earth ${ }^{31}$ provides online resources for satellite imagery, maps and terrain, whilst the Earth Engine ${ }^{32}$ has global imagery including historical imagery going back more than forty years which can be used to map an area and assist in providing baseline habitat data.

Global Forest Watch ${ }^{33}$ can analyse an area drawn on to its base map for forest loss statistics over this millennium. In Peru, the regional network in San Martin is using the Global Forest Watch platform to monitor deforestation in PPAs and is part of a multi-sector working group together with regional authorities to tackle issues related to forest management.

Planet.com ${ }^{34}$ with $175+$ satellites in orbit is able to image anywhere on Earth daily at $3 \mathrm{~m}$ and $72 \mathrm{~cm}$ resolution.

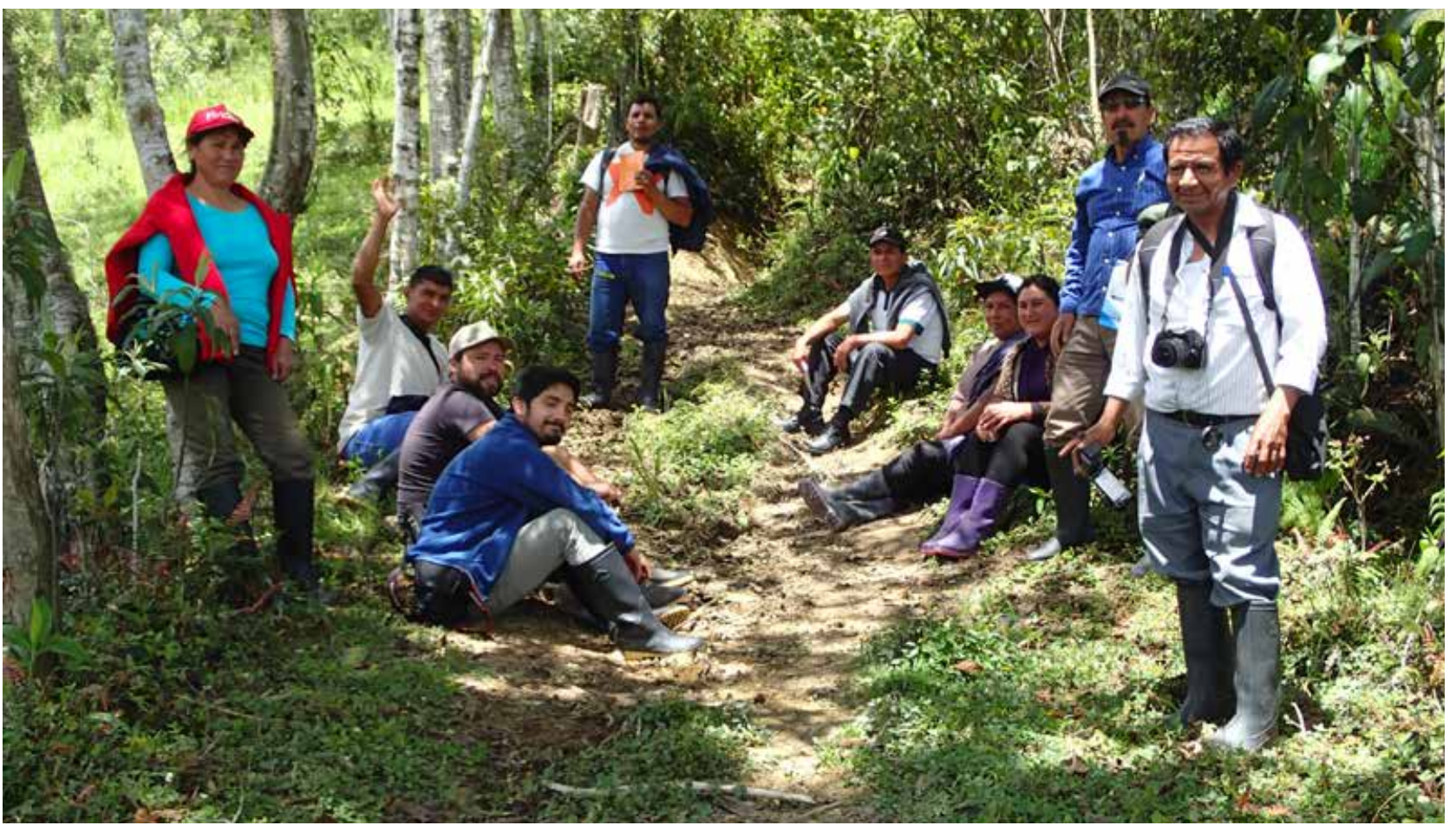

Members of the PPA network RED AMA, in Amazonas, Peru ground-truthing deforestation alerts at PPA Bosque de Palmeras - Molinopampa, based on information from Global Forest Watch (C) Aaron Groth 


\section{Box 2.4 \\ Traditional Ecological Knowledge and Bush Heritage Australia}

For Bush Heritage Australia ${ }^{35}$, working to incorporate Traditional Ecological Knowledge into PPA management is a fundamental operating principle that recognises and respects Aboriginal people's rights and interests over land and water. This starts when Bush Heritage is either invited onto Aboriginal lands or before land is purchased to create a PPA. It continues throughout PPA management to identify ecological, cultural and social values of importance to Aboriginal people, and to support Aboriginal knowledge systems and practices and their use. This is achieved through meetings with Aboriginal corporations and family groups, 'on Country' trips [trips to the field], cultural heritage assessments and by inviting involvement in conservation planning and land management. This helps to build long-term trusting relationships and partnerships and facilitates community involvement. The values identified by Traditional Owners are incorporated into Healthy Country Plans and PPA management plans, with strategies and actions flowing into work plans. The descriptions of values and selection of indicators for monitoring progress also incorporate cultural knowledge.

Collaborative management agreements between Aboriginal organisations and Bush Heritage are developed to guide governance arrangements that support the partnership and express the mutual commitment to putting the plan into action. As one example, Naree Station Reserve $^{36}$ in northern New South Wales is Budjiti Country and the Traditional Owners were involved in the PPA from the beginning. The property was purchased by Bush Heritage Australia in 2012 and in the ensuing six years, Budjiti people involvement has included participation in the initial ecological 'BioBlitz' (Best Practice 2.5.4), 'on Country' trips (2-3 per year), one large family gathering per year with the Elders and younger generations, and cultural heritage assessments which were based on important areas to the Budjiti.

Author: Sarah Eccles, Bush Heritage Australia

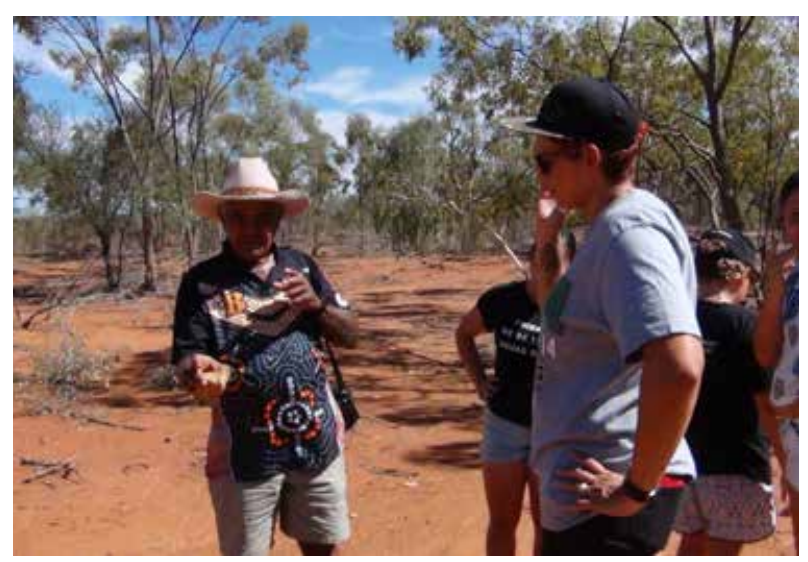

Budjiti Elder Phil Eulo sharing cultural knowledge at Bush Heritage Australia's Naree Station Reserve @ Sarah Eccles
Best Practice 2.1.4: Good consultation with stakeholders helps support their engagement and contribution to the development and management of the PPA

Mechanisms are needed that enable social and experiential knowledge and learning to be fed into management plans. Working with stakeholders and rightsholders is important to gaining a good understanding of the PPA, or potential PPA. This can help avoid threatening traditional access rights (Best Practice 1.4.1), avoid duplication of efforts (Best Practice 2.1.1) and find solutions to any challenges cooperatively. It will help potential PPA landholders who are not local to the area to get a better understanding of the context and ensure the relevance of the PPA locally in terms of social, economic and conservation outcomes. Consultation can help with communicating the PPA's goals and objectives, ensuring transparency and increasing support and engagement in the PPA. Collaboration can also increase skills and knowledge. Through the process of management, landholders develop place-based knowledge about conservation that can be valuable to PPA networks, conservation agencies and future landholders.

\section{Principle 2.2: Management systems should focus on the achievement of defined PPA objectives}

Management systems are generally laid out in written documents (e.g. five-year management plans and annual operational plans) that help develop a shared understanding of and a vision for a PPA. Management systems can also be made up of a number of smaller plans targeted at specific management issues or zones (e.g. tourism plans, business plans, research plans, patrol plans, restoration plans, monitoring plan, etc.) rather than one main plan, although it is important that these are bound together by an overall vision and agreed objectives. Management planning does not necessarily need to be a complicated or formal process, but it is important to think through what type of management the site needs and to record exactly what the PPA is trying to achieve.

Best Practice 2.2.1: Create a clear strategy (e.g. vision, mission, objectives and actions) as part of the management plan for the PPA

Developing and agreeing on a common purpose helps focus management activities and is good for communication and fundraising (see Box 2.11). This can be achieved through defining a vision for the PPA relevant to the local environment. The vision should describe the desired state that the landholders are working to achieve and will often include both conservation, social, cultural and economic elements (for example see Case Study 4 from Costa Rica). This can sometimes be ensuring maintenance of current conditions (in which case little active management may be needed). In others, the vision might describe a PPA transformed, for example, through restoration or reintroductions. A vision statement, as the name suggests, should be inspirational 
and brief. Management should focus on delivering the vision. Once a vision statement is in place, various other elements of a management system can be developed.

\section{Best Practice 2.2.2: Develop plans of activities based on conservation objectives against which progress can be assessed}

Worboys and Trzyna (2015) provide a good introduction to the art of management planning. Ideally, plans of activities should include timelines, responsibilities, resource allocation (e.g. budget, equipment, etc.), scheduling, prioritisation and mapping (e.g. zones).

Best Practice 2.2.3: Conduct a risk assessment and develop a mitigation plan, so when a problem arises there is a plan of action ready to implement

Although this level of planning may seem a burden, particularly for small PPAs with little management capacity, it is exactly such areas that are least able to cope when problems arise. Mitigation planning (i.e. the process of developing options and actions to enhance opportunities and reduce threats to a PPA's objectives) should be part of the overall management system and be known by everyone involved in the PPA's management. Assessments should consider major risks (e.g. potential threats) to the site's objectives such as fire (see Box 2.5), major poaching, flood, insurrection, collapse of funding, etc. Other types of risk assessment (e.g. risks to any volunteers, partners working on the site or visitors) will also have to be assessed and insurance policies may be needed. As with management plans, PPA landholders should check if similar plans are available locally that can be adapted.

\section{Principle 2.3: The full costs and benefits of the PPA should be understood as the basis for management}

The costs associated with management of PPAs will vary depending on factors including the size, natural features and goal of the PPA. Even leaving land in its current state can incur costs in fire-management, legal defence, etc. (Rissman \& Butsic, 2011). Some PPAs will be funded by the landholders, often through earned income (e.g. from tourism or membership of an NGO), whilst others from foundations, grants, etc. (see Section 3 on incentives) or a mix of these. Whatever the source of funds, it is important to clearly link activities in the management plan/system with realistic budgets. Developing a detailed management plan which cannot be implemented is a waste of resources. Working within PPA networks (see Section 8) or with neighbouring conservation lands/waters can help spread both workloads and financial outlay (Best Practice 2.1.1). In addition, the management of a PPA may require other types of resources such as equipment, technical and human resources and should be considered when structuring the management plans (Ojidos, 2017). As well as the costs, the full range of benefits of PPAs needs to be clearly understood and benefit sharing activities developed where feasible.

\section{Box 2.5}

\section{Mitigating fire risk: An example from Brazil}

Although fire is a natural part of many ecosystems, wildfires can pose significant risk to habitats, wildlife, PPA staff, visitors, infrastructure and neighbouring properties. Fire management is an area where many PPA landholders feel they do not have enough capacity (e.g. Halliday et al., 2012). In areas prone to fire, mitigation planning should include identifying fire risk zones where a fire is likely to start and spread. A precise evaluation of forest fire problems and decisions on responses can be informed by a fire risk zone map. Satellite data plays a vital role in identifying and mapping forest fires and in recording the frequency at which different vegetation types/zones are affected. A geographic information system (GIS) can be used to combine different forest-fire-causing factors on the map. Tools which can assist fire planning include near real-time global fire data from satellite imaging, available via NASA's Active Fire Data ${ }^{37}$ and the Global Forest Watch Fires $^{38}$ (GFW Fires) platform.

In Brazil, two PPAs, Salto Morato and Serra do Tombador, are maintained by a Brazilian cosmetic company, through the Grupo Boticario Foundation. The sites have several procedures and standards applied to the assessment and mitigation of risks and safety of the company employees. At Serra do Tombador, a Fire Risk Zone Map is developed every year due to the high threat of fire. Maps are developed considering an integrated analysis of the risk factors that directly influence the ignition and propagation of fire (climate, wind and biomass), as well as the conditions of access within the PPA, the establishment of priority areas for protection and locating protective actions that will be carried out during the year. In addition, as the fire threat occurs beyond the limits of the PPA, in 2014 the Grupo Boticario Foundation created a regional network that monitors and optimises fire prevention actions and encourages the government to improve enforcement.

In the State of São Paulo, the Private Reserves Association (FREPESP Federation of Private Ecological Reserves of the State of São Paulo ${ }^{39}$ ) has entered into a partnership with the State Government and military police to tackle fire outbreaks. PPAs in the State can make Protection Plans knowing they have the support of the military police and public fire-fighting capacity to help protect their reserves.

Author: Flávio Ojidos, National Confederation of Natural Heritage Private Reserves, Brazil 


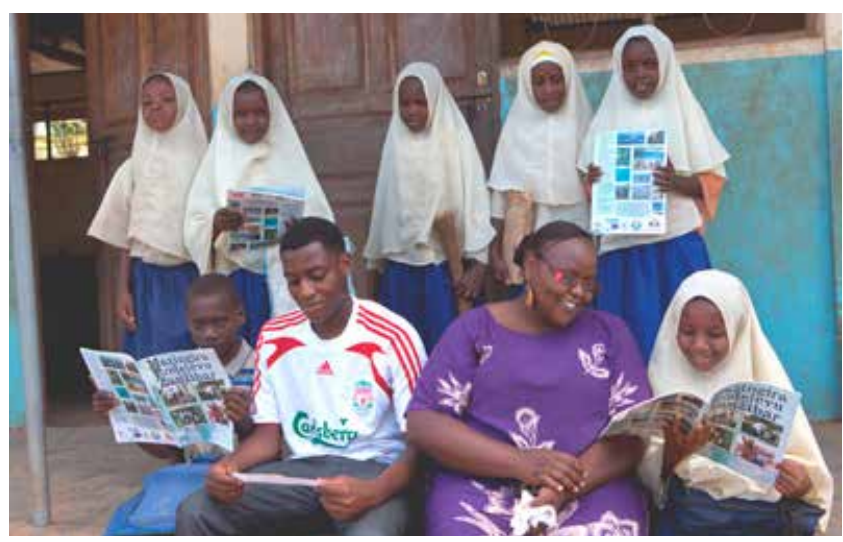

The education programme at Chumbe Island Coral Park

\section{Best Practice 2.3.1: Link management activities to a realistic budget}

Once a draft management plan/system has been developed it is important to link activities to a realistic budget to understand the minimum costs for maintaining the PPA. Risks to financial sustainability also need to be assessed, and it is important that landholders understand risks and plan for disruption (Best Practice 2.2.3). It is useful to distinguish between operational costs (e.g. the daily management costs of the site such as staff, equipment, maintenance, enforcement and anti-poaching activities) and costs of specific management actions (e.g. restoration projects or specific research). According to the Grupo Boticario Foundation in Brazil, this dual approach also improves operational efficiency and evaluation and makes strategic activities easier to plan. El Cañi Sanctuary ${ }^{40}$ in Chile is managed by the Grupo de Guías Cañi (GGC), a local association which spent five years preparing to finance management through ecotourism. However, increasing environmental impacts due to rising visitor numbers (visitors increased ten-fold between 2007 and 2017), the lack of formal planning and limited human and financial resources made it clear that GGC needed to design a Visitor Management Plan based on the actual management capacity (two people) and financial resources. (See the Tourism and Visitor Management in Protected Areas BPG (Leung et al., 2018) for more information on visitor planning.)

\section{Best Practice 2.3.2: The PPA should contribute benefits to the local community}

PPAs, and in particular for-profit PPAs, should wherever possible contribute to the local community, through direct employment, local supply/sourcing, supporting community capacity (e.g. in health, education, finance or security issues) and knock-on effects such as boosting visitor numbers for restaurants, hotels and touring guides (see Case Study 6 from Kenya). Undertaking such activities should be carefully planned, potential markets and customers assessed and care taken to avoid unrealistic expectations. Enterprises wherever possible should keep developments appropriate with the local environment, building traditions, etc. (see Case Study 4 from Costa Rica). Tourism based in PPAs can act as a catalyst to raise awareness about conservation and social issues faced by guests or other stakeholders and leverage support for infrastructure development, health or other education programmes, etc. (see Box 2.6). PPAs can also be effective training grounds for local community involvement in conservation linked development. One of the lodges in Makuleke Contractual Park ${ }^{41}$ in South Africa, for example, is managed by the 'Seasons in Africa' company on a 30-year concession from the local community who own the land. At the end of this period, the lodge ownership will pass to the community who will have been trained with the skills to operate it profitably. Finally, but critically importantly, any involvement of local communities and indigenous peoples in decision-making, and distribution of any associated costs and benefits, should be equitable (Franks et al., 2016).

\section{Box 2.6 \\ Supporting coastal communities in Indonesia}

An ecotourism venture supports conservation of the 15 ha Nikoi Island in Indonesia. Management focuses on marine conservation, both to sustain the business and to help restore the health of the area's reefs, which have been threatened by overfishing. For many years, Nikoi has been working towards the establishment of a marine protected area. Buy-in of the local population is an essential element of success, both to raise awareness about sustainable resource use and to strengthen the capacity of the local population to engage in tourism as a livelihood. In 2010, the founders established The Island Foundation. ${ }^{42}$ The Foundation has established seven education centres focused on delivering high quality education through an innovative curriculum supporting literacy programmes and a range of skills development. So far 1,100 teachers from 25 state schools have been trained and 2,300 children have participated in the programmes. In addition through the revival of the cultural tradition of Jong boat racing and community beach clean ups, Nikoi is able to raise awareness about the health of the marine ecosystem with local fishers, creating further buy-in for the development of a protected area.

Author: Delphine Malleret King, The Long Run and Andrew Dixon, Nikoi Island

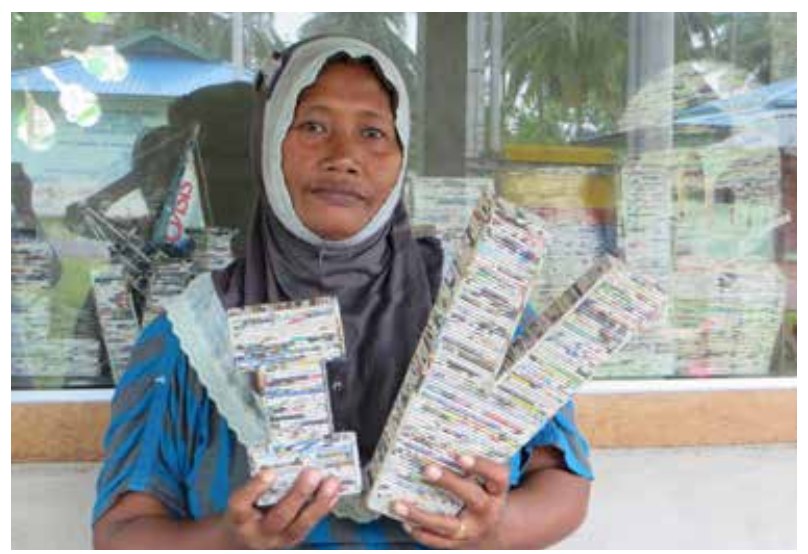

Nikoi Island Foundation products @ C Nikoi Island, Indonesia 


\section{Box 2.7}

\section{Monitoring at Haller Park, Mombasa, Kenya}

Haller Park ${ }^{43}$ (formerly Bamburi Nature Trail) is located south of Lafarge's Bamburi cement plant along the Mombasa/ Malindi highway. The history of the park, which combines a PPA and a zoo, goes back to the 1970s when Dr Rene Haller started to experiment on techniques for rehabilitating extensive open disused limestone quarries. Over the decades, the barren landscape has developed into a diverse ecosystem of forest, grasslands and wetlands. This longterm restoration is particularly important in this region; East African coastal forests have high biodiversity value and are classified as one of the 21 global biodiversity hotspots, but much of the coastal forest has been destroyed and only few patches remain.
A long-term partnership between WWF and Lafarge focused on a range of issues including a quarry rehabilitation management system. Because of this long experience in developing restoration, generic guidance on monitoring (Lafarge, 2007) was also developed, along with specific monitoring plans for a number of restored sites including Bamburi. Lafarge staff were interested in having a more comprehensive monitoring system in part to learn about the effectiveness of different indicators, to provide information to other tropical quarry sites. Table 4 below summarises the monitoring system developed.

Author: Nigel Dudley, Equilibrium Research

Table 4: The draft Bamburi monitoring system

\begin{tabular}{|c|c|c|c|c|c|}
\hline & Aim & Indicator & Collection method & Collector & Notes \\
\hline 1 & \multirow[t]{7}{*}{$\begin{array}{l}\text { Self-sustaining } \\
\text { forest }\end{array}$} & Tree planting & $\begin{array}{l}\text { Number planted per } \\
\text { year }\end{array}$ & Lafarge Eco Systems staff & Already collected \\
\hline 2 & & Biomass & Total biomass of trees & To be decided (TBD) & \\
\hline 3 & & $\begin{array}{l}\% \text { (or number) of native tree } \\
\text { species }\end{array}$ & $\begin{array}{l}\text { Data from planting but } \\
\text { also surveys }\end{array}$ & Lafarge Eco Systems staff & \\
\hline 4 & & Invasive species & Focus on 1-2 species & TBD & (e.g. Neem) \\
\hline 5 & & $\%$ under rehabilitation & GIS & Would need regular images & \\
\hline 6 & & Water quality & & Lafarge Eco Systems staff & Already collected \\
\hline 7 & & Soil profile & $\begin{array}{l}\text { Either humus depth or } \\
\text { number of millipedes }\end{array}$ & Lafarge Eco Systems staff & \\
\hline 8 & \multirow[t]{5}{*}{ Biodiversity } & Birds & $\begin{array}{l}\text { Perhaps particular focus } \\
\text { on rarer birds }\end{array}$ & Lafarge staff, students & $\begin{array}{l}\text { For example, return of } \\
\text { hornbills }\end{array}$ \\
\hline 9 & & Bats & Number of species & TBD & Showing increase \\
\hline 10 & & Monitor lizards & Abundance & TBD & $\begin{array}{l}\text { Still uncertain what it } \\
\text { would tell }\end{array}$ \\
\hline 11 & & Animal health & $\begin{array}{l}\text { Physical condition, dung } \\
\text { worms, ticks, browsing } \\
\text { impacts }\end{array}$ & $\begin{array}{l}\text { Lafarge staff already collect } \\
\text { data }\end{array}$ & $\begin{array}{l}\text { Probably most useful } \\
\text { in wild animals }\end{array}$ \\
\hline 12 & & Rare species & Monitoring return & & \\
\hline 13 & $\begin{array}{l}\text { Variable } \\
\text { landscape }\end{array}$ & $\begin{array}{l}\text { \% water (or other landscape) } \\
\text { feature }\end{array}$ & GIS & Would need regular images & \\
\hline 14 & $\begin{array}{l}\text { Educational } \\
\text { value }\end{array}$ & Visitors (foreign, Kenyan, school) & Numbers per year & Lafarge staff collect data & $\begin{array}{l}\text { Good also to get } \\
\text { feedback }\end{array}$ \\
\hline 15 & \multirow[t]{2}{*}{ Social values } & Baobab trees & $\begin{array}{l}\text { Maintenance of trees for } \\
\text { cultural reasons }\end{array}$ & Lafarge staff collect data & \\
\hline 16 & & Value of products from site & E.g. timber, NTFPs & & $\begin{array}{l}\text { This indicator not fully } \\
\text { developed }\end{array}$ \\
\hline 17 & $\begin{array}{l}\text { Scientific } \\
\text { research }\end{array}$ & Number of students working & & & To be developed \\
\hline 18 & $\begin{array}{l}\text { Cost-effective } \\
\text { restoration }\end{array}$ & $\begin{array}{l}\text { Reduction in costs to reach self- } \\
\text { sustaining forest }\end{array}$ & & & $\begin{array}{l}\text { Would need clear } \\
\text { targets }\end{array}$ \\
\hline
\end{tabular}




\section{Principle 2.4: Management should be adaptive}

All good management involves 'learning by doing' because uncertainty is common in ecological management, so that management interventions can produce unexpected outcomes (both successes and failures). This is particularly true given that future ecological conditions remain uncertain under climate change (Gross et al., 2016). PPA managers should take steps to understand how management actions will impact conservation targets, collect data on how targets have responded and modify future actions based on that learning. Such adaptive management aims to ensure that practitioners incorporate reflection into action to enhance the practice of conservation and learning (Groves \& Game, 2016).

\section{Best Practice 2.4.1: Learn from successes and} failures and adapt management systems accordingly

A monitoring system should be developed to assess any changes in the status and trends of factors related to the PPA's objectives (e.g. species population trends, habitat condition, water quality, volunteers working at the site, tourist numbers, educational visits, etc.). Results from monitoring should feed directly back into management. Box 2.7 provides an example of a simple monitoring system developed for a PPA in Kenya and Box 2.8 gives details of network-wide monitoring in Australia. Where possible and appropriate, PPA managers should involve indigenous peoples, local communities, company workers (see Box 2.7), volunteers (see Box 2.10) or broader groups of stakeholders (e.g. visitors, guests in tourism based PPAs) in monitoring.

\section{Best Practice 2.4.2: Set up self-assessments of management effectiveness}

Conducting regular self-assessments of protected area management effectiveness (PAME) will pay dividends in terms of identifying weaknesses and inefficiencies. There is considerable guidance on the tools and implementation of PAME (see Box 2.9). In Chile, the Association of Conservation Initiatives on Private and Indigenous Lands (Así Conserva Chile ${ }^{48}$ ) developed a tool to assess the current situation of PPAs wanting to join the association. The Management Effectiveness Tracking Tool (Stolton et al., 2007) was adapted into the 'HEEM' Evaluation to create a tool that brings together six fundamental aspects: management, protection, personnel, planning, budget and community engagement. The rapid questionnaire allows owners to understand their context, set priorities and develop action planning. It helps the Association understand the situation of candidate sites, make recommendations and support management aspects that are weak or require assistance. The Association also uses the HEEM as a baseline to measure progress of actions taken. South Africa has also developed an annual assessment system based on the METT (see Box 2.2) and Colombia has a methodology for assessing the effectiveness of management of PPAs in the Colombian Association Network of Nature Reserves of the Civil Society (RESNATUR) developed and tested by WWF Colombia (Mayorquín et al., 2010 and see Box 2.2).

\section{Box 2.8 \\ Bush Heritage Australia reporting impact using IRIS metrics}

Bush Heritage Australia ${ }^{44}$ reports PPA data to the CAPAD (Collaborative Australian Protected Area Database, see Best Practice 7.1.3) and in addition tracks and reports its conservation impact within its PPAs in its Annual Report. It uses a range of strategic indicators adapted from the Global Impact Investment Network's internationally accepted standards known as 'Impact Reporting and Investment Standards' (IRIS). ${ }^{45}$ Using the Open Standards for the Practice of Conservation ${ }^{46}$ and Miradi $^{47}$ software allows Bush Heritage Australia to plan, implement, monitor and evaluate management of PPAs over time. Using data derived from using the Open Standards process, Bush Heritage reports the aggregate output, outcome and impact data across the portfolio of its PPAs. Using IRIS standardised metrics allows donors/funders to assess organisational performance. Along with detailed financial and social indicators, Bush Heritage annually reports against the following environmental IRIS metrics:

- Area of lands protected and sustainably managed by Bush Heritage and/or its partners (total hectares under protection).

- Percentage of lands with adequate biodiversity baseline assessments (knowledge of what is protected).

- Percentage of reserves in poorly represented areas of the National Reserve System and Aichi Biodiversity targets (protection in the areas of greatest need).

- Length of boundary with adjacent protected land (leveraging impact through working with others).

- Area of adjacent protected land (leveraging impact through working with others).

- Number of threatened species and communities on reserves and partners' lands (protection in the areas of greatest need).

- Annual rating of status of key threats compared to the original baseline rating (conservation outcome).

- Annual rating of health of high conservation targets compared to the original baseline rating (conservation impact).

Author: Kate Fitzherbert, Bush Heritage Australia 


\section{Box 2.9 \\ The Protected Area Management Effectiveness Framework}

IUCN WCPA defines Protected Area Management Effectiveness (PAME) as the assessment of how well an area is being managed - primarily the extent to which it is protecting natural and cultural values and achieving goals and objectives. It has developed a framework of six elements to be considered when assessing PAME (Hockings et al., 2006). This provides a framework for undertaking assessments (see Figure 1) and advice on all aspects of assessments. More information on PAME systems (including the Management Effectiveness Tracking Tool, METT) and information on where PAME has been undertaken can be found on protectedplanet.net (see Box 7.1).49

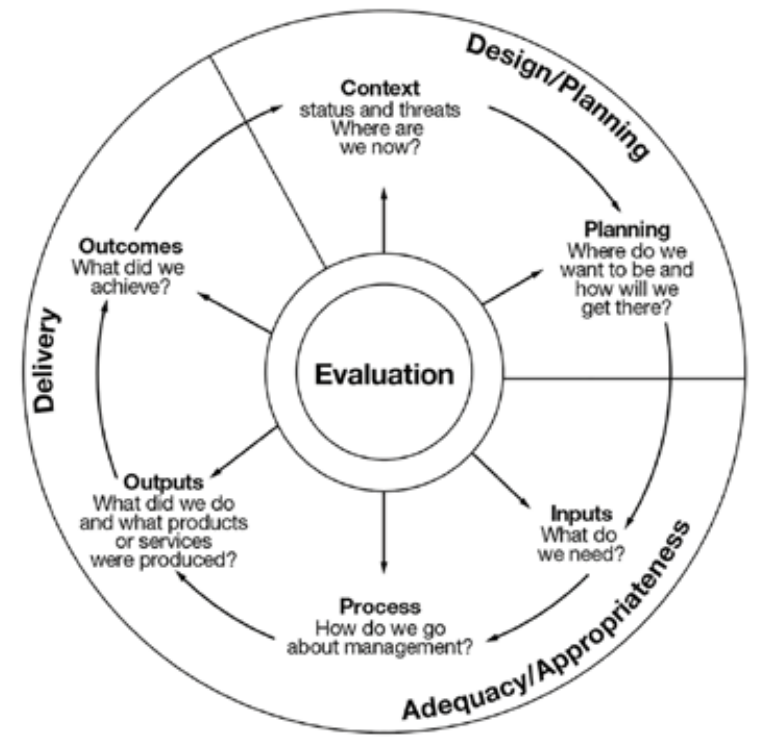

Figure 1: The IUCN WCPA PAME Framework

Best Practice 2.4.3: Complement self-assessment with independent assessments of management effectiveness

External reviews and certification of management effectiveness can be particularly important for PPAs for a number of reasons including: recognition (Best Practice 1.1.3), accessing expertise not available in the PPA (Best Practice 2.2.4) and accessing funding. International, regional and national systems for independent assessment exist (Best Practice 1.1.3). The IUCN Green List of Protected and Conserved Areas (see Box 1.1) is a relatively new global standard for protected and conserved areas of all governance types. It is run nationally or sub-nationally and many countries are now setting up Green List processes. Two PPAs in Kenya, Lewa and OI Pejeta, took part in the pilot phase of the Green List in 2014 (see Case Study 6 from Kenya). The Land Trust Alliance, ${ }^{50}$ based in the US (see Box 8.2), also offers an accreditation system recognising high standards for land conservation. Other certification systems are available which focus on PPA creation and maintenance, for example, LIFE certification ${ }^{51}$ in Brazil, which focuses on the environmental management systems of a wide range of companies. Companies can document contributions to biodiversity conservation, such as through the establishment and maintenance of PPAs, and thus improve their assessment score. The Long Run ${ }^{52}$ accredits tourism-supported PPAs through its Global Ecosphere Retreats ${ }^{\circledR}$ (see Box 8.3).

\section{Principle 2.5: Building a team should help develop PPA management capacity}

Many small PPAs will have very few, if any, permanent paid staff who can focus full-time on management. However, management capacity can be built through engaging help from other PPA landholders, neighbours, volunteers, researchers or alliances with other institutions. In some areas, participation by indigenous peoples and local community members living in and around PPAs may be particularly important (see Boxes 2.6 and 2.11).

Best Practice 2.5.1: Different management activities can be carried out by different organisations

In some cases, landholders may choose to perform some aspects of management while finding associates to perform others, for example focusing on conservation whilst contracting out for-profit activities such as tourism (see Case Study 4 from Costa Rica). For example, the 168 ha Osununú Nature Reserve in Argentina is owned by the Temaikèn Foundation and legally recognised in the System of Protected Areas of the government of the Province of Misiones. To ensure the fulfilment of the conservation objectives of the area and its buffer zone, a joint work programme (backed by agreements) has been established with the neighbouring Provincial Park (managed by the government of Misiones). Since 2010, actions such as fire contingency plans, training in heritage interpretation, environmental education and dissemination (e.g. radio programmes, guided tours for students) and access maintenance have been planned and executed together. In other cases, specific management entities, for instance, an NGO, may be set up to manage a site (see Case Study 3 from China).

\section{Best Practice 2.5.2: Encourage collaborative networks of PPA landholders}

PPA networks can help develop the capacity of owners/ managers and increase management effectiveness (see Section 8 and Case Study 8 from Peru and Case Study 9 from Samoa). Support can include sharing equipment (e.g. camera traps), expertise and experience (e.g. budgeting) and in practical management (e.g. fire management/restoration techniques, see Box 2.5). 


\section{Best Practice 2.5.3: Volunteer programmes can help support management activities}

Volunteers can provide much needed help in carrying out activities outlined in PPA management plans/systems. However, developing and managing a volunteer programme requires work and expertise (see Box 2.10). Advice on developing volunteer programmes (e.g. How to set up a Volunteering Programme ${ }^{53}$ ) can be a useful starting point. It is critical that permission be obtained from PPA landholders before volunteers' access private land.

In the UK, 85 per cent of the people who work for the Royal Society for the Protection of Birds ${ }^{54}$ are volunteers, representing almost 1 million hours of volunteer time a year. Similarly, in Canada, the Nature Conservancy of Canada ${ }^{55}$ Conservation Volunteers programme held over 200 volunteers' events in 2017, engaging close to 2,750 Canadians, contributing almost 13,200 hours of actions dedicated to nature. In South Africa, the Custodians of Rare and Endangered Wildflowers ${ }^{56}$ work with private landholders to undertake botanical surveys of properties, as well as citizen science projects (Ellwood et al., 2017) such as the 2nd Southern African Bird Atlas Project.

\section{Best Practice 2.5.4: Develop alliances/working agreements with external partners}

Selinske et al. (2015) found that learning how to manage their property was a primary goal of individual PPA landholders, but often not explicitly recognised. Given that many PPA managers will have little formal training in ecology or conservation biology, developing partnerships with learning institutions (Shackleton et al., 2009) is often a critically important element of management. Partnerships can improve the results of PPA management. Partners may include universities, research institutes, businesses and indigenous peoples and local communities, governments and for-profit and not-for-profit organisations (see Case Study 6 from Kenya, Case Study 8 from Peru and Case Study 9 from Samoa). Different PPA entities may have different but complementary skill sets. For example, company PPAs may bring business skills to a partnership, whilst NGOs can support the company's conservation work by bringing knowledge and skills, providing credibility, helping save costs and sometimes ensuring continuity (see Box 2.5).

Seeking partnership with conservation specialists can also be a very cost-effective way to gain skills and implement conservation activities, particularly for PPAs with limited capacity. Fundación Jocotoco ${ }^{60}$ in Ecuador, for example, manages its 18,000 ha reserve based on external scientific advice, which proved to be the most cost-effective approach for this local NGO. Research institutions generate information which can be widely disseminated, further embedding the PPA within broader conservation approaches. In Peru, Conservamos por Naturaleza ${ }^{61}$ promotes the 'Donate your Talent' campaign, ${ }^{62}$ which seeks professionals from different fields such as economics, architecture, biology or tourism to donate time and knowledge to a PPA to solve a specific problem. To date, more than one hundred professionals and students have joined in.

Universities can support citizen science activities to gather management-relevant data and build a sense of support and stewardship. A good example of collaborative working is through a 'BioBlitz' (i.e. an intense period of biological surveying which attempts to record all the living species within a designated area). The BioBlitz concept was developed in the late 1990s to bring together scientists, naturalists and volunteers to conduct an intensive field study usually over 24 hours. BioBlitzes have been carried out across the world, in all types of conservation areas, including PPAs.

\section{Principle 2.6: Information about PPA management should be communicated widely}

Communications are important for all protected areas, but are particularly vital for many types of PPAs, such as those owned by NGOs with large memberships with whom they need to communicate. For-profit tourism providers in PPAs also need to market themselves, sometimes against stiff competition from more conventional holiday activities. Use of social media, for example, encouraging satisfied visitors to give endorsements, is one of the key ways of advertising.

\section{Best Practice 2.6.1: Develop effective communications to inform the public of PPA management and successes}

Updating people (neighbours, interest groups, the general public) on how an area is doing is key to gaining support and engagement for conservation. Communication with indigenous peoples and communities who live within and around the PPA is particularly important, as it is in other cases with donors and government officials. This can include regular updates on wildlife sightings but also information on management, projects and calls for volunteers. The Internet provides a wealth of virtually free opportunities to get a PPA's message across. IUCN WCPA has produced some general guidance (Cohen et al., 2015) on using opportunities relating to science communication and media relations. Communication among PPA landholders is also important (see Section 8 on networking). Information should be kept up to date regarding, for example, special events or sightings of unusual wildlife. Care will be needed in determining whether to publicise species-based information as this may increase the risk of disturbance to, or even poaching of, highly valued species or their nests, eggs or young. Conservamos por Naturaleza in Peru is a large communications effort which provides a platform to owners and PPAs to demonstrate their conservation and life experiences through videos and stories. ${ }^{63}$ The platform connects donors with specific campaigns $^{64}$ such as individual PPAs seeking funds for reforestation, habitat and species survival, etc. 


\section{Box 2.10}

\section{Lessons learnt from working with volunteers: Namibia, Brazil and Canada}

Volunteers from all backgrounds have visited Namibia to assist with conservation through the N/a'an ku sê Foundation ${ }^{57}$ since its beginning in 2006. Key lessons learnt include:

1. Job gratification: It is important for volunteers to know that the work they are doing is vital to the project and they can see the direct impact it is having on the environment.

2. Providing knowledge: Especially when working with often misunderstood species (e.g. spotted hyenas, Crocuta crocuta), it is important to ensure volunteers are taught the importance of the species to the ecosystem and why the work is being conducted.

3. Sense of ownership: Volunteers are encouraged to take home the knowledge they learn and experiences they gain to become international conservation ambassadors. Volunteers are a key point in conservation public and international outreach initiatives.

More than 500 people have taken part in the Salto Morato Natural Reserve ${ }^{58}$ volunteer programme in Brazil since its inception in 1996. The programme has recently been reformulated based on an assessment of this 20-year experience. Some key lessons learnt include:

1. Clear expectations: The objectives of the volunteer work should be fully understood.

2. Integration with other PPA activities: It is very important that the volunteers understand their role in achieving the objectives of the PPA.

3. Alignment: All PPA staff should be aware of the volunteer's role in the PPA.

4. Measure results: It is recommended that sites undertake an evaluation of the volunteer's experience.
5. Safety first: Programmes should consider providing volunteers with accident insurance.

6. Attention to legal compliance: Each country has a legal framework concerning workers and working conditions which PPAs must be aware of. In some cases, specific regulations for volunteer work also exist.

In Canada, the Nature Conservancy of Canada (NCC) $)^{59}$ offers a variety of hands-on volunteer events within priority conservation areas across the country. Each volunteer event is designed to ensure meaningful conservation impact. Whether the event is directed at removing invasive species, conducting inventories, monitoring species, improving visitor experience via trail maintenance and signage updates, or planting native trees, shrubs and grasses, events are designed to address urgent, necessary and beneficial actions originating in NCC property management plans.

Year after year, surveys indicate the top two motivations for volunteers choosing to engage in Conservation Volunteers programming are:

- To contribute to the protection of natural places and species through meaningful and strategic action.

- Engaging with like-minded people.

As one volunteer survey respondent stated: "I was impressed with the sense of community, the gathering of people with a common goal to contribute to the greater good of nature, wildlife and the environment."

Authors: Georgina Hockings and Karl Fester, N/a'an ku sê Foundation, Marion Letícia B. Silva, Grupo Boticario Foundation and Lisa McLaughlin, Nature Conservancy of Canada

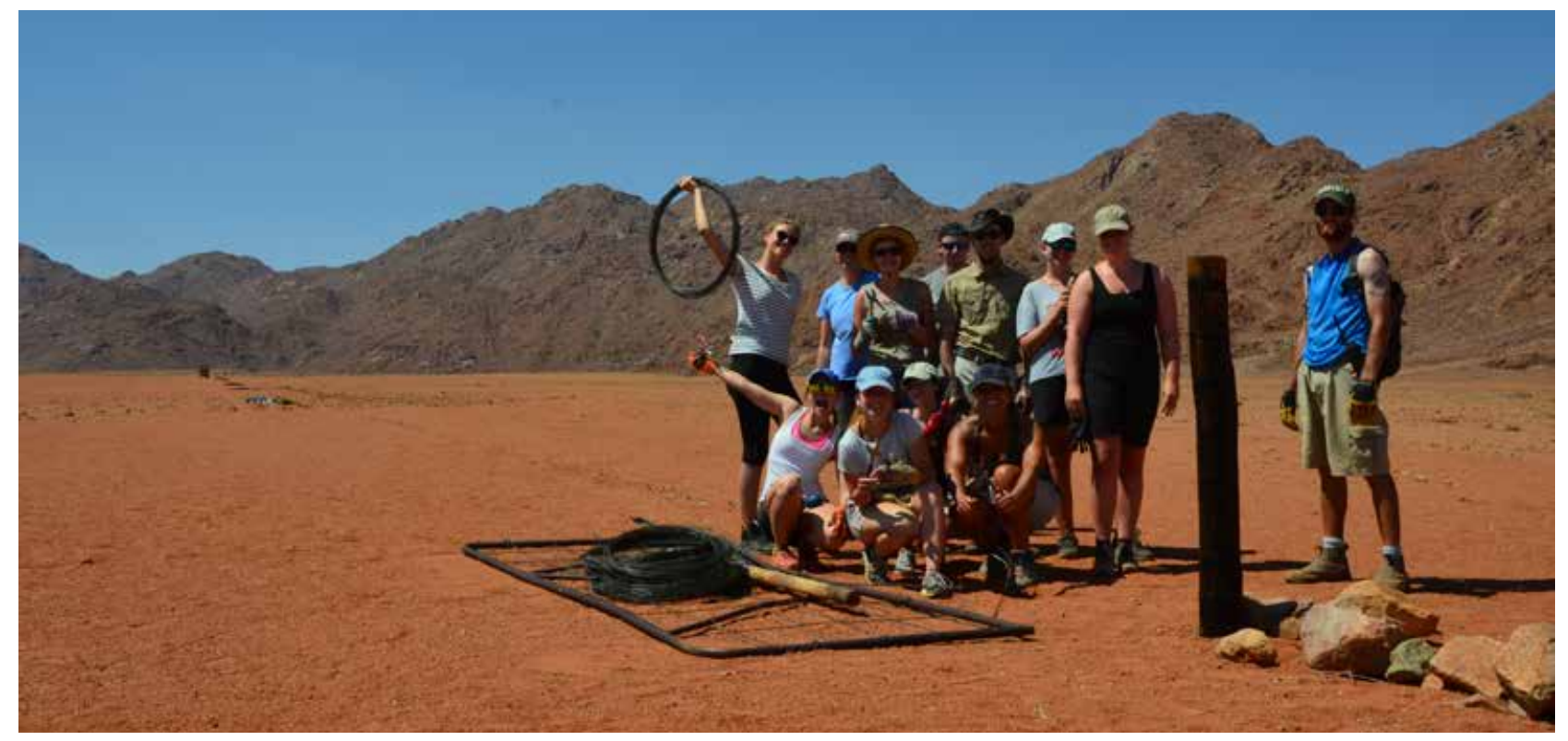

Volunteers are removing old fencing in Kanaan N/a'an ku se Desert Retreat, Namibia to open up migratory routes for wildlife. It is important volunteers see their impact, in this case, how many metres of fence they have removed (C) Boel Nilsson 


\section{Box 2.11 \\ Building community awareness for conservation in Canada}

The Galiano Conservancy Association ${ }^{65}$ in British Columbia was founded in 1989 as one of Canada's first communitybased land trusts. It owns several parcels of land, adding up to 185 ha, and covenants covering over 200 ha, on Galiano Island in the Southern Gulf Islands. Galiano has a temperate rainforest ecosystem dominated by Douglas fir (Pseudotsuga menziesii), located within the Coastal Douglas Fir biogeoclimatic zone. The goals of the Association are: land and marine conservation, stewardship and restoration, and environmental education and public awareness.

The education and awareness goal has primarily been achieved through nature-based education programmes for learners of all ages, including primary school students, teachers, Canadian and international university students, community groups and the interested public. Their properties serve as a field laboratory for courses in ecological restoration and many graduate research projects. The annual 'Musical Walkalong for Learning'66 has musicians serenade walkers along forest and seaside trails, in a unique mix of music, nature and a celebration of environmental education, which raises funds for bursaries that support school groups such as inner-city children who cannot otherwise afford to attend their programmes. Galiano Conservancy Association programmes not only draw in the island community and visitors to share conservation goals, but also provide an important incentive for landholders to donate property for conservation (Best Practice 3.1.1). As one landholder stated: "Giving the next generation of scientists and decision-makers opportunities to develop a conservation ethic and love of nature is something I am very happy to support."

Author: Risa Smith, Galiano Conservancy Association

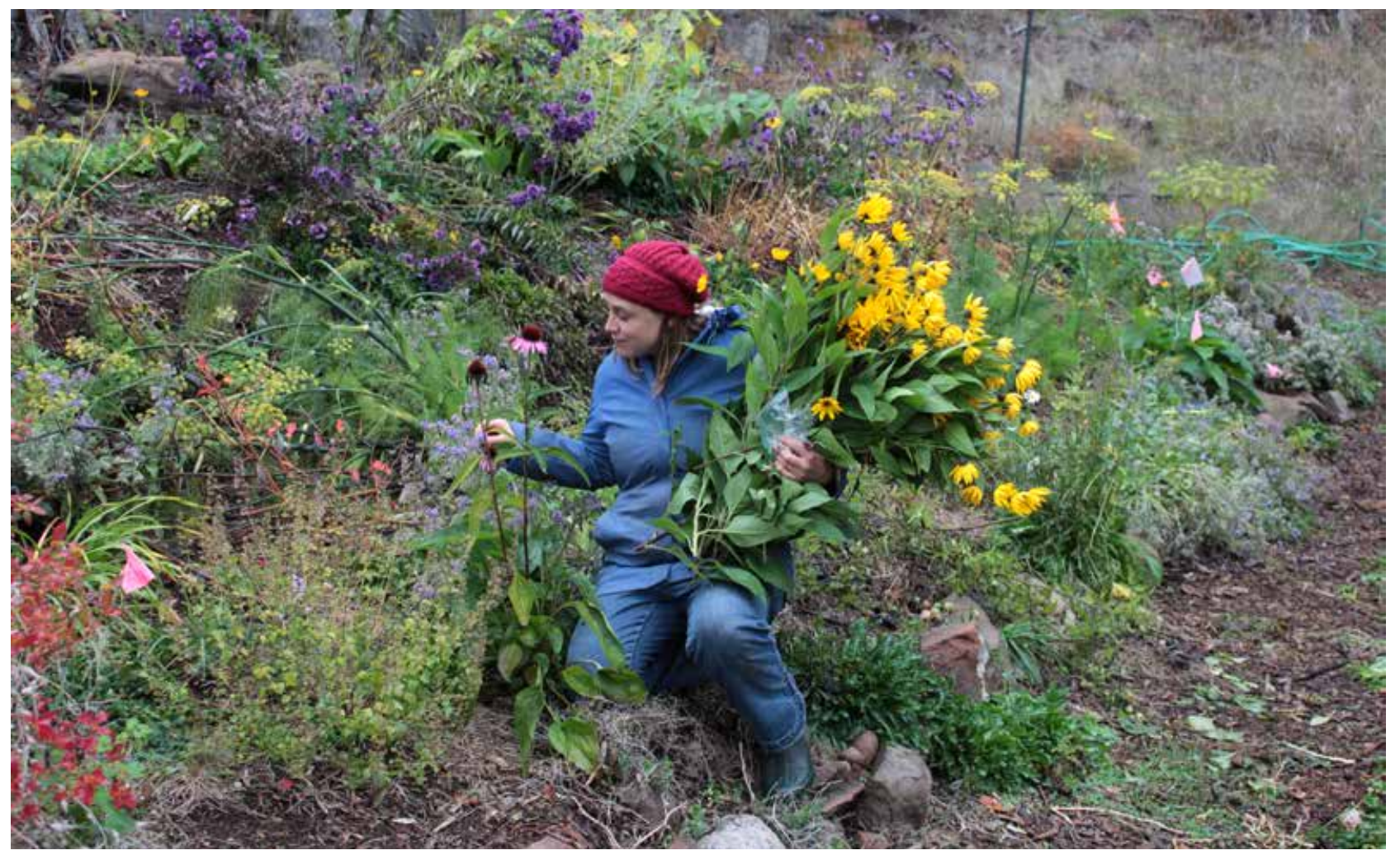

Galiano Conservancy (c) Galiano Conservancy Association 


\title{
Section 3: Incentives for privately protected areas
}

\author{
Who should read this section? \\ Much of this section will be of more interest to governments and PPA funding bodies \\ (e.g. NGOs, private foundations, etc.) that are developing policies for incentivising PPA \\ designation and management.
}

Incentives to create PPAs involve providing benefits to landholders or potential landholders (e.g. NGOs, foundations, etc.) to motivate them to create PPAs and/or to support their long-term management. A range of different types of incentives have been shown to be effective (see Box 3.1), including recognition and relationship building, support for managing and marketing the PPA and direct and indirect financial incentives (Selinske et al., 2016). Different incentives may be necessary for different landholders as people are driven by a variety of motivations, beliefs and value systems.

This section provides general guidance on designing and implementing incentives and on some of the more common types of incentives and presents some best practices learnt over the years and around the world related to specific types of incentives. It does not seek to provide a comprehensive overview of all the different incentives that may be offered to landholders.

\section{Principle 3.1: PPA incentives should be carefully designed, communicated and implemented to ensure effectiveness}

Thinking about and designing suitable incentives should occur when a PPA programme is being developed by a government or other entity and continue as the programme evolves. There are many things to consider, from both the demand side, namely what incentives would appeal most to landholders, and the supply side, what incentives are affordable, practical, fair and sustainable to offer and what incentives work within the legal and institutional framework (see Case Study 1 from Australia and Case Study 10 from South Africa).

Best Practice 3.1.1: Incentives should be tied to achieving desired conservation outcomes and be clearly understood by all parties

Incentives should be linked to the ongoing conservation management and performance of a PPA (see Principle 1.5 and Box 3.2). They should provide clear guidance on the eligibility for accessing incentives, as well as guidance on any penalties attached to breaking the PPA agreement. In some cases the motivation of landholders to focus on

\section{Box 3.1 \\ Different incentive types for PPAs}

A wide range of different types of incentives exists, including:

- Aligning with and supporting landholder's conservation ethic, cultural identity and sense of place through education and awareness (see Case Study 7 from New Zealand).

- Recognition of landholder's efforts and connection to PPA networks (see Case Study 4 from Costa Rica, Case Study 7 from New Zealand and Case Study 8 from Peru).

- Management assistance, which can have economic benefits for the landholders, create good relationships and build connections, and can increase learning and awareness.

- Improved marketing opportunities and access to markets for green products.

- Financial incentives, including direct payments, tax breaks and green subsidies (see Case Study 1 from Australia and Case Study 10 from South Africa).

- Improved law enforcement for landholders (e.g. such as government intervention for supervision, protection and prosecution of environmental crimes from the Brazilian and Mexican Governments and see Case Study 6 from Kenya).

conservation can be enhanced by an external threat to an area (e.g. infrastructure development, mining, etc.), which can be halted when PPA status is achieved. Incentives can also be developed to encourage neighbouring landowners to develop more conservation-friendly management to help ensure connectivity, corridors, etc. In the USA, for example, American Prairie Reserve ${ }^{67}$ aims to create the largest nature reserve in the continental United States primarily through land purchase. This ambitious aim inevitably leads to a patchwork of conservation areas within the larger target landscape. American Prairie Reserve has therefore developed an incentive, the Wild Sky Program, ${ }^{68}$ which provides a premium to beef ranchers who are willing to make their lands hospitable to wildlife and create wildlife migration corridors. 


\section{Box 3.2 \\ South Africa's first effective biodiversity tax incentive}

South Africa's Income Tax Act makes reference to a specific biodiversity tax incentive (section (S) 37D) which is geared towards creating financial sustainability for protected areas on private or communal land as well as motivating and rewarding landowner commitment. S 37D allows the value of land of a Nature Reserve or National Park to be deducted from taxable income, reducing the tax owed by a landowner, thus ensuring greater cash flow for the management of the site. This tax incentive is a national first and its successful inclusion in a PPA landowner's tax return in 2016 created the first fiscal reward for private biodiversity conservation in South Africa.

The two primary benefits of this specific biodiversity tax incentive include: 1) Support for the creation of robust PPAs, and 2) The creation of an innovative tool for financial sustainability for PPAs. Benefits include: 1) The requirements of the Income Tax Act correlate precisely to the requirements of the Protected Areas Act ensuring that PPAs qualifying for this tax deduction are formally declared protected areas that can attest to legal certainty, permanence, management and long-term intent, and 2) S 37D creates a substantial and tangible financial benefit that aids landowners in meeting management responsibilities, bolsters landowner motivation over the medium to long term, and facilitates tax efficiency essential to the sustained success of economic activities compatible with PPAs.

Author: Candice Stevens, BirdLife South Africa

\section{Best Practice 3.1.2: Design 'degrees' of incentives}

Eligibility for incentives can be more nuanced than simply having PPA status. Different degrees of incentives can be offered. For example, greater rewards might be provided for PPAs that are of broader conservation and societal value, as in Australia where incentives are greater for areas with high biodiversity and identified as priority for expanded conservation protection, or to those that provide benefits additional to conservation such as water security or job creation. Incentives may also be used to increase commitment, such as more land-use restrictions and longer duration of protection, as offered in South Africa (see Case Study 10).

\section{Best Practice 3.1.3: Provide a mix of incentive options}

The wider the array of incentive types offered, and the more flexible the PPA programme, the greater the appeal to a landholder (Cumming, 2007; Selinske et al., 2017).
Best Practice 3.1.4: Incentives can come from multiple sources

The main implementing entity engaging with PPAs need not provide all the incentives. Organisations such as NGOs, corporate entities or other government programmes could be brought in as partners to offer incentives such as mentoring on governance or training on fire management. The implementing agency would need to find these other partners and facilitate their support. Similarly, networks of landholders could support each other, as demonstrated in Best Practice 3.5.1 (see also Section 8).

Best Practice 3.1.5: Address disincentives that landholders may face for establishing or managing PPAs

Try to understand the barriers that landholders face in creating and managing PPAs, sometimes referred to as disincentives. Some of these barriers can be addressed by the creation of 'positive' incentives. For example, a landholder daunted by the prospect of actively managing a protected area may be encouraged by hands-on management support offered by the state, NGO or other PPAs (Principle 2.5). Barriers may be financial in nature, such as a lack of funding for long-term management, or non-financial, such as a lack of ecosystem knowledge or access to markets for green products such as sustainable nature-based tourism (see Leung et al., 2018). Barriers may also be legal or fiscal penalties, such as increased land taxation, rent for 'not developing' land or the loss of subsidies that might be available to other sectors, for example, primary industries (Smith et al., 2016).

\section{Best Practice 3.1.6: Work with landholders to adapt} and revise incentives

Think about incentives, disincentives and addressing perverse incentives early on, when designing a PPA programme, and as the programme evolves. Listen to feedback from landholders and be willing to adjust incentives accordingly. The original tax incentives designed in South Africa proved not to be effective with landholders. As a result, new work was undertaken to amend the relevant tax legislation to improve their effectiveness (see Case Study 10 from South Africa).

\section{Principle 3.2: Incentives should be designed to encourage both PPA establishment as well as long-term governance and management}

Creating incentives for establishing a PPA might require different incentives than those that help ensure long-term management (see Box 3.3). Although landholders can be motivated by a conservation ethic to enter into long-term agreements to protect their land/water, their likelihood of remaining committed to the programme can be based on their experience with, for example, the conservation agencies providing support or the management assistance they receive (Selinske et al., 2015). 


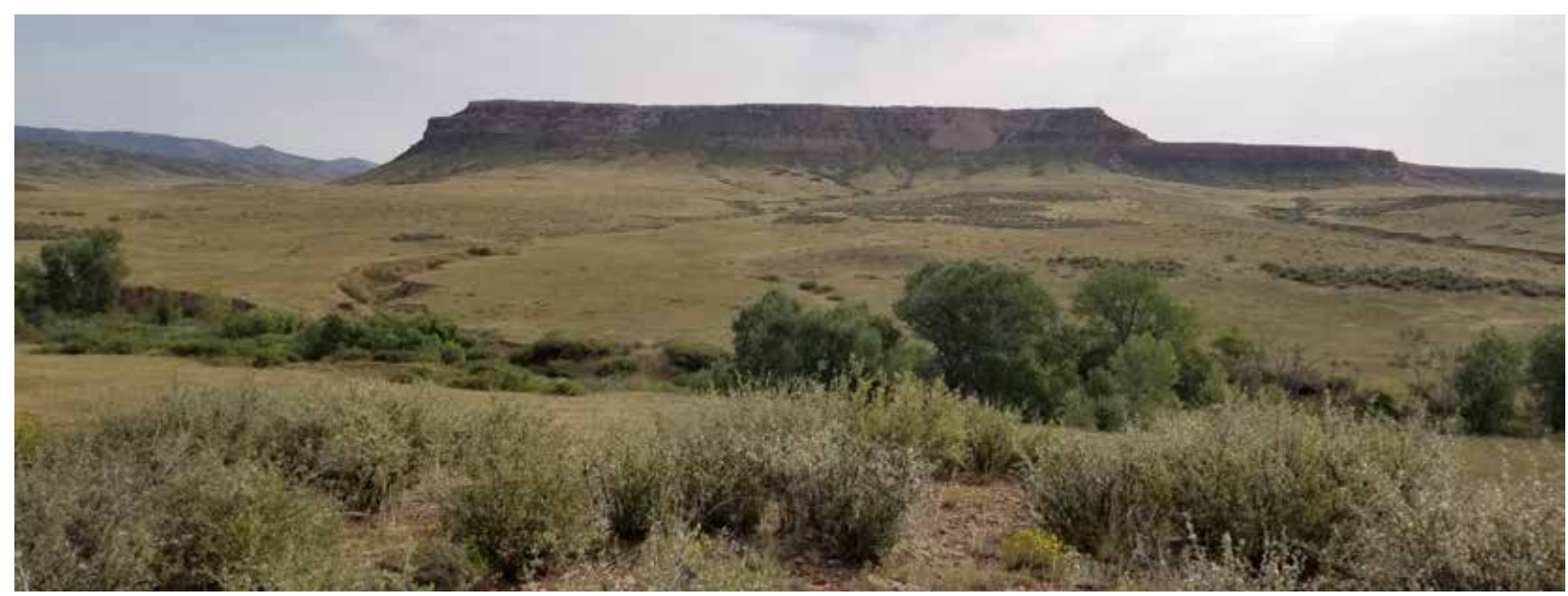

Table Top Conservation Bank @ C Ben Guillon

\section{Box 3.3 The Table Top Conservation Bank, USA}

The Table Top property is located in the northern part of Colorado's Front Range in the USA. It is recognised critical habitat for the endangered Preble's meadow jumping mouse (Zapus hudsonius preblei). The Colorado State Land Board (CSLB) ${ }^{69}$ owns the property. CSLB is a public agency with a mission to manage its land to generate reasonable and consistent revenue over time for kindergarten to 12th grade public education and to provide sound stewardship of its trust assets. The land was previously used for cattle grazing, which impacted the riparian areas critical to the mouse. Table Top Conservation Company, limited liability company (LLC), a subsidiary of Conservation Investment Management LLC (CIM), a conservation finance advisory company, and CSLB entered into an innovative private-public partnership to develop a conservation bank under the US Endangered Species Act. CIM, working with a leading consulting group and individual investors, expects to dedicate over US\$2,000,000 for development and management of the conservation bank, including restoring the riparian areas and implementing strategies to balance conservation with the needs of the ranchers. The investors share revenue generated from the sale of mitigation credits with the CSLB in exchange for using the land and an obligation to permanently protect the land. This structure allows CSLB to fulfil its dual mission of generating revenue and longterm stewardship without taking on significant financial risk or having to develop internal expertise in conservation banking (Colorado State Land Board, 2017).

Author: Ben Guillon, WRA, Inc.
Best Practice 3.2.1: Incentives aimed at encouraging long-term commitment should be sustainable for a similar length of time

The existence of ineffective or impermanent incentive structures can create the risk of 'temporary' PPAs being created which disappear when the incentives lapse, even when the initial aim was for permanent protection. Dedicated funds with a long-term plan for investment, such as endowment funds, are a valuable tool for supporting PPAs (see Box 3.3). Incentives should be flexible and adjustable to changing conditions. In Brazil, for example, there is a pilot project in development called 'Continuous cycle conservation: Management model for the financing of Private Natural Heritage Reserves' ${ }^{10}$ which aims to develop projects and actions to generate financial resources, part of which are allocated to the formation of an endowment fund. This fund supports the management and protection of the reserve over the long term. In Australia, a condition of funding NGOs for land acquisition through The Nature Conservancy's David Thomas Challenge ${ }^{71}$ was that an endowment fund for future management had to be established.

\section{Principle 3.3: Identify and avoid perverse incentives}

Perverse incentives are incentives that are developed with another goal in mind, such as stimulating agriculture or energy production, but have unintended negative consequences on biodiversity conservation (Gordon et al., 2015). To avoid such unintended consequences there should be careful consideration of the ways that different incentives might interfere with each other in delivering conservation outcomes.

Best Practice 3.3.1: Address perverse subsidies that discourage the establishment and management of PPAs

Removing subsidies that create perverse incentives can be done by direct lobbying against the subsidy, creating an 'equal but opposite' subsidy to support conservation, as has been done in South Africa with the development of tax 
and property rates incentives for PPAs to offset the loss of agricultural incentives, or 'greening' the original subsidy (such as greening agricultural subsidies). This last approach is often the most effective.

\section{Principle 3.4: Recognition and support are powerful incentives for PPAs}

Feeling part of a community doing something that is recognised as being beneficial to conservation can be a powerful incentive for PPA landholders (see Case Study 7 from New Zealand). Relationships between landholders, NGOs and government conservation authorities are important motivators for setting up a PPA. Non-financial incentives can be equally, if not more, important than the financial incentives to certain landholders (Selinske et al., 2015). However, it is important to realise that not all PPA landholders wish to have external recognition of their efforts.

Best Practice 3.4.1: PPA landholders should be recognised and made to feel connected to the larger protected area community

Peer recognition and connection can be important incentives, particularly when PPAs are set up by a single individual (see Case Study 9 from Samoa). In Brazil, for example, the government has declared the 31 January as the National Day of PPAs. This recognises the effort that all PPA landholders undertake to preserve nature, highlights the importance of private investment in maintaining biodiversity and acknowledges public efforts for conservation. Annually, several events take place in celebration and usually new reserves are created, new support programmes announced and the positive mobilisation around the PPA theme generates media interest. The Argentine Network of Private Natural Reserves implements an 'Open Reserve Day' for its members, which consists of a group visit to a PPA (with other landholders and members) in order to better understand how it is managed, exchange experiences, learn and spend a day with other landholders of the Network. This practice has generated recognition, motivation and learning for the whole group. In Peru, receiving the governmental 'Ministerial Resolution'72 which recognises individual PPAs, is a great incentive and a matter of pride for local owners, even if this Resolution has proved to add no extra value to direct incentives or benefits (SERNANP, 2014).

Research in South Africa has shown that positive relationships formed between landholders, conservation agencies and NGOs play an important role in motivating landholder commitment, particularly in incentivising landholders to remain in long-term PPA agreements (Selinske et al., 2015). In New Zealand, covenants have become a social norm with landholders (see Case Study 7). Feeling connected to a likeminded community helps to keep people in PPA agreements.

\section{Principle 3.5: Direct management and technical support are an incentive for PPA management, supporting long-term commitment}

Direct management and technical support to landholders is a powerful motivator, combining the benefits of tangible cost saving with creating a sense of belonging to a larger community. Such linkages can build relationships and improve environmental awareness. Developing management plans with landholders and helping with practical and specialist issues, such as fire management and invasive species control, are useful approaches (Best Practice 2.5.4 and Case Study 8 from Peru and Case Study 9 from Samoa). Management support could include biodiversity management, as well as support with governance, support with obtaining certification, dealing with bureaucratic processes, and management operations more generally. Training and peerlearning opportunities are also valuable.

Financial planning and provisions to guarantee long-term protection of properties require covering the full cost of stewardship needs. In cases where only specific land use rights to a property (e.g. easements or restrictions) are acquired by the organisation, while the landholder still occupies and uses the land, stewardship costs may be lower than those for fee-simple ownership. However, financial provisions need to be made for monitoring expenses and legal defence costs in the case that existing conservation agreements are breached.

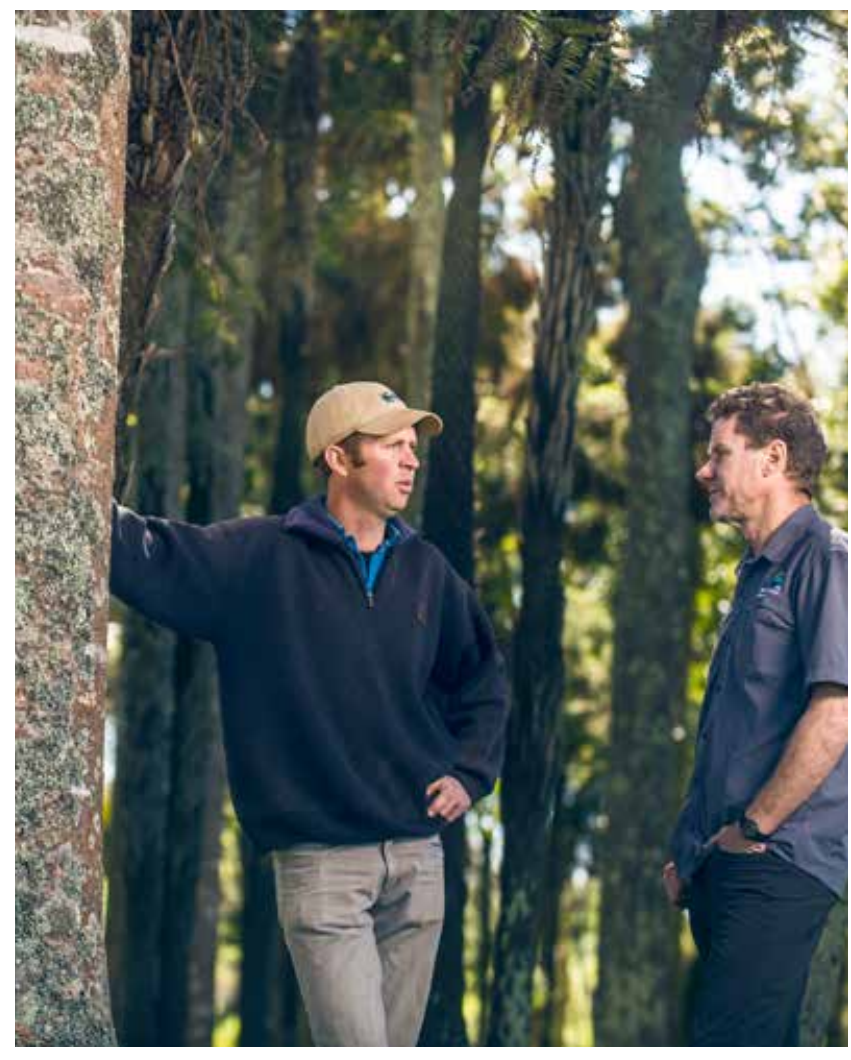

A QEIl regional rep meeting with a covenantor in a Kauri (Agathis australis) tree stand in Waikato (C) QEII National Trust 
Best Practice 3.5.1: Management support can come from a range of actors

'Covenanters' clubs', such as in New Zealand, offer peer mentoring and field trips, and members collectively work on each other's land (Best Practice 8.2.1). In South African biodiversity stewardship programmes, management plans are developed by the state conservation authority in collaboration with the landholder, often with input from participating NGOs. In the State of São Paulo, Brazil, the owners of reserves prepare the Protection Plan together with the environmental police who will support the actions of protection and inspection.

\section{Principle 3.6: Marketing assistance is an effective incentive to PPAs that have income-generating potential}

PPAs might have different income-generating opportunities than those of state protected areas, for example by appealing to a different ecotourism market. PPAs are generally in a better position to retain income than state protected areas, where income such as gate fees is often channelled into general state funds and not retained for protected area management.

Best Practice 3.6.1: Design incentives that provide recognition and marketing value for income-earning PPAs based on their PPA status and biodiversityfriendly practices

PPAs that are combined with income-earning operations can benefit from the added marketing value of formal recognition as a PPA (see Section 5, which looks specifically at forprofit PPAs that are income generating as a sub-type). This provides an opportunity for income-earning PPAs to use the 'green' recognition to improve their market access, such as those in the ecotourism sector (see Box 8.3).

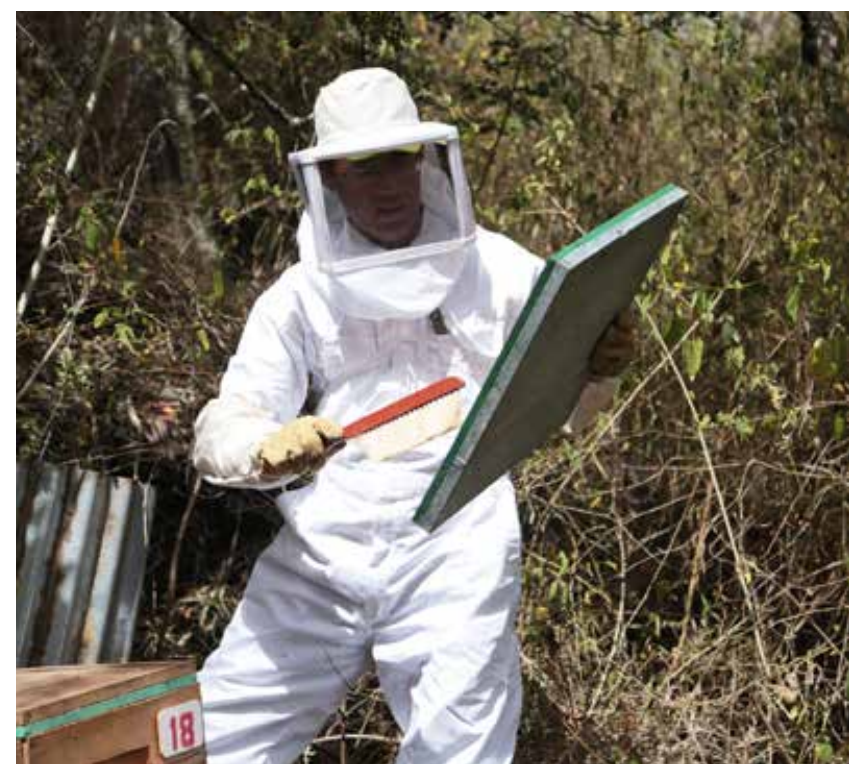

Perico Heredia, owner of Milpuj-La Heredad PPA in Amazonas, extracting honey which is sold in stores around Peru thanks to marketing promotion by the PPA network (C) Conservamos por Naturaleza / SPDA

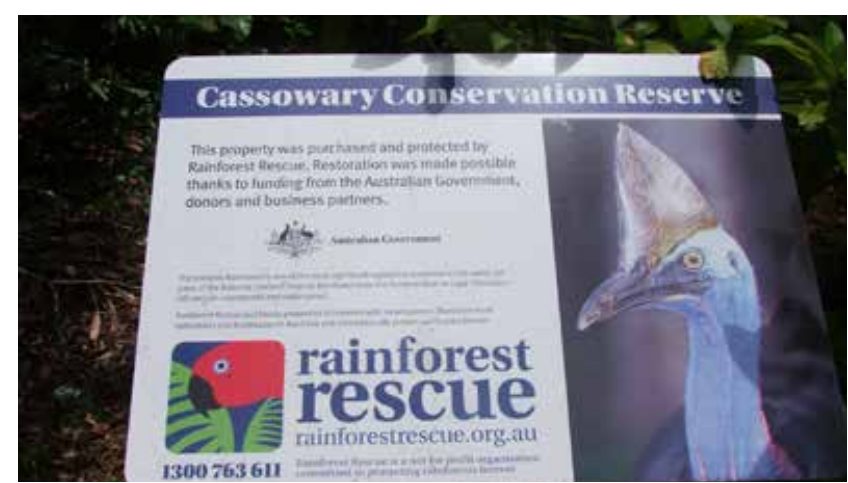

The Australian Government has helped fund many PPAs, including for the protection of the southern cassowary (Casuarius casuarius) $\odot$ James Fitzsimons

\section{Principle 3.7: Financial incentives are important for the establishment and management of PPAs}

Financial incentives include direct payments, fiscal incentives and leveraging matching funds. Some are designed to encourage the establishment of PPAs such as for land purchase, others compensate landholders for costs related to PPA management or provide additional financial benefits beyond costs incurred.

Best Practice 3.7.1: Seek opportunities for leveraging additional funds to complement PPA investment

PPA status may help to provide credibility to projects that are seeking donors to invest in conservation. The formal protection of a PPA may make it easier for a landholder to attract funds, as PPA status may provide credibility for funders who want to invest in conservation. Leveraging funds and matching funds by PPA organisations (such as Land Trusts) are important drivers for facilitating PPA development. For example, the Australian Government, as part of its National Reserve System Programme, provided private land trusts with up to two-thirds of the purchase price for land with high conservation value and filled gaps in the representativeness of the protected area system from 1996-2013 (Fitzsimons, 2015). The North American Waterfowl Conservation Action Plan $^{73}$ a trilateral funding source between Canada, the USA and Mexico, also provides matching funds to PPAs.

Best Practice 3.7.2: Direct payments can be used to compensate landholders for actual costs or opportunity costs

Arguably the two best known forms of direct payments for PPAs are purchases of conservation easements and payments for ecosystem services (see Box 3.4). Often conservation easements are donated by owners, but sometimes they are purchased by a public or private organisation. In the USA, for example, The Nature Conservancy occasionally purchases conservation easements when the landholder cannot benefit from the related tax breaks and the land is considered to be of high priority. Another type of easement is a split receipt, where the landholder receives some cash and donates the remainder of the value. 


\section{Box 3.4 \\ Using payments for ecosystem services to fund PPAs}

Payments for ecosystem services (PES) is based on a model in which beneficiaries, or users, of an ecosystem service, such as water regulation, make a direct or indirect payment to the provider of that service in exchange for service provision and maintenance (Greiber, 2009). The provider is typically a landholder or entity responsible for the management of the land. The buyer is the downstream user, who could be public or private and local, national or international. The scale of a PES scheme depends on the ecosystem service. Common examples of ecosystem services in PES schemes are carbon storage, water quantity and water quality. PES schemes are based on voluntary arrangements.

Many PES schemes exist which do not necessarily result in PPAs or benefit PPAs (for example, when agreements with landholders result in short-term contracts to protect the land). However, PES schemes can be used to provide direct payments to owners of PPAs. For example, some states in Brazil direct PES programmes to PPAs, as in São Paulo. Here, landowners are paid for biodiversity conservation and water production. An Action Plan must be drawn up for the PPA, and verification of the provision of these services is required. Another example is in Fiji, where Conservation International has partnered with Fiji Water $^{74}$ to fund the 16,340 ha Sovi Basin Protected Area ${ }^{75}$ through a 99-year lease with iTaukei Lands Trust Board and Sovi Basin landowners. To generate revenue for the landholders, a trust fund was created and endowed by the bottled water company Fiji Water. The interest accumulated by this trust fund facilitates the payment of lease premiums, compensates foregone timber royalties, provides community development opportunities, and implements the management plan (Keppel et al., 2012).

Mexico's PES programme, implemented by the National Forestry Commission (CONAFOR), provides five-year support to prevent land-use change on forested areas. Benefiting properties are not considered PPAs, due to the short duration of the support and the fact that, while these agreements are renewable, landholders need to resubmit to continue their inclusion in the programme and compete with many other landholders who also want to participate. A small portion of Mexico's PES programme has, however, evolved towards long-term permanence through the establishment of a land support trust fund, the Biodiversity Fund, also administrated by CONAFOR. The fund has been capitalised to provide support by using only the interest, while maintaining the principal and is oriented at protecting critical biodiversity present in a limited set of targeted landholdings (private and communal) outside governmental protected areas, thus becoming an effective incentive for the establishment of a limited number of permanent PPAs. There is a great deal of literature available on PES (Grêt-Regamey et al., 2017; Neugarten et al., 2018). ${ }^{76}$
Best Practice 3.7.3: Financial incentives should encourage additionality

Extra financial resources could be channelled to the PPA if it provides ecosystem services beyond biodiversity conservation, such as climate change adaptation and mitigation, or catchment management for an important water supply. If this is a possibility, the initial PPA agreement or covenant must be designed to allow for this. For example, in New Zealand, landholders with covenants on their land are able to benefit directly from carbon-trading schemes related to regenerating forest, and in some catchments can also benefit from nutrient-trading schemes to protect freshwater quality of lakes and rivers.

Best Practice 3.7.4: Fiscal incentives should be developed cooperatively between government finance departments, other relevant government agencies, NGOs and landholders

Fiscal incentives refer to the use of taxes and subsidies to change behaviour. Examples include providing tax breaks to PPA owners (see Case Study 10 for South Africa and Case Study 11 for the USA) or for obtaining subsidies for environmental services provision, as in Mexico. The creation of fiscal incentives, often led by a government's environment department or by NGOs, needs to be in collaboration with other relevant government departments and/or NGOs. Those negotiating incentives should demonstrate to the government the significance and value of supporting PPAs through the use of fiscal incentives. (Incentives need not stop at borders. American Friends (AF) of Canadian Land Trusts ${ }^{77}$ has been established to allow American owners of land in Canada to donate properties to the US organisation and qualify for tax incentives, while AF transfers ownership to a Canadian land trust for long-term stewardship.)

\section{Best Practice 3.7.5: Fiscal incentives should be designed to be applicable to the highest number of PPAs}

For example, designing tax incentives that may only be realised by a few high-net worth individuals and not other landholders of PPAs with similar biodiversity importance can be problematic. In these cases, other incentives need to be available to these landowners. 


\title{
Section 4: Ensuring privately protected area permanence
}

\begin{abstract}
Who should read this section?
This section is relevant to both those developing policy/incentives for PPAs (e.g. governments, NGOs, private foundations, etc.) and landholders in the process of setting up or formalising PPAs. The focus, as with all other sections in these guidelines, is on areas which are developed and managed to meet IUCN's definition of a PPA.
\end{abstract}

The 'long-term conservation of nature' is at the core of the IUCN protected area definition. For government-managed protected areas this is usually embedded in the process of establishing a protected area in policy and legislation. For other protected area governance types the concept of 'longterm' is not always as straightforward.

In The Futures of Privately Protected Areas (Stolton et al., 2014) 'long-term intent' was proposed as an alternative to 'long-term conservation', to encompass a broader set of situations. The report proposed that PPAs should demonstrate an intent to conservation 'in perpetuity', or at least 'long-term'. Defining long-term for any protected areas is fraught with difficulties and some government-managed protected areas may not be secure in the long term (Mascia et al., 2014). With PPAs it is understood that it can take time to put in place arrangements (covenants, tenure agreement, etc.) which ensure permanent protection. IUCN's guidance is that PPAs should demonstrate conservation in perpetuity or at least the intent for conservation in the long term, the latter being defined in this case as for a minimum of 25 years (Stolton et al., 2014).

\section{Principle 4.1: PPA governance should embody the long-term intent to achieve conservation}

PPAs may not have the same legal protection as stategoverned protected areas (Lausche, 2011; Bingham et al., 2017). Though this principle is a prerequisite of a protected area, by definition, it bears repeating. Where PPAs are not legally protected, long-term intent (and other effective means) becomes a central component of their permanence. An environmental NGO's registered charitable purpose (for long-term conservation) and appropriate conservation land disposition policies should also serve as a demonstration of long-term intent. Trust agreements established with donors of the land or the funding needed to acquire it, can also serve to demonstrate long-term conservation intent.

In a few countries, PPA declaration brings legal obligations for long-term protection (see Case Study 2 from Brazil), putting
PPAs on equal footing to state-run protected areas. Where this is not the case, long-term intent can be demonstrated through one or more of the following:

- Demonstrating that PPA status will transcend changes of ownership, through easement, covenant, wills, transfer of development rights and other appropriate legal measures.

- Where formal agreements relating to PPAs are short-term demonstrating a commitment to long-term protection (e.g. renewable agreements or long-term stated objectives) can demonstrate long-term intent. The ending of term agreements should never specifically prohibit continuation of a PPA. Some form of systematic long-term monitoring that demonstrates adherence to the original conservation intent, should be established and become available, while long-term conservation measures can be established.

- Active or passive management practices being applied in order to safeguard the integrity of natural resources present in the PPA, that are validated by governments or local or regional units of a national association of PPAs with guidelines and a national inventory.

In the case of PPAs held fee simple by organisations with a conservation mission, a conservation restriction given to a third party (government agency or other non-governmental organisation) or specific legislation legally securing the conservation status provides protection. However, it may be enough for an organisation with a conservation mission to document intent through management plans. Best Practice 4.1.1: Permanence is best secured
through legal instruments empowering governance

Long-term conservation of PPAs is often most effectively achieved with a legal conservation instrument linked to an institutionalised conservation agent or legal status through an appropriate government agency (see Case Study 11 from the USA). In Brazil, PPAs are created in perpetuity by a law which guarantees conservation of the land, even if the ownership or governance changes over time. In the UK, PPAs owned by the National Trust are inalienable, which means land cannot be sold or mortgaged against the Trust's wishes without special parliamentary procedure (Crofts 


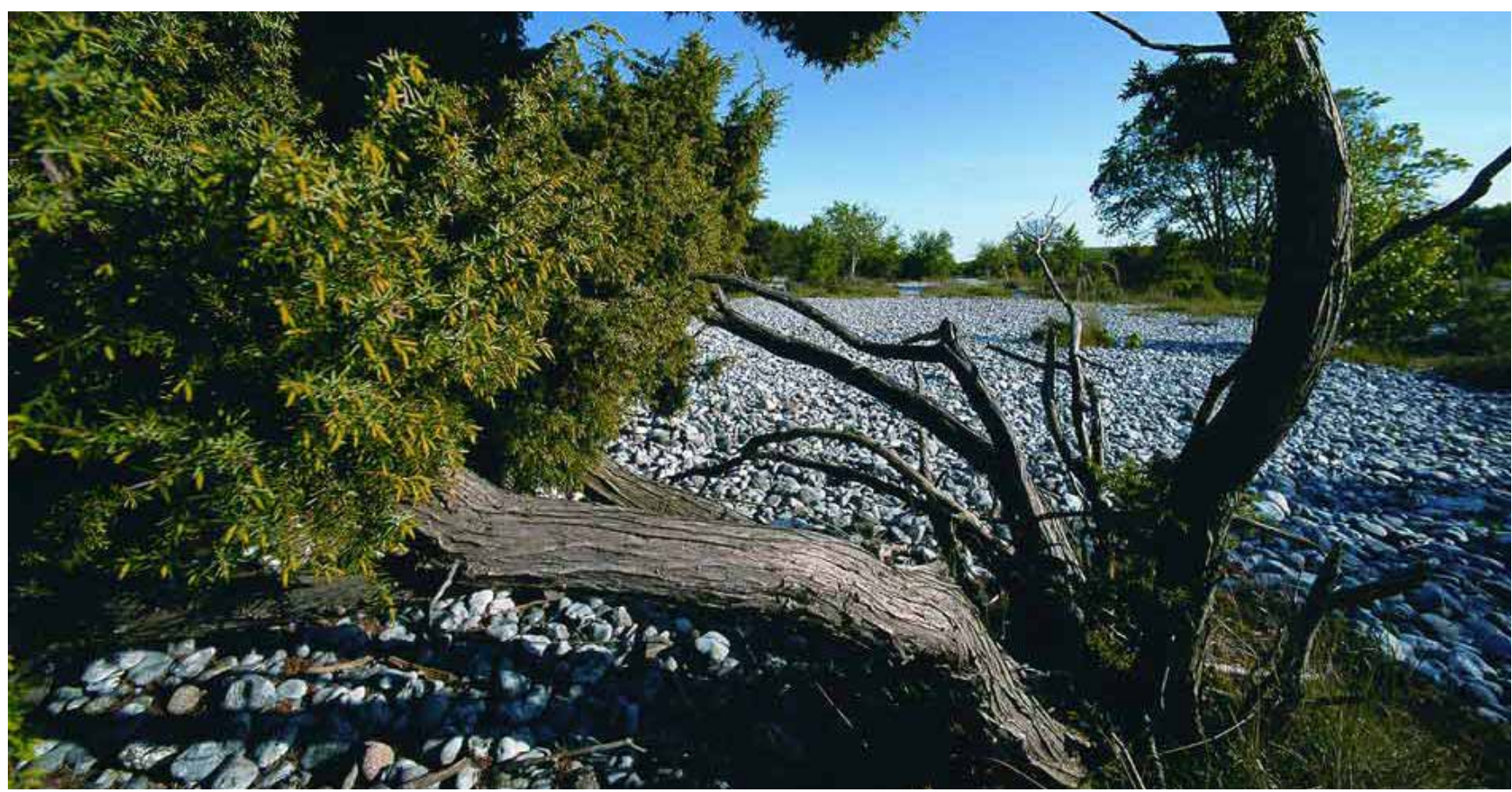

DBU owns the largest part of the National Natural Heritage network in Germany. The flintstone areas on Ruegen used to be part of a military training ground (C) Norbert Rosing

et al., 2014). New Zealand has similar arrangements (see Case Study 7). Legally-binding provisions within land trusts' incorporation charters that include appropriate conservation land disposition practices to same-minded institutions, guaranteeing the persistence of conservation objectives in case of unforeseeable land trust institutional failure, are also considered as an appropriate legal conservation instrument.

In Germany, the federal government through the National Natural Heritage ${ }^{78}$ initiative exempts federally-owned land of high nature conservation value from privatisation and transfers it free of charge to states (Länder), nature conservation organisations or foundations, to be permanently protected for nature conservation (see Case Study 5 from Germany). As well as being binding on future owners, appropriate mechanisms should have security measures that ensure ongoing permanence of PPAs (e.g. using multiple parties to a conservation covenant, see Hardy et al., 2017) such as in Australia (see Case Study 1). In Kenya in 2012, the Lewa Wildlife Conservancy (see Case Study 6) purchased the majority of the land upon which the Conservancy had been established. This deal, the first of its kind in Kenya, transferred land ownership from private individuals to institutional ownership, ensuring Lewa's existence and role as a foundation for community and development-centric conservation. Another first in Costa Rica saw Lapa Rios PPA sign the first easement applied to a private business to ensure the future of the reserve (see Case Study 4).

Many different private instruments are employed for private land conservation around the world, each having unique legal implications derived from national or regional legislation. Definitions for some of these tools appear in the glossary. Chile, for example, pioneered a new legal instrument for private land protection, the Derecho Real de Conservación (literally, Royal Conservation Right) or DRC. Previously, the legal system required that a conservation agreement (servidumbre) can only be made between two adjacent properties. Passed by the legislature in 2016, the DRC fundamentally changes the law to allow protection of private lands anywhere. Chile quickly established the first DRC between a private conservation initiative and a public service, between Hacienda El Durazno and the National Forestry Service (CONAF). This significant development may serve as a precedent for other countries whose land tenure system is based on the civil code.

Best Practice 4.1.2: Where a legal instrument is not possible, agreements should be renewable and the conservation intent should be in perpetuity

Ensuring PPA permanence is crucial for attaining long-term conservation benefits. Nevertheless, best practices for PPA permanence should not inhibit the development of a wide range of private lands/water conservation initiatives and practices, that in the future could be formally incorporated as PPAs. In many cases, permanent agreements are not possible, or landholders are just beginning to experiment with conserving their lands/water and commitments. While fixed-term conservation agreements should be renewable and the intention should be to renew in perpetuity (Best Practice 3.2.1), in some countries short-term governmental financial incentives, such as PES (see Box 3.4), become the point of entry to short-term private lands conservation practices, steps that could evolve into long-term initiatives. In other cases, funding provided by government agencies or conservation NGOs to protect critical environmental values on private holdings can only be provided for limited periods while a more permanent solution is sought. In these cases, the ending of an agreement does not necessarily mean the ending of PPA 


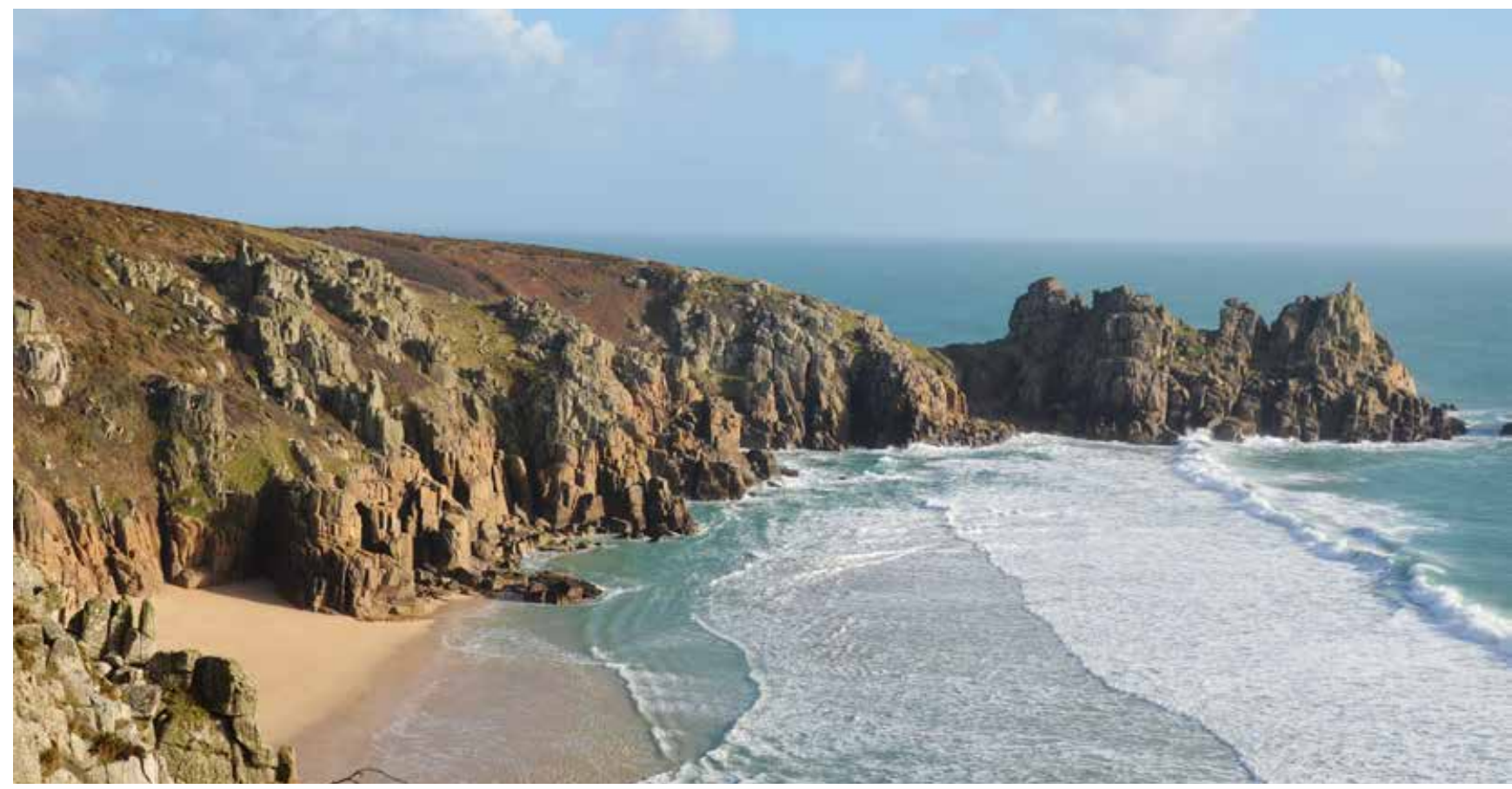

Areas owned by the National Trust in the UK, such as parts of the Land's End Peninsula in Cornwall, are some of the most securely protected places in the UK (C) Sue Stolton

status if the intent is to find an alternative mechanism for longterm conservation (Stolton et al., 2014).

\section{Best Practice 4.1.3: Where a legal instrument or status is not available or feasible, some transparent proof of 'long-term' intent should be developed}

If a legal instrument is not achievable, areas which wish to be formally recognised as PPAs (see Principle 7.1) should have proof of long-term conservation intent in writing available to interested parties together with a description of how the intention will be implemented over time. Examples would include long-term management plans. Any process to change this documentation needs to be transparent, so it is evident if an area should no longer be considered a PPA. Transparency does not have to mean that information is available to everyone, but this information should be provided to a recognised land conservation institution, an established PPA network or an appropriate government agency. Legal or formal documentation of long-term intent to conserve is presently difficult to achieve in many countries. This practice should be viewed as a feature of a maturing PPA system and an objective for developing systems. Contemporary constraints on achieving these best practices should not in themselves inhibit expansion of PPAs in those countries with potential to develop such systems.

National or regional institutionalised land conservation agents can help provide proof of intent and transparency, while maintaining anonymity (Best Practice 7.1.4). Transparency can be challenging in areas where central or rural governance structures are weak or have deteriorated due to illegal activities. For example, during the compilation of a PPA database for Mexico (Bezaury-Creel et al., 2012), concerns were raised by some private landholders that the misuse of information by others could lead to instances of incursions. (In parts of Mexico, there is a perception that lands that are uncultivated or not used for cattle ranching are 'wasted' and therefore others have a 'right' to encroach and use the land.) In other cases, landholders questioned whether PPAs might be perceived by local communities as disused or unproductive land, that could be better used to provide shortterm benefits to local populations, without due regard to the broader range of environmental services potentially provided by PPAs in the long term (Bingham et al., 2017).

\section{Best Practice 4.1.4: Individual conservation intent should be secured for future ownership}

Landholders should think about succession and how the conservation intent of their PPA is continued when ownership changes. PPAs should therefore be structured so that the intent for conservation is incumbent on all future owners (see also Principle 1.5, Best Practice 3.2.1 and Case Study 1 for Australia). A clear succession plan for the continuation of the PPA should be required including land-use restriction, financing and transfer of ownership. In cases where successors are unwilling or unable to uphold the conservation intent, the option should be available to transfer the PPA to a credible conservation institution.

In its most basic form, an individual conservation initiative can result from the intent of an independent private landholder to protect land for spiritual, aesthetic, practical or other reasons. These initiatives can deliver effective conservation over the lifetime of an individual and perhaps over longer time periods if they become a family generational project. Nevertheless, if no legal instruments are in place for achieving long-term protection of the land/water, and no planning for the financial resources required for management, these initiatives are more 
likely to fail with the passage of time. These independent initiatives are usually non-third party verifiable and thus their transparency of intent is not always evident. If legislative instruments are not suitable or available, best practices in this case range from the establishment of a verifiable conservation statement (Best Practice 4.1.3) to long-term financial support mechanisms, such as dedicated trust funds that provide for future stewardship costs. Another alternative is to make legal provision to transfer governance and/or ownership to a conservation management institution (e.g. NGO or land trust) should the establishing landholder vacate the property, and if there is a lack of interest from their inheritors to continue protecting the land (see Case Study 4 from Costa Rica).

\section{Best Practice 4.1.5: Being part of a private conservation network can help ensure long-term conservation}

Permanence of protection can be made more likely when landholders organise themselves formally with the intent to privately conserve and manage lands over the long term (see Section 8).

\section{Best Practice 4.1.6: PPAs should have mechanisms in place to ensure that intent for conservation does not change with leadership}

PPA owners with short-term planning cycles, or where leadership and landholding can change rapidly (e.g. some companies), can potentially affect the continuity necessary for long-term conservation (See Best Practice 1.5.1). (For example, in Slovenia, a company established a PPA for philanthropic reasons but later dropped its commitment to save costs.) Ensuring a conservation focus can be facilitated through other means as well, such as a policy approved by the oversight board as well as reserving seats for representatives with a conservation focus on decision-making boards, etc., to help maintain the companies' conservation focus.

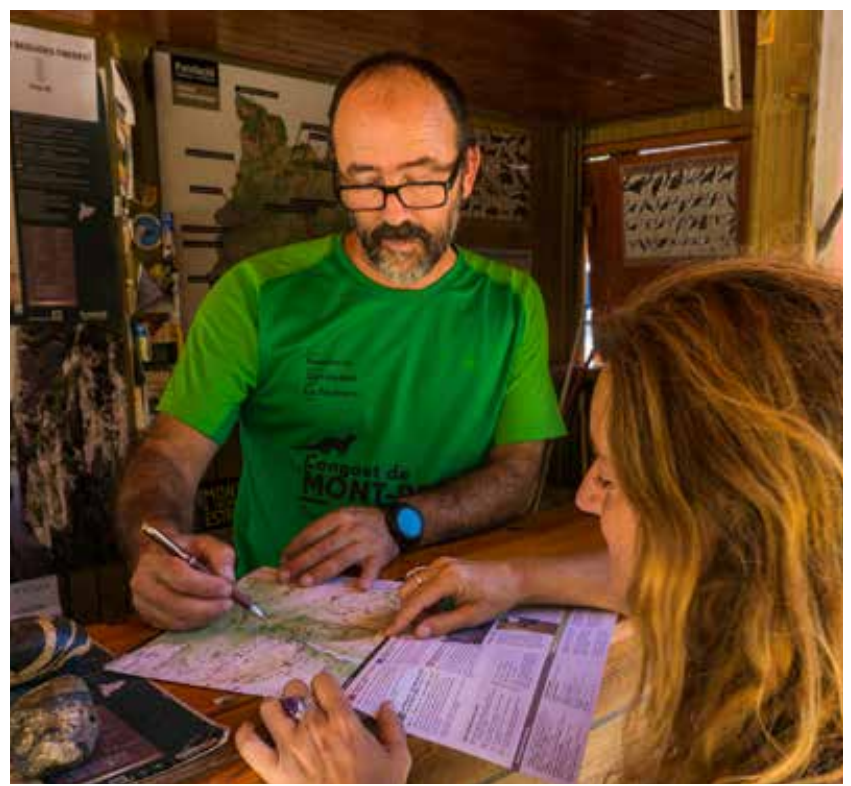

Spain has several well established private conservation networks, the Montrebei Gorge reserve was purchased by the Fundació Catalunya-La Pedrera in 1999 @ F Fundació Catalunya La Pedrera

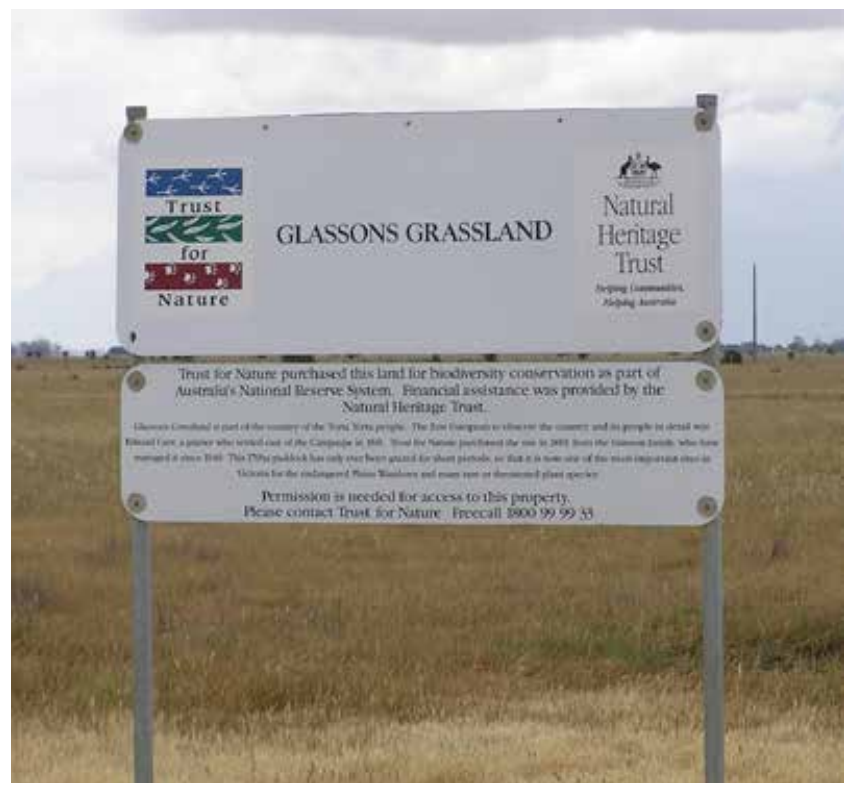

Glassons Grassland, Trust for Nature, Northern Victoria, Australia @ James Fitzsimons

\section{Best Practice 4.1.7: Government programmes enabling or encouraging private conservation should include provisions for permanence}

Many national and sub-national governments throughout the world have explored collaborative efforts in numerous ways, either incorporating PPAs within their conservation strategies (Best Practice 1.2.1) or providing specific economic and/ or tax incentives in support of private land conservation practices (Best Practice 4.1.1 and Case Study 2 from Brazil).

Lands incorporated into government conservation strategies have been integrated into wider biodiversity protection systems, through a range of tools including legally-binding covenants established in perpetuity between a government and the landholder as in New Zealand (Case Study 7), where the covenant is registered with the land title (see also Case Study 11 from the USA). In Mexico, landholders can voluntarily declare PPAs for a minimum of 15 (much less than the 25 years recommended in these Guidelines) to a maximum of 99 years; they are considered equivalent to government protected areas. In both cases, PPAs are integrated into the national protected area system. In Europe, land acquisition for conservation purposes with the help of LIFE $^{79}$ money from the European Union is only eligible if the land is dedicated to conservation in perpetuity. In Australia, the federal government's funding for land acquired by NGOs for addition to the National Reserve System requires a conservation covenant to be established soon after purchase (Fitzsimons, 2015). 


\section{Principle 4.2: Many different private conservation instruments can contribute to PPA permanence}

The number of PPAs is growing globally as is the number of people involved and the range of practices. As the diversity of types of PPA develops, there is an increasing range of approaches which can contribute to ensuring permanence of conservation outcomes.

Best Practice 4.2.1: Conservation restrictions limiting some uses while allowing others, can be effective conservation tools, and can sometimes meet the definition of a PPA

Land and water ownership includes several distinct types of use rights, for example, the right to develop the land, undertake farming activities, manage for forestry production, fishing, hunting or recreation. Legally-established conservation covenants include several types of instruments with enough legal force to exclude some or most of the use rights, while allowing other rights to continue being used (see Case Study 11 from the USA). Landholders will not always have control over all the rights to the land and water conserved when established. These areas can still be considered PPAs if plans are in place to secure rights which are likely to impact conservation success, and thus secure long-term conservation (see Box 4.2).

\section{Box 4.1 \\ 'Purchase-protect-resale': A conservation strategy of The Nature Conservancy}

The Conservation Buyer Program is one of the strategies used by The Nature Conservancy to achieve long-term conservation, while freeing up financial resources to acquire new PPAs, particularly in the USA. This strategy is applied through three basic steps: land is acquired in critical conservation areas; appropriate conservation easements are designed for the land to protect natural features; and finally, the land is sold to individuals who agree to the terms of the protective conservation easement, thus achieving PPA permanence (TNC, 2018). The Conservation Buyer Program is part of a broader conservation approach 'Purchase-protect-resale', which includes the use of revolving funds, revolving loan funds and larger capital funds to buy, protect and resell private land with conservation values around the world (Hardy et al., 2018 a,b,c).

Author: James Fitzsimons, The Nature Conservancy

\section{Box 4.2 \\ Controlling rights, securing conservation: Karukinka Reserve, Chile}

Karukinka Reserve ${ }^{80}$ (300,000 ha) in Tierra del Fuego, Chile, is owned and managed by the Wildlife Conservation Society (WCS). Though WCS is the owner, the mineral rights to extract peat (25 per cent of the land is covered with peatbogs) were available to anyone interested in mining this resource. After years of research and sharing the message of the global conservation value of peatbogs with different stakeholders, WCS was able to have Karukinka declared an Area of Scientific Interest by the Chilean government in 2015. This means that Chile, through the Mining Ministry, declares that scientific research will be a priority over mining inside Karukinka Reserve. Thus peat mining is banned, protecting the land from this threat in perpetuity (Saavedra et al., 2011; Gobierno de Chile, 2015).

Author: Melissa Carmody,Wildlife Conservation Society

Best Practice 4.2.2: Processes should be put in place to deal with potential violations of conservation restriction

Wherever compliance issues arise, there should be a mitigation and action plan prepared. For example, that plan should indicate when the enforcement organisation should negotiate breaches of obligations, or when to take legal recourse (including with third parties) (Rissman \& Butsic, 2011; Hardy et al., 2017). 


\section{Section 5: Issues related to specific subtypes of privately protected areas}

\section{Who should read this section? \\ This section is aimed primarily at company managed PPAs, and PPAs which are based on a for-profit model primarily through tourism. Other specific subtypes of PPAs, for example, research institutions or religious entities would also find this section relevant.}

Not all PPAs are run by individuals or conservation NGOs/ trusts. Some are owned and managed by institutions not usually associated with conservation, such as mining or fossil fuel companies, tourism operators, forestry and farming operations, religious institutions and research institutions. Though less known than individual and NGO governed PPAs, PPAs of corporations, for-profit companies (including social entrepreneurs), research institutions or religious entities can be equally valuable. PPAs run by these different institutions may face particular challenges but they also provide important opportunities, including by engaging new sectors of society in conservation management.

When companies own land or water outright, they sometimes choose to establish PPAs in the set-aside areas. Some countries also oblige companies to offset damage from their operations, which can lead them to purchase land and water elsewhere to establish a PPA. Religious institutions may devote part of their land to a protected area as a practical expression of faith and stewardship. Research institutions and universities (Levitt, 2014) can set aside areas specifically for protection as part of the institution's research mandate (see Box 5.1). Individual laws and policies can act as an encouragement. Finally, an increasing number of PPAs are being set up explicitly as income-generating ventures, for example through tourism where people go for day visits or overnight stays. In a context where the funding gap for protected areas constrains both the expansion of protected area coverage and the maintenance of the existing network, for-profit PPAs potentially provide a sustainable financial model where profit underwrites long-term biodiversity and development outcomes. Broadening the type of stakeholders engaged also brings dynamism, new skills and new thinking to the PPA sector. However, systems and best practices need to be in place to ensure that sufficient profit is generated to sustain conservation and development outcomes in the long term, and that the profit motive does not undermine conservation.

As with all examples of PPAs in these guidelines, according to IUCN such sites would need to meet the definition of a
PPA (see Section A) and would ideally manage their PPA in accordance with the relevant best practices in this volume. Other sites with a conservation objective which are not PPAs could fit the evolving definition of an 'other effective areabased conservation measure' (see Appendix 1).

\section{Principle 5.1: Specific subtypes of PPAs may require tailored forms of recognition, support and encouragement}

While PPAs run by large NGOs are often quite well integrated into broader national or regional conservation strategies, those governed by companies, universities and religious organisations may be more isolated from mainstream conservation. Furthermore, some of these PPA owners/ managers may have relatively little practical conservation knowledge, experience or access to scientific information. While the same standards apply here as in all PPAs, managers may need different kinds of help and incentives to build up knowledge and experience. Best practices therefore address both the needs of the individual PPA and their place in the broader conservation community in terms of outreach and engagement.

Best Practice 5.1.1: Encourage companies owning/ managing PPAs to list them on the World Database on Protected Areas (WDPA)

Specific guidance on listing and recording PPAs is provided in Section 7. However, entities managing sites outside the mainstream conservation community may need encouragement or specific guidance to help get their sites listed as part of the national and international protected area estate. In some countries, external evaluations and advisors may be needed to ascertain whether areas fit the definition of a PPA and provide assistance on being added to national lists of protected areas. Linking with NGOs which also manage PPAs may provide a good entry point or working with national IUCN bodies like the National and Regional Committees ${ }^{81}$ (see Case Study 12 from the UK). The Long Run (see Box 


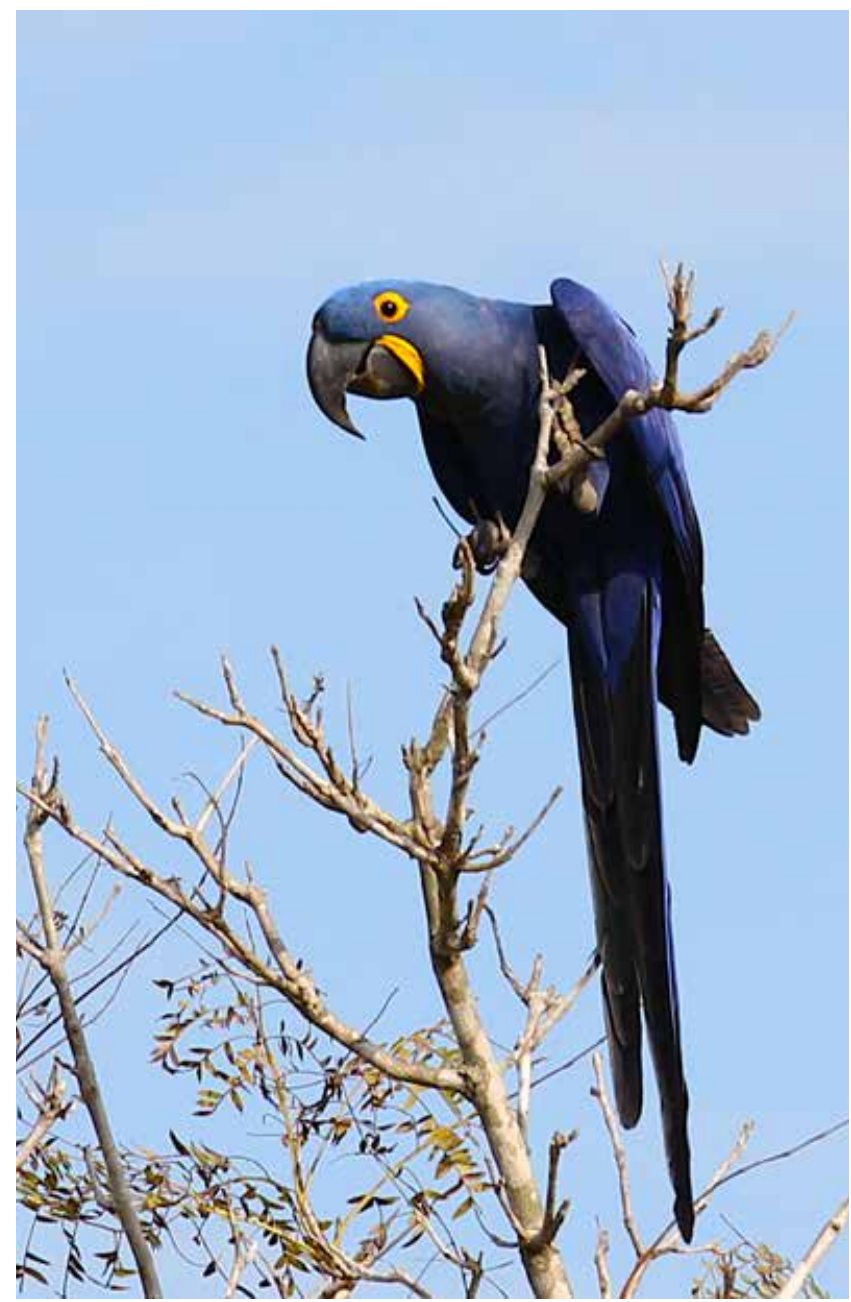

Hyacinth macaw $($ ) Brent A. Mitchell

8.3), which represents a network of PPAs owned or managed by tourism enterprises, acts as a data provider to the WDPA (Best Practice 7.1.4). It can propose a PPA to be listed providing that the PPA definition (see Section $A$ ) is met, acts as a contact point for the WDPA and helps its members assemble the information required. This information is verified by a local expert or government body to confirm the site's suitability and approve the listing. For example, the Lapa Rios Reserve, in Costa Rica (see Case Study 4), decided to be listed on the WDPA, further strengthening the recognition of its conservation focus. Developing PPAs under legally binding instruments (see Section 4) will also usually ensure national recognition, as will sometimes also be the case when becoming part of a PPA network (see Section 8).

\section{Best Practice 5.1.2: Investigate partnerships with NGOs, academics or other specialists to maximise the value of the PPA}

Not all PPA owners or managers will have the expertise to manage a PPA, nor wish to or be able to afford to invest in hiring specialised staff. Help may be available, formally or informally, from local NGOs, interested citizens, other specialists or academics willing to help in return for a place to carry out research (Best Practice 2.5.4). The kind of help might be advice on conservation practice, for example drawing up a simple management plan, surveys of species present and long-term monitoring. In some cases, volunteers may even be available to help with management, such as restoration or removal of invasive species. These partnerships not only strengthen the capacity of PPAs but also further embed them within the wider conservation landscape.

Many examples exist including:

- In Laikipia, Kenya, the Lion Landscapes and Living with Lions projects carry out research with the aim of reducing predator-human conflict. Partnering with these has helped Borana Conservancy, ${ }^{82}$ a private conservancy underpinned by tourism revenue, to strengthen its management for improved lion conservation and reduce human/predator conflicts with pastoralist neighbours.

- The ecotourism venture, Caiman Ecological Refuge ${ }^{83}$ in Brazil (Best Practice 1.5.2), has for many years contributed towards the conservation of the hyacinth macaw (Anodorhynchus hyacinthinus), and collaborated with the Oncafari Project focused on jaguar (Panthera onca) conservation. Both projects have enabled Caiman to become a haven for the two species, increased the population sizes of these species, contributed significant knowledge and helped Caiman develop a unique tourism opportunity. Similarly, a partnership with INEA, the State Institute for the Environment, supports the tourism enterprise Sinal do Vale ${ }^{84}$ to keep track of restoration progress in the Mata Atlantica forest, Brazil.

- In the Maldives, marine biologists from two UK-based NGOs supported the Six Senses Lamuu resort ${ }^{85}$ in developing a marine reserve.

- The forestry company UPM manages the 1,400 ha Griffin Forest, ${ }^{86}$ located next to the state-owned Repovesi National Park in southern Finland. The area is managed as a whole by the Aarnikotka Forest Administrative Committee, which consists of representatives from UPM, Metsähallitus Parks and Wildlife (the national protected area agency) and the South-Eastern Finland Centre for Economic Development, Transport and the Environment. 


\section{Box 5.1}

\section{Research institution PPAs: Nanya Station, Australia}

Nanya Station ${ }^{87}$ in western New South Wales, Australia, was bought by the University of Ballarat (now Federation University Australia) in 2004 for conservation, research and education. The 40,000 ha property was purchased with funds from the Australian Government's National Reserve System Program (see Case Study 1 from Australia) and contains a unique system of natural salt lakes, old growth Mallee (eucalypt species with multiple stems), and a variety of intact ecosystems. Conservation activities all have associated research projects and include:

- Reducing grazing pressure on the land by closing artificial water (ground tanks) provision, goat control and ripping rabbit warrens.

- Regenerating endangered flora and fauna communities by using exclusion fencing around critical communities.

- Protecting the malleefowl (Leipoa ocellata) population by exotic predator control and monitoring their nest sites.

Author: James Fitzsimons, The Nature Conservancy

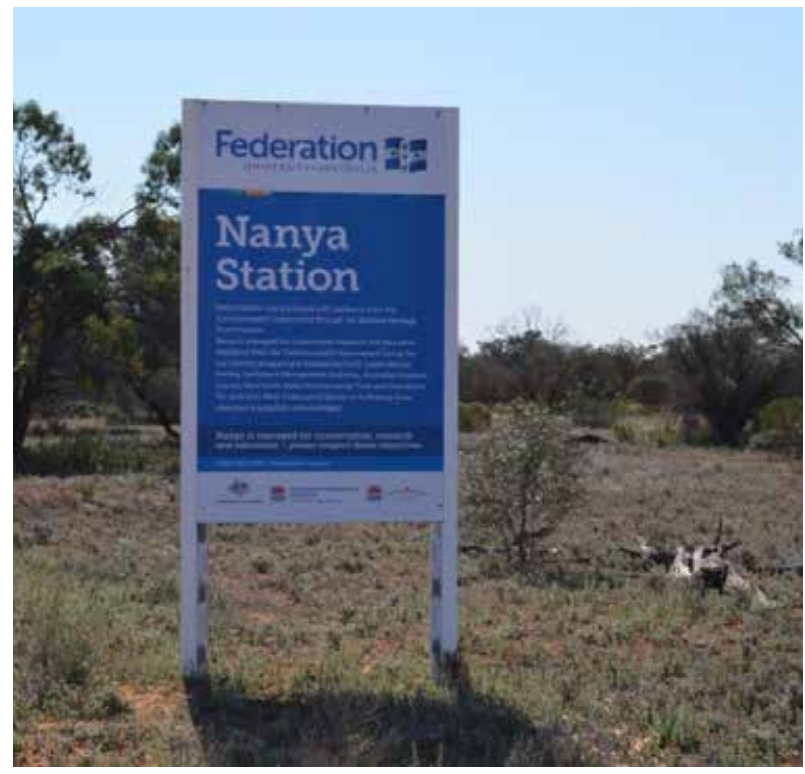

Nanya Station @ Jamie McDonald

\section{Box 5.2 \\ Mixing wine and conservation: An example from South Australia}

The Banrock Station ${ }^{88}$ property in South Australia is managed by a major private agro-business (Accolade Wines Ltd). In addition to operating 250 ha of vines, the company has committed for over 25 years to restore surrounding wetlands and woodlands through the removal of stock-grazing pressure, control of feral and weed species, re-establishment of a natural hydrological regime, reintroduction of native threatened species and re-vegetation. Because of its environmental credentials and status as a Ramsar site, the site was selected in 2013 by the state government environment agency to reintroduce a long-thought extinct plant: the spiny daisy (Acanthocladium dockeri) into its former range. Welcoming on average 60,000 visitors annually, up to two university/ school classes per month and volunteer groups (such as International Student Volunteers) ${ }^{89}$ since 2005, Banrock Station has become a demonstration site for on-theground conservation work by a private business acting for the common good (Tourenq et al., 2016).

Author: Banrock Station

\section{Principle 5.2: Corporate PPAs offer specific benefits to companies and vice versa}

The reasons for setting up company PPAs are varied, as with any other PPA (see Section 1):

- They could be a personal interest of the company director.

- To enhance green credentials, for example, wine producers in South Australia (see Box 5.2) use green credentials gained by owning protected areas to access additional export markets.

- To make the best use of land and water owned but no longer needed by the company (such as former quarry or mine sites, see Boxes 2.7 and 5.3).

- Be areas set aside because they are not suitable for exploitation.

- Be areas particularly valuable from a conservation perspective (and possibly requiring protection under certification schemes).

- Be areas under restoration.

Areas set aside for conservation now but with the intention of future exploitation would not qualify as PPAs as they could not demonstrate long-term intent as described in Section 4.

Companies can benefit in different ways from creating protected areas, including:

- Demonstrate commitment to social good.

- Develop a more positive image, generating support from the wider public. 
- Attract innovative teams to work on PPA management, bringing new mindsets and skill sets to the company.

- Strengthen the credibility of their Corporate Social Responsibility (CSR) efforts and environmental engagement, resulting in differentiation in the market place, often strengthened by third-party verification.

- Protect resources and ecosystem services on which the company may rely for its operations, such as water quantity, water quality, pollinators, natural pest control.

- Provide opportunities to generate other sources of income, for example, through visitation, sale of carbon credits.

- Create opportunities to integrate the company further with local communities, for example, through research or by encouraging educational tours.

- Provide an inspirational and/or recreational place for company staff, which can be used for a range of benefits including team building.

Best Practice 5.2.1: Companies and other subtypes of PPAs can deploy strengths such as management skills, capital, financial resilience and capacity for conservation management

PPAs that are maintained by a company can benefit from management tools and skills used in the main business that help leverage capacity building, supplies, IT, legal, budgetary skills, among others. In addition, PPAs can benefit from the entrepreneurial spirit, management effectiveness, innovation and risk taking. If businesses become part of the wider PPA network in a region or country, opportunities can be created to transfer these skills to other PPAs from different sectors and to other types of protected areas. Research organisations that manage PPAs can be leaders in protected area management globally. Cedar Creek Ecosystem Science Reserve ${ }^{90}$ in central Minnesota, USA, is owned and operated by the University of Minnesota in cooperation with the Minnesota Academy of Science. Researchers at the site were the first to use radio collars for animal tracking, have been researching prescribed burning since the 1960s, and the PPA has one of the most intensely studied insect communities in the world.

\section{Principle 5.3: PPAs managed by extractive industries must demonstrate contributions to biodiversity conservation}

Extractive industries, such as forestry, mining and fossil fuel companies, have complex operations. They frequently own large tracts of land not actually used for extraction and/ or areas where extraction is no longer operational (e.g. see Boxes 2.7 and 5.5), which can be restored for conservation and become important wildlife PPAs (particularly in cultural landscapes), or geoheritage and geotourism sites.

\section{Box 5.3 \\ Recreating habitat after sand and gravel extraction: Attenborough Nature Reserve, UK}

Attenborough Nature Reserve, ${ }^{91}$ owned and managed by Nottinghamshire Wildlife Trust, is a PPA on the site of a disused gravel pit in Nottinghamshire's Trent Valley in the UK. The site operated between 1929 and 1966 (when the reserve was formed) and the company CEMEX is still extracting sand and gravel from surrounding areas. Its barges pass through the reserve to reach the processing plant. As sections of the site are worked out they are restored to wetland, with a series of large lakes dotted with islands where native woodland regenerates. Reed beds, floating nest platforms, nest boxes and artificial nest banks encourage the return of species such as bittern (Botaurus stellaris), terns, sand martins (Riparia riparia) and owls. The reserve now covers 226 ha with bird hides, footpaths and an award-winning nature centre. The River Trent flows along one edge, bringing occasional flood waters and acting as a wildlife corridor. There is heavy visitation, by bird watchers, walkers and runners, but careful planning means that large undisturbed areas remain for wildlife. Profoundly unnatural in origin, the area now substitutes for floodplain wetlands that have been lost through hundreds of years of agriculture and is an important habitat for waterbirds, particularly over winter: more than 250 bird species have been recorded since the reserve was created (Dudley, 2011).

Author: Nigel Dudley, Equilibrium Research

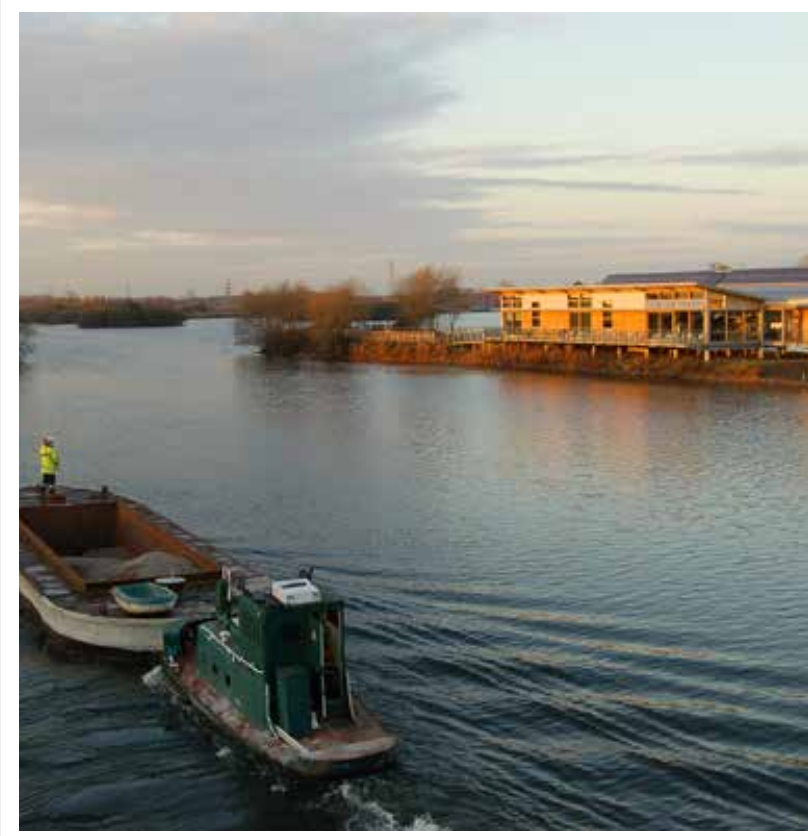

Attenborough Nature Reserve @ C Nigel Dudley 


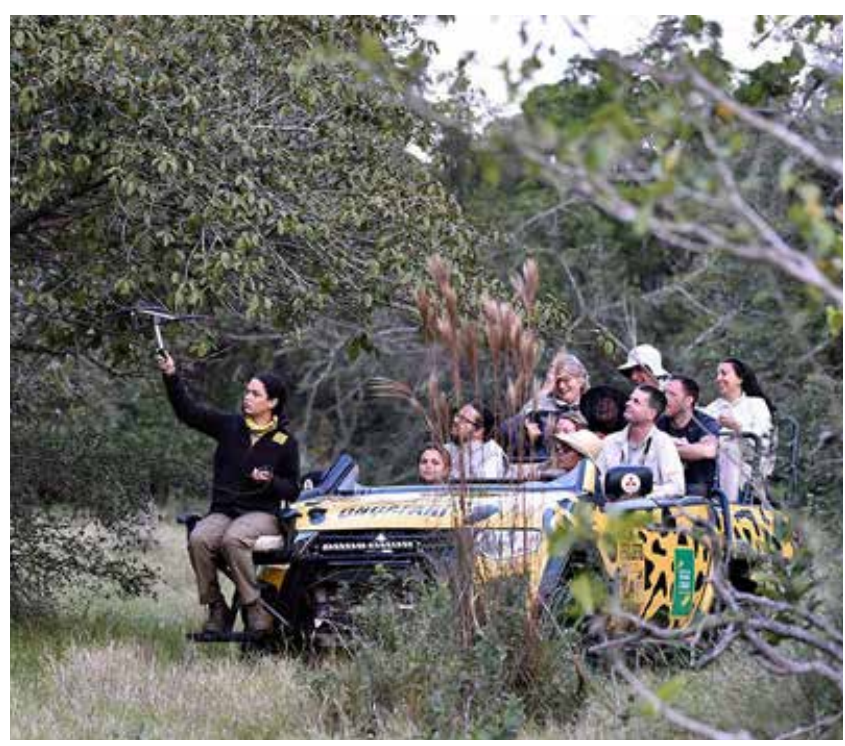

(C) Project Oncafari

Best Practice 5.3.1: A PPA managed as part of an extractive operation should be separate from that operation

PPAs linked to extractive operations (i.e. management which is not focused on conservation) such as mining or forestry should have clearly separate and delineated boundaries between the extractive and conservation use. This means that the PPA does not include incompatible land use within its boundaries. For example, the first PPA in Uruguay's National System of Protected Areas (SNAP), Esteros y Algarrobales del Río Uruguay (EARU) ${ }^{92}$, is an FSC-certified High Conservation Value Forest owned and managed by a forestry company, UPM-Forestal Oriental. Added to the national system in 2015, the 1,550 ha protected landscape includes estuaries, carob trees (Ceratonia siliqua) and native forests and is part of a larger Ramsar Site.

\section{Principle 5.4: PPAs set up as for-profit companies/enterprises should ensure they achieve their specified conservation outcomes}

For-profit companies can provide a sustainable financial model for PPAs, potentially ensuring their longevity. In the case of sustainable nature-based tourism for example, there is an intrinsic and direct link between the profit of the company and conservation, where profit depends on the conservation and the conservation often depends on profits (see Case Study 4 from Costa Rica). However, in naturebased tourism, and more so in less compatible land uses, it is essential that the tension that can arise between short-term profit requirement and conservation outcome is addressed. Similarly, it is important to buffer conservation outcomes from a downturn in the economy, or from sudden crashes in the market, which reduces the profit element of the PPA (e.g. major tourism downturns due to global economic factors, security issues, disease outbreaks, etc.).
Best Practice 5.4.1: PPAs built as for-profit ventures should develop resilient financial models to ensure sustainable conservation outcomes

All PPAs should build business models that incorporate the management costs of maintaining their nature conservation outcomes (see Principle 2.3); this is particularly the case for for-profit ventures. Direct support by commercial operations of conservation activities should be viewed as a prudent reinvestment strategy. It is useful to decide on a set proportion of income or profit to be re-invested in the conservation activities. This helps secure a predictable budget for core activities. Many options for direct funding mechanisms exist, including bed night conservation fees in the case of tourism. For example, visitors staying at Segera Retreat $^{93}$ in Kenya, pay a levy per night and per person which is dedicated to supporting conservation. External factors can affect the profitability of the operations, threatening conservation activities. It is thus a good strategy and useful, over time, to diversify income sources. In the case of tourism, it can be useful to think about developing tourism products that expand markets. Where the enterprise targets international tourists and is highly seasonal, developing special packages for local tourists in the off season can help reduce cash flow issues. Non-tourism based but compatible products can also be considered. For example, Tahi ${ }^{44}$ in New Zealand has developed a unique sustainable brand of Manuka Honey as a way to strengthen the financial viability of its PPA. Building a reserve fund is good practice and ensures continued management of a PPA if the main funding stream collapses (see Box 5.4). Finally, setting up a not-for-profit vehicle to raise external funding for specific activities or to create a reserve could also be considered. Wolwedan ${ }^{95}$ in Namibia has established the Wolwedans Foundation ${ }^{96}$ which enables the PPAs to raise funds from international donors to conserve the NamibRand (see Box 8.4).

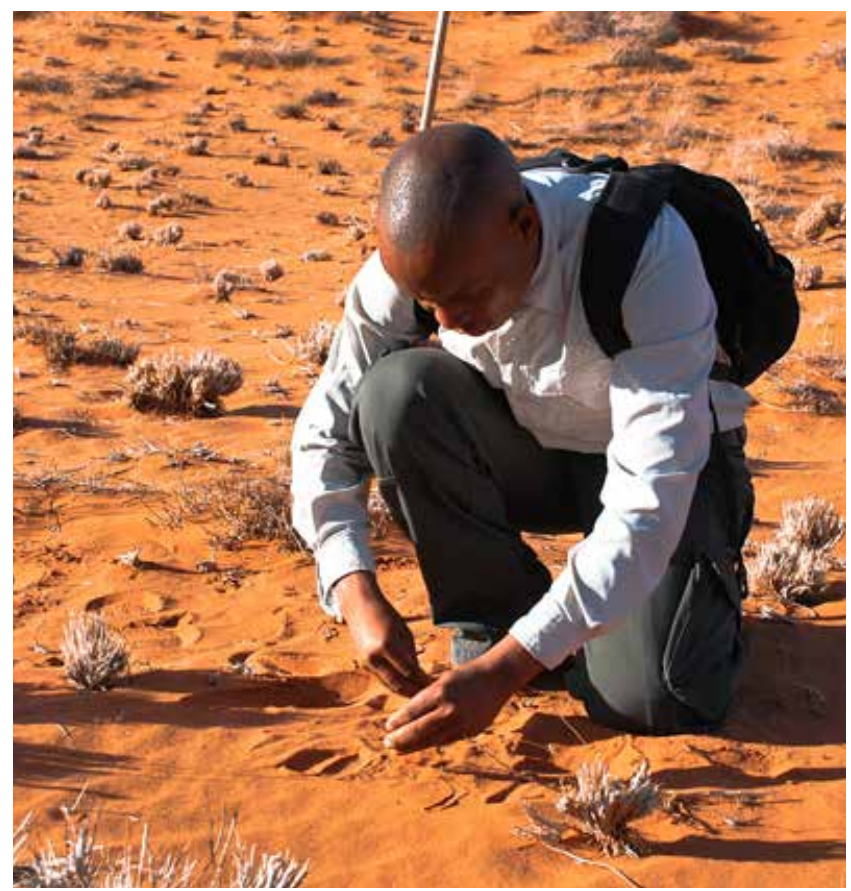

(C) Wolwedans, NamibRand Nature Reserve, Namibia 


\section{Box 5.4}

\section{Creating long-term financial security for managing the Borana Conservancy, Kenya}

Borana $^{97}$ is located in Laikipia, Kenya. It is part of one of the largest black rhino landscapes in Kenya (see also Case Study 6 for Kenya). Borana created a 14,000 ha not-forprofit conservancy entity (PPA) with a clear conservation purpose. Over time it has diversified its income streams to increase its ability to support the running costs of the conservancy. Tourism and a sustainable livestock enterprise are the main contributors to the management costs.

Recently, Borana established a permaculture farm supplying produce to the tourism operations, expanding the guest experience and creating opportunities for education. As a not-for-profit entity, Borana seeks donor funds to help rhino conservation and support outreach programmes to provide education and health care as well as micro-enterprise developments that secure ongoing support from the wider community. To reduce the vulnerability of conservation activities to a downturn in the tourism business, Borana also established a financial reserve by selling shares in the conservancy. Shareholders commit to underwrite management costs in proportion to their shareholding. Finally, the capital raised through the shareholding was used to establish an endowment fund to buffer the conservancy against any sudden drop in business returns.

Authors: Delphine Malleret King, The Long Run and Michael Dyer, Borana

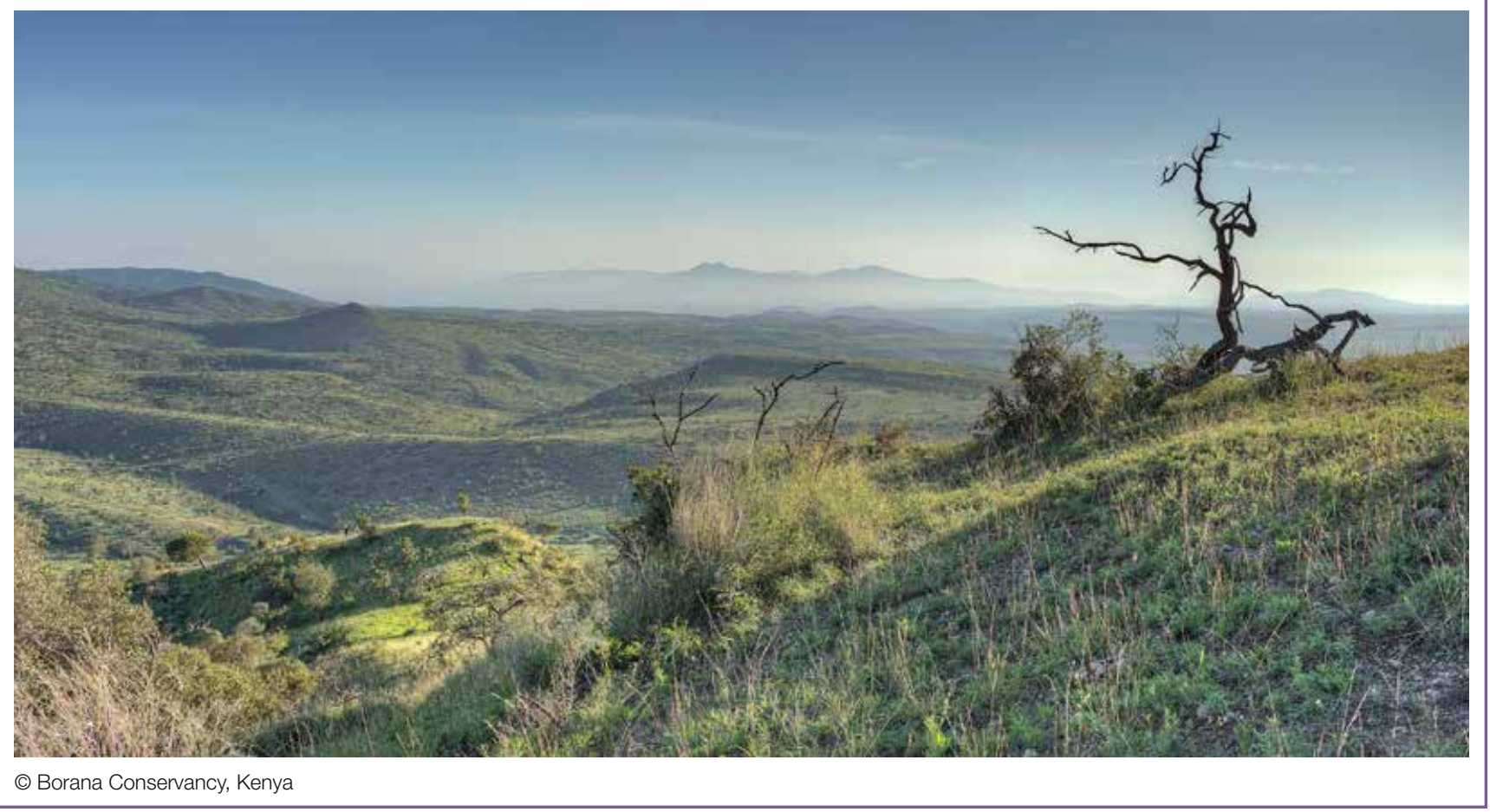

Best Practice 5.4.2: Any inherent tension between profit and conservation should be addressed through well-articulated objectives

\section{Company operations should not negatively affect} conservation activities and values of a PPA, nor undermine any social and economic considerations (see Case Study 4 from Costa Rica and Case Study 6 from Kenya). To ensure this, it is useful for companies to have a clear understanding of the impacts of their activities and how to mitigate them. It is also important to have well-articulated conservation objectives (see Principle 1.2), in line with the PPA definition (see Principle 1.1), which support commercial elements but are not dictated by them. Tourism can have negative environmental impacts if it is not well managed. For example, visitors can affect animal behaviour (e.g. predator hunting patterns, sites), degrade habitat (e.g. trampling vegetation or coral), and even affect the business itself. To ensure that conservation objectives are met, it is useful to apply standards-based management frameworks. These can be used to establish indicators and standards for visitor management, and establish visitor-use limits if required. These tools can help to identify vulnerabilities of the system and take precautions to minimise impacts on habitats or wildlife (see Box 3.4 in Leung et al., 2018). For example, codes of conduct for guiding could include minimum distance for viewing wildlife, minimum number of cars at one time in an area, keeping to tracks, and potentially establishing no-go zones where reproduction or sensitive nesting areas are located. In Mara Conservancies ${ }^{98}$ in Kenya, made up of land leased from community owners and managed by tourism operators, the number of beds (thus visitors) is capped. The general rule is one person-bed for 350 acres (just over 140 ha). This is integrated in the conservancy rule to avoid threatening conservation objectives by shortterm profit goals. Certification or accreditation processes, such as The Long Run GERß recognition (see Box 8.3), can help companies ensure an optimal balance between profit, conservation and social outcomes. 


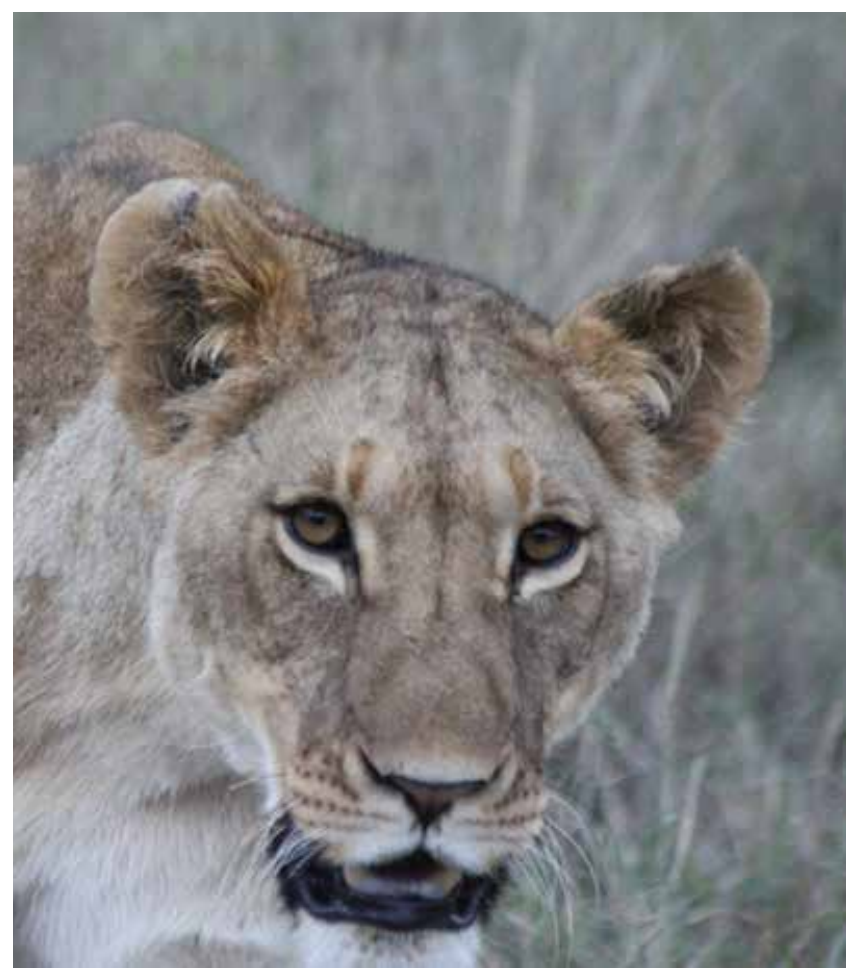

Lion, Ol Pejeta Conservancy @ Brent A. Mitchell

Best Practice 5.4.3: Encourage PPA neighbours and other stakeholders to adopt conservation compatible land uses by sharing knowledge and lessons learnt

The success of tourism-based PPAs, like that of other PPAs, can depend highly on the nature of surrounding land use. In many cases, environmental degradation, land fragmentation and unsustainable use can affect wildlife populations and habitat and thus impact tourism value. Ensuring a collaborative attitude and disseminating information and knowledge about conservation as an economically competitive land use through tourism could expand protected area coverage and enhance the natural asset of the company (see Case Study 6 from Kenya). For example, by demonstrating the value of conservation-based tourism as competitive with farming in Kenya's Maasai Mara, Cottars 1920s Camp ${ }^{99}$ supported development of the 2,670 ha community-based Olderkesi Conservancy, ${ }^{100}$ which protects wildlife movement, enhances guest experience and provides income to the Olderkesi community. Grootbos Private Reserve, ${ }^{101}$ demonstrated the environmental and economic value of the South Africa Fynbos floral system, and thus convinced neighbours to convert their land from livestock farming to conservation. The original 121 ha of land for conservation in 1991 was expanded to 19,000 ha by 2015 and formalised as the Walker Bay Fynbos Conservancy. ${ }^{102}$ Finally, PPAs can help to raise awareness and share information with the public. For example, Caiman Ecological Refuge $^{103}$ in Brazil supported the creation of an NGO, SOS Pantanal, ${ }^{104}$ which has been fundamental in raising awareness of public, research and government stakeholders about the Pantanal and its challenges. This resulted in the creation of a Caiman Charter for the Pantanal and the recognition of the Pantanal as a critical biome.

\section{Principle 5.5: Religious entities can contribute to conservation through developing PPAs on their own land}

PPAs owned by religious/faith-based organisations may include areas around sacred buildings (e.g. temples, monasteries), land owned and managed by religious authorities and sacred natural sites which themselves have links to the faith and may be the subject of pilgrimage. Many sacred natural sites have high conservation values (Dudley et al., 2010) and religious lands also protect important fragmented ecosystems. Linking conservation closely to the faith also creates strong disincentive to sell off land of value to nature. Faith-based PPAs are important in that they reach people who might otherwise be completely divorced from mainstream conservation thinking.

\section{Best Practice 5.5.1: Encourage faith groups to integrate their wider faith objectives with place-based conservation}

Most of the world's major faith groups have statements explicitly linking their belief systems with conservation objectives, usually through reference to scripture (Palmer \& Finlay, 2003). Many more own land that is either leased for conservation (see Box 5.5) or is actively managed by the faith group. In Brazil, for example, the Soka Institute ${ }^{105}$ maintains a PPA belonging to a Buddhist entity that focuses on restoration and environmental education actions, including distribution of seedlings to more than 87,000 people in 35 communities in the Brazilian Amazon.

\section{Best Practice 5.5.2: Support faith groups through active partnership and advice}

Many faith groups may have a commitment to conservation but little practical management experience. Support from the conservation community can strengthen ties to conservation through mechanisms like serving on advisory committees. The group A Rocha ${ }^{106}$ works with churches to develop nature reserves in churchyards and other church property in Europe; these places can, for example, support extremely old individuals of the yew tree (Taxus baccata) that have disappeared from the rest of the landscape. Similarly, many churches in the UK manage all or part of their churchyards as nature reserves (for example in partnership with the Norfolk Wildlife Trust ${ }^{107}$ ) and encourage parishioners to get directly involved in management, monitoring and other activities often working with 'Caring for God's Acre', ${ }^{108}$ which advises burial ground managers about site management for nature conservation. 


\section{Box 5.5 \\ Working with religious endowments to set up a PPA: Jabal Moussa, Lebanon}

With the Adonis River, famed for its mythology, at its border, the mountainous area known as Jabal Moussa in Mount Lebanon was described in 1861 by French Historian Ernest Renan in his 'Mission de Phénicie' as both the 'wildest' and 'most remarkable' region in Lebanon. Owned in large part by the Maronite (Roman Catholic) Patriarchate and several Church endowments, the area remained protected for centuries, witnessing a symbiotic relationship with neighbouring villages in the areas of forestry, charcoaling and small-scale pastoral and agricultural activity. However, towards the end of the 20th century, pressure from expanding building activity, road construction and various forms of poaching (tree-cutting, quarrying, hunting) began to threaten this biodiversity-rich animal and plant sanctuary.

In 2007, following an attempt to blast a road in the heart of the mountain, near to the famous Roman Road and Emperor Hadrian's forest inscriptions, a group of local nature lovers and their urban friends formed the 'Association for the Protection of Jabal Moussa'109 (APJM) NGO to conserve the area's cultural and natural heritage. However, Lebanese legislation did not recognise Nature Reserves on private lands. APJM negotiated and funded a 10-year lease contract with the religious endowments to rent large areas of the mountains. APJM then turned to various international organisations and conventions to convince the Lebanese Government of the importance of the site becoming a UNESCO Biosphere Reserve in 2008, a Global Important Bird Area (according to BirdLife International criteria) in 2009, a member of IUCN in the

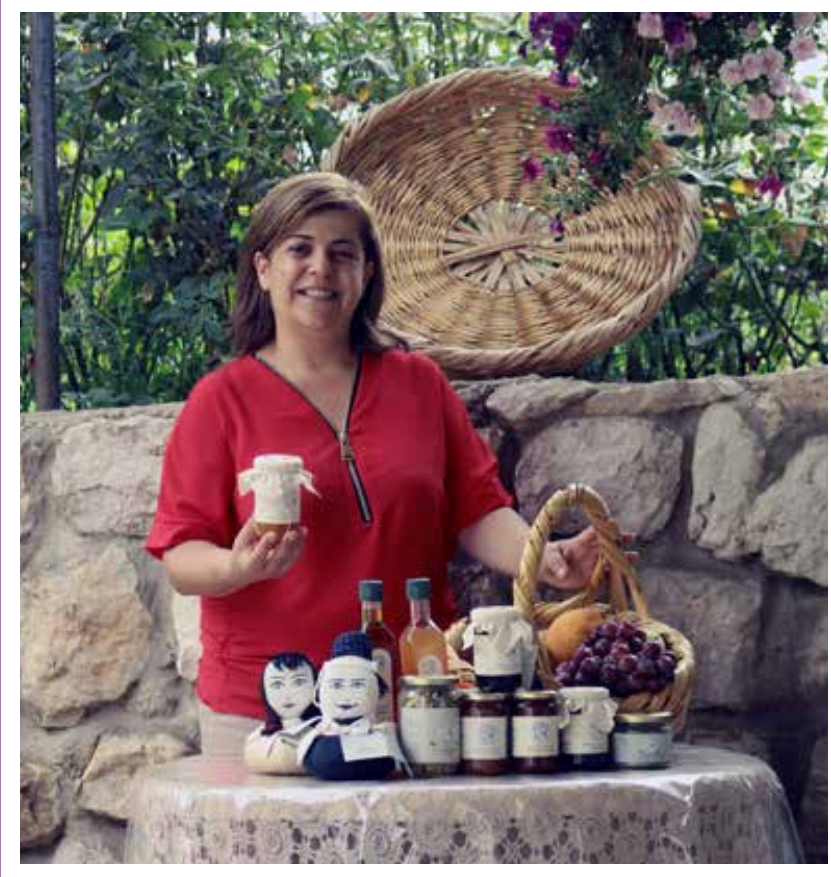

Food and handicraft products, Jabal Moussa (C) Association for the Protection of Jabal Moussa same year and subsequently an Important Plant Area and Key Biodiversity Area (Best Practice 1.3.1).

Today, Jabal Moussa is a well-known local and regional ecotourism destination offering diverse hiking packages guided by local youths, bed-and-breakfast guesthouses operated by local residents and a series of typical artisanal and food products made by local women in an APJMfunded central workshop/kitchen. These products are sold at reserve entrances and increasingly, in various outlets across Lebanon (the most renowned specialities are honey and thyme). From fewer than a thousand visitors at inception, the reserve hosted 22,000 ecotourists in 2017. Socio-economic activities also include beekeeping and native-tree nurseries, which contribute to the conservation effort.

Ten years into this exhilarating endeavour, international archaeologists are documenting important remnants ranging from the Cananean Bronze Age (2500 years before Christ) to the Mameluk Middle Ages, botanists are studying an increasing number of endemic species and APJM is negotiating a 50-year renewable lease on Church properties, while strengthening its ties with locals to give as many of them as possible a stake in long-term conservation. This PPA is increasingly becoming a protected area for nature, culture, inhabitants and international visitors alike.

Author: Pierre Doumet, Association for the Protection of Jabal Moussa

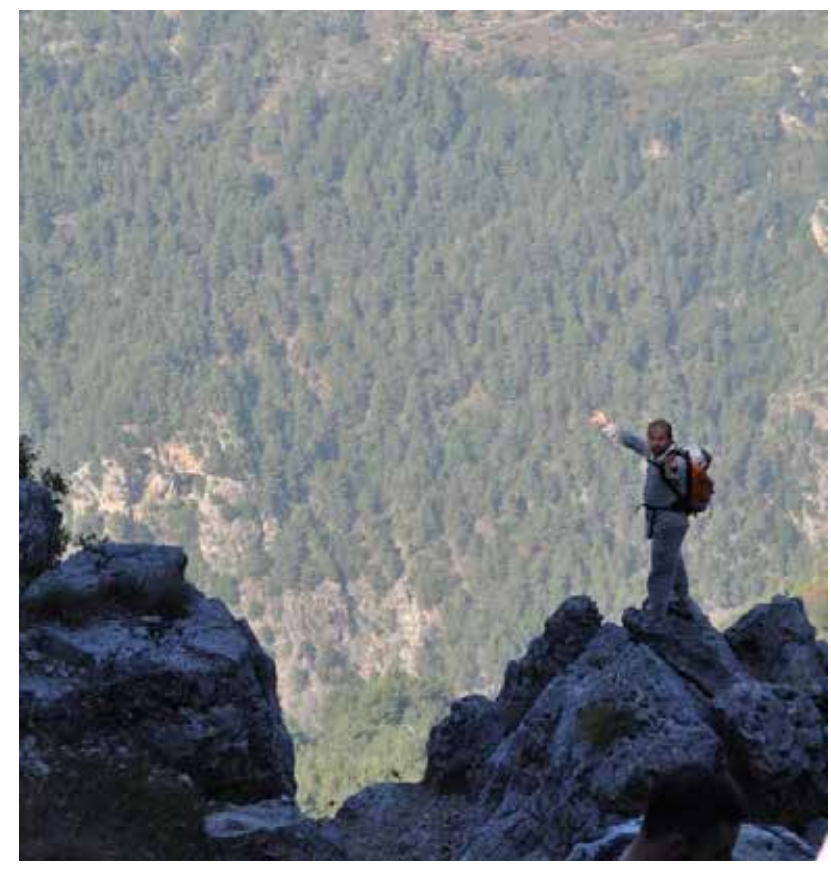

Local guide, Jabal Moussa @ Association for the Protection of Jabal Moussa 
Section 6: Coordination with national protected area systems

\section{Who should read this section?}

This section is relevant to those developing national networks of PPAs (e.g. governments, NGOs, etc.), to sub-national governments or other entities that may be responsible for creating PPA agreements and landholders with an existing PPA or considering establishing a PPA.

PPAs should be recognised for their contribution to national protected area systems (Best Practice 1.2.1), both for their own value and for the differences and diversity (to management, governance, stakeholders and ecological values) they bring. They are a vital and as yet undervalued contribution to national and global conservation efforts whose contribution needs to be recognised and bolstered.

Governments and the conservation sector are displaying increasing interest in incorporating PPAs into national systems of protected areas, both to meet international conservation targets and for more comprehensive landscape-scale conservation planning. For many countries, the concept of incorporating non-state protected area governance types into national protected area systems is relatively new. However, experience over the last two decades with protected areas governed by indigenous and local people has shown the need to include all governance types. In some cases, PPAs will have been established independently from the national system of protected areas, in other cases they may be actively encouraged by governments and NGOs to fill important gaps in conservation coverage (Best Practice 1.2.1). The diversity of owners of PPAs and of their objectives can provide challenges for coordinating a national protected area system, but this diversity can also be a strength.

A precondition for the successful inclusion of PPAs into national systems of protected areas is trust and confidence between national coordinating bodies (usually government) and the owners/managers of PPAs. Such trust should be based on a clear mutual understanding of what a PPA is (see Section 1), how it is managed (see Section 2), funded (see Section 3) and secured for the future (see Section 4). Both national protected area system managers and PPA owners should understand the benefits and obligations for inclusion in national protected areas systems.

\section{Principle 6.1: Conservation benefits when PPAs are coordinated with other types of protected area as part of a national system of protected areas}

Coordination of PPAs as a part of national protected area systems can create a range of conservation benefits for government protected areas, PPAs and other protected areas types. These benefits could be in the form of better prioritisation for protected area network expansion, better understanding of protected corridors and more coordinated management across the landscape.

Best Practice 6.1.1: Inclusion of PPAs in national systems should only occur with landholders' consent

The 2016 IUCN World Conservation Congress approved a resolution supporting PPAs (see Box 1.5) which calls on IUCN members to "include privately protected areas that meet the requirements of IUCN Protected Area Standards when reporting about protected area coverage and other related information, including to the World Database on Protected Areas and to the CBD, in collaboration and agreement with the owners of such areas" (IUCN, 2016a). Inclusion of PPAs in national systems should only occur with the consent of the landholders (see Clements et al., 2018); for instance, through a collaborative process as developed for reporting PPAs in the UK (see Case Study 12).

Best Practice 6.1.2: Affiliation with national systems should not impose additional legal or management obligations beyond their existing PPA conditions

Where existing PPAs are included in or affiliated with national systems after their establishment, it is important that this does not inadvertently impose additional legal or management obligations upon landholders beyond the conditions of their existing PPA. 


\section{Principle 6.2: PPAs can complement other protected area governance types to develop effective national protected area systems}

PPAs can provide multiple benefits to national systems, by increasing not just the total area under protection but also the representation of habitat types in national systems; improving connectivity or buffering other types of protected areas; and protecting ecosystem services (Fitzsimons \& Wescott, 2008a,b). PPAs can also be the most logical mechanism to secure particular ecosystems or species that occur predominantly or only on private land. For example, half of the endangered East African black rhino (Diceros bicornis michaeli) in Kenya is located in PPAs (Leménager et al., 2014 and see Case Study 6). Nonetheless, national systems should recognise both PPAs that have highly prioritised natural values and those considered potentially less valuable (see Principle 1.2).

\section{Best Practice 6.2.1: Recognition of PPAs} by government is an important first step for incorporation of PPAs into national systems

Recognition can be at various levels including: individual PPAs, groups of PPAs under the same organisation (e.g. local, national or regional NGOs, research, business or faith groups) or a PPA mechanism (e.g. covenant or easement) by a protected area authority (e.g. a jurisdictional government) (see Principle 1.3). Ideally, the definition of what constitutes a PPA at the relevant jurisdictional level is made explicit in a public policy document or guidelines to ensure transparency and should align with IUCN's definition of a PPA (see Section A). Recognition has a spatial element; formally recognised PPAs can be incorporated into system maps, with the consent of the landholder, and thus contribute fully to local, national and regional conservation planning. For example, the Strategy for Australia's National Reserve System 2009-2030 clearly recognises the importance of different protected area governance types in contributing to the objectives of a comprehensive, adequate and representative reserve system in Australia (NRMMC, 2009 and see Case Study 1 for Australia). In Peru, official maps by government agency SERNANP include all existing PPAs along with national and sub-national protected areas.

Best Practice 6.2.2: Recognition and support of PPAs can occur at different scales (national, regional, local)

Support for PPAs can be made available at different jurisdictional levels. For example, in Australia, while national recognition may be important for national inventory, statebased legislation may be required to legally protect the site and local authorities may be able to provide financial incentives. In Argentina, a federal country, there is no protected area law at national level (though one has been proposed); this is taken up at sub-national level. Of the 23 provinces in the country, 12 include PPAs in their protected area laws. The law in Misiones, for example, calls for a commitment of 20 years and sets out guidelines for

\section{Box 6.1 \\ Making connections: The Northeast Biological Corridor in Belize}

\section{Belize has recently secured an important habitat} connectivity corridor, one of three identified as critical to biodiversity conservation through national planning. The North East Corridor connects a government protected area, Freshwater Creek Forest Reserve, with two PPAs: the Shipstern Conservation \& Management Area and Fireburn Reserve. Some of the land in between is owned by Balam Jungle Estate, a timber management organisation. A trust is being negotiated by the NGO reserve managers and the company, with approval from government. The company is honouring an earlier agreement to set aside a portion of its land for conservation, and in return hopes to secure a favourable rate of taxation on its land holdings. From the perspective of the Government of Belize the provision of environmental services for nearby communities and agricultural lands, from the forest and wetlands within the NE Corridor, was a key factor in designation of the Corridor. In addition to the value for maintaining water security, the maintenance of forest connectivity between major forest nodes supports the long-term survival of wide-ranging species such as the vulnerable white-lipped peccary (Tayassu pecari) and jaguar (Panthera onca). Belize's NE Corridor allows for the expansion of the country's highly successful reintroduction programme for the endangered Yucatan black howler monkey (Alouatta pigra) and soon also for the endangered Geoffroy's spider monkey (Ateles geoffroyi), both using rehabilitated animals confiscated from the illegal wildlife trade (Mitchell et al., 2017).

Author: Paul Walker, Wildtracks Conservation and Wildlife Rehabilitation Centre, Belize

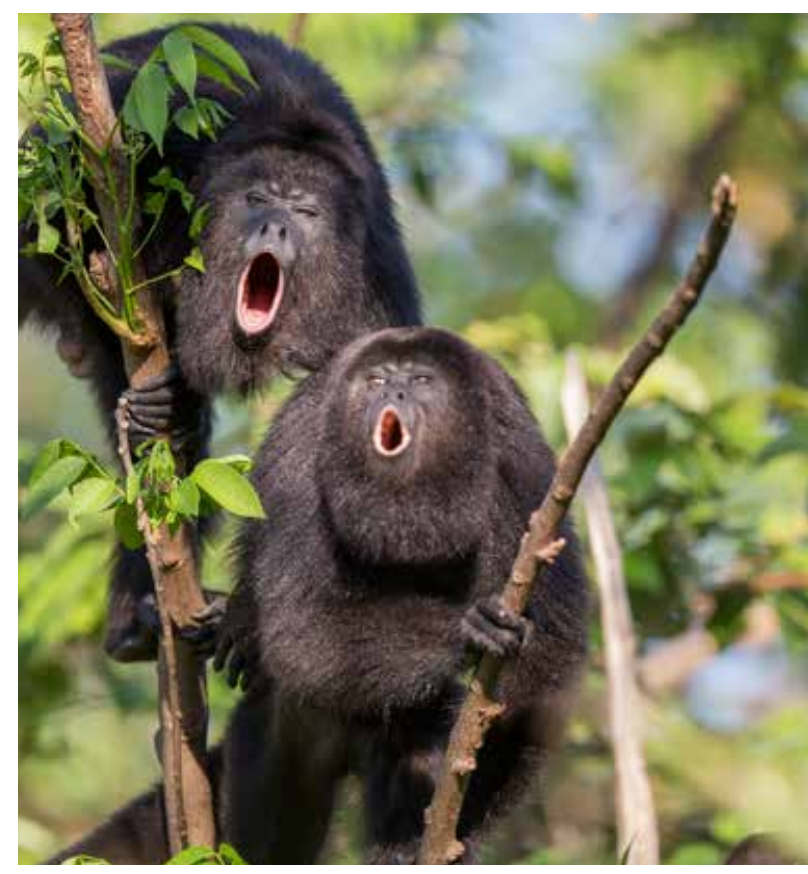

Yucatan black howler monkeys (c) E. Gissis/Wildtracks 


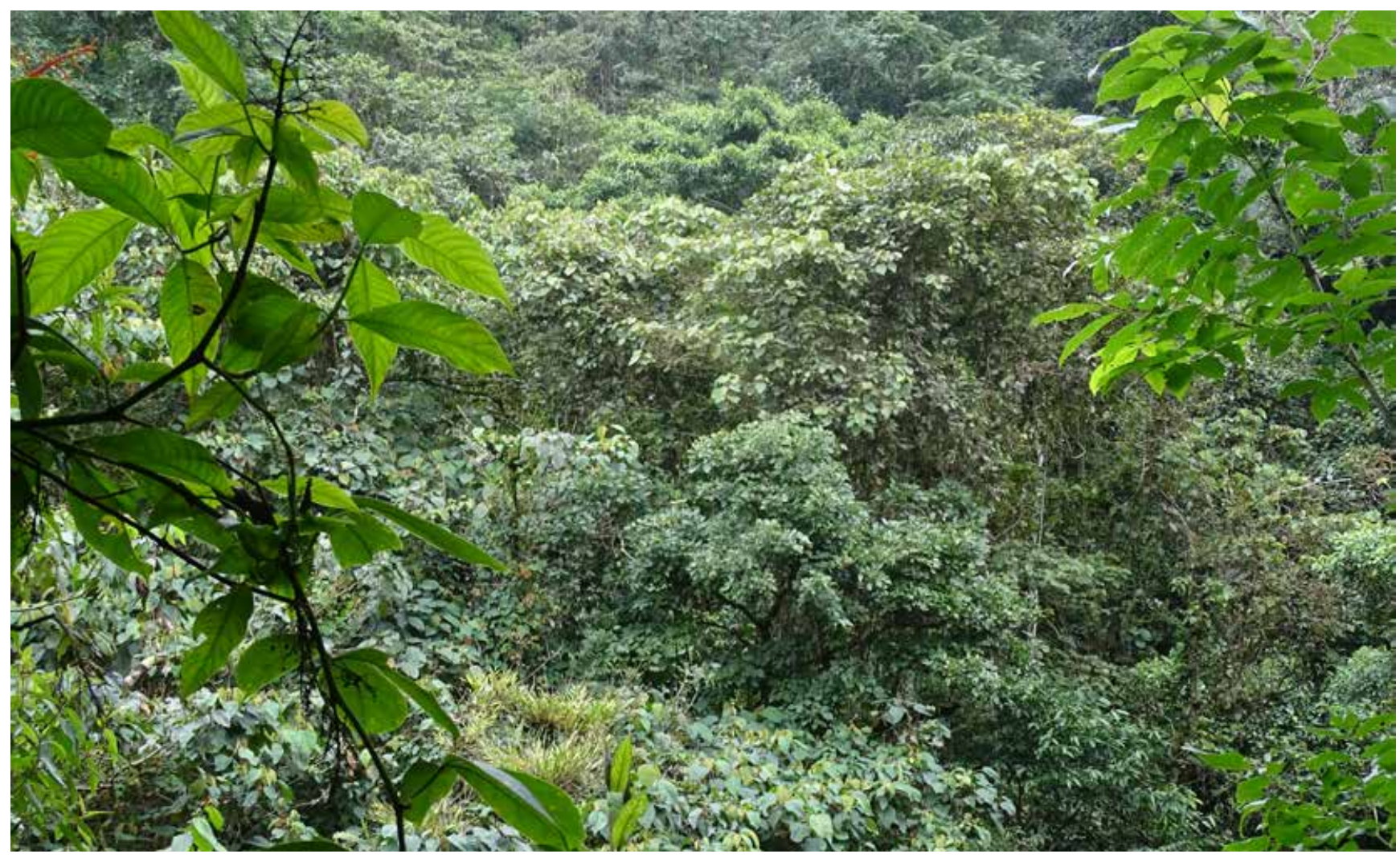

Kasaguadua Natural Reserve, Colombia @ Sue Stolton

management plans. In other countries there may be different national and sub-national jurisdictions that are important for PPA recognition. Many PPAs are recognised by the national system of protected areas (SINAP) in Colombia; however, many municipal protected areas are not. More than 80 municipalities have established systems of protected areas (Municipal (Sistema Municipal de Áreas Protegidas SIMAP ${ }^{110}$ ) or Local (El Sistema Local de Áreas Protegidas SILAP $\left.{ }^{111}\right)$ ). Lacking central guidelines, these systems vary, but private reserves are an important component of many local conservation systems. SIMAP and SILAP have the potential to establish links between municipal territorial zoning-plans (which designate municipal conservation and environmental protection areas), departmental planning and sub-national systems of protected areas.

\section{Best Practice 6.2.3: The national protected areas system should coordinate strategies for incorporating PPAs}

Strategies for incorporation of PPAs into national protected area systems can be driven by government, as is the case in Australia (see Case Study 1) and in South Africa (Case Study 10), the private/NGO sector (see Case Study 4 from Costa Rica), or a hybrid approach with initiative from both sides (see Case Study 12 from the UK). Regardless of the approach, ensuring mutual trust and transparently articulated dual benefits is likely to result in greater success in the long term. Brazil, Colombia and Peru ${ }^{112}$ are among the few countries in Latin America to include PPAs in their official systems of protected areas. In Colombia, in some cases, the coordination of PPAs with the national system of protected areas (SINAP) is being done through the Network of Natural Reserves of Civil Society. ${ }^{113}$ Several of these NGOs are locally based and are also the main resource managers for the implementation of management plans for private reserves.

\section{Best Practice 6.2.4: Coordination of PPAs and} national systems brings a number of benefits to conservation which should be promoted to agencies and managers of all protected area governance types

Benefits of integrating with the national system include improved ability to meet global conservation targets and their on-ground implementation at national and regional scales (such as representation, connectivity, ecosystem services); more efficient placement of future protected areas of various governance types, which benefits existing landholders by increasing the viability of their conservation assets; the potential for coordinated management of threats or ecological processes occurring across public and private land; coordinating endangered species conservation and, if necessary, reintroduction; and increasing the constituency for protected areas and national systems through incorporating committed landholders. Ultimately, a better understanding of the location, assets and directions of the respective governance types leads to more informed conservation planning. 


\section{Box 6.2}

\section{Collaboration across protected area governance types to save the Orinoco crocodile in Colombia}

The conservation of the Orinoco crocodile (Crocodylus intermedius) is an example of coordination between PPAs and the national system to benefit a species at serious risk of extinction. The Palmarito Foundation ${ }^{114}$ is a Colombian NGO that has worked since 2011 on the conservation of one of the most endangered species in the world. Estimates are that less than 2,000 crocodiles survive in the species' entire distribution area, the Llanos region which is shared by Colombia and Venezuela. Since 2008, Palmarito has promoted more than 20 PPAs covering around 76,000 ha. With a landscape scale conservation plan, the Palmarito Foundation has reintroduced 102 captivebred crocodiles in different locations within its historical distribution area including El Tuparro Natural National Park (41 crocodiles), La Aurora PPA (32) and the Cravo Norte River (29), a future public protected area ${ }^{115}$ (BalagueraReina et al., 2017).

Author: Rafael Antelo, Palmarito Foundation

Best Practice 6.2.5: Official incorporation of PPAs as part of national protected area systems should include recognition and support

Inclusion of a PPA in a national system can range from formal recognition of its contribution to biodiversity conservation to improved financial incentives for undertaking protection and management (see Section 3). However, it is important to recognise not all owners of PPAs wish their land to be 'incorporated' into national systems. This reluctance may stem from a concern that governments could report on PPAs rather than investing in new (government) protected areas elsewhere, which is seen by some as a way for governments to meet their international obligations while avoiding difficult decisions (Fitzsimons \& Wescott, 2007). It is essential for coordinators of national networks to communicate to PPA owners whether their properties will be counted towards targets. Some landholders may also want recognition but not have their properties count towards targets (see Clements et al., 2018 and Section 7).

Best Practice 6.2.6: If PPAs do not wish to be recognised as part of a government system, other mechanisms can allow for alternative forms of 'recognition'

In cases where a PPA landholder does not desire national recognition, alternatives should include a process that recognises a site's legitimacy as a PPA, as well as ways to receive support from other conservation actors to improve conservation outcomes of the PPA. Section 7 discusses in more detail options for reporting to international level (and thereby tacit recognition) without formal government recognition, but this remains an area where more clarity is required (Clements et al., 2018).

Best Practice 6.2.7: Creating a national system of protected areas that incorporates multiple governance types requires active and extensive coordination with all protected area managers

Achieving a coordinated national system of protected areas involves more than simply compiling a list. Building communication and discussion to achieve a coordinated system may include annual forums, strategic workshops and communities of practice meetings to discuss common issues and resolve barriers to better coordination. In some countries, national conferences for private land conservation (e.g. US Land Trust Alliance Rally; Australia National Private Land Conference; Brazil National Confederation of Private Natural Heritage Reserves CNRPPN) help identify common issues and strengthen the PPA sector. The conference of the International Land Conservation Network is a new global forum for strengthening the sector. IUCN national committees can play an important role in developing good links between PPAs and government (see Case Study 12 for the UK). Sometimes a more formal approach to coordination has been successful. For example, in Kenya, a formally constituted board meets several times per year with representatives from all governance types of protected areas to discuss issues. This includes bringing together all conservancies, giving them a direct input into government policy making, for example in developing legislation for conservancies.

Best Practice 6.2.8: PPA representatives should be included when national protected area strategies and plans are being developed

To improve the effectiveness of landscape- or jurisdictionallevel conservation and protected area plans and their implementation, PPA governance authorities should be involved from the early stages of the strategic planning process. Including PPA networks or NGOs on national protected area committees is a logical way to do this. For example, by legislation the Belize Association of Privately Protected Areas (BAPPA) has a seat on the National Protected Areas Advisory Council. 


\section{Section 7: Recording privately protected areas}

\section{Who should read this section?}

Government agencies responsible for national reporting on protected areas, as well as landholders. Both groups have the option to record PPAs.

National recording of protected areas is a key element of international agreements, enabling countries to demonstrate progress towards agreed targets such as those of the Convention on Biological Diversity ${ }^{116}$ (CBD) and certain targets within Sustainable Development Goals 14 and $15^{117}$ (see Case Study 10 for South Africa). At the global level, these targets are tracked using indicators derived in large part from the World Database on Protected Areas (WDPA) which compiles data from national governments and other sources.

Almost all national governments around the world report protected areas to the WDPA (see Box 7.1), but currently only 28 governments report on PPAs (UNEP-WCMC \& IUCN, 2018). Some governments do not recognise PPAs within their national system and some owners do not wish their PPAs to be listed (Best Practices 6.2.5 and 6.2.6). Reporting to the WDPA can, however, be a route to increased recognition of the role of PPAs, thus highlighting the position of individual PPAs as part of a global community of private conservation initiatives and their role in protected area systems. By reporting to the WDPA, landholders participate in knowledge production that informs international planning, collaboration and ambition. At the national level, increased visibility of PPAs may facilitate the development of more coordinated conservation networks and stimulate increased support from governments.

\section{Principle 7.1: PPAs should be recorded in the World Database on Protected Areas}

PPAs represent a significant opportunity to strengthen the conservation of biodiversity and ecosystem services nationally and globally. In order for these multiple benefits to endure, PPAs need to be recognised, supported and incentivised. An important aspect is ensuring that PPAs are mapped and documented, enabling their extent and contributions to be understood. Accurately documented PPAs can feed into planning exercises, both for conservation initiatives and other land-use planning. For example, the government of Mexico ${ }^{120}$ has made good progress in reporting protected areas under all IUCN governance types to the WDPA.

\section{Box 7.1 \\ World Database on Protected Areas and Global Database on Protected Area Management Effectiveness}

Protected Planet ${ }^{118}$ is an initiative managed by UNEPWCMC in collaboration with IUCN and UN Environment. It includes the WDPA and Global Database on Protected Area Management Effectiveness (GD-PAME). UNEPWCMC is mandated through the CBD to collate data on all countries' protected areas and holds the most comprehensive global database of protected areas. To be included in the WDPA, PPAs should meet the IUCN definition of a protected area. When reporting a protected area to the WDPA, all data-providers must provide:

- Spatial boundary of the protected area in a GIS format (e.g. shapefile).

- Descriptive information in the format of the WDPA schema.

- Signed Data Contributor Agreement.

- Source information.

Details on the above are available in the WDPA Manual ${ }^{119}$ Submissions to either database, or requests for further information, should be sent to protectedareas@unepwcmc.org

Best Practice 7.1.1: Governments, private landholders or third parties can provide data on PPAs to the WDPA and GD-PAME

The WDPA can be divided into data that have been provided and/or verified by governments ('State Verified'), and data that have been provided by non-government data-providers and verified by non-government experts ('Expert Verified') (Best Practice 7.1.5). PPAs can thus be reported to the WDPA and GD-PAME either by governments, landholders or third parties (e.g. interested NGOs or networks) (Bingham et al., 2017 and Case Study 2 from Brazil, Case Study 12 from the UK and Best Practice 5.1.1). PPAs not currently recognised by governments can still be reported to the WDPA, while remaining readily distinguishable from those that are. Users of the WDPA can therefore easily select out information on government- 


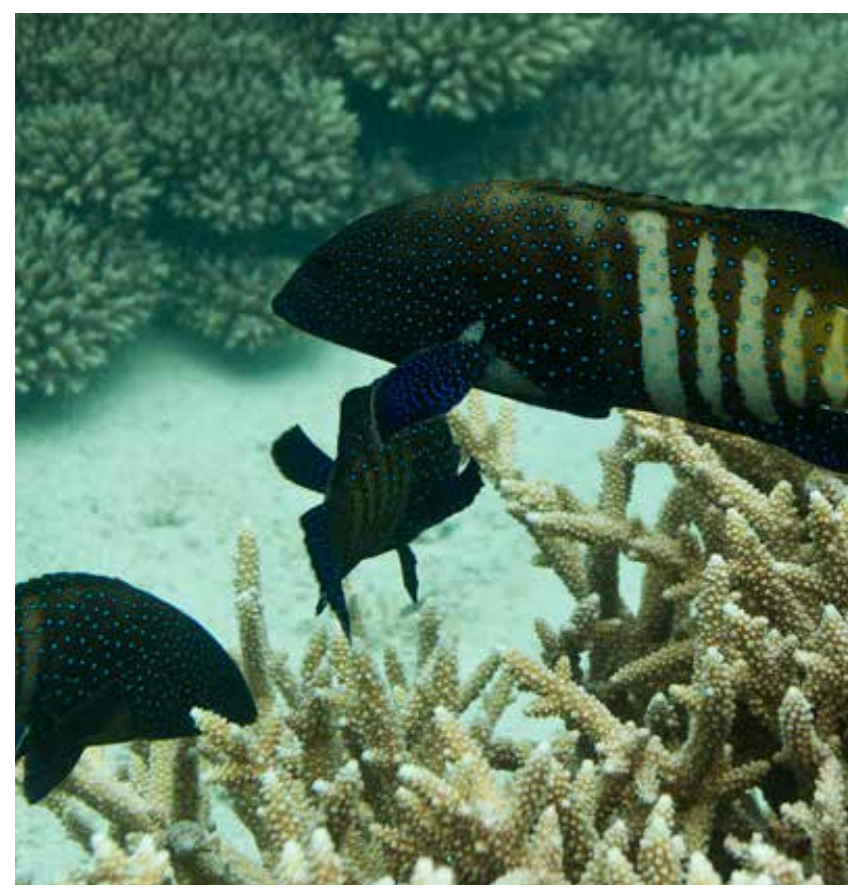

Chumbe Island Coral Park Limited successfully negotiated with the semiautonomous government of Zanzibar, Tanzania for the island to be gazetted and reported as a MPA (see Box 1.7) @ C Chumbe Island Coral Park

recognised protected areas, or other verified protected areas, depending on their needs (Bingham et al., 2017).

\section{Best Practice 7.1.2: Governments should report on PPAs only with the agreement of the private landholders}

Governments are encouraged to report on all areas in their countries that meet the IUCN definition of a protected area, including PPAs. When reporting PPAs, it is important that governments only do so with the agreement of the relevant stakeholders (for example, the individual or organisation responsible for the PPA) (Best Practices 6.1.1 and 6.2.6 and Case Study 1 from Australia). When signing agreements that involve data-sharing (e.g. conservation covenants), it is important that landholders are made fully aware of how the data will be used, and consent to this. Governments should review data on PPAs previously reported to the WDPA and seek the agreement of landholders who have not already consented to their information being shared. If landowners do not agree, governments should request UNEP-WCMC to remove the relevant data from the WDPA. Engaging with existing or developing national networks of private landholders may be an efficient way of facilitating discussions around reporting to the WDPA (see Section 8) (Clements et al., 2018).

\section{Best Practice 7.1.3: PPA data should be standardised by the reporting entity}

In most cases, governments report to UNEP-WCMC via a single focal point. In situations where a governmental focal point is tasked with collating data from multiple jurisdictions, those jurisdictions should each report on PPAs in a standardised manner. Carrying out trials with specific data providers can help develop effective systems to facilitate this (see Case Study 12 from the UK). This means that all jurisdictions should have a shared understanding of the definition of a PPA, and consistent processes for securing landholder consent before sharing data (see Section 6). This is also true in the minority of cases where reporting to UNEP-WCMC is carried out by more than one focal point. For example, the Collaborative Australian Protected Area Database (CAPAD), ${ }^{121}$ through which the Australian Government reports to the WDPA, is collated largely from databases held by state and territory governments. Under the Strategy for Australia's National Reserve System 20092030 (Commonwealth of Australia, 2010), all sub-national governments within the country have agreed to a common standard for protected areas, including alignment with the IUCN definition of a protected area, helping to establish a shared standard for reporting to CAPAD. Governments that gather data in this way should ensure that guidelines on reporting PPAs are built into their advice provided to subnational government authorities and other NGO partners.

Best Practice 7.1.4: If the government is unable or unwilling to report on PPAs, another competent authority should be appointed to do so

In cases where the national government lacks the capacity to report on PPAs (for example, where a centralised database on protected areas does not exist), it is advisable for the government to appoint another competent authority to report to the WDPA and GD-PAME (see Case Study 12 from the UK). Data reported via such authorities are considered 'State Verified' if the authority has been officially appointed in writing by the government. In the case of PPAs, national networks of private landholders, or large landowning NGOs, may perform an important role in reporting on behalf of the government. For example, the Bahamas has appointed the Bahamas National Trust, an NGO, as the national data provider for the WDPA. Data provided by the Bahamas National Trust are labelled 'State Verified' in the database.

\section{Best Practice 7.1.5: PPA landholders should} consider whether to report directly, via the national government or via a third party, and be aware of the options for data-verification

Non-government data-providers can choose to report directly to UNEP-WCMC, or through their national government. If they choose to report directly, UNEP-WCMC will arrange for their data to be verified by either the national government or relevant non-government experts. The data-provider is the one to decide which verification path is taken. There are advantages to both options, and landholders should carefully consider which option is most suitable for their PPAs. Expert verification may be most appropriate in cases where the PPA is not recognised by the national government, but state verification can act as a stepping-stone towards greater national support for PPAs. Although landholders may wish to report on an individual basis, they could also consider reporting via a non-government third party. For example, national networks of landholders can play a role in efficiently reporting larger datasets (see Section 8). National-scale 
collation of data by organised networks, and subsequent reporting to the WDPA, may prove to be effective in generating recognition of PPAs from other stakeholders. Such networks could be particularly effective where they include individuals who have the capacity and skills to support others to report (e.g. GIS skills). Networks may also be better placed than individuals to raise funding for systematic reviews and mapping, and to enlist external support where needed.

Best Practice 7.1.6: Third-party data providers should report on PPAs only with the agreement of private landholders

As with government data-providers, non-government data-providers should ensure that they have secured the consent of all relevant landholders before providing data. In particular, landholders should consider whether the location and boundaries of their PPA are sensitive (e.g. due to the presence of valuable resources) before deciding to contribute to the WDPA (Best Practice 7.1.7). Organisations considering national-scale reviews of PPAs may find informative the Putting Nature on the Map project, which mapped PPAs in the United Kingdom (see Case Study 12). The project involved collaborators from the IUCN National Committee UK, the UK Government and landholding NGOs, thereby facilitating multistakeholder agreement on the extent of PPAs in the country (Crofts et al., 2014; Bingham et al., 2017).

Best Practice 7.1.7: Data-providers should familiarise themselves with the options available for restricting sensitive data

Restrictions can be applied in cases where data are deemed sensitive by the data-provider. This may be a useful option for PPAs where particularly vulnerable species or natural resources are being managed. Data are useful even when restrictions are applied because they can be used by UNEPWCMC to inform national and global statistics without being shared further. Two levels of restriction are available:

1. The data are available to all users, and for all uses, except for use by or on behalf of a commercial entity.

2. The data are made available only to UNEP-WCMC, UN Environment and IUCN, and are not otherwise shared.

Best practice 7.1.8: Data-providers should familiarise themselves with the principles of the data-verification process

Data from non-government data-providers can go through either a state- or expert-verification process. This is the choice of the data-provider. State verification is carried out by WDPA focal points within government agencies. For expert verification of PPAs, the WDPA relies on the voluntary support of members of IUCN's World Commission on Protected Areas (WCPA). In these cases, WCPA members are asked for assistance based on their expertise on PPAs and knowledge of the country or region in question. The primary purpose of the verification process is to confirm that the areas in question meet the definition of a PPA and are therefore eligible for inclusion in the WDPA. Both state and expert verifiers are encouraged to engage with other local experts and stakeholders to ensure that they fully understand the local context.

From 2018, UNEP-WCMC has implemented a policy of providing summarised data to governments on an annual basis. This summary will include details of the number and area of expert verified protected areas within their country. 


\title{
Section 8: The role of privately protected area networks
}

\begin{abstract}
Who should read this section?
Owners and landholders who are running, or willing to run, their own PPAs; organisers/ managers of networks; and NGO representatives who support biological conservation strategies.
\end{abstract}

PPA networks are generally alliances of owners and practitioners, sometimes including supporting private organisations and NGOs. Networks have a strong role in creating a voice for PPAs. They vary widely in scope, scale and strength. Land trust associations and conservation landholder coalitions, for example, are a spreading and wide-ranging institutionalised land conservation phenomenon in many countries. The Land Trust Alliance ${ }^{122}$ based in the US has been in operation since 1982 and represents more than 1,000 member land trusts nationwide. A similar network is being developed in Europe. ${ }^{123}$ The Australian Land Conservation Alliance ${ }^{124}$ has recently expanded from primarily conservation covenanting NGOs to a broader range of land trusts and NGOs interested in private land conservation. Many countries also have national networks of PPAs such as in Costa Rica, Chile, Argentina and Brazil. In some cases more locally-based (e.g. state or regionally-based) networks are developing, which are then brought together in national forums. For instance, in the Peruvian Amazon (see Case Study 8), the various regional networks are brought together in the annual Amazonian Private and Communitybased Conservation Conference ('Amazonía que Late') and an Amazonian Voluntary Conservation Network is being developed.

PPA networks are usually designed to strengthen capacities of members on a range of issues including financing, management and legal protection of land (Ruseva et al., 2016). In some countries, networks also have a role in registering PPAs (see Sections 6 and 7). In most cases, networks organise meetings for sharing experiences and challenges, and have been crucial for empowering owners, developing their capacities and securing better conditions for them from governments. The role of networks can contribute to the success of PPAs by scaling up messages and outcomes as well as facilitating dialogue between landholders and governments. PPA networks can also encompass multitenure networks specifically set up to accomplish landscape connectivity (e.g. Crosthwaite et al., 2013).

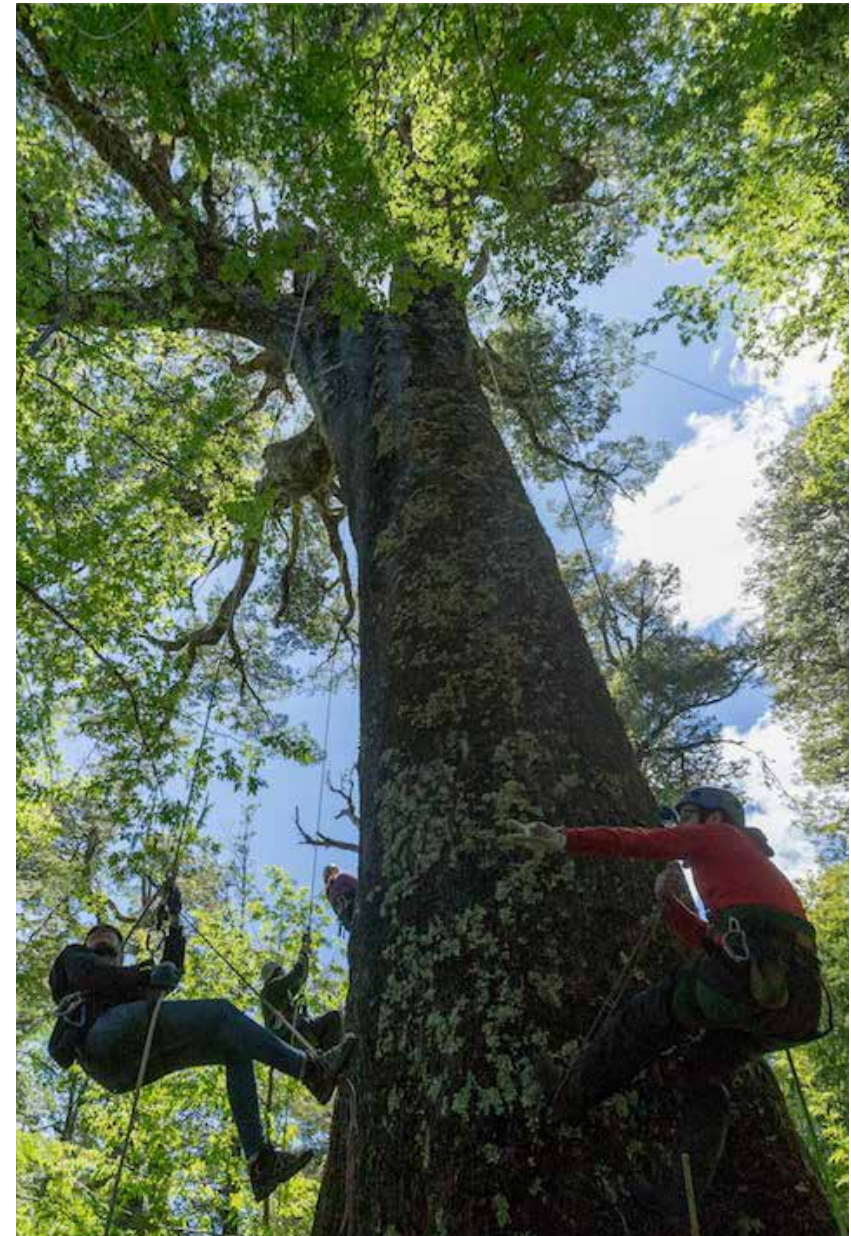

Bosque Pehuen, Chile @ Juan Pablo Miranda

\section{Principle 8.1: Networks can be effective mechanisms to represent the interests and concerns of landholders}

Functionally equivalent to an industry association, PPA networks can create a platform for expressing the needs of PPAs and collectively lobbying to reduce barriers to, and build incentives for, establishing and managing PPAs. 
Best Practice 8.1.1: National and regional PPA networks should play a role in representing, explaining and defending owners' interests in public and in private

PPA networks can create transparent and consistent messages and content based on collectively developed communication and advocacy strategies (Best Practice 2.6.1). Strengths of individual members can be maximised, for example, by selecting spokespersons for their strong communications skills. They should also generate positive publicity for their commitment to PPA management. In Peru, a good example is Karina Pinasco, who owns a PPA in San Martin and also holds a conservation concession through her NGO 'Amazónicos por la Amazonia'125. For years, Karina has been a leader in representing, and the voice for, hundreds of landholders in her region, reaching both media and government, as well as donors and investors (Best Practice 1.3.2).

\section{Best Practice 8.1.2: Networks can be effective advocates to increase support for PPAs}

Fiscal and economic incentives often come from government or legislative decisions (see Section 3). PPA Networks can generate public support for conserving biodiversity and environmental services. Networks act as facilitators, helping to gain support for funding requests to governments, NGOs, bilateral donor agencies, etc. In São Paulo, Brazil, the advocacy work of the PPA owners' network ${ }^{126}$ was a decisive factor in the creation of the Environmental Services Payment and Protection Plan programmes and many other support structures for PPA owners. These programmes work as an incentive for landowners to create PPAs by freeing them of the responsibility to pay the taxes the federal government charges regular landowners. The same programme allows for the possibility of the PPA landowners accessing a National Environmental Fund (FNMA) and having priority for loans for agricultural credits (Monteferri \& Coll, 2009).

\section{Box 8.1}

\section{Land Trust Alliance, USA}

Founded in 1982, the Land Trust Alliance (LTA) is the oldest and largest network of PPA organisations in the world. ${ }^{127}$ The LTA is a national land conservation organisation that represents more than 1,000 member land trusts supported by over five million members nationwide. The network provides educational materials, promulgates standards and convenes practitioners (the Land Trust Rally attracts 1,800 people each year). Importantly, the LTA advocates for funding for conservation and defends tax incentives for PPAs. It also provides accreditation ${ }^{128}$ through a separate programme (see Box 8.2), and conducts a census every five years, providing a snapshot of the growth of the movement (Bernstein \& Mitchell, 2005).

Author: Brent A. Mitchell, QLF

\section{Principle 8.2: Networks can provide support structures for PPA landholders}

Networks can benefit from economies of scale, developing technical and legal assistance capacity that most members could not afford on their own (Principle 2.5). Providing such services helps to ensure consistency across the de facto system of PPAs in a country and encourages landholders to set up PPAs. For example, through supporting individual landholders the Argentine Network of Private Natural Reserves ${ }^{129}$ has increased the number of PPAs in Misiones province by more than 30 per cent in three years.

Best Practice 8.2.1: PPA networks help centralise a range of technical and legal services for members through dedicated staff, external expertise and/or peer support

These services can include:

- Training and advising PPA landholders on administrative, legal and technical issues (see Case Study 8 for Peru).

- Lightening the burden of bureaucracy on PPA owners/ managers (both for existing PPAs and those being set up) by providing advice on organisations that can help, and giving landholders access to funding, helping to fill in paperwork, etc.

- Providing safeguards when problems arise, for example, legal defence, assistance, reaching the media.

- Facilitating the reporting of individual PPAs to public agencies (See Section 7), through the development of standardised formats (Best Practice 8.3.1) and capacity building.

- Preparing guidance and membership review of management, strategic and annual work plans, including monitoring, management effectiveness assessments (see Principle 2.4) and audits of the network.

- Networks can help landholders with practical issues like fire management, invasive species control, etc. It can be an advantage to have access to 'specialists' to help both landholders and organisations.

- Develop manuals and guidelines for PPAs on activities such as business plans, land trusts, ecotourism, Payment for Ecosystem Services schemes, marketing and sustainable products.

- Facilitate peer-to-peer mentoring, support and information exchange (see Case Study 2 from Brazil and Case Study 8 from Peru).

- Development of joint projects across several PPAs or PPA networks (see Case Study 6 from Kenya and Case Study 8 from Peru).

Involvement in networks of PPAs, or conservation lands more broadly, can have a range of positive benefits for social and management support. For example, in multi-tenure reserve networks in south-eastern Australia, over half (55 per cent) of the managers of public and private conservation lands were in regular correspondence with other managers within their networks, just less than half (48 per cent) of managers indicated they had altered their management regimes as a result of participating in their network, and 54 per cent of 
managers suggested that management decisions on their site were influenced by the actions of other sites within their network (Fitzsimons \& Wescott, 2007).

\section{Principle 8.3: Networks can have a role in the monitoring and verification of PPAs}

Networks can help to identify, verify and monitor conservation objectives of PPAs (Principle 2.4).

Best Practice 8.3.1: Where PPA standards are required by government, networks can help to set and certify compliance

Networks can help develop formats to identify conservation values (Best Practice 1.1.3), as well as monitoring and assessment (Best Practice 2.4.1) protocols that can be followed either by owners or networks specialists (see Box 8.1). For example, in Colombia, ${ }^{130}$ it is a common practice for networks to support monitoring and summarise verification data from PPAs.

\section{Box 8.2 \\ Land Trust Accreditation}

Anticipating regulation by government, the Land Trust Alliance set up a voluntary certification programme in the United States, and a commission to administer it. The Commission ${ }^{131}$ developed specific standards and a rigorous documentation system for groups to receive Land Trust Accreditation. The accreditation system is based on 65 indicators organised in four themes: governance, finance, transactions and stewardship. The Commission operates as an independent programme of the Land Trust Alliance. As of February 2018, there were 398 accredited land trusts in 46 USA states and territories.

Author: Brent A. Mitchell, QLF

\section{Principle 8.4: Networks can play an important role in promoting PPA products}

Individual PPAs are often linked to small business practices for sustainable products and services. Networks can facilitate marketing these products and connecting PPAs to suppliers and markets.

Best Practice 8.4.1: Networks can centralise promotion of products and services of individual PPAs, as well as provide guidance for developing products and services

Marketing products and services can create spaces for showcasing PPA outcomes and products (see Box 8.3), but can also create competition among members if processes are not clear. When success is achieved, lessons learnt should be recorded and accompanied by clear guidance on how that success can be replicated. Networks can develop centralised brands or certification systems for products. However, before developing individual brands or certificates, networks should promote and support existing national or international certification systems and standards. For tourism, standards should be based on internationally recognised criteria, such as the Global Sustainable Tourism Council's Destination Criteria $^{132}$. In Peru (see Case Study 8), the PPA network has published a guide on tourism services provided by members. The Argentine Network of Private Natural Reserves (RARNAP) developed a brochure with PPAs that offer ecotourism opportunities, which is promoted by RARNAP on social media every holiday. Networks can only promote PPAs based on information provided by owners, so it important that members are engaged and take part in joint activities where feasible and appropriate.

\section{Principle 8.5: PPA networks should match structures and governance to their mission and objectives}

Network design and governance should be proportional and adequate to achieve expected goals considering, for example, the number of members, geographical scope and complexity of tasks.

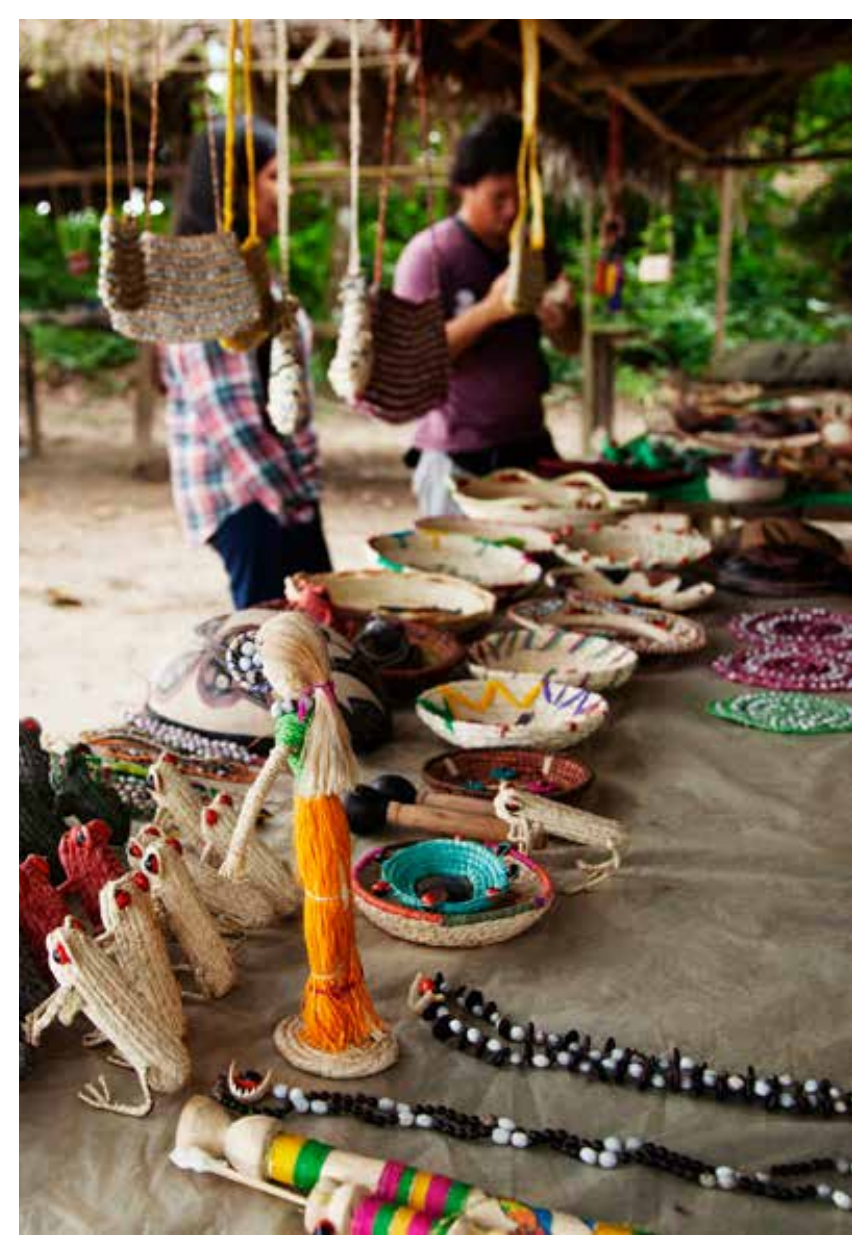

Artisanal products being sold at PPA Paraíso Natural Iwirati in Loreto, Peru @ Conservamos por Naturaleza / SPDA 


\section{Box 8.3 \\ The Long Run: Supporting tourism-orientated PPAs}

The Long Run ${ }^{137}$ is one of the few global networks of tourism businesses which fully supports PPAs. It is a UK-based NGO which brings together owners/managers of nature-based tourism supported PPAs committed to using business as a vehicle for conservation and social empowerment. The goal of The Long Run is to "conserve ecosystems globally to be used sustainably for economic development by using a holistic approach" encompassing the 4Cs of Conservation, Community, Culture and Commerce.

The organisation was established to support and inspire tourism PPAs to continuously expand their conservation and social impacts. The Long Run connects its members to facilitate peer-to-peer learning, experience sharing and innovation and provides technical assistance on site and remotely. By bringing people together, facilitating strategic planning, documenting and disseminating knowledge, The Long Run helps cross-pollination, accelerates learning and provides the moral support of a like-minded community. It also strengthens the collective voice of tourism based PPAs and showcases best practice by disseminating information to inspire others to follow. To benchmark the performance of its members, The Long Run developed a Global Ecosphere Retreats ${ }^{\circledR}$ (GER) standard, recognising the need to adopt a balanced approach around the 4Cs for tourism based PPAs to drive positive change. The standard provides a benchmark as well as a strategic framework to integrate social and biodiversity considerations in all aspects of business operations and to adopt resilient financial models that sustain PPAs' conservation outcomes in the long term. Members commit to achieving the standard requirements, supported by The Long Run, within five years of joining the network. Once the standard is achieved, members become recognised as centres of excellence of tourism based PPAs. The Long Run members aim to protect over 8 million ha of nature and positively impact the lives of two million people by 2020 (World Tourism Organization, 2016).

Author: Delphine Malleret-King, The Long Run

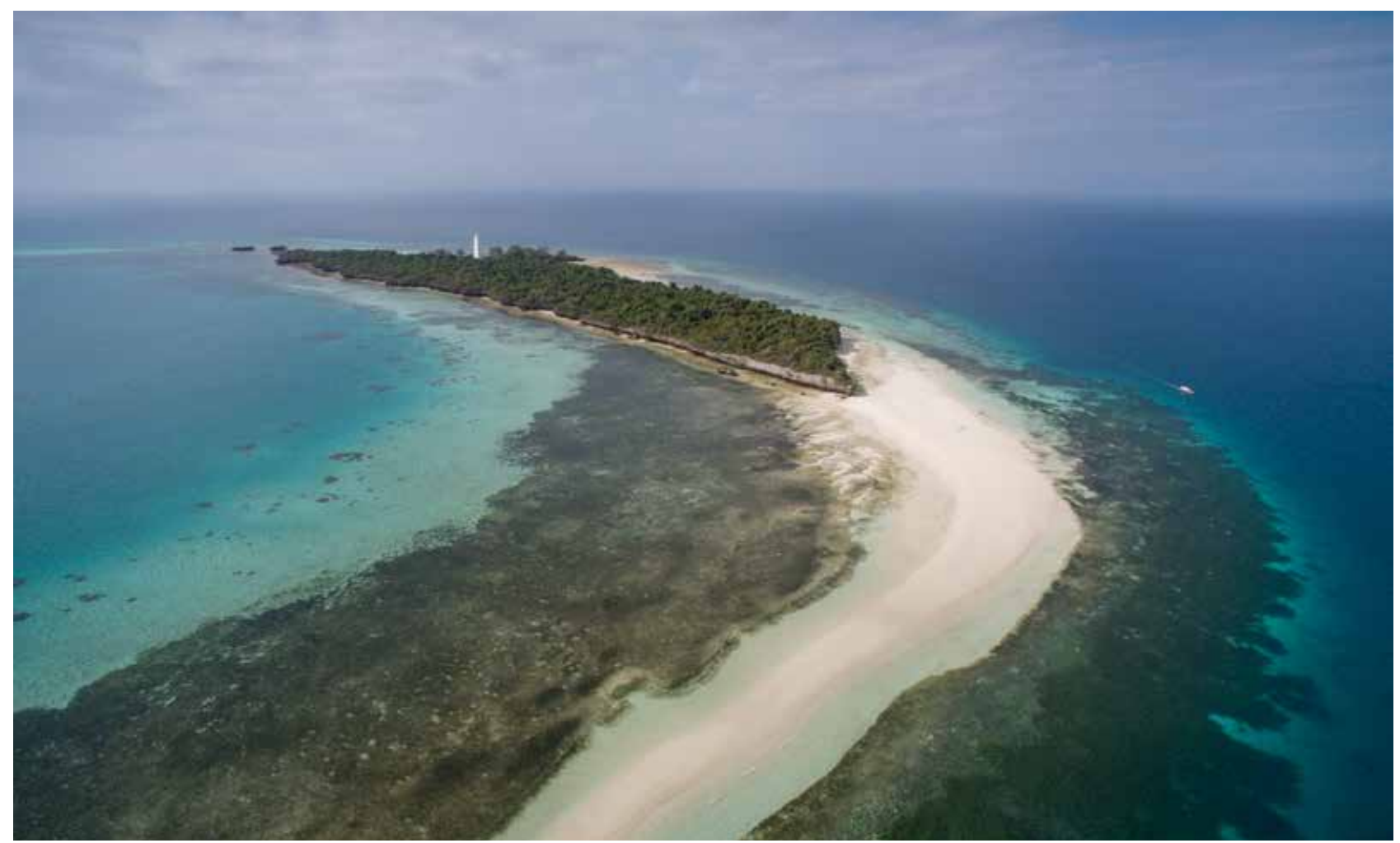

Aerial view Chumbe Island, Zanzibar, Tanzania @ Chumbe Island 
Best Practice 8.5.1: Develop a statement of purposes and objectives and define the geography to establish the network (i.e. local, regional, national)

Although purposes and objectives can change, at any given time the network should be certain of its parameters. Networks can be established at international, continental, national, sub-national and local levels. For example, continental networks like the Latin American Network of Voluntary Reserves mostly work with a regional approach, whilst many countries in the network have national networks and even local PPA networks, which are the basis of everyday activities. All of them are functional, but it is important to have clear scope and purposes of each type. Local networks usually bring together owners with common problems and targets, so it is easier to set up the objectives, governance and management of the network and to plan and undertake activities. Recently, an international network has been formed, the International Land Conservation Network. ${ }^{133}$ Modelled on the US Land Trust Alliance, it seeks to empower a global community for land conservation, and operates as a project of the Lincoln Institute of Land Policy. ${ }^{134}$

\section{Best Practice 8.5.2: Institutionalise the network so that it is not dependent on an individual}

Who establishes the network is important. Leadership, and with it organisational direction, however, can change over time. It is good practice to rely on members of the network, rather than outsiders, and to rotate roles among them; so leadership is shared and distributed. A formula used in Colombia encourages owners to involve their children in their own coordinating spaces in a programme for PPAs named 'herederos de la naturaleza' (nature heirs).

Best Practice 8.5.3: Networks can begin informally, but may be more robust if they progress to formal organisations

Reviewing the objectives and purpose is important as the network evolves, as networks often respond to specific needs as they arise. A strategic plan and annual work plans are highly recommended; they help to build a vision, define priorities and set up activities according to a budget. While informal networks can be effective in the short term, formalised networks may be more likely to persist over time, and more inclusive (see Case Study 9 from Samoa).

Options vary, depending on whether the network is a profit or non-profit organisation; many start with a simple goodwill agreement under a Memorandum of Understanding (MOU) or similar. As the network progresses, they often develop some form of legal entity (e.g. Foundation, NGO, etc.). There are different models for establishing networks: government registered, privately defined under civil code legal status, privately defined under MOU, etc. This legal status is independent from the success of a network. Each one has proved to be valid and successful when objectives are clear, and governance is defined.
Best Practice 8.5.4: Networks should define the rights, duties and responsibilities of membership

Networks should clearly define how the membership works together. For example, the purpose of the Greater Sossusvlei Namib Landscape Association, ${ }^{135}$ which encompasses a million hectares in Namibia, is to foster and enhance collaboration and cooperation between its members, and where relevant and agreed, harmonise their planning, management and development at a landscape level. This is achieved through a shared vision, objectives and principles contained in a signed Constitution and in a Co-Management and Development Plan. Networks sometimes distinguish different categories of membership, including non-owners and stakeholders such as NGOs, which may have different rights and responsibilities. It is very important to maintain a members' directory and membership should ideally be public information.

Best Practice 8.5.5: Networks should ideally be independent organisations to reduce undue influence and preserve objectivity

Networks need to be perceived as a landholders' initiative; so stakeholders are not confused over the interests networks represent when problems or opportunities arise. However, existing organisations can play important incubation roles for networks. For example, the Lincoln Institute of Land Policy ${ }^{136}$ played this role for the Land Trust Alliance in the United States, and currently for the International Land Conservation Network. Support from such organisations will in most cases be temporary.

\section{Principle 8.6: PPA networks, like any organisation, should find ways to support and sustain their activities}

Networks need a budget to operate. It is crucial to make it clear to members from the start what their financial obligations are and to be transparent about the use of external sources.

Best Practice 8.6.1: Networks can set up income generating programmes, though in some countries these should be established as separate, for-profit entities

Some PPA networks set up a company to sell products from the member PPAs related to tourism or sustainable activities (Best Practice 3.6.1). In other cases, members can pay fees, though these are rarely sufficient to cover the costs of running the network. 


\section{Box 8.4 \\ The NamibRand Nature Reserve, Namibia: A landholders' association}

The NamibRand Nature Reserve, ${ }^{138}$ in south-western Namibia, is made up of 17 formerly over-grazed livestock farms that have been rehabilitated into a contiguous conservation area. The Reserve now covers over 200,000 ha and aims to manage the critically important Pro-Namib ecosystem for the enhanced conservation of landscape and biodiversity. The land is owned by 10 different individuals or companies that retain their individual title deeds but have signed articles of association and pledged their properties to a single not-for-profit conservation association. Landowners are directors of this Association to ensure overall governance and staff are appointed to implement the conservation management plans and the day-to-day management of the reserve. The reserve is financially self-sufficient and all operational and capital expenditure is covered by park fees paid by guests who visit the tourism establishments in the reserve. Land-use zonation, such as the designation of wilderness areas, and other limitations, such as a rule stating that there may not be more than 25 beds per location, further ensure environmental sustainability. The NamibRand Nature Reserve is seen by the government as an important environmental partner as the area forms a buffer zone to the neighbouring NamibNaukluft National Park (Odendaal \& Shaw, 2010).

Author: Nils Odendaal, NamibRand Nature Reserve

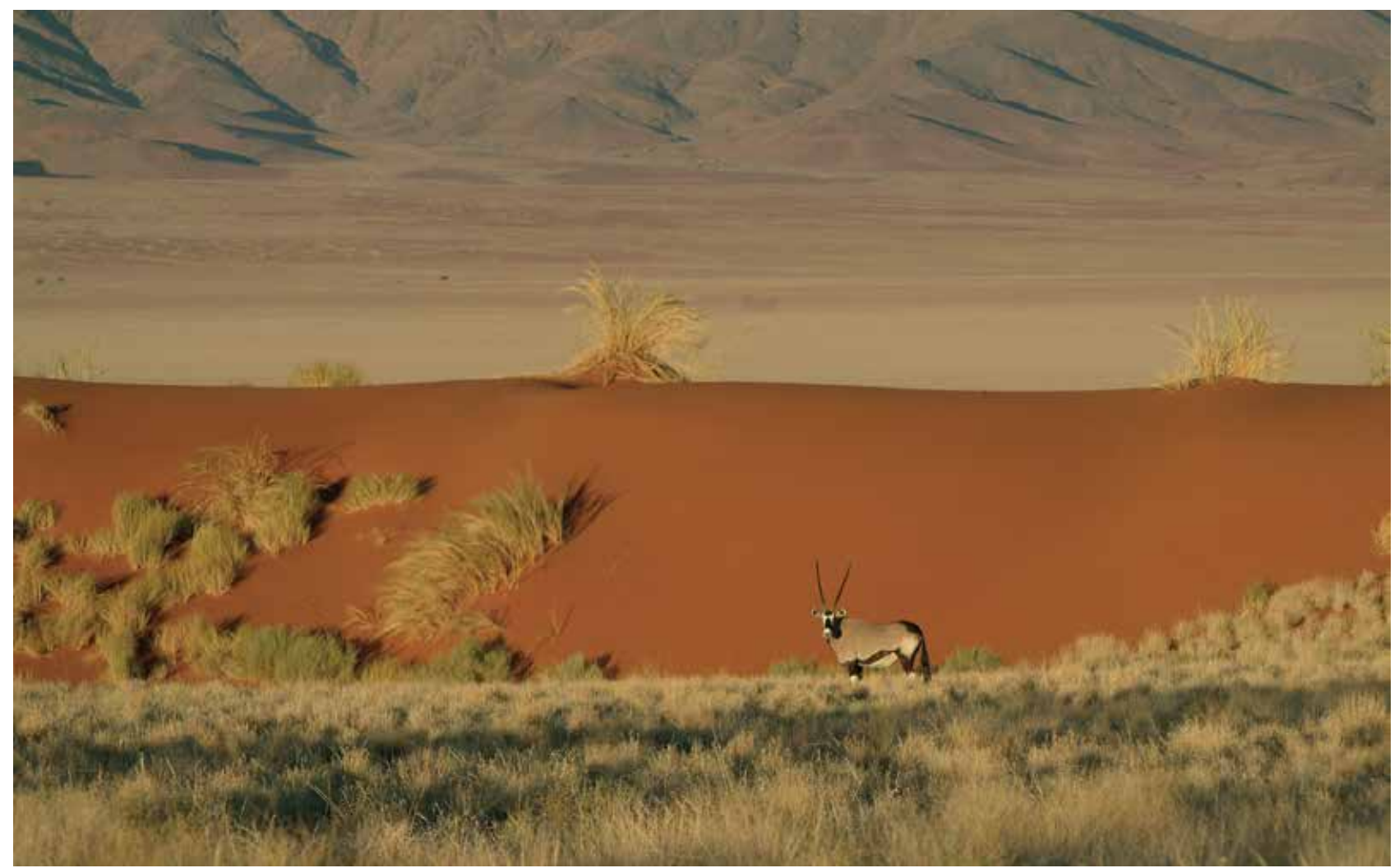

(C) Wolwedans, NamibRand Nature Reserve, Namibia 
At the global level, attention to the governance of protected areas is a relatively recent phenomenon. Until about two decades ago, it was broadly assumed that protected areas are the responsibility of governments. This thinking persists in many parts of the world, despite the fact that the first private land trusts are as old as the first national parks. Private stewardship of natural resources goes back much further. But as appreciation of different types of protected areas grows, and recognition of the benefits of such governance diversity increases, the potential for success in biodiversity conservation expands as well.

\section{The need for governance diversity}

Biological diversity underpins ecosystem functioning and the provision of ecosystem services essential for human wellbeing (CBD, 2010). Governance diversity in protected areas underpins our systems of in situ conservation of biodiversity. Protected areas of different types have different strengths and challenges that influence their effectiveness in the long-term conservation of nature. For example, generally government protected areas are not susceptible to changes in ownership, whereas PPAs may be. On the other hand, being private, PPAs can be less vulnerable to political change than their government counterparts. Thus, a diversity of governance types lends resiliency to any protected area system (Leménager et al., 2014).

PPAs also contribute to good citizenship. As a private, voluntary action, establishing and managing a PPA is a way for individuals to participate in conservation. That is true whether the person acts as an individual or family landholder, as a member of an NGO, a director, executive or even employee of a company with a PPA. From large wilderness areas to tiny plots of private land harbouring endangered species, PPAs provide an avenue for very direct engagement of people from many walks of life.

\section{Private means for public benefit}

IUCN has adopted the term privately protected areas to help express the reality that PPAs have many public benefits despite the fact that they are established and managed by private entities. These benefits include: in situ biodiversity conservation; habitat conservation, restoration and connectivity; ecosystem functions such as water supply; geoheritage conservation; providing for research; religious attachments; personal fulfilment; and often public access.

PPAs often provide public benefits at a lower cost than public agencies managing protected areas. Managed by private means, PPAs reduce public costs of land and water purchase and management by governments, and hence tax payers. Countries can maximise these benefits by encouraging and supporting PPAs.

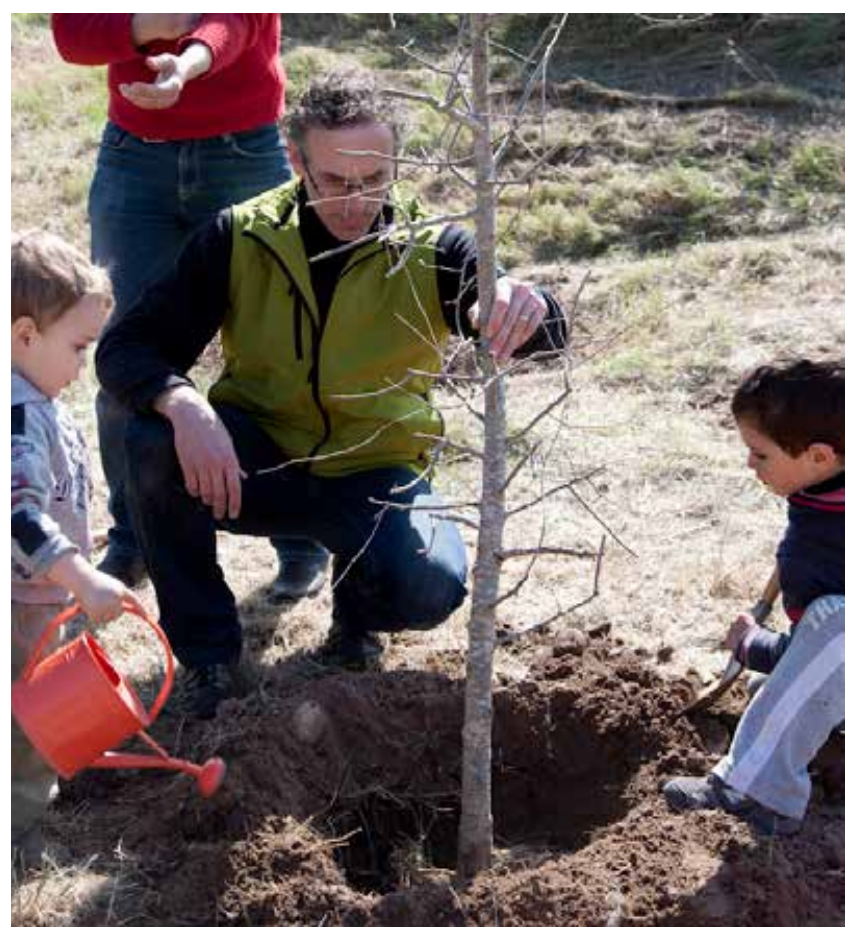

Tree planting at Món Sant Benet @ F Fundació Catalunya La Pedrera

\section{The futures of PPAs}

As with all protected areas, there remain many challenges in ensuring PPAs fulfil their full promise and the ideal set down by IUCN in its guidance for protected areas (Dudley, 2008). IUCN WCPA's The Futures of Privately Protected Areas report highlighted these challenges and included eight overarching recommendations to further develop PPAs, including production of these guidelines (Stolton et al., 2014). We still have much to learn about the PPA estate globally, both what works and what does not. And just as much as we need PPAs to be better recorded we also need systems to identify where sites are failing (Mascia \& Pailler, 2011).

As societies confront the greatest environmental crises of our time such as climate change and biodiversity collapse, PPAs, alongside other types of protected and conserved areas, offer enduring natural solutions (Lopoukhine et al., 2012). 


\section{Case studies}
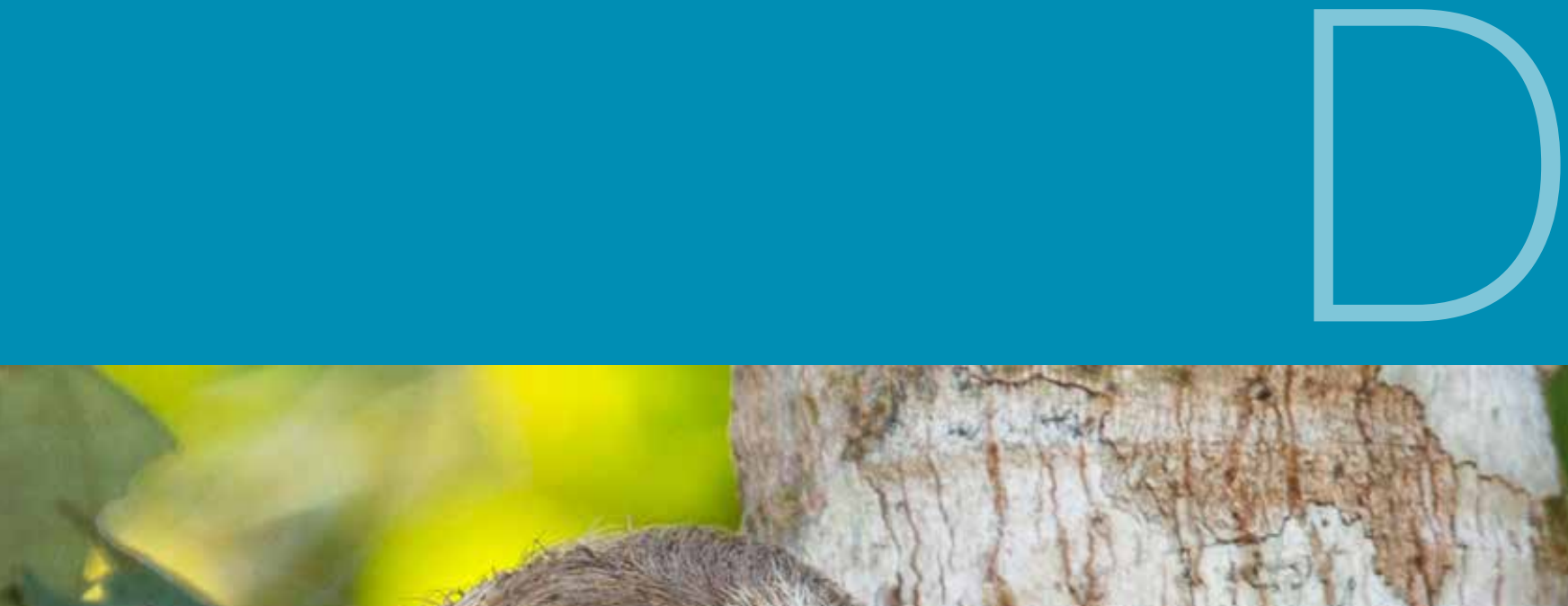

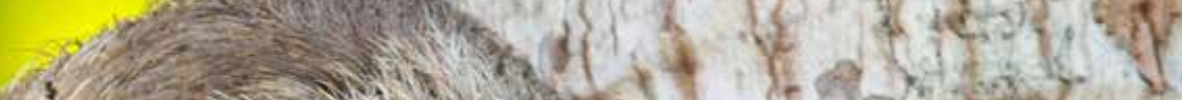
tis

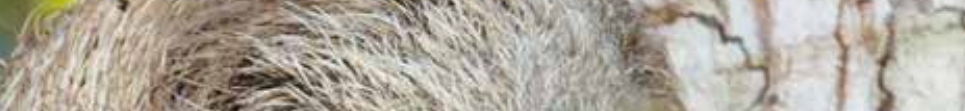

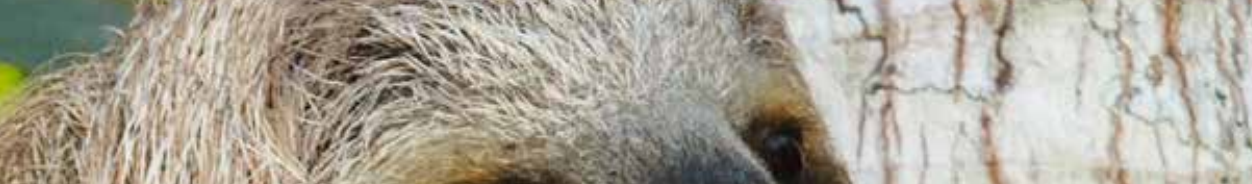

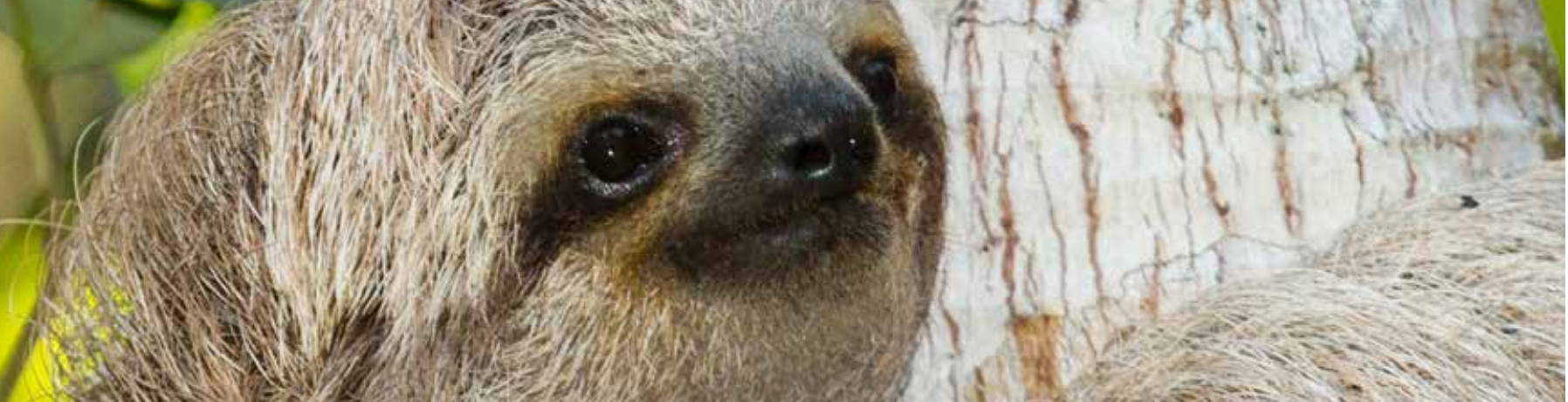

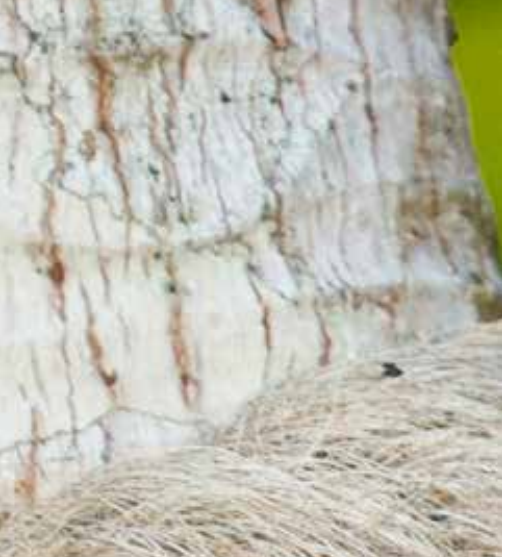

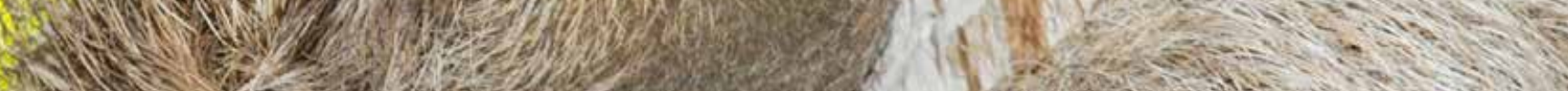

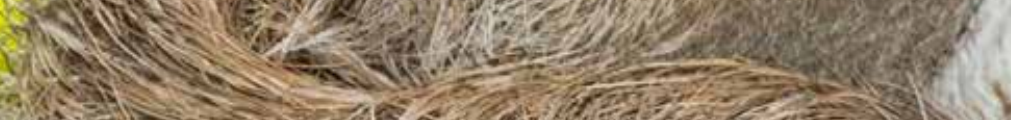

6. Yo.

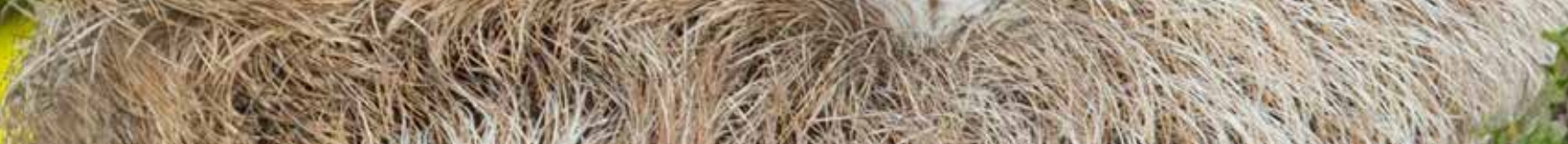

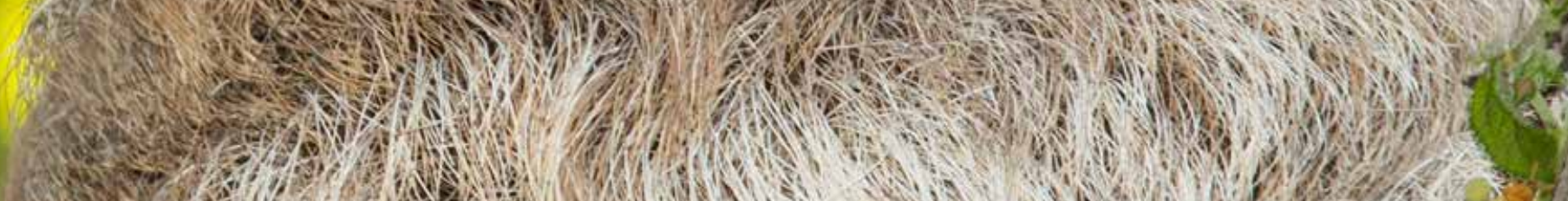

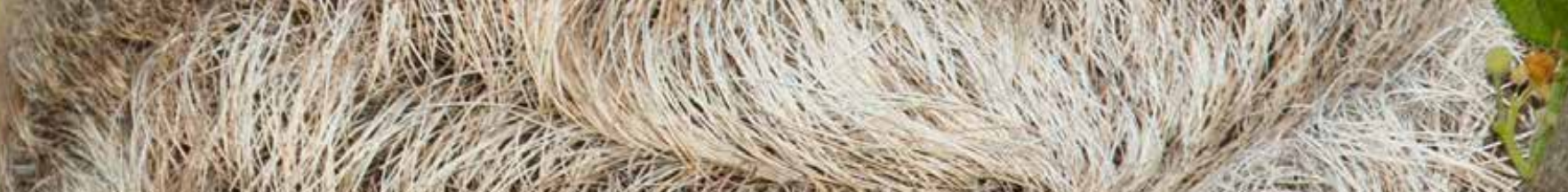

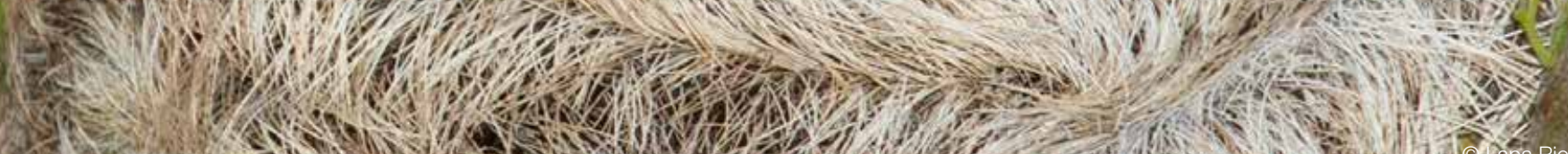

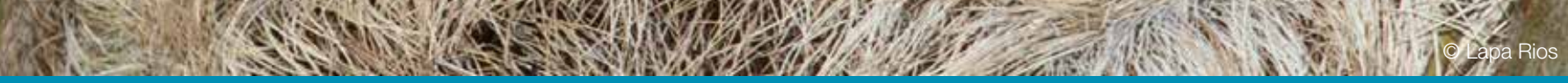


This final section presents 12 case studies from around the world. Each has been chosen to illustrate a range of the best practices presented in this document. The main focus for each was illustrated in Table 1 and is reiterated in the opening paragraph of each study. We encourage all those interested in PPAs to read all of the case studies as together they represent the diversity of global PPAs.

\section{Case Study 1 Australia's National Reserve System of public, private and indigenous protected areas}

James A. Fitzsimons, The Nature Conservancy and Deakin University

The extent to which PPAs are integrated into national networks of protected areas varies around the world, and even within countries. Australia is provided as an example where PPAs are recognised as important to the national system (see Part B, Section 6), where active encouragement for inclusion has occurred but where some further integration of the variety of different types of PPAs is still required.

\section{Overview}

Australia is a federal nation with responsibility for land management, including public protected areas, remaining mostly with the six state and two mainland territories. Up until the mid-1990s, each state and territory developed their own protected area estates, mostly from public land, with little coordination in approaches. Upon ratifying the Convention on Biological Diversity, the national Australian government and the states and territories agreed to work together to create a science-based National Reserve System using the principles of comprehensiveness, adequacy and representativeness (CAR). This sought to ensure that representative samples of ecosystems in each of Australia's more than 80 bioregions were reserved in protected areas.

However, it was recognised that this could not be achieved through increasing the public protected area estate alone and that encouragement of the incorporation of protective arrangements on private and indigenous land would enhance the system. Beyond recognition in policy (e.g. JANIS, 1997; NRMMC, 2005, 2009), the Australian Government provided funding through two programmes, the National Reserve System Program (NRSP) which provided up to two-thirds of the purchase price for strategic land acquisitions of private land by NGOs and state governments and the Indigenous Protected Areas Program to facilitate the incorporation of these tenures into the reserve system. For land purchases under the National Reserve System Program, a key criterion for the funding was that the land improved the representation of the reserve system (focusing on under-represented biogeographic regions and ecosystems).

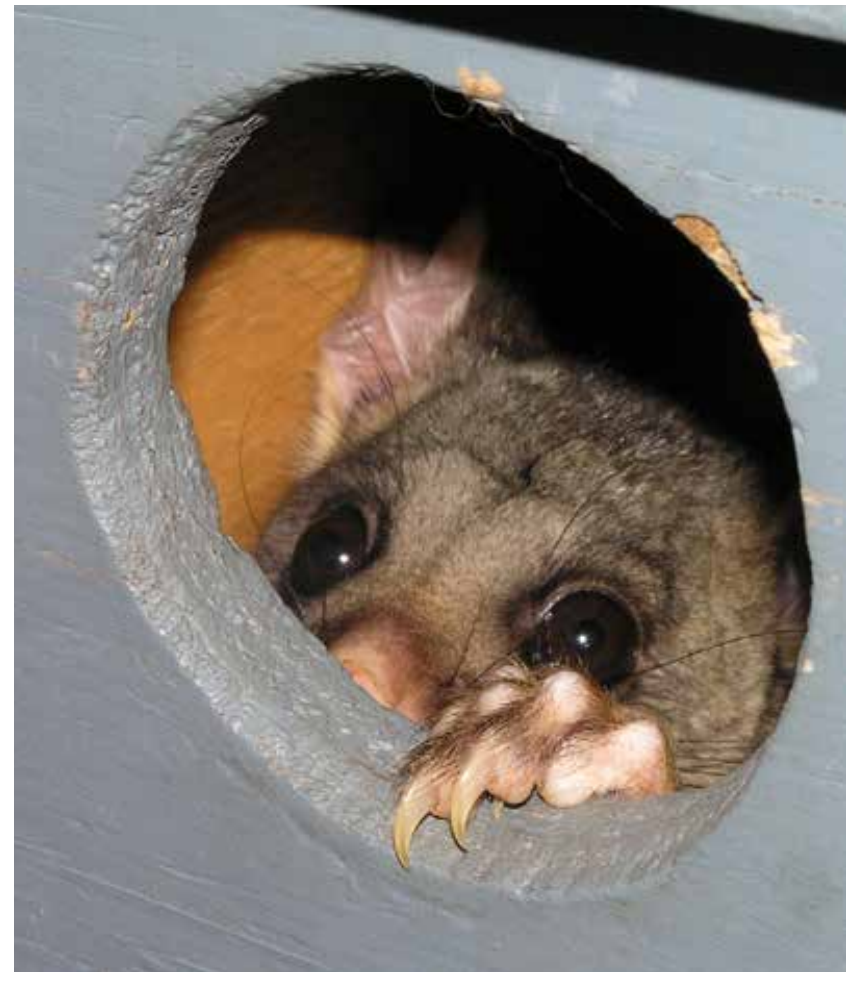

A common brush-tail possum (Trichosurus vulpecula) in a nest box at Creighton Hills conservation covenant

\section{Incorporating PPAs into the National Reserve System}

From 1996 to 2013, the Australian Government's NRSP offered up to two-thirds of the purchase price for private land that was acquired by state governments or land trusts/ community groups for new public protected areas or PPAs, respectively. The funding agreement between the Australian Government and the purchaser of land expressly states the land is purchased for inclusion in the National Reserve System (NRS) (Fitzsimons, 2006). The remaining one-third of the purchase price needed to be sourced from elsewhere, and for land trusts this was mostly from philanthropic sources, who were often stimulated by the leverage inherent in this model (Humann, 2012). Private land purchased through the NRSP required agreements to be binding on the title of that land and carry over to future owners in perpetuity, or 99-year agreements were specified as a minimum time for qualification (NRMMC, 2005; Fitzsimons, 2006). 


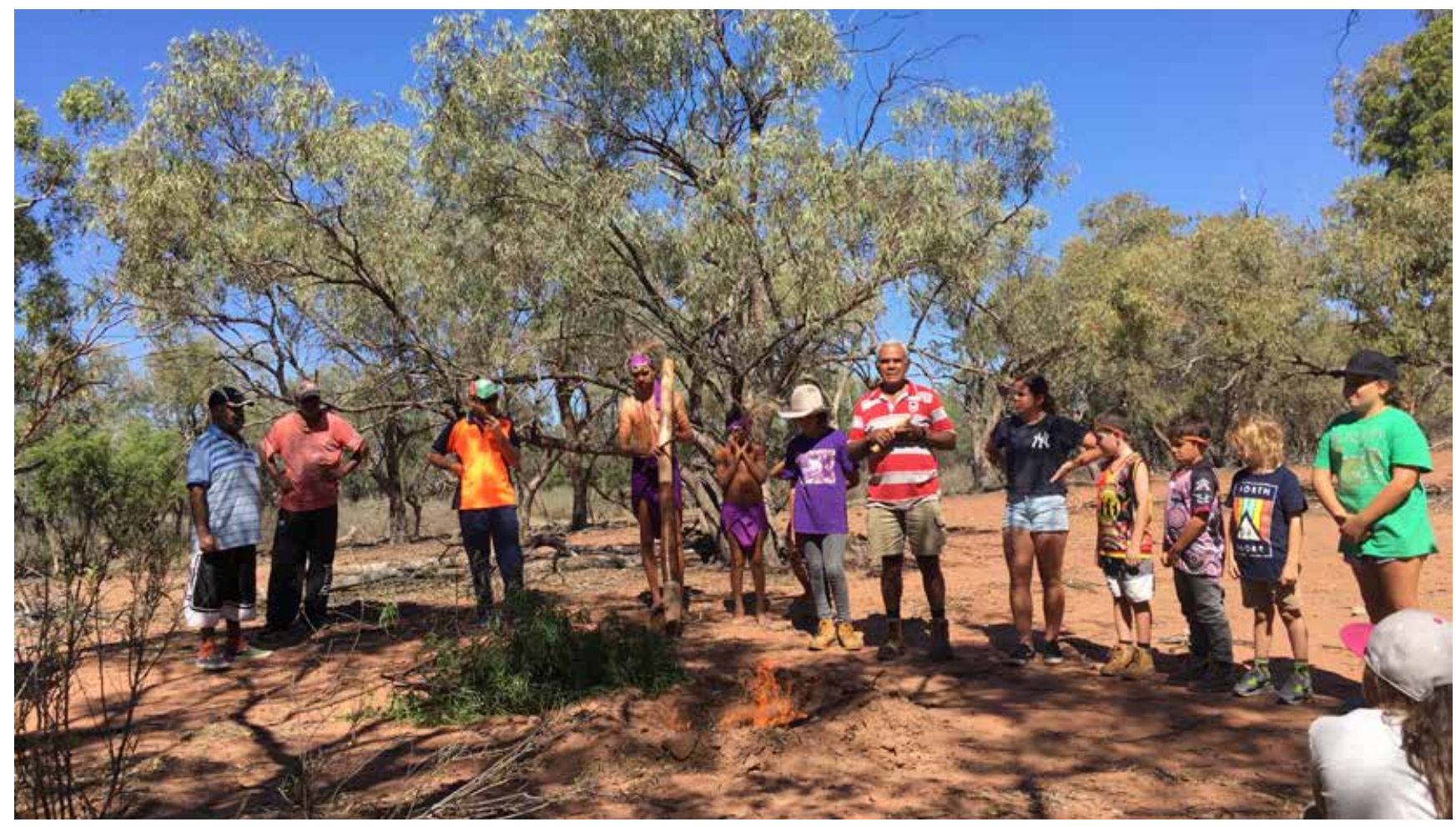

Smoking ceremony; part of repatriating Budjiti artefacts to Bush Heritage Australia's Naree Station Reserve, New South Wales, April 2018 @ Sarah Eccles

Incorporation of PPAs in Australia's NRS has resulted in an increase in representation of bioregions and ecosystems (Taylor et al., 2014). Land trusts were encouraged to discuss potential purchases with the Australian Government beforehand to ensure the property was likely to qualify for funding before an application was made.

In the state of Tasmania, the Australian Government also provided AU\$ 30 million (approx. US\$ 22 million) for a targeted approach to sign conservation covenants on private land, again focusing on under-represented ecosystems. Landholders were offered an up-front payment and management assistance for conserving forest on their properties, with a clear understanding (Best Practice 7.1.2) that they were formally contributing to the NRS (Gilligan \& Syneca Consulting Pty Ltd, 2007).

\section{Challenges}

The majority of conservation covenants have not been established for the explicit purpose of contributing to or incorporation into the National Reserve System nor have the majority of landholders expressly permitted their properties to be included. Nonetheless, some Australian states have included all of their conservation covenants in the Collaborative Australian Protected Areas Database (Fitzsimons, 2015), which is a de facto representation of the NRS, without having explicitly sought their permission for inclusion in the NRS (Best Practice 7.1.2). To comply with the IUCN resolution regarding PPA owners giving permission for inclusion in national and international databases, this needs to be resolved.

\section{Summary}

- Strong science and policy guidance helped guide priorities for future protected area expansion, including PPAs established through the NRSP (Best Practice 1.2.1).

- A dedicated land acquisition budget over multiple years allowed confidence in the land acquisition process, which often spanned over multiple years of negotiation (Principle 1.4 and Best Practice 1.2.1).

- Potential new PPAs were only funded if they met national targets for increasing reservation levels for under-represented bioregions or ecosystems (Best Practice 1.2.1).

- Most conservation covenants, established through covenanting programmes, while qualifying as PPAs, have not been explicitly established for incorporation into the national protected area system. Further work is required to formally seek approval from the landholders for their inclusion into this network (Best Practices 6.1.1 and 6.2.7).

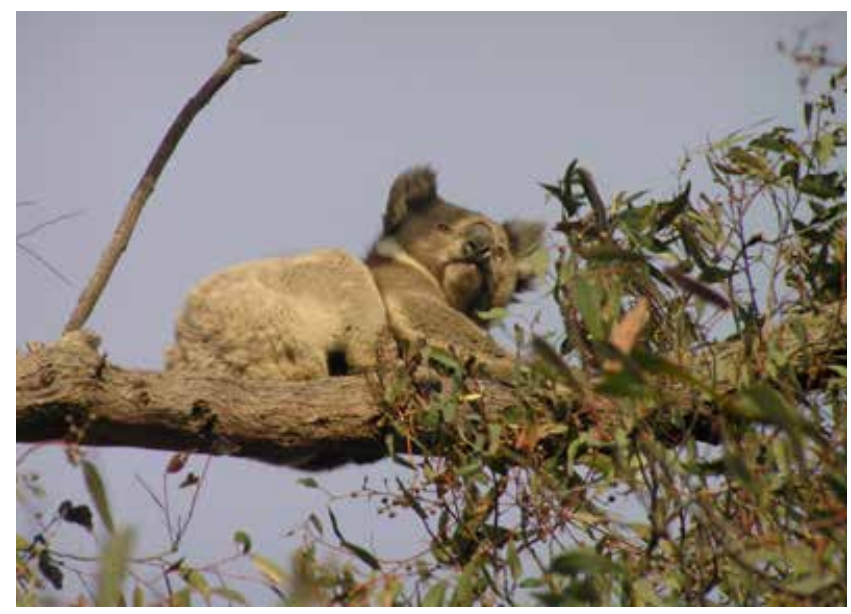

A koala (Phascolarctos cinereus) in Creighton Hills conservation covenant (C) James Fitzsimons 


\section{Case Study 2 Brazil's Private Natural Heritage Reserves: Private initiative as public policy}

Renata Bomfim, RPPN Eluz, Beto Mesquita, independent consultant, Flávio Ojidos, National Confederation of Natural Heritage Private Reserves (CNRPPN) and Maria Cristina Weyland Viera, Association of RPPN and Other Private Reserves Minas Gerais

In Brazil, PPAs are recognised by law in perpetuity; once declared they cannot be rescinded, by the owner or the government (Best Practice 4.1.1). Permanent protection is the main benefit to the landholder. The system is also supported by a strong and growing network providing technical and peer support (Principle 8.2).

\section{Overview}

Brazil has a well-established and growing system of what are known as Private Natural Heritage Reserves, or RPPN from the name in Portuguese (Pellin \& Lima Ranieri, 2016). RPPN are protected in perpetuity and created at the initiative of landholders (De Vasconcellos Pegas \& Castley, 2015). Activities allowed in these areas include scientific research and tourism and recreation and education, as long as such activities are not incompatible with the protection of the resources in the area. RPPN emerged in 1990 and have been incorporated in the national system of protected areas by federal law since 2000. This is significant because it provides permanent protection; land use cannot be changed, even by the government, except in exceptional cases. The land stays in private ownership. It can be sold or otherwise transferred, but the certificate of the protected area is transferred to a new owner.

\section{Filling the gaps in a protected area network}

There are nearly 1,500 PPAs in Brazil, totalling 772,000 ha. This is not a large area compared to over 76 million ha of federal protected areas, but RPPN are often well-placed to protect areas of high biodiversity. RPPN can also be better managed than their government counterparts. As one crude measure, there is only one manager per every 45,000 ha of federal protected area. Assuming a minimum of one manager per RPPN, the average is one per 550 ha. These are just averages over a huge country, but this metric provides some sense of scale. A recent assessment of management effectiveness in the state of Mato Grosso do Sul found that the RPPNs are indeed better managed than their government counterparts, though both needed improvement (Pellin \& Lima Ranieri, 2016).

RPPNs can be certified by any level of government, federal, state or municipal, but do not receive much in the way of financial incentives from the recognising government. They do qualify for relief from property tax but, unlike in the US (see Case Study 11), that is not a major driver, except for

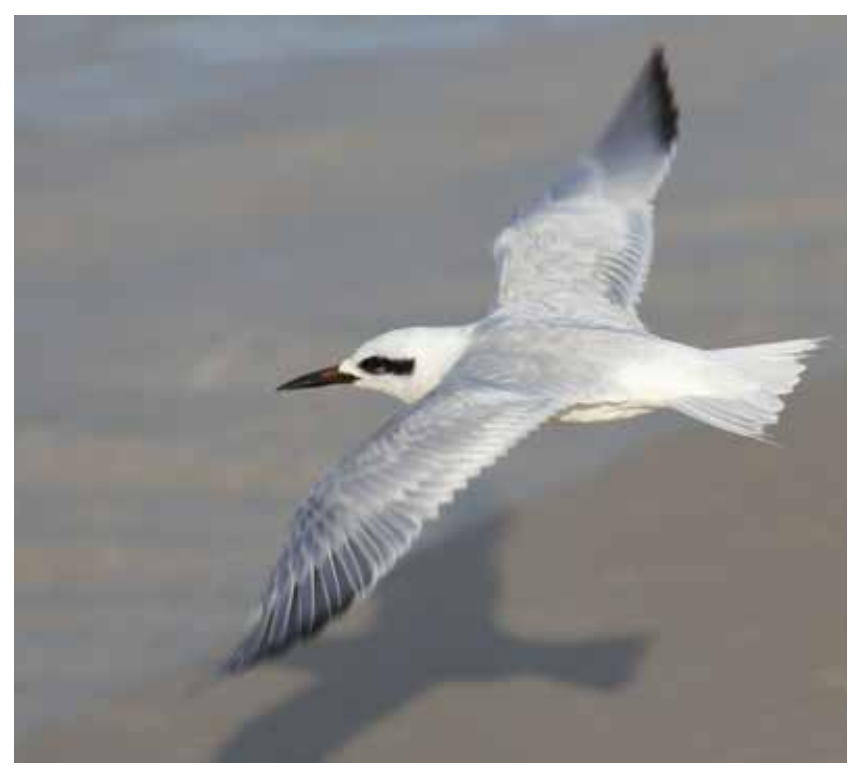

Snowy-crowned tern (Sterna trudeaui) at the RPPN Costau do Santinho (C) Brent A. Mitchell

the Pantanal biome, where the largest RPPNs are. They do support each other through a national network, including advice on how to achieve financial sustainability. For example, in the states of São Paulo and Paraná the RPPN owners' associations successfully advocated for the creation of a Payment of Environmental Services scheme. A leader in the network is working on a guidebook on this subject, and management skills within the network are growing. From the perspective of the national system, government is seeing greater conservation capacity with little direct investment.

RPPN are not evenly distributed across the country. There are relatively few of these PPAs in the wetland Pantanal, but on average they are quite large. In contrast, though there are now PPAs in all Brazilian states, by far the largest number of individual RPPNs is in the Atlantic Forest biome. But on average they are much smaller in size.

RPPNs came to international attention through the reintroduction of the golden lion tamarin (Leontopithecus rosalia) from captive breeding programmes in zoos around the world. PPAs provided the habitats. The Atlantic Forest is a biodiversity hotspot, where two-thirds of the country's population lives. So, only about 16 per cent of the original forest remains, and more than 80 per cent is privately owned. It is therefore difficult to create new public protected areas there. This is an excellent example of how PPAs can address habitat fragmentation and provide connectivity in areas where other approaches are less effective. 


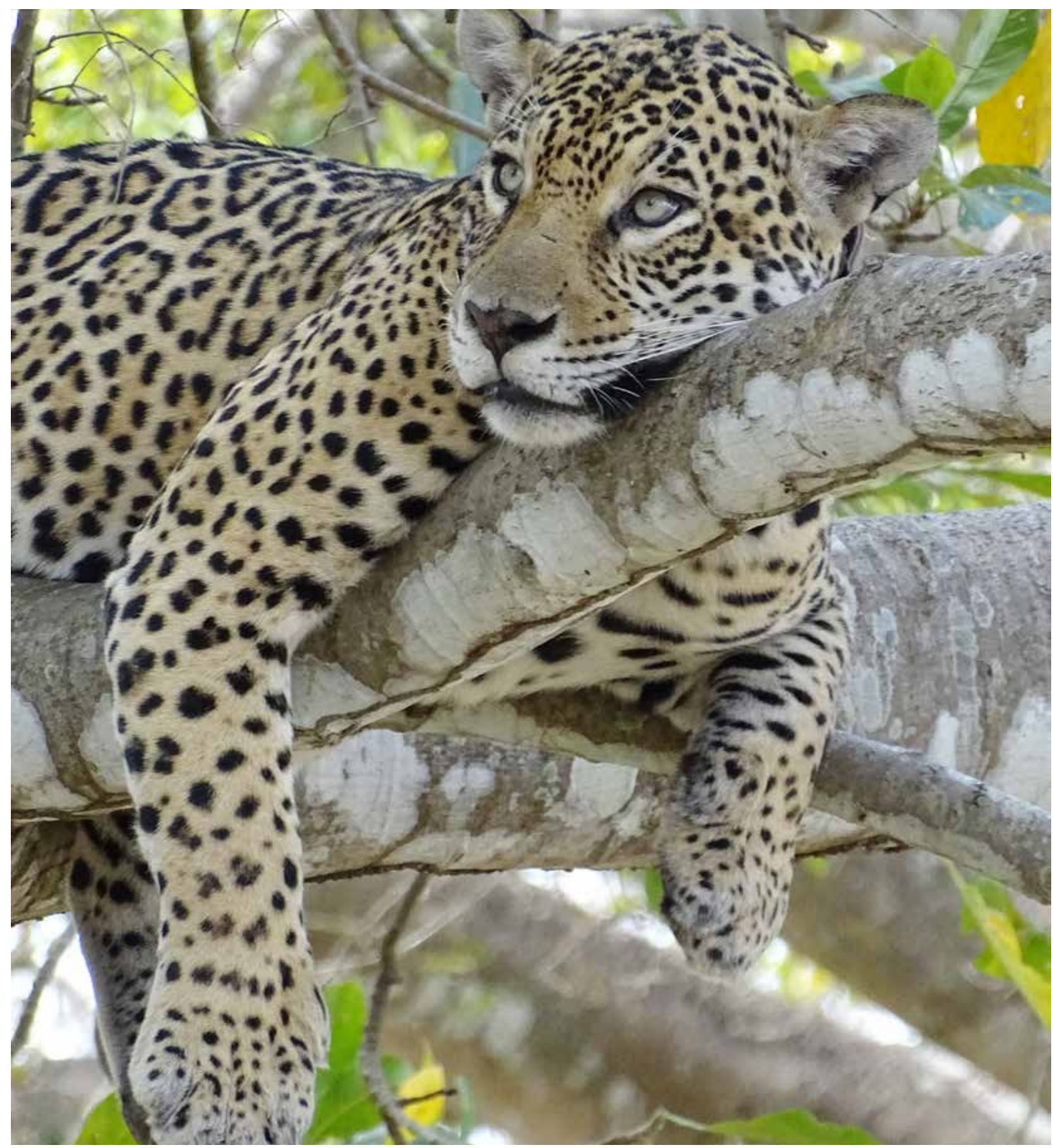

Jaguar (Panthera onca) @ Project Oncafari

\section{Summary}

- RPPNs are protected in perpetuity; their status as protected areas cannot be changed, even by the government (except in cases of public utility development where no other local alternative is available) (Best Practice 4.1.1).

- RPPNs play a disproportionately large role in conservation as they often exist in biomes that are under-represented in public protected areas, and/or provide connectivity in mosaics of protected areas of different governance types (Principle 6.2).
- Networks of RPPNs at state and federal level are committed to provide technical and peer support to individual landowners (Best Practice 8.2.1).

- The national network maintains a database and RPPNs are considered part of the national system of protected areas. There is a national task force currently working to increase the registry of RPPNs in the World Database on Protected Areas (Best Practice 7.1.1). 


\section{Case Study 3 China's Land Trust Reserves}

\author{
Jin Tong, The Nature Conservancy China Program
}

Traditionally, in China all lands belong to 'the people' and there is no 'privately owned' land, as such. Since 2008, a series of policies on forest tenure reform, advocating separating land ownership from contracted management rights, have opened the door for private individuals and organisations to hold management rights without changing land ownership. Meanwhile there has been a call for diversification of funding channels for conservation to include social capital investment. The rapid growth of the Chinese economy and growing domestic philanthropy also makes it possible for private citizens to support conservation financially. These have ultimately led to the birth of a new private conservation model in China during the past decade, bringing private funding and management into China's protected area systems. This new model is adapted from the classical US land trusts, therefore named the 'Land Trust Reserve'. The case study provides an example of establishing a PPA (see Part $B$, Section 1) in a country where until recently PPAs were not considered feasible.

\section{Overview}

Currently, more than 15 per cent of China's land has been designated as protected areas, within which 2,750 nature reserves have the highest level of legal protection. However, there are still many conservation gaps in the existing protected areas system in China, while most local and provincial reserves within the system are essentially 'paper parks', with many lacking in funds, enforcement and management staff, and facing frequent conflicts with local economic development. For example, almost half (46 per cent) of the giant panda's (Ailuropoda melanoleuca) habitat has not yet been covered by existing nature reserves.

Laohegou was one such conservation gap. Located in Pingwu County, Sichuan Province, Laohegou is a key corridor for pandas and connects two existing national panda reserves. It covers approximately 11,000 ha of old-growth forest including a state-owned forest farm and surrounding collective forest and has an estimated population of 10 pandas. Commercial logging has been prohibited because of the natural forest protection programme, but only limited conservation activities such as fire prevention were performed and continuing unsustainable natural resources extraction by nearby villagers included hunting, fishing and non-timber forest product collection.

\section{In 2011, The Nature Conservancy (TNC) China Program} started a collaboration with the local government to explore the establishment of the country's first Land Trust Reserve following the model of the US land trusts. TNC China developed a new entity, the Sichuan Nature Conservation Foundation (SNCF) (which was later renamed as the Paradise Foundation ${ }^{139}$ ), with support from 22 top Chinese entrepreneurs. One year later, SNCF signed the nation's

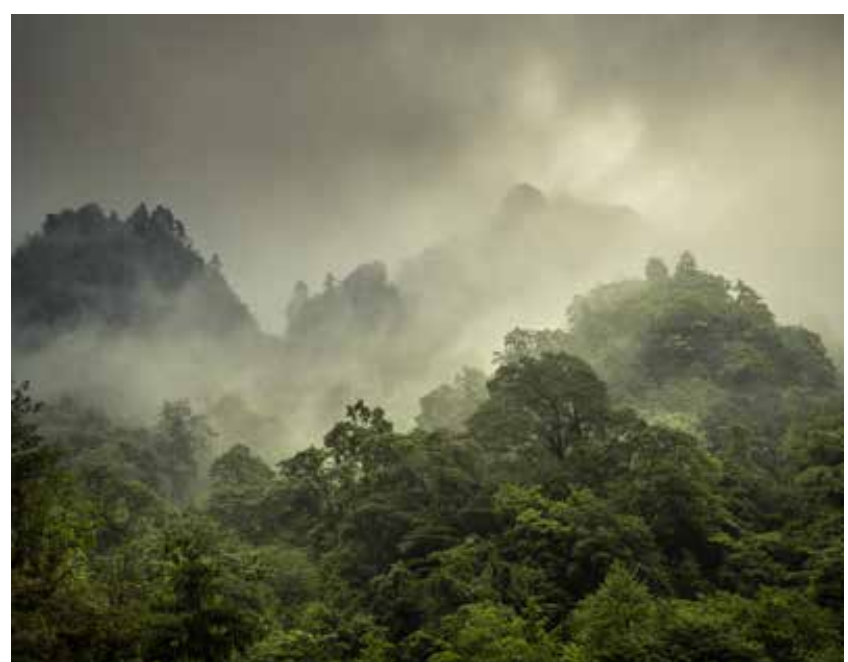

Laohegou Nature Reserve @ TNC

first conservation lease, allowing it to manage an 11,000 ha forest parcel for the next 50 years (Best Practice 1.4.2). To further consolidate its legal safeguards for protection, Laohegou was officially declared as a county-level nature reserve in September 2013, with SNCF as its funder and management rightsholder under supervision from the local government (Best Practice 1.1.1). SNCF has invested about US\$3.3 million for the reserve establishment in the first three years and an annual operational cost of about US\$500,000 thereafter (Stolton et al., 2014).

To manage the reserve, SNCF sponsored the creation of a local NGO, the Laohegou Nature Conservation Center (LNCC), which has hired former forest farm staff and nearby residents for daily management and received technical support from TNC China (Best Practice 2.5.1). Led by TNC China and a group of scientists from top research institutions, Laohegou has conducted thorough baseline surveys and then developed its management plan using the Open Standards framework (Best Practice 2.5.4). Strict entry and exit management, to avoid human disturbance, as well as a range-wide patrol system and law enforcement working closely with Forest Police to detect and deal with illegal activities, are regularly performed within the reserve. A relatively simple but reliable ecological monitoring system using camera traps has been implemented since the latter half of 2014 to help evaluate conservation effectiveness (Best Practice 2.4.1).

Beside conservation, Laohegou is also piloting mechanisms to increase income in nearby communities (Best Practice 2.3.2), as well as to fund the reserve stewardship sustainably (Best Practice 3.2.1). An expansion area has been set up to include the nearby communities and a master plan is in place to guide environment-friendly development in this area. SNCF helped set up a system to link the community's ecofriendly agricultural products to outside high-end markets for higher prices than before. Revenues from the sales augment community income and reduce the pressure from the local 


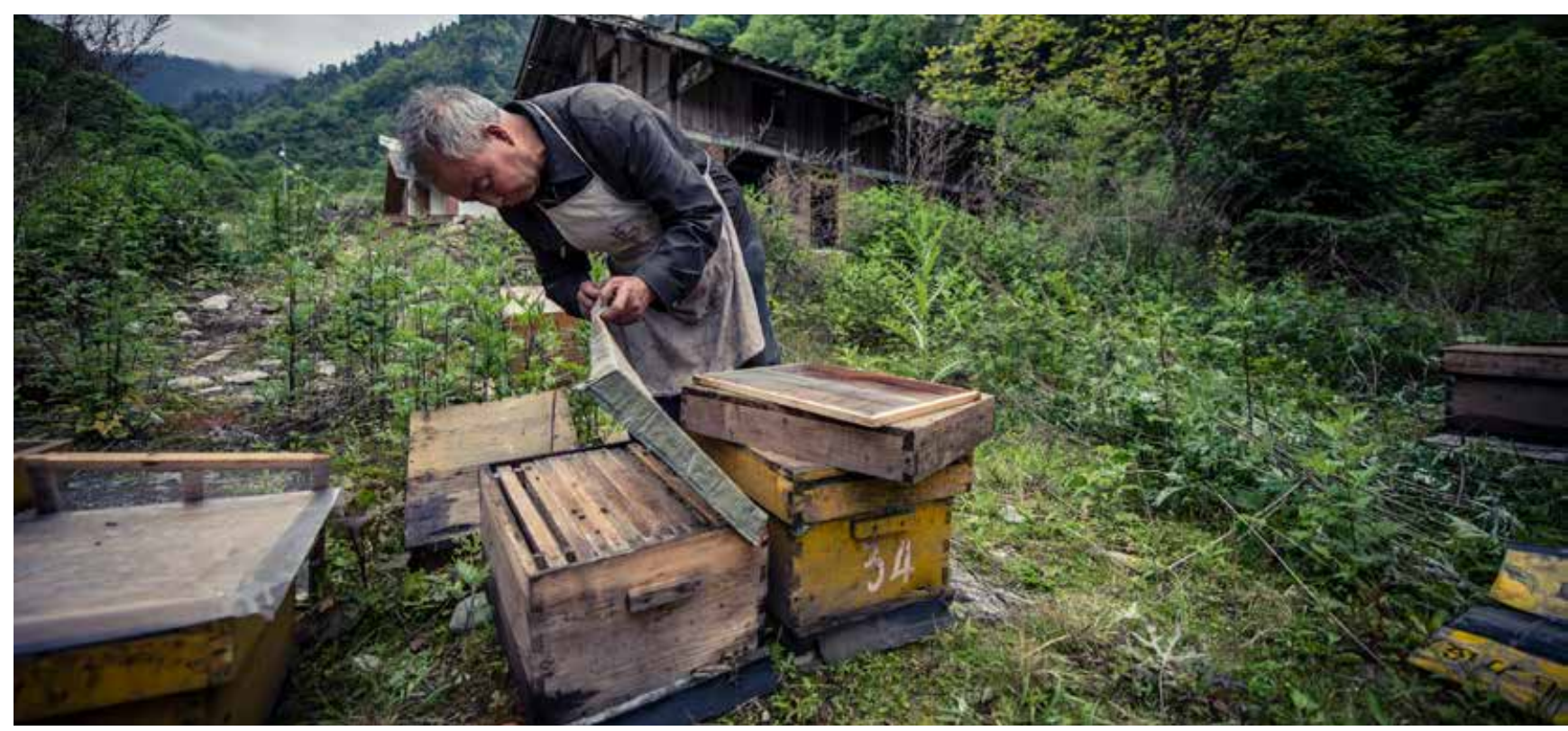

Bee keeping in Laohegou Nature Reserve@ Nick Hall

residents who want to hunt and forage within the reserve. In 2015, SNCF funded a social enterprise to produce and sell honey wine using the honey from bee-keeping in the reserve, and the profit from this business will contribute to fund the operations of the reserve.

Very positive changes have occurred since the establishment of the Laohegou Land Trust Reserve. Equipped with adequate funding, qualified staff and a sound management plan, the PPA has eliminated almost all destructive human activities, and today the population of pandas has increased to 13 , according to the latest nation-wide population census, and endemic fish have returned to the rivers. Meanwhile, more than one-third of households within the expansion area have been able to double their income through eco-friendly agriculture. The land trust model has been recognised broadly by different government agencies, conservation organisations and businesses, and has demonstrated that this model could be an effective supplement to the current government-led protected area system.

Beyond Laohegou, TNC China and its partners are also exploring other models to demonstrate the flexibility of this approach, such as civil society organisations assuming complete or partial management responsibilities of an existing poorly-managed reserve. "We've been testing this localized land trust model as a way to expand society's ability to protect and sustainably manage China's most important lands and waters, while providing green livelihood solutions for local communities and creating a mechanism to finance long-term reserve management through private contributions. We believe that this new model could become an important supplement to China's current protected area system," says Science Director of TNC China, Dr Jin Tong. Borrowing the idea of the US land trust movement, 23 international and domestic environmental NGOs/Foundations launched the China Civic Protected Areas Alliance in November 2017, aiming to catalyse the 'Chinese land trust movement' by providing a platform for communications, funding, standards, policies and capacity building (see Part B, Section 8). The long-term vision of the Alliance is to collaboratively protect 1 per cent of China's terrestrial land by civic and private organisations and individuals.

\section{Summary}

- SNCF's establishment was fundamental for the Land Trust Reserve model; it serves as a funding vehicle to receive philanthropic money to support reserve establishment and management, and also an appropriate body to sign the conservation lease or agreement to hold the management right of the land (Best Practice 8.2.1).

- A management team run by local people in Laohegou is very important to securing the long-term stewardship of the reserve (Best Practice 2.5.6).

- The concept of an 'expansion area' around the PA links conservation inside the reserve with eco-friendly community development around the reserve (Best Practice 2.3.2).

- A sustainable and diversified financial plan to fund the land stewardship is vital to the long-term stability and viability of the PPA model (Principles 2.3 and 3.2). 


\section{Case Study 4 PPAs and tourism: A site-based example from Lapa Rios, Costa Rica}

Delphine King, The Long Run and Karen Lewis, Lapa Rios

The Lapa Rios, a leading conservation tourism initiative in Costa Rica, showcases the power of a tourism business as a vehicle for conservation, of well-articulated and embedded conservation goals which permeate through the business (Principle 5.4), the importance of collaboration (Best Practice 5.1.2) at different levels, and how using an approach such as the 4Cs framework (Box 8.3) integrates Conservation, Community, Culture and Commerce to strengthen the conservation impacts of the business to further secure biodiversity outcome into the future (Principle 1.5).

\section{Overview}

The Lapa Rios Reserve is located near the point where the Golfo Dulce meets the Pacific Ocean, in Costa Rica's Osa Peninsula. The Peninsula contains some of the highest levels of biodiversity in the most carbon-dense forests in the world (Taylor et al., 2015). In the 1990s, at a time of human population increase when unsustainable and extractive business practices threatened the Peninsula, John and Karen Lewis purchased 420 ha of land, stretching from the ocean to the spine of Osa. They set out to demonstrate that "However you cut it, a rainforest left standing is worth more." Their goal was to protect the over 300 ha of primary forest, regenerate 80 ha of pasture patches, and "...provide livelihood opportunities to local communities and improve awareness about conservation and sustainable environmental management" (Karen Lewis, founder).

Using an approach linking Conservation, Community, Culture and Commerce (the 4Cs) they managed just that. There has been a dramatic recovery of the forest; vigorous secondary forest growth now covers all previously degraded areas. The area hosts 400 species of birds, 500 tree species, four species of monkeys, and jaguars, tapirs and sloths to name a few (Toft \& Larsen, 2010). It demonstrates that ecotourism can be a competitive economic driver for conservation. Creative thinking, persistence, core values and strategic collaboration were all ingredients contributing to this success.

\section{Responsible tourism as an opportunity to conserve the Osa Peninsula}

The owners' motivations for purchasing land were to establish a lodge and reserve as a means to protect the contiguous rainforests in the Peninsula. They realised that a competitive alternative to existing economic drivers was necessary; both to provide sustainable livelihood options locally and financially support the reserve. The location and rich biodiversity of Lapa Rios created a unique opportunity for tourism.

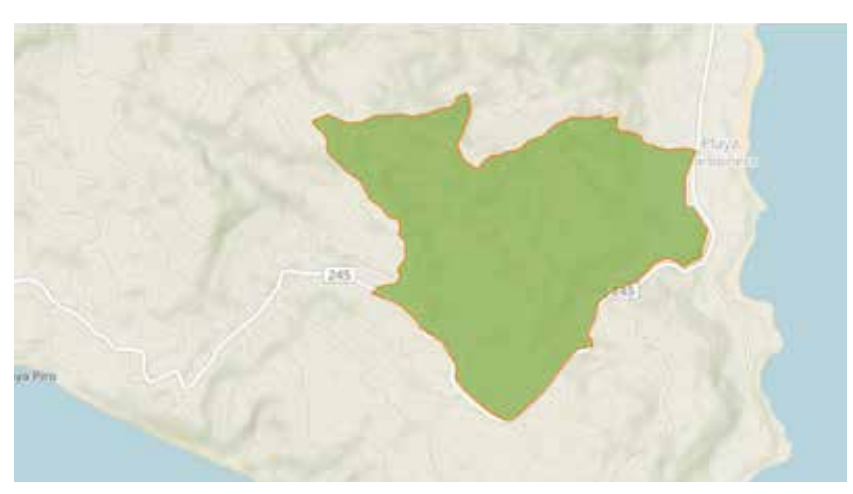

Lapa Rios was included in the WDPA after being verified by experts from IUCN's World Commission on Protected Areas @ Protected Planet, UNEP-WCMC

From the onset, goals integrated land conservation, community and commercial objectives. This combination enabled conservation to be part of the DNA of the business (Best Practice 5.4.2). Thus, alongside its conservation objective, Lapa Rios set out to demonstrate best environmental management practices for ecotourism. Its bungalows and buildings were inspired by the area's indigenous culture, renewable materials were used, water is solar-heated and local food is celebrated (see Best Practice 2.3.2). The open design allows air to circulate, removing the need for air conditioning and provides guests a wildlife experience separated only by screening. Visitor experiences revolve around nature and the lodge's low impact existence. The 2010 Sustainability Master Plan creates a framework for new development for the business. Over the years, the operation has been able to invest more than US\$1 million in the conservation of the reserve.

\section{An inclusive success}

To achieve long-term success the tourism enterprise had to be inclusive (Best Practice 2.3.2). Thus, Lapa Rios focused on:

- Providing preferential employment and business opportunities to Osa Peninsula residents.

- Creating basic capacity building through on the job training.

- Ongoing environmental education for employees, community members and visitors.

All 55 Lapa Rios employees are from the region (Best Practice 2.5.6), and most of the food is sourced locally. The owners actively invested in their team, providing continuous training and a stimulating working environment. As a result, there is very low turnover of employees (2-4 yearly) and 10+ members have worked there more than 20 years. Employees are part of all Lapa Rios community endeavours. As such, they are given time to support community initiatives of their choice and are considered community leaders. This has strengthened the relevance of Lapa Rios' community actions 


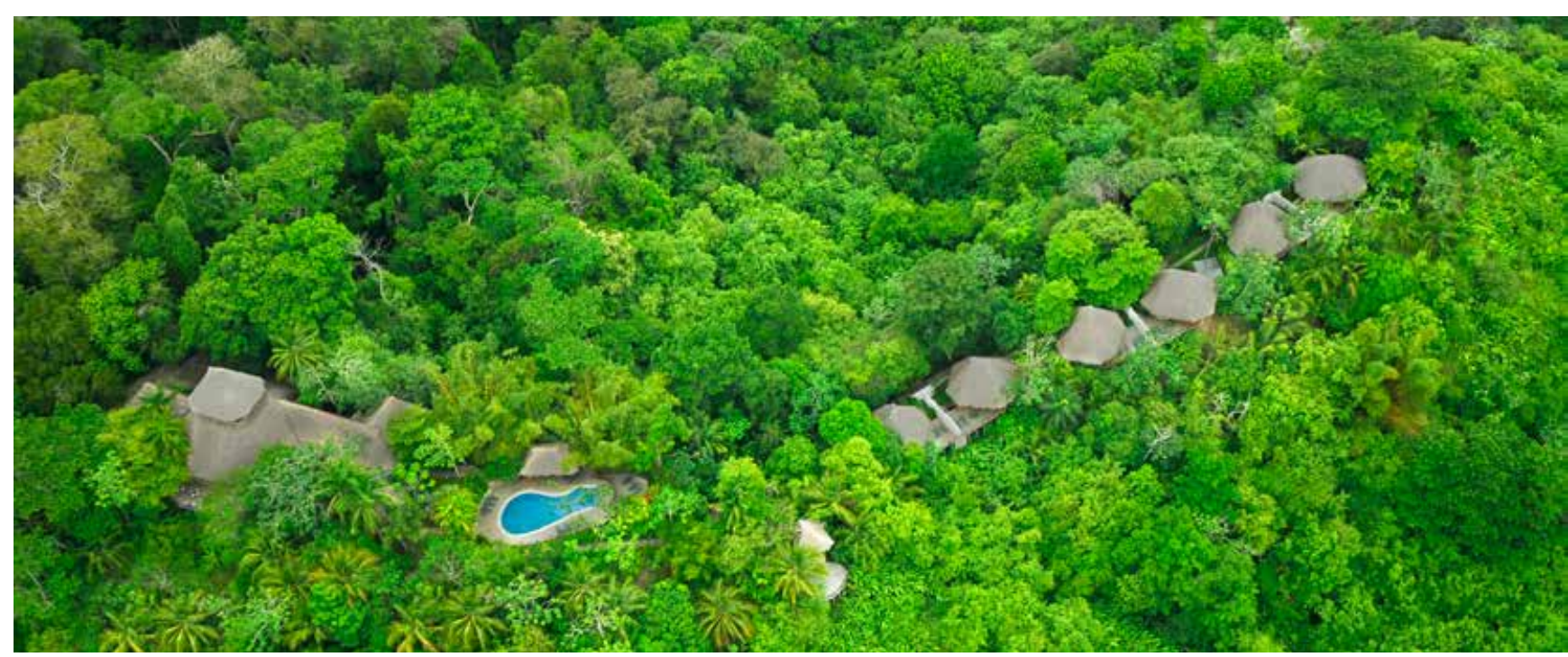

C Lapa Rios, Osa Peninsula, Costa Rica

and the engagement of employees in Lapa Rios conservation objectives. Investments in education and capacity building have taken many forms, from school infrastructure development, to environmental education, and initiating a naturalist-guide school in 2017. In 1991, Lapa Rios built the area's first primary school, and since then, it has expanded its impacts to over 600 children and in 13 other Osa schools.

Many opportunities are created for the local people and the lodge's guests to experience, learn and care for nature. One example is the 'Families Hike' programme where staff members are taken on a guided hike with their families, to experience the forest, its flora and fauna with a guided interpretation; and by doing the 'Twigs, Pigs and Garbage' tour, they gain insights into ways to reduce waste, water and energy consumption. Over lunch, staff members and their family discuss what was experienced as well as its relevance to their lives. As a result, employees are proud of what they do and, excited by their experiences, children become advocates for conservation at an early age.

\section{Addressing challenges}

Collaboration has been particularly significant in securing Lapa Rios into the future (Best Practice 5.4.2). Conscious about the challenge of protecting Lapa Rios' biodiversity beyond their ownership, the Lewises convened an 'Ecolodge Owners' Dilemma' conference, inviting conservation NGOs, environmental lawyers and tourism experts in 1999. The meeting aimed to brainstorm: "How owners could protect the land and people supporting their tourism business after they move on" (Principle 4.1). Several solutions were explored, and the obvious responses were to secure the land legally and only sell to environmentally and sociallyconscious buyers. The Lapa Rios owners learnt about the opportunity for conservation easements/covenants to restrict development and land division, which would threaten the capacity of the reserve to remain an economic driver for the region and flagship conservation business. At the time, the easement option was available in Costa Rica's legal system but was untested within a private land context. Subsequent to the meeting, the Lewises met numerous potential buyers, some of whom were aligned to their vision. Most focused on the financial bottom line. Although they realised that this was not something all buyers wanted, the owners signed the easement in 2013 "To make the selling process easier and remove the need to negotiate re conservation vs. expansion or development." This became Costa Rica's first easement applied to a private business (Best Practice 4.1.1).

The second outcome of the workshop led the owners to bring in Cayuga Sustainable Hospitality, a management company which fully aligned with their vision. The management company has brought professional management, improved skills, guest satisfaction, community connectivity and economies of scale. This enabled the owners to step back from the day-to-day running of the lodge but allowed the conservation and community elements to continue underpinning the business, until the time when they could find a suitable buyer. Undergoing The Long Run's GER® recognition processes (Box 8.3) and the Costa Rica tourism certification process ensured the owners' requirements continued to be met (Best Practice 1.1.3).

\section{Summary}

- The economic success of Lapa Rios' ecotourism operation is fundamental to the sustainability of the PPA (Best Practice 5.4.1).

- To reduce the tension between profit and conservation, clear goals for the business that integrate conservation, commerce, as well as community and culture considerations are useful (Best Practice 5.4.2).

- Community inclusion is important to securing biodiversity outcomes into the future (Best Practices 2.3.2 and 2.5.6).

- Collaborations bring skills to PPAs, support advocacy, expand impacts and offer solutions to specific issues (Best Practice 2.5.4).

- Securing the land with an easement for conservation in perpetuity has brought peace of mind to the owners and made the selling process straightforward (Best Practice 4.1.1). 


\section{Case Study 5 The National Natural Heritage: Contributing to private engagement in nature conservation in Germany}

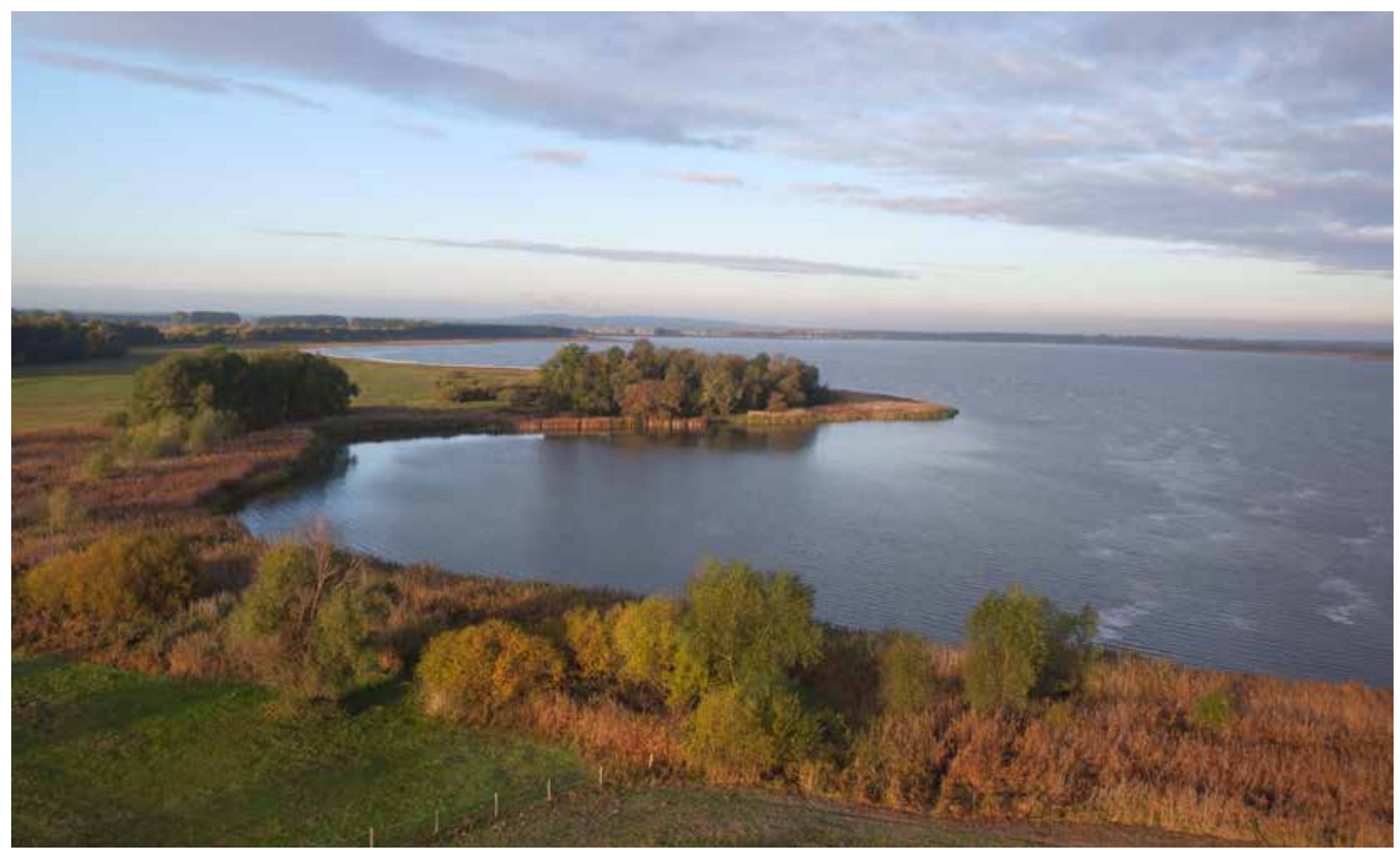

Guelp Lake is managed by NABU-Stiftung Nationales Naturerbe, the German partner of BirdLife International @ Thomas Stephan / Bundesamt für Naturschutz

Gisela Stolpe, BfN Vilm, Karin Reiter, BfN Bonn and Tilmann Disselhoff, NABU

In 2005, Germany began a national project to transfer large tracts of federally owned land to the federal states (Länder), conservation NGOs and foundations in order to protect these properties for nature conservation in perpetuity. This large-scale land transfer called the National Natural Heritage (NNH) has considerably advanced the role of environmental NGOs and foundations as managers of conservation land in Germany. This case study illustrates a range of best practices primarily from Section 2 of the guidelines relating to mechanisms to ensure and monitor the quality, effectiveness and coherence of conservation approaches.

\section{History of the National Natural Heritage}

With the ending of the Cold War and the reunification of Germany in the 1990s, many military and lignite mining sites and areas along the inner-German border between the east and west ('Green Belt') no longer had a use. The lack of agricultural or other intensive land uses resulted in much of this area having a high conservation value with many rare and/or threatened species. Moreover, land use such as military exercises had caused habitat disturbance (e.g. fire, tank tracks, etc.) that enabled threatened pioneer species to colonise the sites. In consequence, the federal government of Germany decided to create a project for transferring free of charge federally-owned land of high nature conservation value to the federal states, conservation NGOs and foundations (Best Practice 1.2.1). This so-called National Nature Heritage ${ }^{141}(\mathrm{NNH})$ approach was unique since by law federally owned land has to be privatised if no further need or .use exists

Between 2005 and 2013 the government transferred free of charge about 156,000 ha of federal land $(120,000$ ha of which was former military land) to nature conservation (BMUB, 2017). The programme was renewed in the coalition agreement of 2018 and will eventually comprise about 186,000 ha of conservation land in total. Using a strategic set of selection criteria together with the other measures outlined below has helped increase the integrity of existing protected areas, conserve sites of high conservation value and contribute to the establishment of wildlife corridors throughout Germany.

The largest owner of NNH sites is the German Federal Environmental Foundation (Deutsche Bundesstiftung Umwelt, DBU). DBU was founded by the German government in 1990 with the proceeds of the privatisation of a state-owned steel company. The DBU now owns about 70,000 ha of $\mathrm{NNH}$ land. Conservation NGOs and foundations own 25,000 ha, while 28,000 ha have been transferred to the federal states 
and 33,000 ha have remained in federal ownership under supervision of the Federal Ministry of the Environment. All these areas are now managed according to strict nature conservation requirements. NNH owners sign contracts binding them to adhere to the project's objectives, to implement adequate management measures and to establish regular reporting procedures (see below).

\section{Objectives, management and monitoring}

The main objective on $\mathrm{NNH}$ sites is for any commercial use of woodland to be discontinued, with the speed of the phaseout depending on the state of the forests. While active forest management is ended immediately from the date of transfer on all (near) natural forests, in other forest habitats, short-term to mid-term 'conversion' management is allowed to help re-establish natural vegetation communities. This supports the goals set for wilderness areas in the German Biodiversity Strategy (to reach a surface area of 2 per cent for large wilderness areas and 5 per cent for forest areas with no forestry use respectively by the year 2020). Some forest types that have developed particular conservation values due to former traditional management practices, such as former wood pastures, some oak and oak-hornbeam forests or coppiced forests, need continuous active management. Also, some safety measures are continued in order to protect visitors.

While natural processes and dynamics are the long-term conservation vision for all forests, wetlands and freshwater habitats require continuous active stewardship and appropriate land uses (e.g. extensive grazing) is required on all valuable 'man-made' habitats (e.g. grasslands, heathlands, etc.) for preserving their conservation value. As some NNH sites have been impacted and/or partially degraded or polluted by previous land uses, restoration or preservation measures are often needed to accelerate their transformation into more valuable habitats or to conserve them.

$\mathrm{NNH}$ owners have to develop a vision for every site (Best Practice 2.2.1), undertake annual reporting and develop management plans for large NNH sites in consultation with the Ministry of the Environment and the Federal Agency for Nature Conservation (Best Practice 2.5.4 and Principle 3.5). Monitoring is included in the management plans in order to evaluate the success of all management measures and allow for adjustments of site management when needed (Best Practice 2.2.2 and Principle 2.4). A 'modular' monitoring methodology is currently in development that allows $\mathrm{NNH}$ owners to choose between basic and more detailed monitoring protocols for different man-made and natural habitats and species groups. At many NNH sites (in particular those owned by conservation NGOs), volunteers are involved in this site monitoring (Best Practice 2.5.3).

\section{Summary}

- A window of opportunity has been used to transfer federally-owned land free of charge to the federal states (Länder), conservation NGOs and foundations resulting in areas being effectively conserved across Germany of which some can be considered as PPAs (Best Practice 1.2.1).

- Transferred land is conserved in perpetuity, in contracts as well as easements (for conservation NGOs and foundations) (Best Practice 4.1.1).

- Detailed and binding directions are given by the government to the new owners with regard to nature conservation management (Best Practices 2.1.1).

- The government maintains a strong role in the governance of the sites since there are annual reporting duties by the owners of the NNH sites (Best Practices 2.4.1).

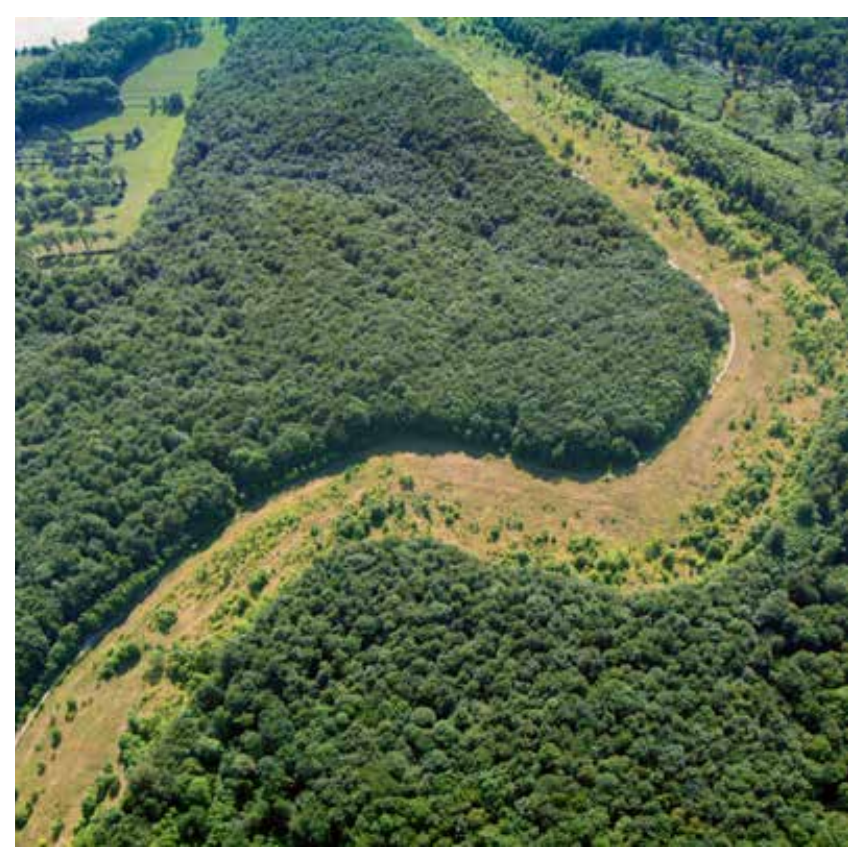

About 6,000 ha of the National Natural Heritage belong to the Green Belt along the former German-German border (C) Klaus Leidorf 


\section{Case Study 6 A successful wildlife conservancy management model: Lewa Wildlife Conservancy, Kenya}

\section{Tuqa Jirmo, Lewa Wildlife Conservancy}

What started out as a 2,000-ha rhino sanctuary in 1984 has grown to become a leading model for wildlife protection and a catalyst for conservation and community development in East Africa. The Lewa Wildlife Conservancy works as a model for the conservation of wildlife and its habitat. It does this through the protection and management of species, the initiation and support of community conservation and development programmes, and the education of neighbours in the value of wildlife. Lewa Conservancy is an exemplar for many of the guidelines in Part B, Section 2 and specifically of a PPA which has met the standards of the IUCN Green List of Protected and Conserved Areas (Box 1.1).

\section{Overview}

The Craig family first came to Lewa Downs in the 1920s and managed the land as a cattle ranch for more than 50 years. In the early 1980s, a woman named Anna Merz approached the family with a request: horrified by the population decline of black rhino (Diceros bicornis) throughout Africa, Anna wanted to establish a black rhino sanctuary to protect the last remaining members of this endangered species. This eventually led to the Craig family devoting their entire 16,000 ha ranch to the formation of the Lewa Wildlife Conservancy, which would later be augmented by over 3,000 ha owned by other farmers and over 5,500 ha of national forest.

Today the Conservancy holds more than 12 per cent of the global wild population of the endangered Grevy's zebra (Equus grevyi), over 12 per cent of Kenya's critically endangered black rhino and over 14 per cent of Kenya's white rhino (Ceratotherium simum), an abundance of 70 other large-bodied mammal species native to East Africa and over 440 bird species. In 2013, Lewa received global recognition, being listed as part of the Mt Kenya World Heritage Site and was selected by IUCN as one of the pioneer 'Green List' sites, which recognises organisations which lead as examples in the management of protected areas (see Box 1.1). From its early days as a rhino sanctuary, Lewa has grown and developed its conservation practice. It is now not only protecting endangered species but also translocating animals to repopulate new conservation areas and government-owned national parks, as well as sharing its best practices in community owned conservancies and other private conservancies across Kenya. Lewa's boundaries have well established corridors to Mt. Kenya National Park and

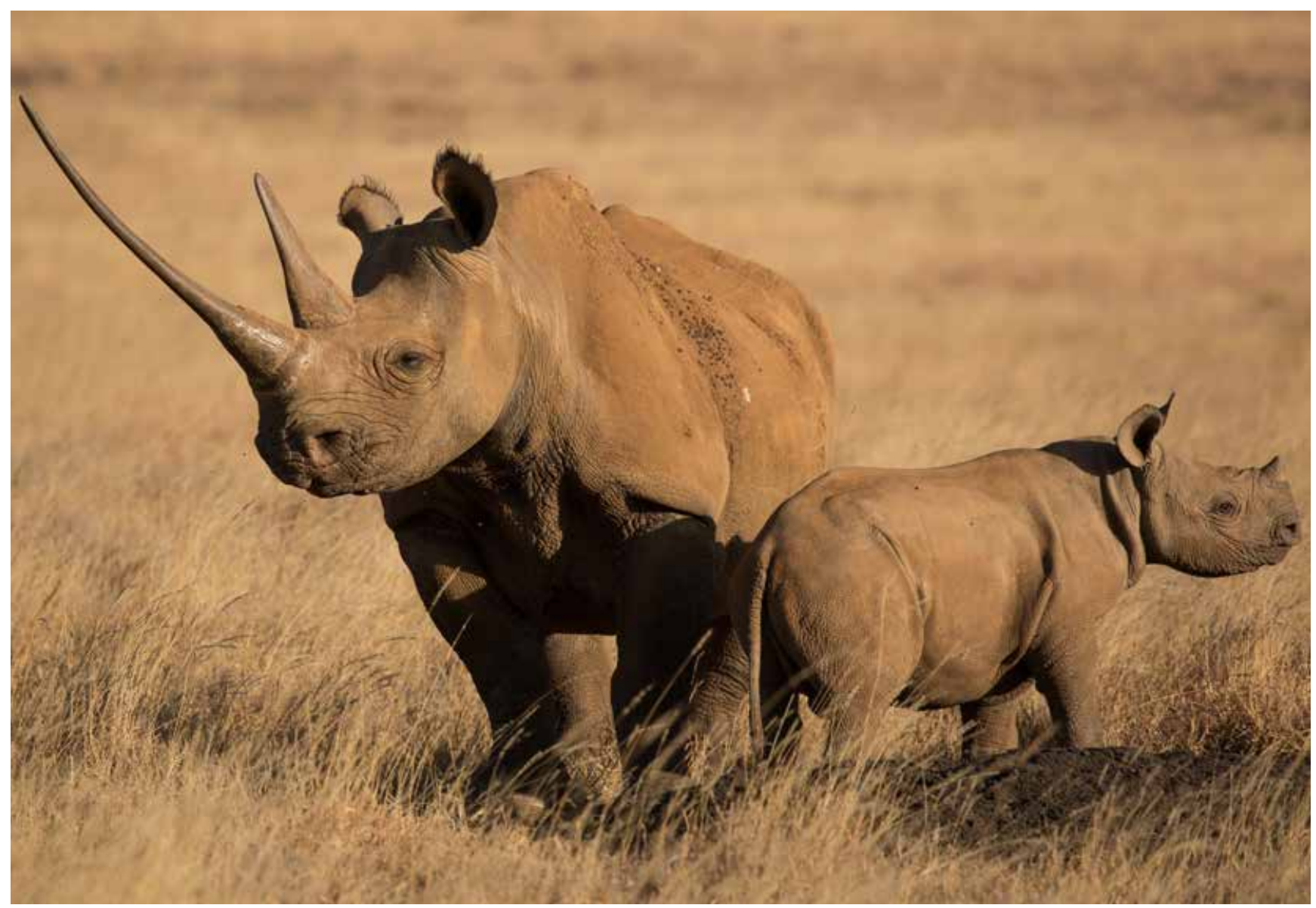

Black rhino (c) Lewa Wildlife Conservancy 
greater Northern Kenya rangelands, allowing connectivity for wildlife movement with surrounding landscapes. Lewa works with its neighbours to encourage collective management of ecosystems. A key example and first crucial step in demonstrating this is the agreement to remove boundary fences between Lewa and its western neighbour, Borana Conservancy (see Box 5.4), allowing free movement of wildlife over more than 37,000 ha.

Lewa supports community ecotourism and cultural tourism ventures and is a destination for those looking for best practice in sustainable tourism, endangeredspecies management and community-based tourism and conservation.

\section{Changing environment and conservation issues around Lewa}

The drastic decline of wildlife populations across Kenya has resulted in a call for the enhanced management of the Conservancy while working to secure the landscape for people and wildlife. This meant effective allocation of resources (Best Practice 2.3.1); promoting of accountability and transparency; embracing community participation in conservation (Best Practice 2.1.3); building partnerships with relevant constituents; and promoting protected area values (Best Practices 2.5.2 and 2.5.5).

Lewa's Community Development Programme has evolved to become a leading example of community-based conservation which generates direct and indirect benefits for local communities through healthcare, education, water and enterprise development, amongst others (Best Practice 2.3.2). Lewa currently supports 21 schools, manages four clinics, 13 community water supply schemes, sustains an adult education programme, a women's micro-credit scheme and agricultural extension programmes. Through this wide range of community development projects, Lewa is leveraging a conservation agenda to meet the needs of communities surrounding the Conservancy, thereby contributing directly towards improving livelihoods. Lewa recognises that its neighbours' engagement in conservation and sustainable use of natural resources is critical to its long-term viability as a core conservation area (Best Practice 2.1.3). Lewa's community work led to the establishment of the Northern Rangelands Trust, ${ }^{142}$ an umbrella body of 33 community conservancies whose mandate is to develop resilient communities, transform lives, secure peace and conserve natural resources in northern Kenya and beyond. Lewa also partners with the Kenya Wildlife Service (KWS), community forest associations, neighbouring ranches and like-minded conservation partners who are integral to Lewa's approach and success (Best Practice 2.5.2).

Lewa adopts a rigorous approach to research and monitoring, with well-qualified and experienced staff, covering applied research on topics such as rangelands, carnivores, ungulates, rhinos, elephants, insects and birds. It has a fully-fledged wildlife veterinary unit, led by a KWS Veterinary Officer on permanent attachment (Best Practice 2.5.5). Security and anti-poaching operations combine cutting-edge monitoring technology with the engagement of the surrounding communities. Lewa's security force protects not only the wildlife within the Conservancy but enhances security for both people and wildlife across the landscape. Members of the Anti-Poaching Team are also National Police Reservists, with a mandate from the Kenyan government to respond to and investigate cases of insecurity on the Conservancy as well as in the neighbouring communities (Best Practice 2.5.5). As the CEO of Lewa Wildlife Conservancy, Mike Watson, notes: "Over the years, conservation has remained the best way in which we can steward a present and a future that benefits both people and wildlife. Through conservation, the endangered species that we protect have a future and the people who depend on this landscape can attach direct value to wildlife."

\section{Summary}

- Lewa's Community Development Programme is designed to create a close collaborative relationship with local communities and decrease community pressure on natural resources (Best Practice 2.1.3).

- Lewa optimises its organisational management effectiveness through continued implementation of management plans, best practice and organisational strategic planning (Best Practice 2.2.3) based on the evolving conservation and community livelihood challenges, as well as diversifying income generating streams (Best Practice 2.3.1).

- Partnership with relevant arms of the national and county government, private and community conservancies, local and international conservation bodies, communities and academic institutions include joint wildlife census, security patrols, disease surveillance and diagnostic labs management among others. Lewa also jointly manages two government forests in partnership with the Kenya Forest Service and community forest associations (Best Practice 2.5.5). 


\section{Case Study 7 Private land conservation in New Zealand as a social movement}

\section{Mike Jebson, QEIl National Trust}

The Queen Elizabeth II National Trust (QEII) model has proven to be a winning formula for cooperative conservation of private land in New Zealand by building on and supporting the aspirations of private landowners to create a legacy. The model provides an excellent example of Principle 3.4 (Part B, Section 3) which notes that recognition and support are powerful incentives for PPAs. QEll's success is also underpinned by many of the aspects of best practice in regards to PPAs, including permanence (Best Practices 4.1.1 and 4.1.7), robust legal and institutional frameworks (Best Practice 1.1.1) and recognition of what private landholders are achieving.

\section{Overview}

Over the last 40 years, private land conservation has gone from an untested concept promoted by a few farming leaders concerned about the impact of the Government farm production subsidies of that time on New Zealand natural heritage, to a highly successful PPA movement. The movement has been embraced by many owners of farms and other rural lands despite very limited financial incentives being available to them.

The movement has been led by the Queen Elizabeth II National Trust (QEII). QEIl operates largely independently from Government under its own legislation (Queen Elizabeth the Second National Trust Act 1977), but with funding support from the New Zealand Government. As part of the funding agreement with Government, QEll focuses on securing covenants that satisfy national priorities for biodiversity protection on private land and/or add to protected corridors or landscapes. This has been a long-standing practice as part of New Zealand's biodiversity strategy (Best Practice 1.2.1). The Queen Elizabeth the Second National Trust Act 1977 has established a robust legal and institutional framework to support covenants as a part of New Zealand's protected areas system to complement public conservation land (Best Practice 1.1.1). However, covenants are not seen by landholders as a regulatory tool of government or environmental NGOs to drive landholder compliance. Instead they are seen as a partnership tool to support rural landholder aspirations for the future of the land they care about.

By supporting private landholders to protect their special areas, QEll has secured an average of two new covenants a week (averaging 40 ha in size) over the last forty years across all the main islands of New Zealand. Today this network of PPAs under the perpetual trusteeship of QEll stands at over 4,450 covenants (180,000 ha), and is expanding at a rate of around 110 new covenants (averaging 3,800 ha) each year with no sign of a slowdown. Once registered on the title of private land, QEIl covenants provide permanence by protecting areas as 'open space' for conservation purposes forever (Best Practice 4.1.1).

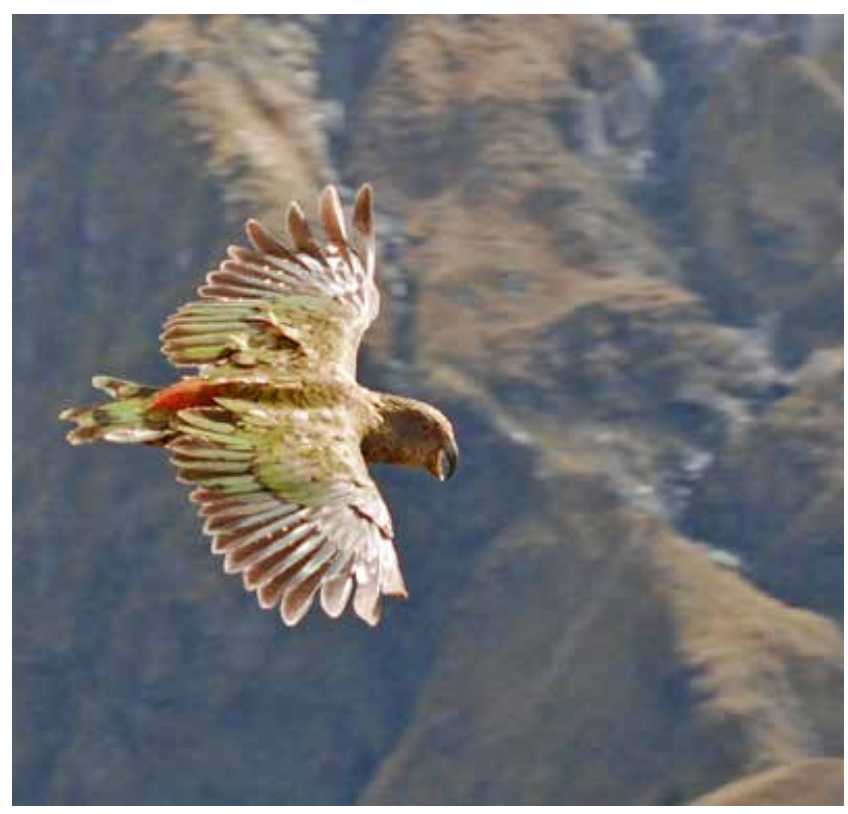

Kea (Nestor notabilis), a native alpine parrot, in flight over Mahu Whenua, QEll's biggest covenant $(53,000$ ha) in Central Otago (c) Bill Wallace, National Trust

QEll covenants provide robust legal protection from: Government/Ministerial interference; mining; quarrying; oil and gas development; commercial forestry; housing development; or any other non-sympathetic commercial use or development. Covenants over farmland are also retired from farm use except for a small number where light stock grazing remains consistent with natural heritage and landscape protection objectives. While rare, and only used as a last option, enforcement action of covenant conditions in Court has proven the legal robustness of the covenant agreement. This enforcement action has been welcomed by other covenant owners as it has given them confidence in the protection provided.

All registered covenants are regularly monitored (approximately every two years) with the cost of monitoring borne by QEII. Monitoring visits are used primarily to support landholders with stewardship advice to aid management, and to inspire new landholders who have acquired covenanted land (Best Practice 8.2.1).

Covenanting landholders all become life members of the QEII National Trust, are invited to covenant events in their region, receive signage to recognise their protected area, are recognised in the QEII magazine 'Open Space' and receive advice on stewardship of their covenant as part of monitoring (Best Practice 8.2.1). Having established a good working relationship with QEIl regional staff and being proud of what they have achieved, these covenant owners will often encourage their neighbours to also protect adjacent natural areas resulting in clusters of covenants to protect remaining natural features and habitats in the wider landscape. 


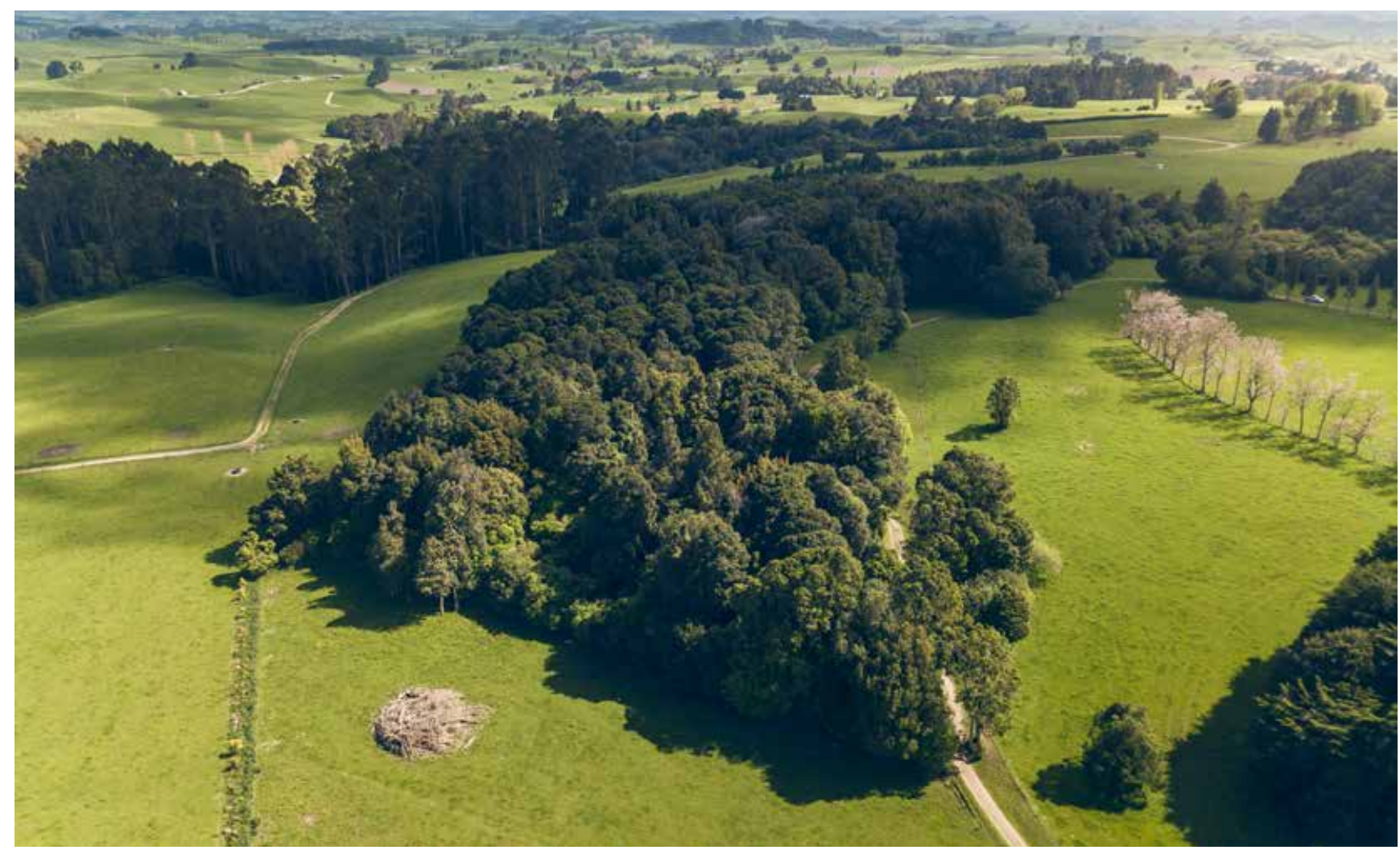

The Stephenson Block in the Waikato, QEll's first legally protected block of bush on the farm of Gordon and Celia Stephenson, leaders in the establishment of QEII and private land conservation in NZ @ QEIl National Trust.

\section{Social responsibility for conservation}

QEll's model embraces most of the best practice elements of PPAs, but is unusual internationally due to the absence of significant financial incentives (like tax breaks or subsidies) to drive its success. The QEII model also requires landholders to contribute to some of the costs of securing legal protection over their land. Landholders continue to be liable for most ongoing costs of land stewardship and management (except for regular biennial monitoring costs which are borne by QEII). Most covenanting landowners in New Zealand have protected special areas of their land because they believe "it is the right thing to do" and are justifiably proud and are recognised for the legacy they have created through their QEll covenants (Best Practice 3.4.1). It is this sense of pride and legacy that the QEIl model is built on rather than financial incentives.

Amongst leading farmers in New Zealand, covenanting is considered a socially responsible thing to do to help protect their native forest areas, natural wetlands and other important natural heritage as part of good farm practice and planning. To date, around 20 per cent of all sheep and beef farms in New Zealand have a QEIl covenant protecting natural areas on their farm and this is increasing all the time. Some environmentally conscious individuals have also purchased land rich in natural heritage with the intention of managing and protecting it for conservation purposes. These landholders then work with QEll to secure their land and investment with covenants to provide permanent protection.

\section{Summary}

- Forward-thinking farming leaders were the driving force behind the establishment of QEIl. These rural roots have given many landowners the confidence to work in partnership with QEII in situations where they may not have been prepared to work with central or local government representatives (Best Practices 8.5.6 and 4.1.5). This model has also had enduring bipartisan support from all governments since its inception forty years ago.

- All covenants have an agreed purpose and objective, and a set of terms and conditions that can be adapted to fit each landholders'sunique situation (Best Practice 1.2.1).

- Covenants provide robust and enduring legal protection (Best Practices 4.1.1 and 4.1.7).

- The QEII regional representatives that work with rural landholders are practical conservationists who live in their local communities (Best Practice 8.2.1).

- Some of QEll's best champions for covenant protection are existing owners of covenants (Best Practice 8.1.2). 


\section{Case Study 8 Private conservation networks in Peru}

\author{
Christel Scheske and Bruno Monteferri, Sociedad \\ Peruana de Derecho Ambiental
}

PPAs in Peru receive relatively little support from the government and there is currently no national-level organisation or association for all PPAs in the country. As a result, in several regions across Peru, networks have been formed, usually with the help of an NGO such as the Sociedad Peruana de Derecho Ambiental (SPDA) or Amazónicos por la Amazonía (AMPA) that bring together the PPAs into a network. Despite the lack of an official national PPA network, NGO-led initiatives link PPAs at the national level. Over the past decade, many insights have been gathered regarding the strengths, weaknesses and challenges of these PPA networks which are discussed here and reflected in the principles and best practices in Part $B$, Section 8.

\section{Overview}

The framework for PPAs was established in Peru between the late 1990s and early 2000s. It allows for a series of legal mechanisms, through which citizens can make officiallyrecognised conservation commitments for a piece of land, including: private conservation areas, which are established on privately or community-owned land, conservation or ecotourism concessions on public land and conservation agreements.

There are currently five PPA networks in Peru (see Table 5). Private conservation initiatives are possible through several different legal tools and in many cases the networks incorporate examples of several or all of these. As a result, member needs can differ vastly: in Amazonas, for instance, some PPAs are owned by urban entrepreneurs who know how to effectively finance conservation through ecotourism, while others are huge areas managed by rural communities whose livelihoods depend on agriculture and livestock, who conserve forests to maintain their water supplies. While in the former case, the PPA manager(s) tend to be the same person over many years, in the case of communities, PPA managers depend on democratically-elected councils that change every few years, thus leading to a lack of management continuity both internally and towards the network. These two groups have different world views, priorities and needs. However, the heterogeneity of members in PPA networks also lends a diversity and representativeness to the network that allows for dialogue and learning between very different conservation stakeholders.

Networks have improved PPA effectiveness in a number of ways. For example, the Amazonas network received two small grants in 2017 and 2018, which for the first time provided them with autonomous funds to implement activities that they had prioritised, such as training in ecotourism service provision. The Amazonas network is also creating tourist circuits including several member PPAs, which are then

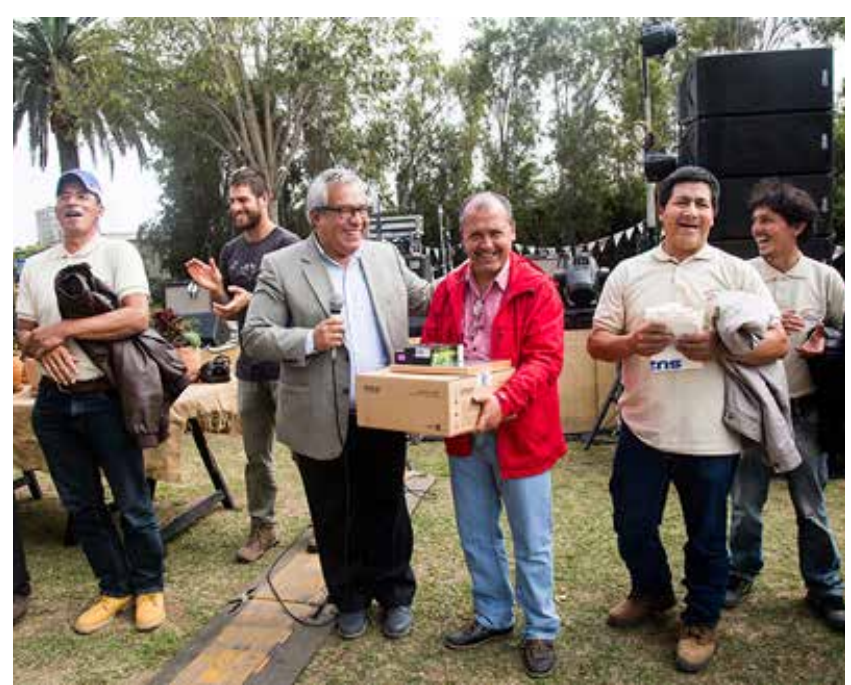

Pedro Gamboa, head of the Peruvian National Protected Area Service, thanks members of RED AMA, the Amazonas PPA network, for their work in private conservation (C) Conservamos por Naturaleza / SPDA

jointly promoted. In San Martín, a sub-group of the network members have created a cooperative to allow for sales of non-timber forest products from their PPAs. In several cases (e.g. private conservation areas Milpuj La Heredad and Bosque Berlin in Amazonas), the combination of public visibility and participation in a PPA network motivated the managers to re-engage with conservation with renewed vigour, create new projects, act as local leaders and expand their efforts.

\section{Challenges}

Although there is a myriad of best-practice guides for conservation (as noted in Part B, Section 2), very few managers of PPAs in Peru make use of them; language barriers and the research/implementation gap are wellknown problems in conservation science (Knight et al., 2008). PPA networks allow for knowledge-sharing between PPAs (Best Practice 2.5.2) and also make it easier for NGOs and other actors to provide capacity-building by targeting the entire group of members (Best Practice 8.2.1). For instance, SPDA has provided the Amazonas network with a series of workshops on legal tools for combating threats to their respective PPAs and AMPA trained members of the San Martín network in project design and management. In Amazonas, SPDA hired a coordinator that worked directly for the regional network. In Loreto, SPDA and AMPA have provided support such as financing for regular meetings and office space to support the regional network. Similarly, although Peruvian PPA networks struggle for funds and have limited access to national or international grants and scholarship programmes, the San Martín, Amazonas and Madre de Dios networks have been able to secure funds for small projects, thanks to the larger NGOs supporting project design and grant-writing.

Overall, despite the many challenges, networks have proven their ability to provide important spaces for dialogue and 
Table 5: Snapshot of PPA networks in Peru (as of June 2018)

\begin{tabular}{|c|c|c|c|c|c|}
\hline & Amazonas & Madre de Dios & San Martín & Loreto & Ucayali \\
\hline Network name & $\begin{array}{l}\text { Red de Conservación } \\
\text { Voluntaria de Amazonas (RED } \\
\text { AMA) }\end{array}$ & $\begin{array}{l}\text { Red de } \\
\text { Conservación de } \\
\text { la Biodiversidad } \\
\text { de Madre de Dios }\end{array}$ & $\begin{array}{l}\text { Red de } \\
\text { Conservación } \\
\text { Voluntaria y } \\
\text { Comunal de } \\
\text { San Martín }\end{array}$ & $\begin{array}{l}\text { Red Amazónica } \\
\text { de Conservación } \\
\text { Loreto (RACOL) }\end{array}$ & $\begin{array}{l}\text { Asociación de } \\
\text { Concesionarios } \\
\text { Conservacionistas } \\
\text { de la Biodiversidad } \\
\text { BioRed Ucayali }\end{array}$ \\
\hline $\begin{array}{l}\text { Number of PPA } \\
\text { members }\end{array}$ & 14 & 16 & 34 & 23 & 13 \\
\hline $\begin{array}{l}\text { Total number of ha } \\
\text { protected }\end{array}$ & $125,316.96$ & 6,543 & 700,000 & $5,431.7$ & $110,125.73$ \\
\hline $\begin{array}{l}\text { Types of PPA } \\
\text { represented }\end{array}$ & Private conservation areas & $\begin{array}{l}\text { Private } \\
\text { conservation } \\
\text { areas, ecotourism } \\
\text { concessions, } \\
\text { conservation } \\
\text { concessions }\end{array}$ & $\begin{array}{l}\text { Private } \\
\text { conservation } \\
\text { areas and } \\
\text { conservation } \\
\text { concessions }\end{array}$ & $\begin{array}{l}\text { Private } \\
\text { conservation areas } \\
\text { and conservation } \\
\text { concessions }\end{array}$ & $\begin{array}{l}\text { Conservation } \\
\text { concessions, } \\
\text { ecotourism } \\
\text { concessions }\end{array}$ \\
\hline Currently active & Yes & No & Yes & Yes & Yes \\
\hline Formally constituted & Yes & No & No & Yes & Yes \\
\hline Has own budget & Yes & No & No & No & No \\
\hline $\begin{array}{l}\text { Website/Online } \\
\text { presence }\end{array}$ & Social networks & None & Social networks & Social networks & Social networks \\
\hline
\end{tabular}

collaboration, while acting as local advocates for conservation towards regional authorities and other interest groups. For example, PPA members often complain about the slowness or lack of action of authorities in response to environmental crimes, such as illegal logging, that affect the PPAs.

Experiences in San Martín, Amazonas and Loreto have shown that authorities react faster when they are pressured to act by PPA networks. Strengthening these networks and helping ensure their long-term independence and sustainability should be a priority for both government and NGOs working in conservation.

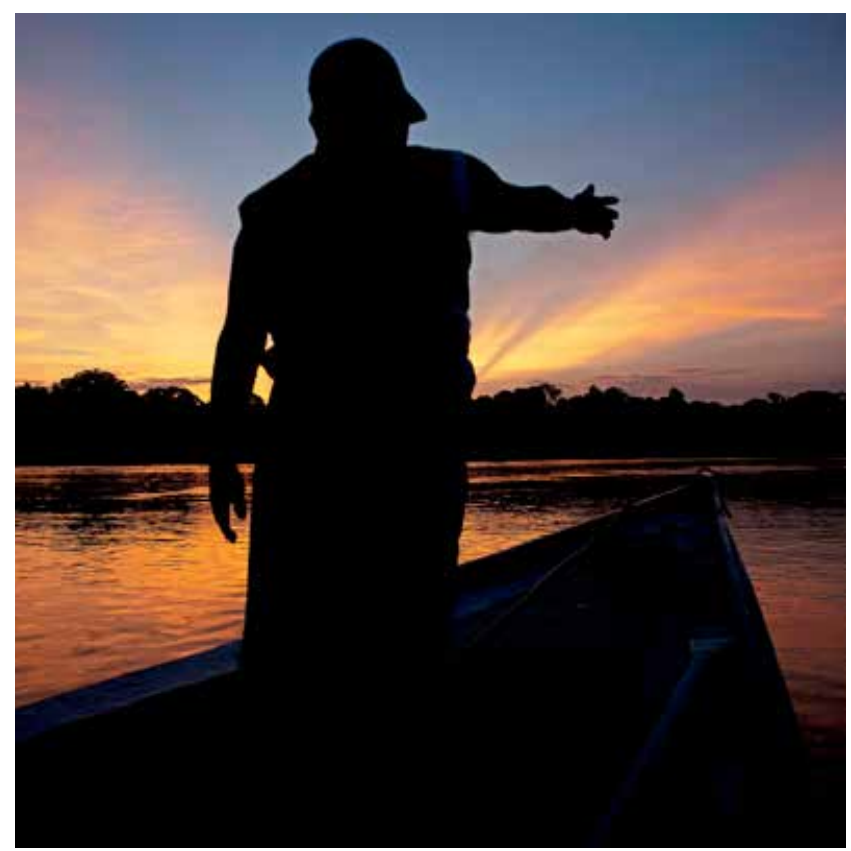

Owner of PPA Bahuaja which is located adjacent to the Reserva Nacional Tambopata and the river Tambopata, generating a landscape corridor for Amazonian biodiversity @ Conservamos por Naturaleza / SPDA

\section{Summary}

- Networks can act as a powerful motivator for PPA managers by making them feel recognised and providing a sense of belonging to a community of like-minded people (Best Practice 8.1.2).

- PPA networks provide platforms for pro-environmental political action. In Peru, many regional environmental authorities are plagued by corruption, inefficiency and lack of resources, and as a result, environmental crimes are committed openly and with impunity (Best Practice 8.1.1).

- PPA networks allow for important knowledge-sharing platforms (Best Practice 8.2.1).

- Networks provide opportunities for joint projects and funding if the networks become formally constituted as non-profits or similar organisations (Best Practice 8.2.1).

- Networks provide platforms for joint business approaches (Best Practice 8.4.1).

- The involvement of larger NGOs is often an important element for the functioning of the networks (Best Practice 2.5.4).

Special thanks to: José Vargas, Martín Vasquez, Fernando Arévalo and Karina Pinasco for contributions to this case study. 


\section{Case Study 9 Malololelei Recreation Reserve: a successful collaboration in Samoa}

Moeumu Uili, Ministry of Natural Resources and Environment

In 2010, an area of 12 ha was bought by Bluebird Lumber and Hardware Ltd (BBL) from the Catholic Church through the Church's Land Board. The forest condition at the time of purchase was very poor. According to the landowner, more than half of the forest had been destroyed, having been logged and replaced with rubber trees and African tulip tree (Spathodea campanulata). The owner of the BBL Company, Mr Tuiaopo Faamausili Andrew Ah Liki, began planting native trees and fruit tree plots. All adjacent lands are owned by the Catholic Church with a few isolated private residential areas nearby. The landowner has taken every opportunity to collaborate with other actors, including by aligning management efforts with the owners of adjacent lands, ensuring the best outcomes for biodiversity (Best Practices 2.5.2 and 2.5.4).

\section{Overview}

Malololelei is a small upland community about $7 \mathrm{~km}$ from Apia, the capital of Samoa. It is located in one of the newlydeveloped areas of the central Upolu Island where a growing number of new residents are buying land in the cooler areas of the island. The land is fairly flat at its highest altitude (approx. $600 \mathrm{~m}$ ), dropping down to valleys bordering the reserve on both the east and west, and two streams running to the coast.

The area supports native birds, including some endangered species. The site also harbours native forest patches remaining in some parts of the reserve that are sheltered from strong winds during the cyclone season, which would otherwise devastate the native forest in the uplands of the island. The landowner's motivations are: "to increase the resilience of the Malololelei Reserve by sustainable management of the site [and] to ensure support for our native wildlife and biodiversity by working collaboratively with our partners. We are supportive of Samoa's efforts to increase our lands protected for the preservation of our rare and endemic species and ecosystems".

\section{Challenges}

At the time of purchase, the degraded land had many open areas and agricultural fields. Invasive plant species were prevalent, as were invasive alien species such as rats. Two highly threatened and endemic birds are present in the reserve, the ma'o or giant forest honeyeater (Gymnomyza samoensis) and the manumea or tooth-billed pigeon (Didunculus strigirostris), and ongoing surveys had identified that the species are at risk of nest predation by rats.

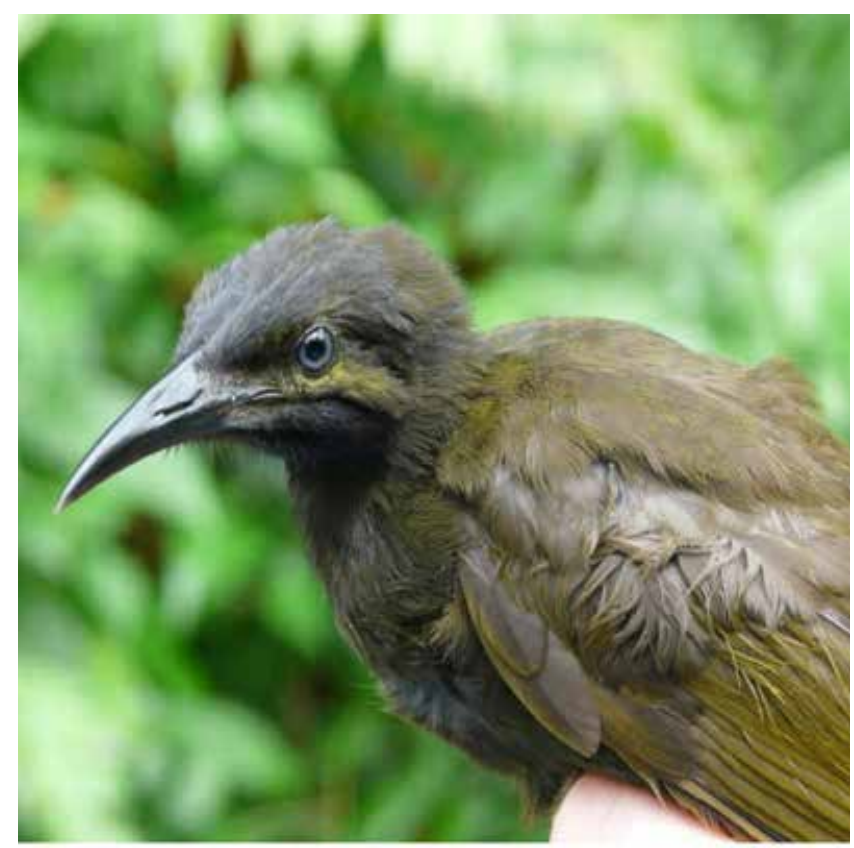

A male ma'o (Gymnomyza samoensis) caught and released during research study at Magiagi village in 2008 ( ) Rebecca Stirnnemann

\section{Finding solutions through partnerships}

The success of Malololelei Recreation Reserve has been based on collaboration with a variety of other groups. Prior to the reserve's establishment, the current landowner Faamausili had been involved in the Central Savaii Uplands Biodiversity Rapid Assessment (BIORAP) survey in 2012, due to his close family association with the lands being assessed. This process was effective in engaging landowners, triggering their interest in sustaining biodiversity and the role they could play in ensuring that the resulting knowledge and benefits were shared amongst the local community. The success stories of the BIORAP in 2012 contributed to the decision by BBL to set aside its privately-owned 12 ha of land at Malololelei, conserved for wildlife and biodiversity in general.

In 2015, the Malololelei Reserve was first established as part of the Biodiversity Day commemoration as a National Reserve in partnership between the Ministry of Natural Resources and Environment (MNRE) and BBL. The recognition was in acknowledgement that Malololelei Reserve is home to the ma'o and the manumea. Since the establishment of the site, MNRE has worked side by side with BBL under a Memorandum of Understanding signed by both parties in 2015. Biodiversity assessments were conducted in 2016 to gather baseline information about the site, and the results indicated the presence of the ma'o and the manumea, which are now listed in the IUCN Red List of Threatened Species. Major concerns over the critical population status of these species and the presence of rats inspired a number of interested partners to collaborate on a solution. Through 


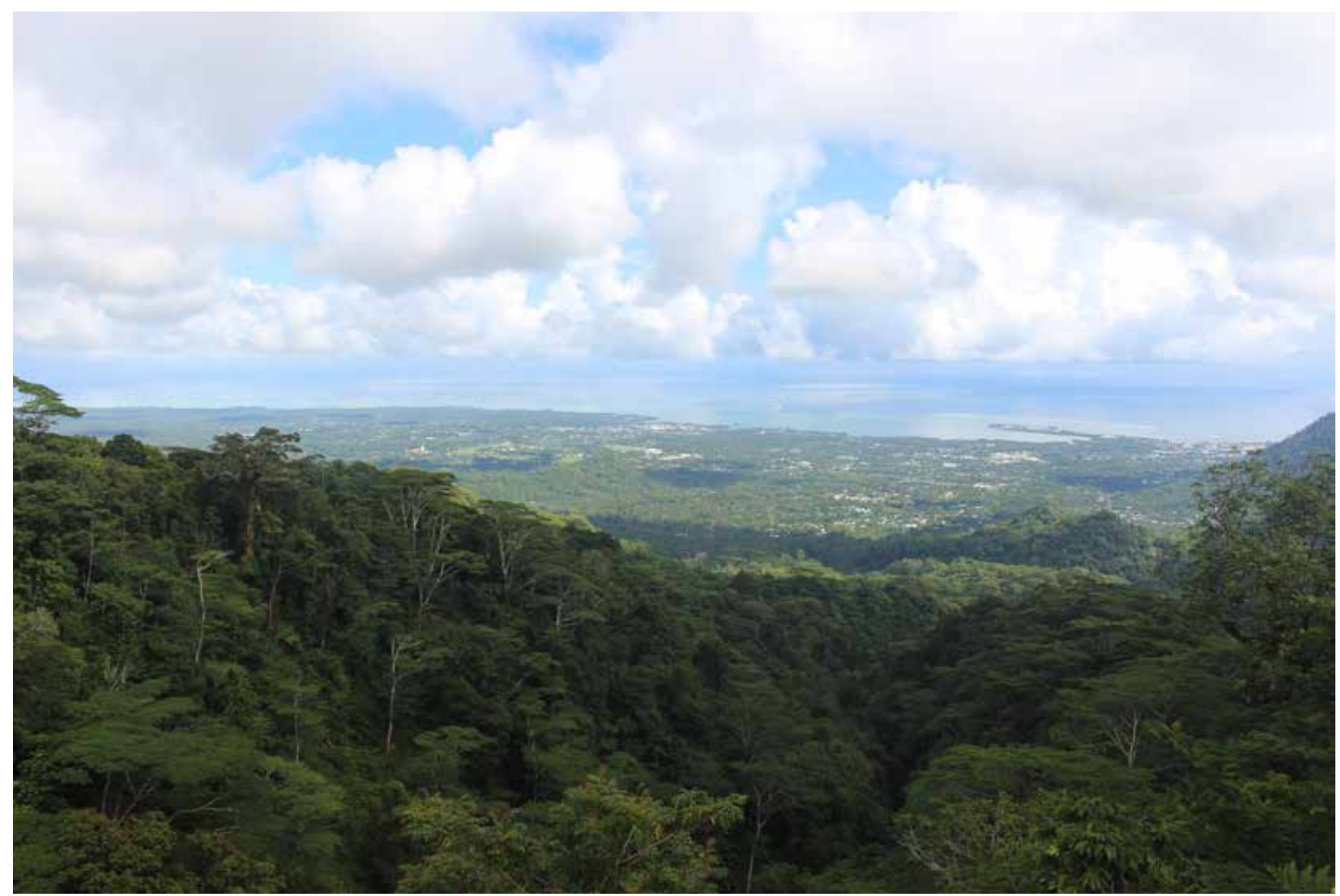

View north-west of Apia from the platform at Malololelei Recreation Reserve ๑ Moeumu Uili

this partnership, a project was developed to control invasive pests in the area and further protect wildlife including the bird species.

In September 2017, the Malololelei Pest Management Project commenced with funding support from Auckland Zoo and the Government of New Zealand Public Development Conservation Trust fund, with technical assistance from PelGar International, Samoa Conservation Society and BBL. MNRE is currently leading and managing the implementation of this project, which will continue for the next two years dependent on the availability of funds.

$\mathrm{BBL}$ is keen to continue to work closely with a number of relevant partners and stakeholders. This includes the Catholic Church Land Board (Principle 5.5), Ministry of Natural Resources and Environment, NGOs such as the Samoa Conservation Society, regional organisations and donor agencies to support and improve the management of the reserve.

The Chief Executive Officer of the MNRE has echoed this sentiment, saying: "The Government of Samoa through the Ministry of Natural Resources and Environment (MNRE) appreciates the tremendous support and efforts of our key partners to conserve and protect our native biodiversity through partnership with the government. It is our mission to ensure [we] engage all our key stakeholders to effectively participate in the sustainable management of our critical landscape and the preservation of our land-based and marine resources, which therefore through this partnership with the $B B L$, we applaud the contribution of our private land owners such as BBL in achieving this milestone for Samoa."

\section{Summary}

- Engage and appreciate community support in the sustainable development of protected areas (Best Practice 2.1.4).

- Include all different groups in a society, ensuring there is a gender balance when promoting biodiversity conservation issues: diverse voices lead to more resilient and effective decisions (Best Practice 2.5.4).

- Do not wait for funding to act; if possible, do something first and receive money to support where relevant (Best Practice 3.7.1).

- Start small and build bigger: protected areas can be a series of many smaller sites that together form a greater well-managed network (Best Practices 8.2.1 and 8.5.3).

- Provide opportunities to local communities and landholders to lead in conservation action (Principle 1.3), government, donor agencies and experts can then provide support and advice to sustain the efforts. 


\section{Case Study 10 Establishing PPAs: Lessons learnt from South Africa}

\section{Candice Stevens, BirdLife South Africa}

South Africa is recognised as one of the world's 17 megadiverse countries, is home to approximately 60 million people, and faces a number of development needs and opportunities. Its diverse ecosystems underpin the health and well-being of its people and its economy. The South African Government's National Development Plan 2030 recognises the "need to protect the natural environment in all respects" (Government of South Africa, 2015a) and identified protected area expansion as a key tool to achieving this in the National Biodiversity Strategy and Action Plan (Government of South Africa, 2015b). South Africa's National Protected Area Expansion Strategy (Government of South Africa, 2010) notes that meeting national policy objectives, and international targets such as Aichi Biodiversity Target 11, requires the expansion of protected areas on state, private and communally owned land. The following case study examines how South African PPAs are established in light of the key principles listed in Part B: Section 3 of these Guidelines and takes a brief look at how both management best practice and innovative incentives are incorporated into this process.

\section{Overview}

South Africa provides for the formal declaration of protected areas through national legislation on state or privately-owned land, with the consent of the landholder, with no differentiation in the legal status, rights or responsibilities of the land on the basis of ownership. South Africa's protected areas on privately-owned land are first and foremost, protected areas, and are a clear example of credible and official recognition of a PPA (Best Practice 1.1.1). Currently, 35 per cent of the terrestrial protected area estate in South Africa is privately owned and 5 per cent communally owned (see Figure 2).

South Africa defines a protected area as a geographically defined area of land or sea that is formally protected in terms of the Protected Areas Act and managed mainly for biodiversity conservation (SANBI, 2016). Detailed spatial planning is used in South Africa to determine protected area expansion strategies at both national and local levels (Best Practice 1.2.1). South Africa's extensive policy and

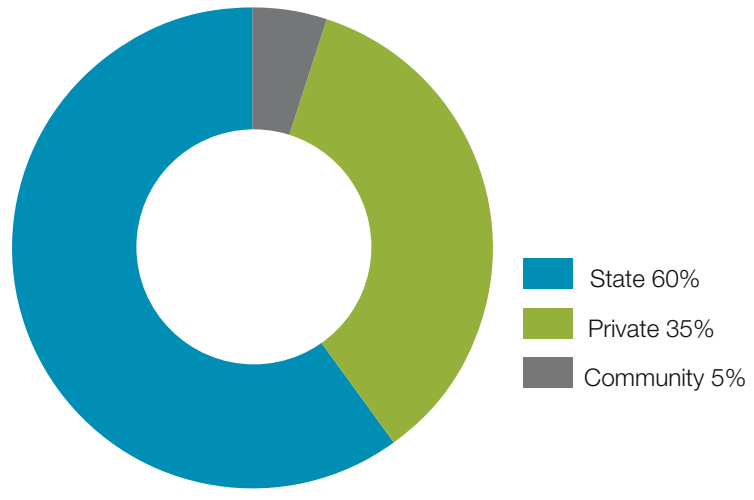

Figure 2: Ownership of protected areas in South Africa (\%)

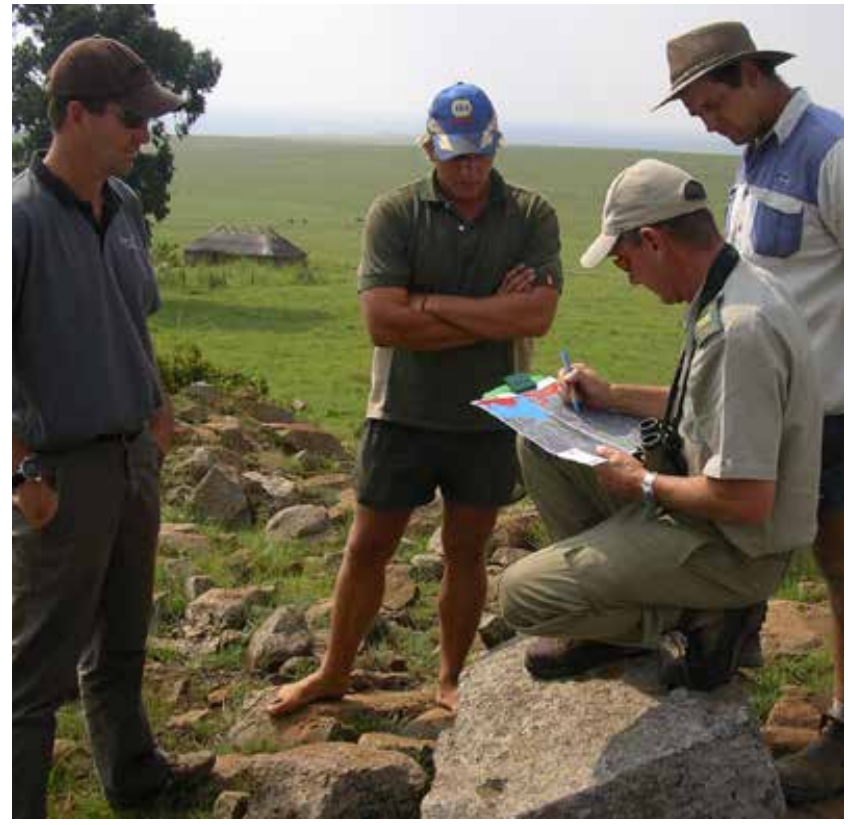

Landowners in the Sneeuwberg Protected Environment PPA constitute the management authority and formulate and implement the management plan (C) BirdLife South Africa

legislative frameworks illustrate the distinction between protected areas and conservation areas. Protected areas have nature conservation as their primary objective, whereas conservation areas as defined in South Africa do not (SANBI, 2016). Protected areas and conservation areas in South Africa are recognised and reported separately and provide a concrete example of the difference between a PPA and other effective conservation measures (see Appendix 1 and Mitchell et al., 2018).

\section{Expanding protected areas though private and communal land stewardship}

South Africa's primary tool for protected area expansion on private and communal land is the National Biodiversity Stewardship Initiative. Biodiversity stewardship is an approach to securing land in biodiversity priority areas through entering into agreements with private and communal landholders, led by conservation authorities and supported by conservation NGOs (SANBI, 2015). Biodiversity stewardship agreements provide for a hierarchy of agreements from formally declared protected areas as defined above, with durations from 30 to 99 years or in perpetuity, to non-binding agreements (see Figure 3 and Best Practice 3.1.2). This hierarchy demonstrates a variety of legal mechanisms that may be used to establish a PPA. Notably, increasing levels of legal protection and permanence correspond with increasing levels of land-use management restrictions and increasing landholder benefits and incentives, such as biodiversity tax incentives (see Box 3.2).

Biodiversity stewardship utilises three primary types of PPA to declare formally-recognised protected areas on privately or communally owned land at the voluntary election of the 


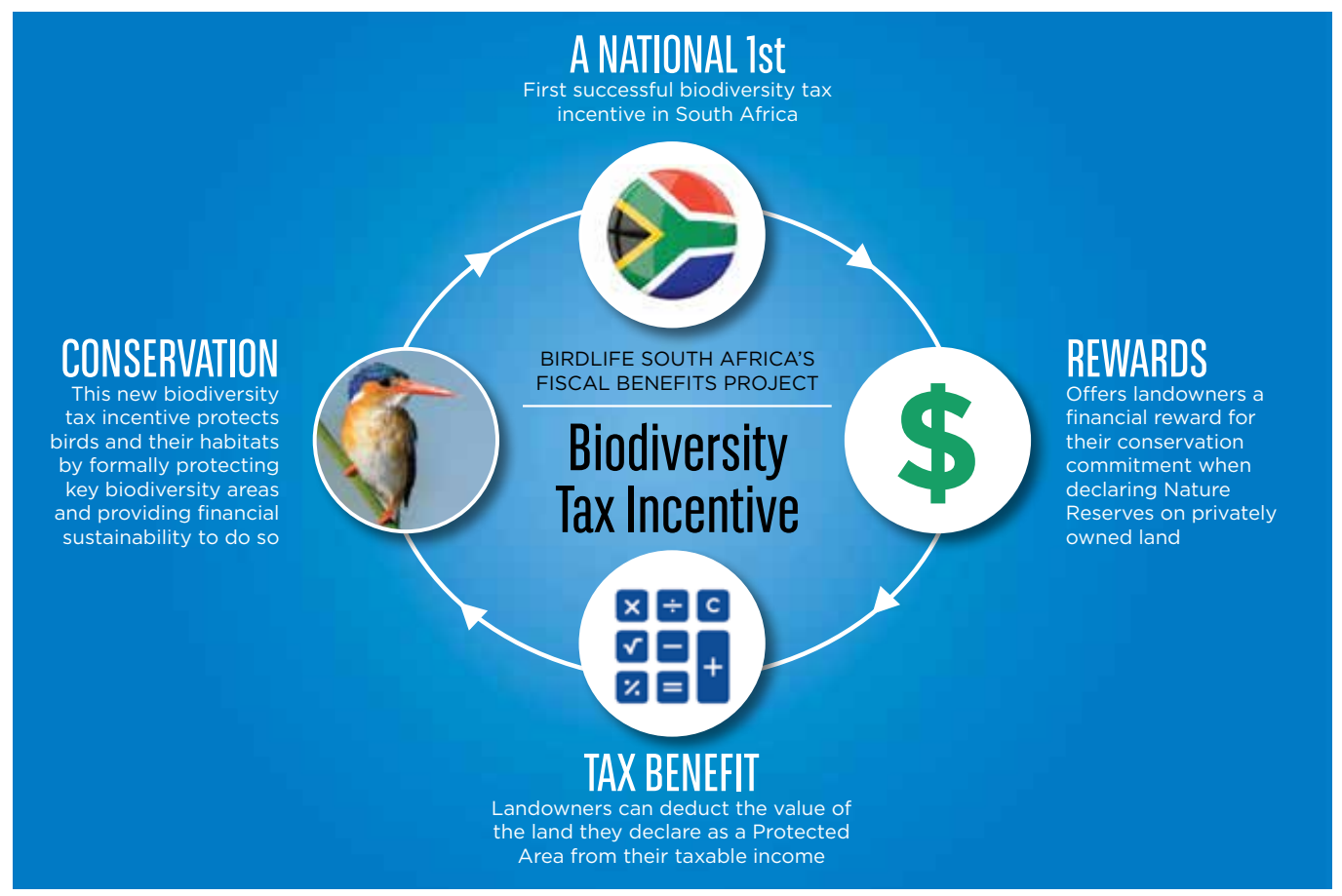

Figure 3: Hierarchy of biodiversity stewardship agreements. Biodiversity stewardship represents South Africa's detailed institutional structure and practical implementation framework that allows for the establishment of PPAs

landholder: National Parks (known as Contract National Parks), Nature Reserves and Protected Environments. Each of these types of PPA also require detailed management plans and annual management audits under the legislation (Best Practice 2.1.1).

Contract National Parks and Nature Reserves are geographic areas with the highest biodiversity value and ecological infrastructure and are formally declared primarily for biodiversity conservation (Best Practice 1.2.1). National Parks fall within the mandate of South African National Parks (SANParks), the body responsible for managing South Africa's national parks per the Protected Areas Act, and which engage in the declaration of this form of protected area on private or communal land in concurrent processes similar to those defined by the biodiversity stewardship approach. Best Practice in South Africa determines that the declaration term of these agreements requires a minimum of 99 years, or in perpetuity. The agreements involve more stringent management regulations, including prohibiting unsustainable land use such as extractive activities. This top category of PPA in South Africa also gains access to a dedicated biodiversity tax incentive through the Income Tax Act (see Box 3.2). Nature Reserves also require a mandatory title deed endorsement through property law, securing the land's protected area status regardless of subsequent changes to land ownership.

Protected Environments are protected areas that can be declared across multiple private properties. This form of PPA targets somewhat larger areas with biodiversity value and landscape level ecological functioning, and due to its slightly flexible nature has reduced management restrictions, allowing for biodiversity conservation to take place in production landscapes. Best practice dictates that Protected
Environments are declared for a minimum of 30 years up to 99 years, or in perpetuity. Management is developed for the area in conjunction with stakeholders and is implemented by landowners with support from conservation authorities and conservation NGOs (see Box 2.2).

\section{Summary}

The biodiversity stewardship community of practice, along with South Africa's legislative and policy frameworks, are the foundational and institutional structures that support the establishment of PPAs and have been key to the success of establishing robust PPAs in South Africa. The most notable lessons learnt from the South African biodiversity stewardship approach include the following:

- Protected areas whether on state, private or communal land in South Africa are all formally recognised by national legislation as protected areas and are reported on as such (Best Practices 1.1.1 and 7.1.2).

- PPAs in South Africa are established with their primary objective as nature conservation through voluntary and long-term commitments by landholders (Best Practices 1.2.1, 3.1.1 and 3.2.1)

- Biodiversity stewardship represents South Africa's most successful approach to PPA establishment, whereby PPAs are facilitated by an institutional framework and community of practice (Best Practices 3.4.1 and 3.7.4).

- PPAs require detailed management plans which are required to be audited annually (Best Practices 2.1.1 and 2.4.2).

- South Africa's PPAs receive access to innovative conservation finance through South Africa's first effective biodiversity tax incentive which directly aids financial sustainability (Best Practice 3.1.1, 3.1.2 and 3.2.1). 


\section{Case Study 11 Essex County Greenbelt: A ‘typical' American land trust}

Brent A. Mitchell, Chair, IUCN-WCPA Specialist Group on Privately Protected Areas and Nature Stewardship and Ed Becker, Essex County Greenbelt Association

PPAs in the United States are often established, monitored and sometimes managed by specialised organisations called land trusts. Permanence is secured through legal means embedded in the land tenure system (Best Practice 4.1.1), and incentives are largely derived from the voluntary surrender of development rights, and reduction of real estate, income and other taxes associated with the value of those rights (Best Practice 3.7.4).

\section{A 'typical' American land trust}

The Essex County Greenbelt Association ('Greenbelt') takes its name from a jurisdiction north and east of the city of Boston, in Massachusetts, and an initial effort to protect remaining forests and fields from an expanding metropolitan area. Since 1961, this private land trust has protected over 7,000 ha throughout its region. How those areas came to be protected is indicative of the way Greenbelt works, and is similar to other land trusts across the United States.

In approximately 1,600 ha, Greenbelt assisted in the conservation of private land, to be owned and managed by other NGOs, municipal governments or state conservation agencies. But for the remaining nearly 5,500 ha, the organisation retains a legal interest in the land, in two very different ways. Just less than half the land is in freehold 'private' reserves, numbering 362 in all. This means they are wholly owned by the NGO, a 'private' organisation with public purpose ('private' in quotes because Greenbelt maintains public access to all of them). Most of these properties would meet the IUCN definition of a PPA as they have a primary conservation objective, alongside recreation, education, etc. The expectation is that Greenbelt will own, protect and manage these areas in perpetuity. An example is the Allyn Cox Reservation which was donated to Greenbelt in 1974 and serves as the NGO's headquarters. A 12 ha tract of coastal upland and salt marsh, the Reservation, is a very popular public destination for walking, wildlife observation and outdoor events.

An additional 2,800 ha are protected in conservation easements. Easements, or restrictions as they are called in Massachusetts, restrict the allowed uses of a property but keeps it in private ownership. Easements are often described in terms of the 'bundle of sticks' analogy of real property ownership (Best Practice 4.2.1). Property easements generally refer to only a proportion of the rights that a landowner might have: for example mineral rights, access rights, the rights to build houses and so on. Conservation easements address rights that had rarely, if ever, been transferred before, such as the power to prevent or prohibit certain activities on the property, and so the easements by which they were granted were called 'negative easements'. (Not all easements would meet all the criteria of PPAs, but many do.)

Traditionally, the law in the United States had been averse to perpetual restrictions on the use of land (that is, restrictions

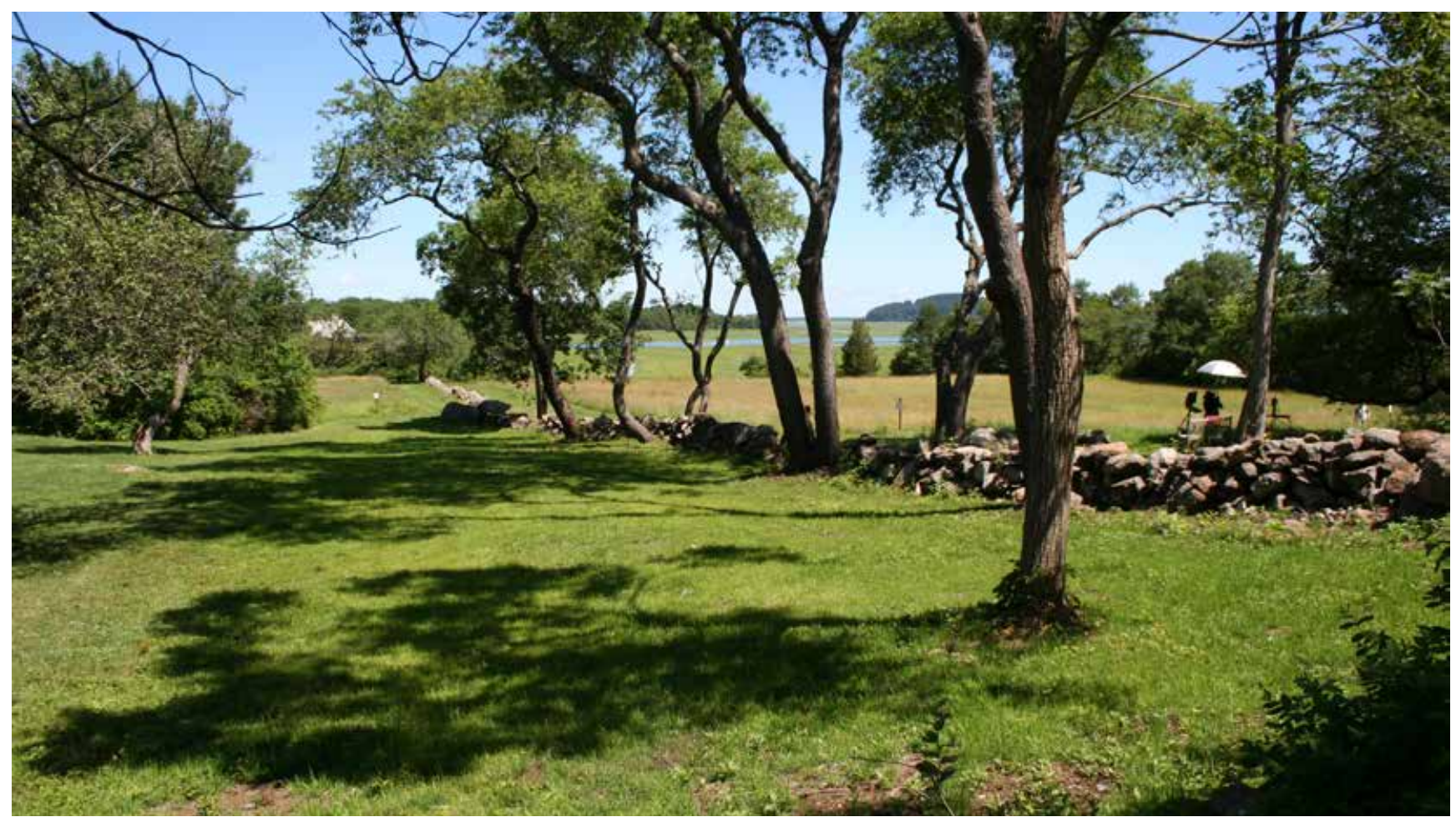

(C) Essex County Greenbelt Association 


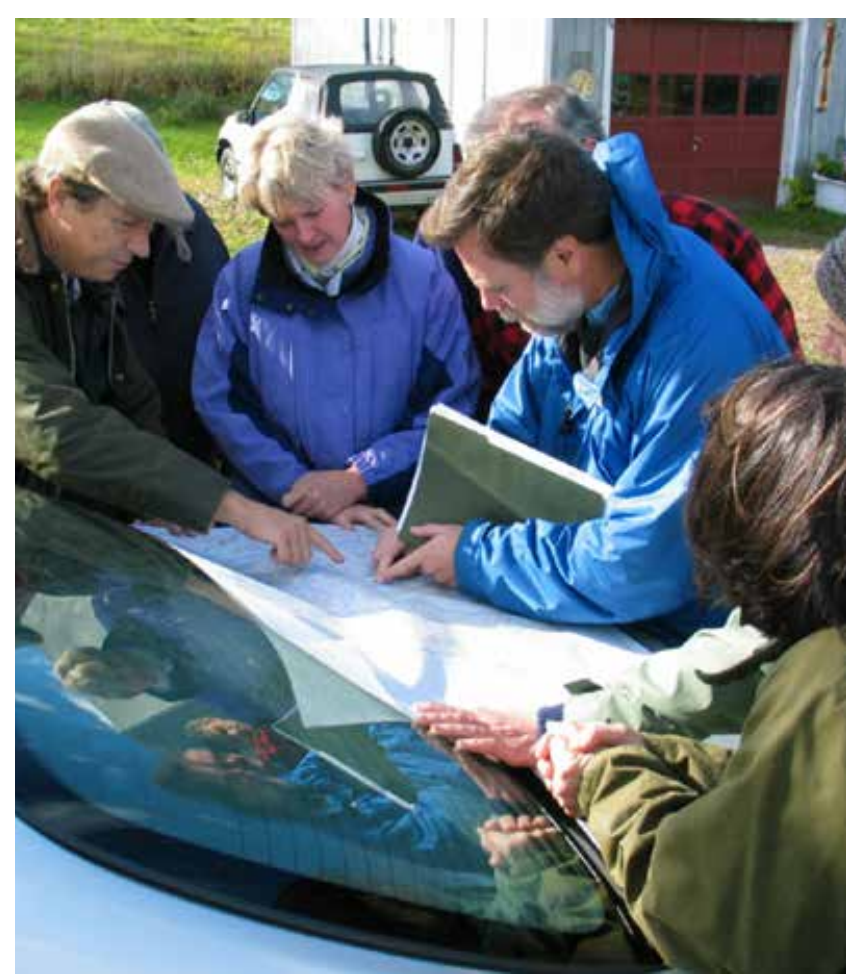

Property evaluation team (C) Essex County Greenbelt Association

that would be permanent, or effective in perpetuity) and this extension of the concept of easements required statutory modifications to the common law, embodied in the Uniform Conservation Easement Act, which was adopted by the National Conference of Uniform State Laws in 1981. This law provided that conservation easements would exit in perpetuity and that they were binding on all subsequent landowners (Best Practice 4.1.7). It also removed the common law requirement that the entity to whom the easement is granted holds other land adjacent to or nearby the restricted parcel. Though conservation easements 'take away' certain rights forever, and are recorded on the land title, the rights cannot just disappear, they must be held by another entity. Thus, the role of Greenbelt and land trusts like it. Greenbelt holds restrictions on 222 properties for which they must monitor compliance and, if it comes to it, enforce the terms of the easement.

Because conservation easements lower the theoretical real estate value of a property, benefits can accrue to the landholder in the form of reduced property and income taxes. Donors of freehold reserves, as well as donors to support land trust operations, may qualify for income tax benefits as well. These are powerful incentives (see Principle 3.7).

\section{PPAs across the USA}

Greenbelt is one of over 1,300 land trusts across the country (Land Trust Alliance, 2015). Despite the title of this case study, there is no 'typical' land trust. Greenbelt has 14 people on its permanent staff. Some land trusts, like The Nature Conservancy, are much larger organisations, but most are smaller than Greenbelt. Some land trusts have no paid staff at all. The majority of land trusts have adopted 'Standards and Practices' promulgated by the Land Trust Alliance, and to date more than 400 land trusts have been certified as meeting high standards by the Land Trust Accreditation Commission.

Of course, there are many kinds of PPAs other than land trusts in the US. Some result from entirely individual initiative and, in fact, all PPA subtypes are represented. Particularly worth noting are permanent academic research areas. Many universities were established by land grants early in the country's history. Land was given by the state to be sold over time to finance the college, but some areas were reserved for ecological research and remain as PPAs today.

Private land conservation in the United States is characterised by an emphasis on perpetuity of protection and fuelled by an array of incentives, largely in the form of tax relief that may accrue to the landholder. However, it would be wrong to conclude that land conservation is an entirely economic decision. Many studies have shown that landholders' primary motivations are not economic but intrinsic, with incentives making it possible to act on a sense of stewardship (see Principle 3.4) (for example, Farmer et al., 2016). As stated by landowner George Leonhard on why he and his brother protected their farm with a conservation easement granted to Greenbelt, "I could not bear to look at the property with houses all over it."

\section{Summary}

- Land protection mechanisms and incentives can be adapted from existing laws and regulations (Best Practice 3.7.4).

- With a highly developed land-tenure system, permanent protection can be secured by attaching restrictions on land title itself, rather than any particular landholder (Best Practice 4.1.1).

- Incentives can be durable when value-based and integrated with market systems (Best Practice 3.2.1).

- Personal stewardship and professional intermediary organisations are important to establishing, managing and monitoring privately protected areas (Best Practice 8.2.1). 


\section{Case Study 12 Putting PPAs on the map: Adding PPAs to the WDPA in the UK}

\section{Sue Stolton, IUCN UK National Committee}

The UK was one of the first countries in the world to develop a system for assessing all nature and landscape conservation areas, covering all governance types, against the IUCN protected area definition, categories and governance type (the '2008 Guidelines'). The UK Putting Nature on the Map (PNOTM) project also created a system for the hitherto unrecognised community, private and local conservation areas to have their sites assessed against the IUCN's 2008 Protected Area Guidelines and be reported on the WDPA. This case study provides an example of how to achieve the best practices set out in Part B, Section 7 of these Guidelines.

\section{Overview}

The origins of nature conservation and landscape protection in the UK can be traced back well over a hundred years to three quite separate movements: a call for measures to protect nature on scientific and ecological grounds; a concern about the aesthetic damage caused by industrialisation; and a demand for working people to have access to the countryside for recreation. These concerns came together in the 1949 National Parks and Access to the Countryside Act. They also gave rise to, and have since sustained, the UK's powerful conservation movement of non-government organisations (NGOs), which has helped to protect many areas for nature and landscape through ownership of land and by exercising political influence.

The development of privately protected areas (PPAs) in the UK has been dominated by the involvement of NGOs working for the protection of nature and landscape. Bodies like the National Trust (NT), now with more than five million members, and the Royal Society for the Protection of Birds (RSPB) with more than one million members, were founded in the 19th century. Both had begun to create nature reserves before 1900 and the number of sites that they protect for landscape and nature has grown nearly every year since. The first of the geographically-focused Wildlife Trusts was established in 1926: today, there are 47 of them in the UK (mainly based on counties in England and Wales, with a single body each for Scotland and Northern Ireland). Collectively, these Trusts have over 800,000 members and a network of more than 1,000 nature reserves. Other NGOs with a more specific focus on wetlands, wildland, woodlands, plants and raptors, for example, have also acquired and developed their own nature reserve systems. All of these are membership bodies, operating under national laws as charities, and wholly independent of government. In addition, many thousands of individual farmers and landowners are involved in site-based protection through national legislation. Communally-owned land, in particular 'commons' also provides a range of conservation benefits.

\section{Applying the IUCN definition to UK conservation}

Although recorded locally by individual organisations and to some extent by government bodies, the data on UK protected areas reported on the World Database on Protected Areas (WDPA) was deficient in several respects. It was not collected using the 2008 Guidelines as a standard; it was not comprehensive; it included some areas that

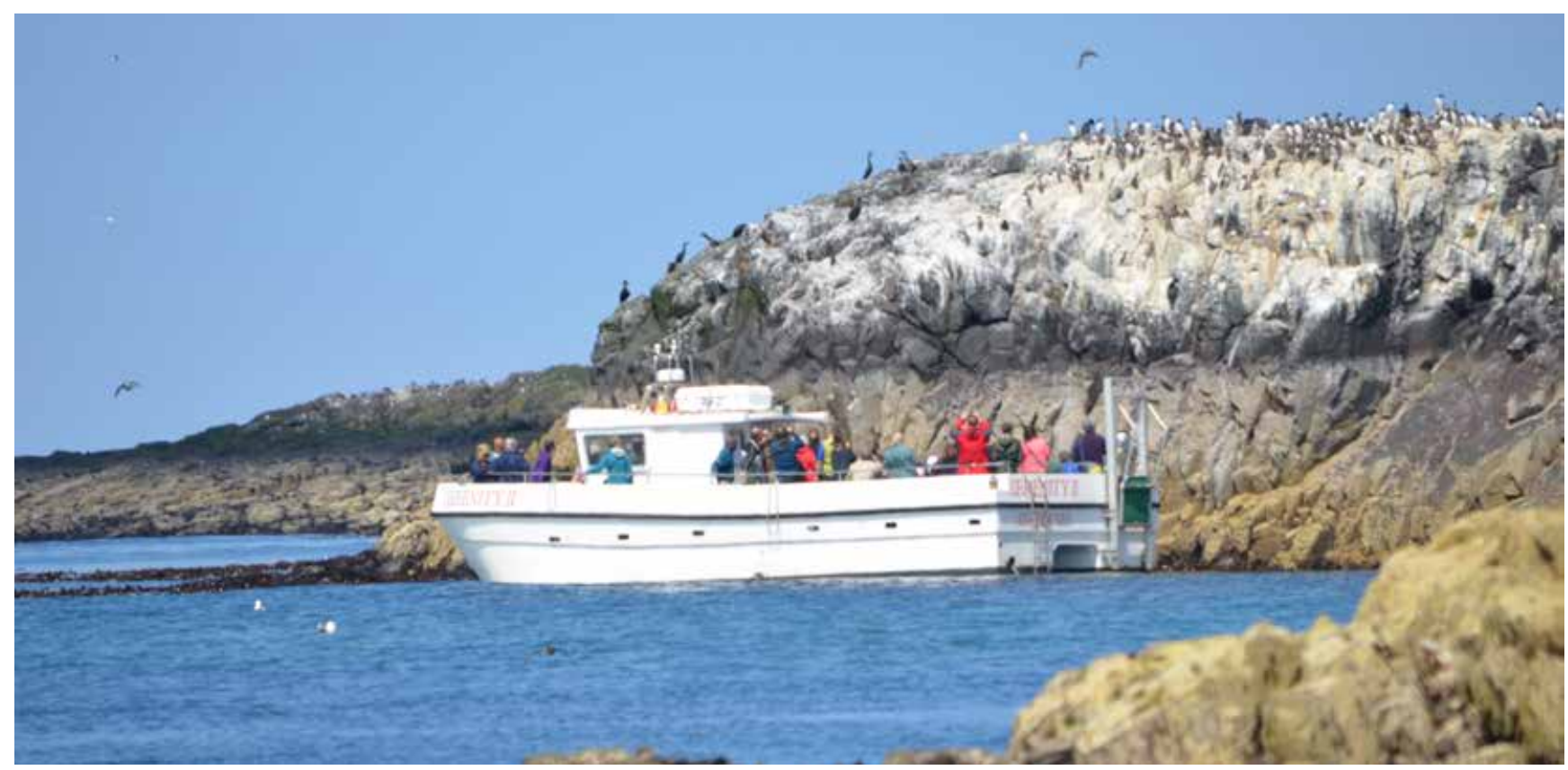

The National Trust has one of the largest private land holdings in the UK and manages some 600 PPAs @ Nigel Dudley 


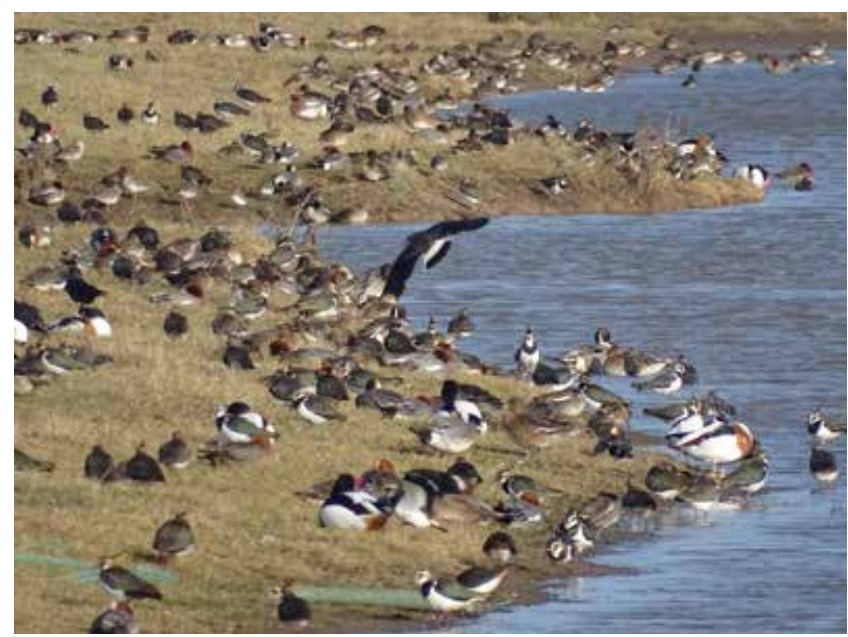

The Slimbridge Wetland Centre is managed by the Wildfowl \& Wetlands Trust one of the many NGOs managing PPAs in the UK () Nigel Dudley

might not meet the IUCN definition; omitted other areas that should be included; some areas were not categorised by the purposes for which sites were managed; and in many cases governance type was not correctly recorded. In 2010, the then Chair of WCPA challenged the IUCN National Committee in the UK to take the lead in a project to apply the 2008 Guidelines across all governance types in the UK, which could act as an exemplar to other countries which have a large number of PPAs and community conserved areas not currently reported on the WDPA.

The Putting Nature on the Map (PNOTM) project was the result. Its aims were to identify all the places in the UK that met the IUCN definition of a protected area, and to assign to them the appropriate IUCN management category and governance type. To do this, PNOTM developed a five-step process:

1. Identify all sites that might possibly be protected areas.

2. Develop UK-specific guidance based on the 2008 Guidelines.

3. Determine what is, and what is not, a protected area under the IUCN definition.

4. Assign management categories and governance types.

5. Collect and report on data, including to the WDPA.

As PNOTM developed, it became clear that there was a need to spread understanding of the project and ensure that consistent standards were adopted. To do this, the project developed three innovations:

1. The production of a UK Handbook. Showing how the 2008 Guidelines could be applied in the UK context (IUCN NCUK, 2012).

2. Statements of Compliance (SoCs). A statement outlining an assessment of protected areas against a standard set of questions to examine systematically whether individual sites or specific designations accorded with the IUCN definition. These statements were developed by the landholders in cooperation with the PNOTM project, and landholders were made fully aware that the objective was to include their data on the WDPA (Best Practice 7.1.6). This process helped identify the key issues in deciding if an individual site or suite of sites per designation type met or did not meet the 2008 Guidelines. The SoCs are a transparent resource available on the IUCN NCUK website for any interested party to review.

3. A National Assessment Panel. The panel, consisting of UK WCPA experts familiar with IUCN's international standards for protected areas, reviewed each SoC in detail and recommended whether sites/designations met the 2008 Guidelines. This fulfilled the WDPA's requirement for data-verification (Best Practice 7.1.8).

\section{Challenges}

Once protected area status had been confirmed, data providers were invited to compile lists of their protected areas, with proposed management categories and governance types. In the case of government statutory nature conservation bodies, established data protocols were respected; but with the NGO data sets, which had never been included before, large bodies of new data on the UK's protected areas were collected, reviewed by the Assessment Panel and then transmitted to UN Environment World Conservation Monitoring Centre (UNEP-WCMC) who manage the World Database on Protected Areas (WDPA) (Best Practice 7.1.4).

Data collection remains challenging. WDPA data standards were new to many stakeholders and additional tasks were not always welcomed by staff already responsible for many other data management jobs. To overcome this, PNOTM invested in a pilot scheme with the Scottish Wildlife Trust to test and demonstrate the practicality of what was being asked, held face-to-face meetings with data staff from a number of NGOs and supported a UNEP-WCMC training workshop and webinar for data managers (Best Practice 7.1.3).

PNOTM has resulted in changes to the UK protected area data flows to the WDPA and provided a view of the UK protected area network that is quite different from that previously reported into the WDPA. Specifically in the context of this document, several thousand PPAs owned or managed by NGOs, protecting almost 500,000 ha have been identified and a diversity of governance types not previously accurately recorded. At a time when resources for conservation in the public sector are declining and policy commitment in some areas has weakened, understanding this contribution to conservation is particularly important (Crofts \& Phillips, 2013; Crofts et al., 2014).

\section{Summary}

- Reporting PPAs is an important contribution to understanding national networks of protected areas (Best Practice 6.2.1).

- National processes run in cooperation but independently from government (Best Practice 7.1.1) can be useful in helping PPA owners/managers to understand and apply the 2018 Guidelines and these standards in a national context.

- Data collection is not always easy and close cooperation with UNEP-WCMC is necessary to help support organisations providing data for the first time (Principle 7.1). 


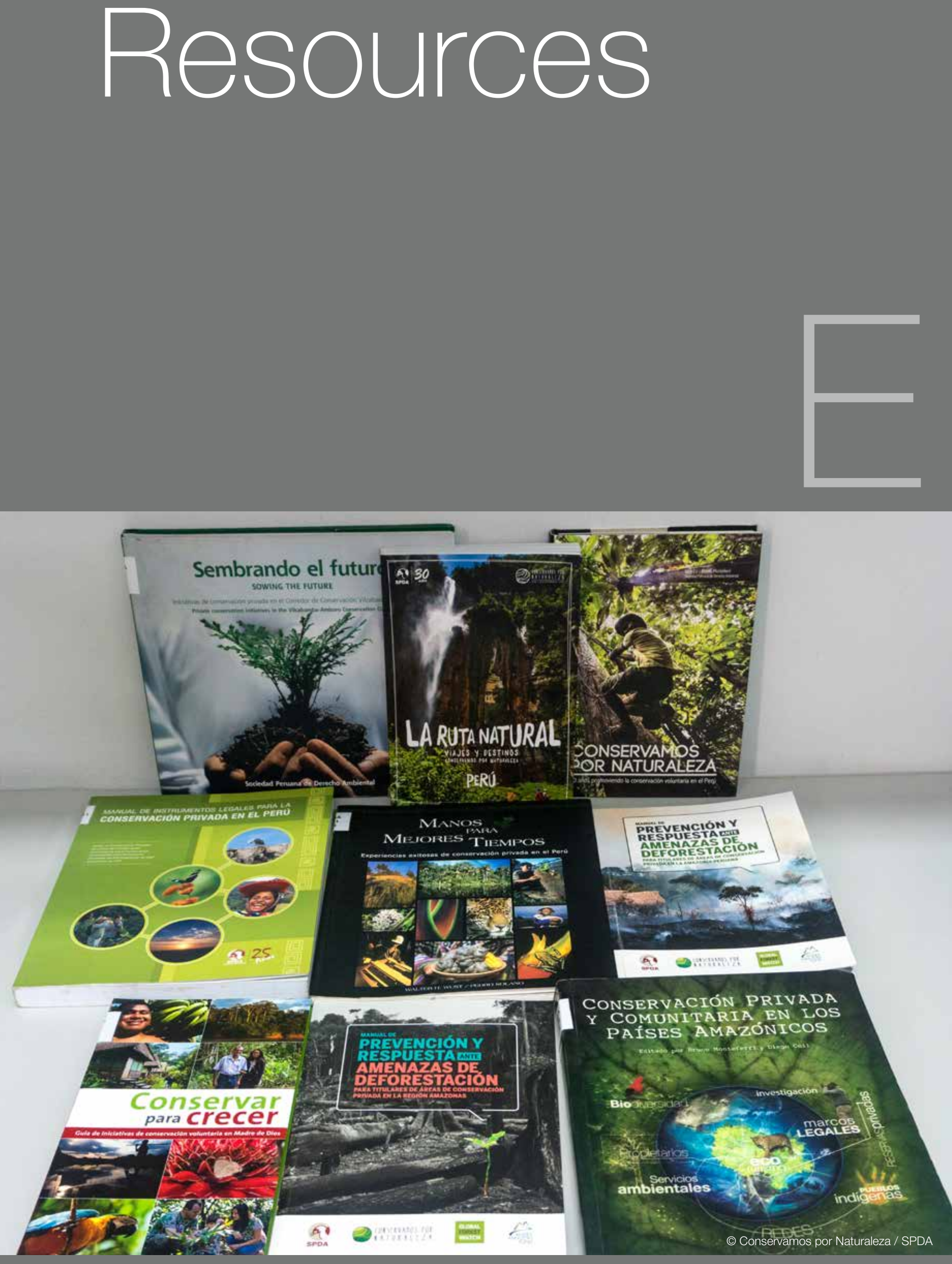


\section{References}

Avalon Marshes Landscape Partnership (2011). Supplementary Document - Full Project List. Available at: http://www. somersetwildlife.org/hres/Microsoft\%20Word\%20-\%201.11\%20 -\%20Full\%20Project\%20List\%2010\%2011\%2011_SML.pdf

Balaguera-Reina, S.A., Espinosa-Blanco A.S., Morales-Betancourt, M.A., Seijas, A.E., Lasso, C.A., Antelo, R. and Densmore III, L.D. (2017). 'Conservation status and regional habitat priorities for the Orinoco crocodile: Past, present, and future'. PLOS ONE 12(2): e0172439. Available at: https://doi.org/10.1371/journal. pone.0172439

Bernstein, J. and Mitchell, B.A. (2005). 'Land trusts, private reserves and conservation easements in the United States'. PARKS 15(2):48-60. Available at: http://parksjournal.com/wp-content/ uploads/2017/07/parks_15_2.pdf

Bezaury-Creel, J.E., Ochoa-Ochoa, L.M. and Torres-Origel, J.F. (2012). Base de Datos Geográfica de las Reservas de Conservación Privadas y Comunitarias en México Versión 2.1 Diciembre 31, 2012. The Nature Conservancy. 2 Capas ArcGIS 9.2 + 1 Capa Google Earth $\mathrm{KMZ}+1$ Archivo de Metadatos en texto. Unpublished, available in $C D$ format.

Bingham, H., Fitzsimons, J.A., Redford, K.H., Mitchell, B.A., BezauryCreel, J. and Cumming, T.L. (2017). 'Privately protected areas: advances and challenges in guidance, policy and documentation'. PARKS 23(1):13-28. Available at: https://doi.org/10.2305/IUCN. CH.2017.PARKS-23-1HB.en (Accessed: 26 September 2018).

BMUB (2017). Das Nationale Naturerbe. Naturschätze für Deutschland. Berlin, Germany: Bundesministerium für Umwelt, Naturschutz, Bau und Reaktorsicherheit (BMUB). Available at: https://www.bmu.de/fileadmin/Daten_BMU/Pools/Broschueren/ nat_naturerbe_bf.pdf (Accessed: 26 September 2018).

Borrini-Feyerabend, G., Dudley, N., Jaeger, T., Lassen, B., Pathak Broome, N., Phillips, A. and Sandwith, T. (2013). Governance of Protected Areas: From understanding to action. Best Practice Protected Area Guidelines Series no. 20. Gland, Switzerland: IUCN. Available at: https://portals.iucn.org/library/node/29138 (Accessed: 26 September 2018).

Clements, H.S., Selinske, M.J., Archibald, C.L., Cooke, B., Fitzsimons, J.A., Groce, J.E., Torabi, N. and Hardy, M.J. (2018). 'Fairness and transparency are required for the inclusion of privately protected areas in publicly accessible conservation databases'. Land 7: 96. Available at: https://doi.org/10.3390/land7030096. (Accessed: 26 September 2018).

Cohen, S., Dengate, J., Morrell, L. and Lee, K. (2015). 'The media and protected areas'. In: G.L. Worboys, M. Lockwood, A. Kothari, S. Feary and I. Pulsford (eds.) Protected Area Governance and Management, pp. 441-472. Canberra, Australia: ANU Press. Available at: http://press-files.anu.edu.au/downloads/press/p312491/ pdf/CHAPTER15.pdf (Accessed: 26 September 2018).

Colorado State Land Board (2017). Conservation Bank for Preble's Meadow Jumping Mouse. Available at: http://www.glo.texas.gov/ wslca/downloads/conferences/2017/winter/surface-committee/ CO_Prebles-Meadow-Jumping-Mouse-Conservation-Bank.pdf (Accessed: 6 October 2018)

Commonwealth of Australia and each of its States and Territories (2010). Australia's Strategy for the National Reserve System 20092030. Canberra. Available at: https://www.environment.gov.au/ system/files/resources/643fb071-77c0-49e4-ab2f-220733beb30d/ files/nrsstrat.pdf. (Accessed: 26 September 2018).
Commonwealth of Massachusetts and the Nature Conservancy (2010). BioMap2 Conserving the Biodiversity of Massachusetts in a Changing World. Massachusetts Department of Fish \& Game and The Nature Conservancy. Available at: https://www.mass.gov/files/ documents/2016/08/wi/biomap2-summary-report.pdf (Accessed: 26 September 2018).

Conservation Measures Partnership (CMP) (2013). Open Standards for the Practice of Conservation. Available at http://cmpopenstandards.org/wp-content/uploads/2017/06/CMP-OS-V3.0Final-minor-update-May-2107.pdf (Accessed: 26 September 2018).

Convention on Biological Diversity (CBD) (2010). Convention on Biological Diversity Strategic Plan for Biodiversity 2011-2020. UNEP/ $\mathrm{CBD} / \mathrm{COP} / \mathrm{DEC} / \mathrm{X} / 2$. Available at: https://www.cbd.int/doc/decisions/ cop-10/cop-10-dec-02-en.pdf (Accessed: 26 September 2018).

Cowan, G.I., Mpongoma, N. and Britton, P. (eds.) (2010). Management effectiveness of South Africa's protected areas. Pretoria: Department of Environmental Affairs.

Crofts, R., Dudley, N., Mahon, C., Partington, R., Phillips, A., Pritchard, S. and Stolton, S. (2014). Putting Nature on the Map: A Report and Recommendations on the Use of the IUCN System of Protected Area Categorisation in the UK. UK: IUCN National Committee UK. Available at: https://portals.iucn.org/library/sites/library/files/ documents/2014-040.pdf (Accessed: 26 September 2018).

Crofts, R. and Phillips, P. (2013). 'Putting Nature on the Map: Applying the IUCN Protected Areas Management Categories in the UK'. PARKS 19.1. Available at: https://doi.org/10.2305/IUCN. CH.2013.PARKS-19-1.RC.en

Crosthwaite, J., Fitzsimons, J., Stanley, J. and Greacen, J. (2013). "'Networking the networks": coordinating Conservation Management Networks in Victoria'. In: J. Fitzsimons, I. Pulsford, and G. Wescott (eds.) Linking Australia's Landscapes: Lessons and Opportunities from Large-scale Conservation Networks, pp. 209-220. Melbourne, Australia: CSIRO Publishing.

Cumming, T.L. (2007). 'Conservation incentives for private commercial farmers in the Thicket Biome, Eastern Cape, South Africa'. MSc thesis. Grahamstown, South Africa: Rhodes University. Available at: http://vital.seals.ac.za/vital/access/manager/Repository/ vital:4745 (Accessed: 26 September 2018).

De Vasconcellos Pegas, F. and Castley, G. (2015). 'Private reserves in Brazil: Distribution patterns, logistical challenges, and conservation contributions'. Journal for Nature Conservation 29:14-24. Available at: https://doi.org/10.1016/j.jnc.2015.09.007

Dinerstein, E., Olson, D., Joshi, A., Vynne, C., Burgess, N.D., Wikramanayake, E., Hahn, N., Palminteri, S., Hedao, P., Noss, R., Hansen, M., Locke, H., Ellis, E.C., Jones, B., Barber, C.V., Hayes, R., Kormos, C., Martin, V., Crist, E., Sechrest, W., Price, L., Baillie, J.E.M., Weeden, D., Suckling, K., Davis, C., Sizer, N., Moore, R., Thau, D., Birch, T., Potapov, P., Turubanova, S., Tyukavina, A., De Souza, N., Pintea, L., Brito, J.C., Llewellyn, O.A., Miller, A.G., Patzelt, A., Ghazanfar, S.A., Timberlake, J., Klöser, H., Shennan-Farpón, Y., Kindt, R., Lillesø, J-P.B., van Breugel, P., Graudal, L., Voge, M., Al-Shammari, K.F. and Saleem, M. (2017). 'An ecoregion-based approach to protecting half the terrestrial realm'. BioScience 67:534-545. Available at: https:// doi.org/10.1093/biosci/bix014 (Accessed: 26 September 2018).

Dodds, R. (2012). 'Eco-tourism for Education and Marine Conservation: the Chumbe Island Coral Park in Zanzibar'. TÉOROS Special Issue: 91-97. Available at: https://journals.openedition.org/ teoros/1990 (Accessed: 26 September 2018). 
Dudley, N. (ed.) (2008). Guidelines for Applying Protected Area Management Categories. Gland, Switzerland: IUCN. Available at: https://doi.org/10.2305/IUCN.CH.2008.PAPS.2.en (Accessed: 26 September 2018).

Dudley, N. (2011). Authenticity in Nature: Making choices about the naturalness of ecosystems. London, UK: Earthscan.

Dudley, N., Bhagwat, S., Higgins-Zogib, L., Lassen, B., Verschuuren, B. and Wild, R. (2010). 'Conservation of biodiversity in sacred natural sites in Asia and Africa: a review of scientific literature'. In: B. Verschuuren, R. Wild, J. McNeely and G. Oviedo (eds.) Sacred Natural Sites, pp. 19-31. London, UK: Earthscan.

Ellwood, E., Crimmins, T. and Miller-Rushing, A. (eds.) (2017). 'The role of citizen science in biological conservation'. Biological Conservation. 208:1-188. https://doi.org/10.1016/j. biocon.2016.10.014

Farmer, J.R., Brenner, J.C., Drescher, M., Dickinson, S., and Knackmuhs, E.G. (2016). Perpetual private land conservation: the case for outdoor recreation and functional leisure. Ecology and Society 21(2):46. Available at: https://doi.org/10.5751/ES-08515210246

Farmer, J.R., Knapp, D., Meretsky, V.J., Chancellor, C. and Fischer, B.C. (2011). 'Motivations influencing the adoption of conservation easements'. Conservation Biology 25:827-834. Available at: https://doi.org/10.1111/j.1523-1739.2011.01686.x (Accessed: 26 September 2018).

Fitzsimons, J.A. (2006). 'Private Protected Areas? Assessing the suitability for incorporating conservation agreements over private land into the National Reserve System: A Case Study of Victoria'. Environmental and Planning Law Journal 23:365-385.

Fitzsimons, J.A. (2015). 'Private protected areas in Australia: Current status and future directions'. Nature Conservation 10:1-23. Available at: https://doi.org/10.3897/natureconservation.10.8739 (Accessed: 26 September 2018).

Fitzsimons, J.A. and Wescott, G. (2007). 'Perceptions and attitudes of land managers in multi-tenure reserve networks and the implications for conservation'. Journal of Environmental Management 84:38-48. Available at: https://doi.org/10.1016/j. jenvman.2006.05.009 (Accessed: 26 September 2018).

Fitzsimons, J.A. and Wescott, G. (2008a). ‘Ecosystem conservation in multi-tenure reserve networks: The contribution of land outside of publicly protected areas'. Pacific Conservation Biology 14: 250262. Available at: https://doi.org/10.1071/PC080250 (Accessed: 26 September 2018).

Fitzsimons, J.A. and Wescott, G. (2008b). 'The role of multi-tenure reserve networks in improving reserve design and connectivity'. Landscape and Urban Planning 85:163-173. Available at: https://doi. org/10.1016/j.landurbplan.2007.11.001 (Accessed: 26 September 2018).

Food and Agriculture Organization of the United Nations (FAO) (2017). Free, Prior and Informed Consent: An indigenous peoples' right and a good practice for local communities: Manual for project practitioners. Rome: FAO. Available at: http://www.fao.org/3/a-i6190e.pdf. (Accessed: 26 September 2018).

Franks, P, Martin, A. and Schreckenberg, K. (2016). From livelihoods to equity for better protected area conservation. Briefing. International Institute for Environment and Development (IIED). Available at: http:// pubs.iied.org/pdfs/17370llED.pdf (Accessed: 5 October 2018)

Gilligan, B. and Syneca Consulting Pty Ltd (2007). Review and Evaluation of the Tasmanian Private Forest Reserves Program. Report for the Tasmanian Department of Primary Industries and Water, Hobart. Available at: https://dpipwe.tas.gov.au/Documents/PFRPEvaluation-Report.pdf (Accessed: 26 September 2018).
Gobierno de Chile (2015). Declara lugar de interés científico para efectos mineros area ubicada en Región de Magallanes, Provincia de Tierra del Fuego, Comuna de Timaukel. Diario Oficial No. 41.219

Gordon, A., Bull, J.W., Wilcox, C. and Maron, M. (2015). 'Perverse incentives risk undermining biodiversity offset policies'. Journal of Applied Ecology. 52:532-537. Available at: https://doi. org/10.1111/1365-2664.12398 (Accessed: 26 September 2018).

Government of South Africa (2010). National Protected Area Expansion Strategy for South Africa 2008. Priorities for expanding the protected area network for ecological sustainability and climate change adaption. Pretoria, South Africa: Department of Environmental Affairs. Available at: https://www.environment.gov.za/sites/default/ files/docs/nationalprotected_areasexpansion_strategy.pdf (Accessed: 26 September 2018).

Government of South Africa (2015a). The National Development Plan. Pretoria: Department: The Presidency.

Government of South Africa (2015b). National Biodiversity Strategy and Action Plan. Pretoria, South Africa: Department of Environmental Affairs. Available at: https://www.cbd.int/doc/world/za/za-nbsap-v2en.pdf (Accessed: 26 September 2018).

Greiber, T. (ed.) (2009). Payments for Ecosystem Services. Legal and Institutional Frameworks. Gland, Switzerland: IUCN. Available at: https://portals.iucn.org/library/node/9497 (Accessed: 26 September 2018).

Grêt-Regamey, A., Sirén, E., Brunner, S.H. and Weibel, B. (2017). 'Review of decision support tools to operationalize the ecosystem services concept'. Ecosystem Services 26:306-315. Available at: https://doi.org/10.1016/j.ecoser.2016.10.012

Gross, J.E., Woodley, S., Welling, L.A. and Watson, J.E.M. (eds.) (2016). Adapting to Climate Change: Guidance for protected area managers and planners. Best Practice Protected Area Guidelines Series no. 24. Gland, Switzerland: IUCN. Available at: https://doi. org/10.2305/IUCN.CH.2017.PAG.24.en (Accessed: 26 September 2018).

Groves, C.R. and Game, E.T. (2016). Conservation planning: informed decisions for a healthier planet. Greenwood Village, Colorado: Roberts and Co.

Halliday, L., Castley, J.G., Fitzsimons, J.A., Tran, C. and Warnken, J. (2012). 'Fire management on private conservation lands: Knowledge, perceptions and actions of landholders in eastern Australia'. International Journal of Wildland Fire 21:197-209. Available at: https://doi.org/10.1071/WF10148 (Accessed: 26 September 2018),

Hardy, M.J., Bekessy, S.A., Fitzsimons, J.A., Mata, L., Cook, C., Nankivell, A., Smillie, K. and Gordon, A. (2018a). 'Protecting nature on private land using revolving funds: Assessing property suitability'. Biological Conservation 220:84-93. Available at: https://doi. org/10.1016/j.biocon.2018.01.026 (Accessed: 26 September 2018).

Hardy, M.J., Fitzsimons, J.A., Bekessy, S.A. and Gordon, A. (2017). 'Exploring the permanence of conservation covenants'. Conservation Letters 10:221-230. Available at: https://doi.org/10.1111/conl.12243 (Accessed: 26 September 2018).

Hardy, M.J., Fitzsimons, J.A., Bekessy, S.A. and Gordon, A. (2018b). 'Factors influencing property selection for conservation revolving funds'. Conservation Biology 32:276-286. Available at: https://doi. org/10.1111/cobi.12991 (Accessed: 26 September 2018).

Hardy, M.J., Fitzsimons, J.A., Bekessy, S.A. and Gordon, A. (2018c). 'Purchase, protect, resell, repeat: an effective approach for conserving biodiversity on private land?' Frontiers in Ecology and the Environment 16:336-344. Available at: https://doi.org/10.1002/ fee.1821 (Accessed: 26 September 2018).

Hockings, M., Stolton, S., Leverington, F., Dudley, N. and Courrau, J. (2006). Evaluating Effectiveness: A framework for assessing 
management effectiveness of protected areas, $2^{\text {nd }}$ Edition. Gland, Switzerland: IUCN WCPA and Brisbane, Australia: University of Queensland. Available at: https://doi.org/10.2305/IUCN.CH.2005. PAG.14.en (Accessed: 26 September 2018).

Hora, B., Marchant, C. and Borsdorf, A. (2018). 'Private Protected Areas in Latin America: Between conservation, sustainability goals and economic interests. A review'. eco.mont 1:87-94. Available at: https://doi.org/10.1553/eco.mont-10-1s87 (Accessed: 26 September 2018).

Humann, D. (2012). 'A personal journey to innovation'. In: P. Figgis, J. Fitzsimons and J. Irving (eds.) Innovation for 21st Century Conservation, pp. 16-23. Sydney, Australia: Australian Committee for IUCN. Available at: https://www.iucn.org/sites/dev/files/import/ downloads/innovation_for_21st_century_conservation_low.pdf (Accessed: 26 September 2018).

International Union for Conservation of Nature (IUCN) (2016a). A Global Standard for the Identification of Key Biodiversity Areas, Version 1.0. First edition. Gland, Switzerland: IUCN. Available at: https://portals.iucn.org/library/node/46259. (Accessed: 27 September 2018).

International Union for Conservation of Nature (IUCN) (2016b). WCC2016-Res-036-EN Supporting privately protected areas. Gland, Switzerland: IUCN. Available at: https://portals.iucn.org/library/sites/ library/files/resrecfiles/WCC_2016_RES_036_EN.pdf (Accessed: 6 February 2018).

International Union for Conservation of Nature and World Commission on Protected Areas (IUCN/WCPA) (2016). IUCN Green List of Protected and Conserved Areas: User Manual, Version 1.0. Gland, Switzerland: IUCN. Available at: https://www.iucn.org/sites/dev/ files/content/documents/iucn_green_list_user_manual_version_1.0_ september_2016_nov.pdf. (Accessed: 26 September 2018).

International Union for Conservation of Nature National Committee UK (IUCN NCUK) (2012). Putting nature on the map identifying protected areas in the UK: A handbook to help identify protected areas in the UK and assign management categories and governance types to them. Mold, UK: IUCN National Committee UK. Available at: https://iucnuk.files.wordpress.com/2017/05/pnotm-handbook-small. pdf (Accessed: 26 September 2018).

Joint ANZECC/MCFFA National Forest Policy Statement Implementation Sub-Committee (JANIS) (1997). Nationally agreed criteria for the establishment of a comprehensive, adequate and representative reserve system for forests in Australia. Canberra, Australia: Joint ANZECC/MCFFA National Forest Policy Statement Implementation Sub-Committee. Available at: http://www.agriculture. gov.au/SiteCollectionDocuments/rfa/publications/nat nac.pdf (Accessed: 26 September 2018).

Jonas H.D., Barbuto, V., Jonas, H.C., Kothari, A. and Nelson, F. (2014). 'New steps of change: looking beyond protected areas to consider other effective area-based conservation measures'. PARKS 20(2):111-128. Available at: https://doi.org/10.2305/IUCN.CH.2014 PARKS-20-2.HDJ.en (Accessed: 26 September 2018).

Jonas, H.D., MacKinnon, K., Dudley, N., Hockings, M., Jesses, S., Laffoley, D., MacKinnon, D., Matallana-Tóbon, C.L., Sandwith, T., Waithaka, J. and Woodley, S. (2018). 'Editorial essay: Other Effective Area-based Conservation Measures: From Aichi Target 11 to the post-2020 biodiversity framework'. PARKS 24 (Special issue):9-16. Available at: https://doi.org/10.2305/IUCN.CH.2018.PARKS 24 SIHDJ.en

Keppel, G., Morrison, C., Hardcastle, J., Rounds, I.A., Wilmott, I.K., Hurahura, F. and Shed, P.K. (2012). 'Conservation in tropical Pacific island countries: case studies of successful programmes'. PARKS 18(1):111-123. Available at: https://doi.org/10.2305/IUCN.CH.2012. PARKS-18-1.GK.en (Accessed: 26 September 2018).

Knight, A.T., Cowling, R.M., Difford, M. and Campbell, B.M. (2010). 'Mapping human and social dimensions of conservation opportunity for the scheduling of conservation action on private land'. Conservation Biology 24(5):1348-1358. Available at: https://doi. org/10.1111/j.1523-1739.2010.01494.x

Knight, A.T., Cowling, R.M., Rouget, M., Balmford, A., Lombard, A.T. and Campbell, B.M. (2008). 'Knowing but not doing: selecting priority conservation areas and the research-implementation gap'. Conservation Biology 22:610-617. Available at: https://doi. org/10.1111/j.1523-1739.2008.00914.x (Accessed: 26 September 2018).

Knight, A.T., Grantham, H., Smith, R.J., McGregor, G.K., Possingham, H.P. and Cowling, R.M. (2011). 'Land manager willingness-to-sell defines conservation opportunity for protected area expansion'. Biological Conservation 144:2623-2630. Available at: https://doi.org/10.1016/j.biocon.2011.07.013 (Accessed: 26 September 2018).

Knight, A.T., Sarkar, S., Smith, R.J., Strange, N. and Wilson, K.A. (2011c). 'Engage the hodge-podge: management factors are essential when prioritising areas for restoration and conservation opportunity'. Diversity and Distributions 17(6):1234-1238. Available at: https://doi.org/10.1111/j.1472-4642.2011.00789.x (Accessed: 26 September 2018).

Lafarge (2007). Driving Quarry Restoration, Paris: Lafarge. Available at: https://www.cbd.int/financial/privatesector/franceprivatewwflafarge.pdf (Accessed: 26 September 2018).

Land Trust Alliance (2015). National Land Trust Census Report. Washington, DC, USA: Land Trust Alliance. Available at: http://s3.amazonaws.com/landtrustalliance. org/2015NationalLandTrustCensusReport.pdf (Accessed: 26 September 2018).

Lausche, B. (2011). Guidelines for Protected Areas Legislation. Gland, Switzerland: IUCN. Available at: https://portals.iucn.org/library/ node/10133 (Accessed: 26 September 2018).

Leménager, T., King, D., Eliott, J., Gibbons, H. and King, A. (2014). 'Greater than the sum of their parts: environmental complementarity between public, private and communities protected areas'. Global Ecology and Conservation 2:238-247. Available at: https://doi. org/10.1016/j.gecco.2014.09.009 (Accessed: 26 September 2018).

Leung, Y.-F., Spenceley, A., Hvenegaard, G. and Buckley, R. (eds.) (2018). Tourism and Visitor Management in Protected Areas: Guidelines for Sustainability. IUCN Best Practice Protected Area Guidelines Series No. 27. Gland, Switzerland: IUCN. Available at: https://portals.iucn.org/library/node/47646

Levitt, J.N. (ed.) (2014). Conservation catalysts. The academy as nature's agent. Cambridge, USA: Lincoln Institute of Land Policy. Available at: https://www.lincolninst.edu/sites/default/files/pubfiles/ conservation-catalysts-full_0.pdf (Accessed: 26 September 2018).

Lopoukhine, N., Crawhall, N., Dudley, N., Figgis, P., Karibuhoye, C., Laffoley, D., Miranda Londoño, J., MacKinnon, K. and Sandwith, T. (2012). 'Protected areas: providing natural solutions to 21st Century challenges'. S.A.P.I.EN.S: 5(2)

Maphisa, D.H., Smit-Robinson, H., Underhill, L.G. and Altwegg, R. (2017). 'Management factors affecting densities of common grassland birds of high elevation grasslands of eastern South Africa: Ingula as a Case Study'. Avian Research 8(5). Available at: https://doi. org/10.1186/s40657-017-0063-8 (Accessed: 26 September 2018).

Marnewick, M.D., Retief, E.F., Wright, D.R. and Theron, N.T. (2015). South Africa's Important Bird and Biodiversity Areas Status Report 2015. Johannesburg, South Africa: BirdLife South Africa. Available at: https://www.birdlife.org.za/images/IBA/Documents/IBA\%20 Status\%20Report\%20low\%20res.pdf (Accessed: 26 September 2018).

Mascia, M.B. and Pailler, S. (2011). 'Protected area downgrading, downsizing, and degazettement (PADDD) and its conservation 
implications'. Conservation Letters 4:9-20. Available at: https://doi. org/10.1111/j.1755-263X.2010.00147.x (Accessed: 26 September 2018).

Mascia, M.B., Pailler, S., Krithivasan, R., Roshchanka, V., Burns, D., Mlotha, M.J., Murray, D.R. and Peng, N. (2014). 'Protected area downgrading, downsizing, and degazettement (PADDD) in Africa, Asia, and Latin America and the Caribbean, 1900-2010'. Biological Conservation 169:355-361. Available at: https://doi.org/10.1016/j. biocon.2013.11.021 (Accessed: 26 September 2018).

Mayorquín, A., Valenzuela, S. and Orlando Rangel Ch, J. (2010). 'Evaluación de la efectividad de manejo en reservas naturales de la sociedad civil: una propuesta metodológica' (Assessing management effectiveness in Natural Reserves of Civil Society: a methodological proposal) Caldasia 32:381-397. Available at: https://revistas.unal. edu.co/index.php/cal/article/view/36230 (Accessed: 26 September 2018).

Mesquita, C.A.B. and Weyland Vieira, M.C. (2004). Reservas Particulares do Patrimônio Natural da Mata Atlântica. São Paulo, Brazil: Conselho da Reserva da Biosfera da Mata Atlântica. Available at: http://www.rbma.org.br/rbma/pdf/caderno_28.pdf (Accessed: 26 September 2018)

Mitchell, B.A. (2005). Editorial. PARKS 15(2):1-5. Available at: http:// parksjournal.com/wp-content/uploads/2017/07/parks_15_2.pdf (Accessed: 26 September 2018).

Mitchell, B.A., Fitzsimons, J.A., Stevens, C.M.D. and Wright, D.R. (2018). 'PPA or OECM? Differentiating between privately protected areas and other effective conservation measures on private land'. PARKS 24 (Special Issue):49-60. Available at: https://doi. org/10.2305/IUCN.CH.2018.PARKS-24-SIBAM.en (Accessed: 26 September 2018).

Mitchell, B.A., Walker, Z. and Walker, P. (2017). 'A governance spectrum: Protected areas in Belize'. PARKS 23(1):45-60. https://doi. org/10.2305/IUCN.CH.2017.PARKS-23-1BAM.en

Monteferri, B. and Coll, D. (2009). Conservación Privada y Comunitaria en los Países Amazónicos. Lima, Peru: Sociedad Peruana de Derecho Ambiental (SPDA).

Natural Resource Management Ministerial Council (2005). Directions for the National Reserve System: A partnership approach. Canberra, Australia: Natural Resource Management Ministerial Council. Available at: https://www.environment.gov.au/system/files/pages/35ded9a10a17-47fa-a518-05f7bfe045ce/files/directions.pdf (Accessed: 26 September 2018).

Natural Resource Management Ministerial Council (2009). Australia's Strategy for the National Reserve System 2009-2030. Canberra, Australia: Natural Resource Management Ministerial Council. Available at: http://www.environment.gov.au/system/files/resources/643fb07177c0-49e4-ab2f-220733beb30d/files/nrsstrat.pdf (Accessed: 26 September 2018).

Neugarten, R.A., Langhammer, P.F., Osipova, E., Bagstad, K.J., Bhagabati, N., Butchart, S.H.M., Dudley, N., Elliott, V., Gerber, L.R., Gutierrez Arrellano, C., Ivanić, K.-Z., Kettunen, M., Mandle, L., Merriman, J.C., Mulligan, M., Peh, K.S.-H., Raudsepp-Hearne, C., Semmens, D.J., Stolton, S. and Willcock, S. (2018). Tools for measuring, modelling, and valuing ecosystem services: Guidance for Key Biodiversity Areas, natural World Heritage Sites, and protected areas. Gland, Switzerland: IUCN. Available at: https://doi. org/10.2305/IUCN.CH.2018.PAG.28.en (Accessed: 26 September 2018).

Odendaal, N. and Shaw, D. (2010). 'Conservation and economic lessons learned from managing the NamibRand Nature Reserve'. Great Plains Research 20(1):29-36. Available at: https://www.jstor. org/stable/23782173 (Accessed: 26 September 2018).

Ojidos, F. (2017). Conservação em ciclo contínuo: modelo de gestão para financiamento de Reserva Particular do Patrimônio Natural.
São Paulo, Brazil: Nazaré Paulista. Available at: https://escas.org. br/download/produtos-finais/nazare-15/Flavio-Silva-OJidos.pdf (Accessed: 26 September 2018).

Palmer, M. and Finlay, V. (2003). Faith in Conservation: New approaches to religion and the environment. Washington, DC, USA: The World Bank. Available at: http://siteresources.worldbank. org/INTBIODIVERSITY/214584-1112712965549/20480342/ FaithlnConservationNewApproachesPreface2003.pdf_(Accessed: 26 September 2018).

Pasquini, L., Fitzsimons, J.A., Cowell, S., Brandon, K. and Wescott, G. (2011). 'The establishment of large private nature reserves by conservation NGOs: key factors for successful implementation'. Oryx 45:373-380. Available at: https://doi.org/10.1017/ S0030605310000876 (Accessed: 26 September 2018).

Pellin, P. and Lima Ranieri, V.E. (2016). 'Voluntary preservation on private land in Brazil: characterisation and assessment of the effectiveness of managing Private Reserves of Natural Heritage'. Brazilian Geographical Journal: Geosciences and Humanities Research Medium 7(1):33-52.

Pence, G.Q.K., Botha, M.A. and Turpie, J.K. (2003). 'Evaluating combinations of on- and off-reserve conservation strategies for the Agulhas Plain, South Africa: a financial perspective'. Biological Conservation 112(1-2):253-274. Available at: https://doi. org/10.1016/S0006-3207(02)00413-5 (Accessed: 26 September 2018).

Rissman, A.R. and Butsic, V. (2011). 'Land trust defense and enforcement of conserved areas'. Conservation Letters 4:31-37. Available at: https://doi.org/10.1111/j.1755-263X.2010.00136.x (Accessed: 26 September 2018).

Röttger, C., Strauss, A. and Horstmeyer, N. (eds.) (2016). Nature Conservation in Eastern Europe, Caucasus and Central Asia. Bonn, Germany: Bundesamt für Naturschutz. Available at: https://www. bfn.de/fileadmin/BfN/service/Dokumente/skripten/Skript447.pdf (Accessed: 5 October 2018)

Ruseva, T., Farmer, J. and Chancellor, C. (2016). 'Networking for conservation: Social capital and perceptions of organizational success among land trust boards'. Ecology and Society, 21(2). Available at: https://doi.org/10.5751/ES-08618-210250 (Accessed: 26 September 2018).

Saavedra, B., Simonetti, J.A. and Redford, K.H. (2011). 'Private conservation: the example that the Wildlife Conservation Society builds from Tierra del Fuego'. In: E. Figueroa B. (ed.). Biodiversity Conservation in the Americas: Lessons and Policy, pp. 357-392. Editorial FEN-Universidad de Chile. Santiago, Chile: Besegraf Ltda.

Sayre, R., Roca, E., Sedaghatkish, G., Young, B., Keel, S., Roca, R.L. and Sheppard, S. (eds) (2000). Nature in Focus: Rapid Ecological Assessment. Island Press, Washington, DC.

Selinske, M.J., Coetzee, J., Purnell, K. and Knight, A.T. (2015). 'Understanding the motivations, satisfaction, and retention of landowners in private land conservation programs'. Conservation Letters 8:282-289. Available at: https://doi.org/10.1111/conl.12154 (Accessed: 26 September 2018).

Selinske, M.J., Cooke, B., Torabi, N., Hardy, M.J., Knight, A.T. and Bekessy, S.A. (2016). 'Locating financial incentives among diverse motivations for long-term private land conservation'. Ecology and Society 22(2):7. Available at: https://doi.org/10.5751/ES-09148220207 (Accessed: 26 September 2018).

Selinske, M., Hardy, M., Gordon, A. and Knight, A. (2017). Policy brief for Privately Protected Areas Futures 2017: Supporting the long-term stewardship of privately protected areas. Available at: https://osf.io/ znsdq/download (Accessed: 26 September 2018).

Servicio Nacional de Áreas Naturales Protegidas por el Estado SERNANP, Sociedad Peruana de Derecho Ambiental (2014). 
Documento de trabajo 10: Áreas de Conservación Privada. Peru: SERNANP. Available at: http://www.sernanp.gob.pe/docume nts/10181/255769/\%C3\%81reas-de-Conservaci\%C3\%B3nPrivada-Documento-de-trabajo-10.pdf/b77fd3a7-f235-40fa-839ab60889e343fe (Accessed: 26 September 2018).

Shackleton, C.M., Cundill, G. and Knight, A.T. (2009). 'Beyond just research: experiences from Southern Africa in developing social learning partnerships for resource conservation initiatives'. Biotropica 41:563-570. Available at: https://doi.org/10.1111/j.17447429.2009.00559.x (Accessed: 26 September 2018).

Solano, P. and Wust, W. (2005). Manos para mejores tiempos: experiencias exitosas de conservación en el Perú. Peru: Sociedad Peruana de Derecho Ambiental (SPDA). Available at: https://spda. org.pe/?wpfb_dl=103 (Accessed: 26 September 2018).

South African National Biodiversity Institute (SANBI) (2015). The business case for biodiversity stewardship. A report produced for the Department of Environmental Affairs. Developed by Cumming, T., Driver, A., Pillay, P., Martindale, G., Purnell, K., McCann, and Maree, K. South African National Biodiversity Institute, Pretoria. Available at: https://www.sanbi.org/wp-content/uploads/2018/04/sanbibiodiversity-stewardship-business-case-factsheet.pdf (Accessed: 26 September 2018).

South African National Biodiversity Institute (SANBI) (2016). Lexicon of Biodiversity Planning in South Africa. Beta Version, June 2016. Pretoria, South Africa: South African National Biodiversity Institute. Available at: http://biodiversityadvisor.sanbi.org/wpcontent/uploads/2016/06/2016_06_02-Lexicon.pdf (Accessed: 26 September 2018).

Smith, F., Smillie, K., Fitzsimons, J., Lindsay, B., Wells, G., Marles, V., Hutchinson, J., O'Hara, B., Perrigo, T. and Atkinson, I. (2016). 'Reforms required to the Australian tax system to improve biodiversity conservation on private land'. Environmental and Planning Law Journal 33:443-450. Available at: http://hdl.handle.net/10536/DRO/ DU:30087854 (Accessed: 26 September 2018).

Stolton, S., Hockings, M., Dudley, N., MacKinnon, K., Whitten, T. and Leverington, F. (2007). Management Effectiveness Tracking Tool. Reporting Progress at Protected Area Sites. $2^{\text {nd }}$ Edition. Gland, Switzerland: WWF International.

Stolton, S., Redford, K.H. and Dudley, N. (2014). The Futures of Privately Protected Areas. Gland, Switzerland: IUCN. Available at: https://portals.iucn.org/library/node/44856 (Accessed: 26 September 2018).

Tasos, H., Dieterich, M., Ibisch, P.L., Mihok, B. and Selva, N. (2014). The challenge of implementing the European network of protected areas Natura 2000. Conservation Biology 29(1):260-270. Available at: https://doi.org/10.1111/cobi.12366

Taylor, M.F.J., Fitzsimons, J. and Sattler, P. (2014). Building Nature's Safety Net 2014: A decade of protected area achievements in Australia. Sydney, Australia: WWF-Australia.

Taylor, P., Asner, G., Dahlin, K., Anderson, C., Knapp, D., Martin, R., Mascaro, J., Chazdon, R., Cole, R., Wanek, W., Hofhansl, F., Malavassi, E., Vilchez-Alvarado, B. and Townsend, A. (2015). 'Landscape-scale controls on aboveground forest carbon stocks on the Osa Peninsula, Costa Rica'. PloS One 10: e0126748. Available at: https://doi.org/10.1371/journal.pone.0126748 (Accessed: 26 September 2018)

The Nature Conservancy (TNC) (2018). Private Lands Conservation: Conservation Buyer Program. Arlington, USA: The Nature

Conservancy. Available at: https://www.nature.org/en-us/about-us/ who-we-are/how-we-work/private-lands-conservation/ (Accessed: 26 September 2018).
The Nature Conservancy and Conservation International (TNC and Cl) (2012). Practitioner's Field Guide for Marine Conservation Agreements: Best Practices for Integrating Rights-based Incentive Agreements into Ocean and Coastal Conservation Efforts. Final V2. Narrangansett, Rhode Island: The Nature Conservancy. Available at: http://www.reefresilience.org/wp-content/uploads/Practitioners_ Field_Guide_for_Marine_Conservation_Agreements_2012.pdf

Thompson Jr., B.H. (2004.) The Trouble with Time: Influencing the Conservation Choices of Future Generations, Natural Resources Journal, 44:601. Available at: http://digitalrepository.unm.edu/nrj/ vol44/iss2/13 (Accessed: 26 September 2018).

Toft, R. and Larsen, T.H. (2010). Osa, where the Rainforest Meets the Sea. Zona Tropical Publications.

Tourenq, C., Field, T. and Searle, A. (2016). 'Restoration of Banrock Station Ramsar wetlands, South Australia: over 20 years of successful involvement by a private agribusiness'. In M.J. Mulongoy and J. Fry (eds.) Restoring Life on Earth: Private-sector Experiences in Land Reclamation and Ecosystem Recovery. CBD Technical Series no. 88, pp. 25-36. Montreal, Canada: SCBD. Available at: https:// www.cbd.int/doc/publications/cbd-ts-88-en.pdf (Accessed: 26 September 2018).

United Nations (UN) (2007). United Nations Declaration on the Rights of Indigenous Peoples. Available at: https://www.un.org/ development/desa/indigenouspeoples/declaration-on-the-rights-ofindigenous-peoples.html (Accessed: 26 September 2018).

UN Environment World Conservation Monitoring Centre (UNEPWCMC) (2017). World Database on Protected Areas User Manual 1.5. Cambridge, UK: UNEP-WCMC. Available at: www.wcmc.io/ WDPA_Manual (Accessed: 26 September 2018).

UN Environment World Conservation Monitoring Centre and International Union for Conservation of Nature (UNEP-WCMC and IUCN) (2018). Protected Planet: The World Database on Protected Areas (WDPA) [On-line], October 2018, Cambridge, UK: UNEPWCMC and IUCN. Available at: www.protectedplanet.net

Wilson, K.A., Underwood, E.C., Morrison, S.A., Klausmeyer, K.R., Murdoch, W.W., Reyers, B., Wardell-Johnson, G., Marquet, P.A., Rundel, P.W., McBride, M.F., Pressey, R.L., Bode, M., Hoekstra, J.M., Andelman, S.J., Looker, M., Rondinini, C., Kareiva, P., Shaw, M.R. and Possingham, H.P. (2007). 'Conserving biodiversity efficiently: what to do, where and when'. PLoS Biology, 5: e223. Available at: https://doi.org/10.1371/journal.pbio.0050223

Worboys, G.L., Lockwood, M., Kothari, A., Feary, S. and Pulsford, I. (eds.) (2015). Protected Area Governance and Management. Canberra, Australia: ANU Press. Available at: http://press-files. anu.edu.au/downloads/press/p312491/pdf/book.pdf?referer=372 (Accessed: 26 September 2018) Also available at: https://doi. org/10.26530/OAPEN_569111 and https://doi.org/10.22459/ PAGM.04.2015.

Worboys, G.L. and Trzyna, T. (2015). 'Managing protected areas'. In: G.L. Worboys, M. Lockwood, A. Kothari, S. Feary and I. Pulsford (eds) Protected Area Governance and Management, pp. 207-250. Canberra, Australia: ANU Press. Available at: https:// doi.org/10.26530/OAPEN_569111and https://doi.org/10.22459/ PAGM.04.2015

World Tourism Organization (UNWTO) (2016). The Transformative Power of Tourism: a paradigm shift towards a more responsible traveller. Affiliate Members Global Reports, Volume 14. Madrid, Spain: UNWTO

Young, M.D., Gunningham, N., Elix, J., Lambert, J., Howard, B., Grabosky, P. and McCrone, E. (1996). Reimbursing the future: an evaluation of motivational voluntary, price-based, property-right, and regulatory incentives for the conservation of biodiversity, Parts 1 and 2. Biodiversity series, Paper no. 9. Canberra: Department of the Environment, Sport and Territories. 


\section{Endnotes}

1. www.iucn.org/theme/protected-areas/ publications/best-practice-guidelines

2. www.conservacionpatagonica.org/home.htm\#

3. www.nps.gov/tapr/index.htm

4. www.iucn.org/theme/protected-areas/our-work/ iucn-green-list

5. www.sneeuberg.com/pages/conservation/

6. www.cbd.int/nbsap/

7. www.keybiodiversityareas.org/about

8. www.birdlife.org/worldwide/programme-

additional-info/important-bird-and-biodiversity-

areas-ibas

9. www.ramsar.org/

10. whc.unesco.org

11. www.unesco.org/new/en/natural-sciences/

environment/ecological-sciences/

12. www.conservamospornaturaleza.org/destino/

reserva-ecologica-chaparri/

13. www.fpwc.org/

14. www.fpwc.org/caucasus-wildlife-refuge/

15. /portals.iucn.org/library/node/46447

16. portals.iucn.org/library/node/44188

17. portals.iucn.org/library/node/44114

18. singita.com/region/singita-grumeti/

19. www.chumbeisland.com/

20. caiman.com.br/en/

21. portals.iucn.org/library/node/46476

22. www.eskom.co.za/news/Pages/2018Jun3.aspx

23. www.iucn.org/pa_guidelines

24. papaco.org/moocs/

25. www.environment.gov.za/sites/default/files/

legislations/nema_amendment_act57.pdf

26. www.protectedplanet.net/

27. Www.gbif.org/

28. www.iucnredlist.org/

29. www.nationalredlist.org/

30. www.keybiodiversityareas.org/home

31. earth.google.com/web/

32. earthengine.google.com/

33. www.globalforestwatch.org/

34. www. planet.com

35. www.bushheritage.org.au/

36. www.bushheritage.org.au/places-we-protect/ new-south-wales/naree

37. earthdata.nasa.gov/earth-observation-data/ near-real-time/firms/active-fire-data

38. fires.globalforestwatch.org/home/

39. frepesp.org.br/sim-rppn/

40. www.theconservationlandtrust.org/eng/el_cani. $\mathrm{htm}$

41. www.seasonsinafrica.com/lodges-in-southafrica/kruger-lowveld-lodges/the-outpost-krugernational-park/makuleke-history/

42. www.theislandfoundation.com/

43. www.lafarge.co.ke/4_A_3-Haller_Park

44. www.bushheritage.org.au/

45. /iris.thegiin.org/

46. cmp-openstandards.org/

47. www.miradi.org/

48. asiconservachile.cl/acch/

49. www.protectedplanet.net/c/protected-areas-

management-effectiveness-pame

50. www.landtrustalliance.org/about-us

51. institutolife.org/en/

52. www.thelongrun.org/

53. knowhownonprofit.org/how-to/how-to-set-up-

a-volunteering-programme

54. www.rspb.org.uk/

55. www.natureconservancy.ca/en/

56. www.facebook.com/CREWCitSciZA

57. naankuse.com

58. www.fundacaogrupoboticario.org.br/en/whatwe-do/nature-preserves/pages/nature-preserversalto-morato-public-usage.aspx
59. www.natureconservancy.ca/en/

60. www.fjocotoco.org

61. www.conservamospornaturaleza.org/

62. www.conservamospornaturaleza.org/colabora/ dona-tu-talento/

63. www.conservamospornaturaleza.org/explora/

64. www.conservamospornaturaleza.org/accion/

dona/

65. galianoconservancy.ca/

66. galianoconservancy.ca/walkalong/

67. www.americanprairie.org/

68. www.americanprairie.org/wild-sky-bee

69. www.colorado.gov/statelandboard

70. escas.org.br/download/produtos-finais/

nazare-15/Flavio-Silva-OJidos.pdf

71. thomasfoundation.org.au/the-david-thomaschallenge/

72. busquedas.elperuano.pe/normaslegales/ reconocen-el-area-de-conservacion-privada-lasnaranjas-ub-resolucion-ministerial-no-147-2018minam-1637750-1/

73. iwjv.org/funding-opportunity/north-american-

wetlands-conservation-act-nawca)

74. www. fijiwater.com/company.html

75. www.conservation.org/projects/Pages/

sustainable-development-for-fiji-people-sovi-

basin.aspx

76. www.ecosystemmarketplace.com/

77. www.afoclt.org

78. www.bfn.de/en/activities/national-natural-

heritage.html

79. ec.europa.eu/environment/life/funding/lifeplus.htm

80. chile.wcs.org/Karukinka.aspx

81. www.iucn.org/about/members/national-and-

regional-committees

82. www.borana.co.ke/

83. caiman.com.br/en/ecological-refuge/

84. www.sinaldovale.org/about-us

85. www.sixsenses.com/resorts/laamu/

sustainability

86. www.upm.com/Responsibility/forests/

Biodiversity/Pages/default.aspx

87. federation.edu.au/research/technology-parksand-nanya-station/nanya-station

88. www.banrockstation.com.au/take-5-with-dr-

christophe-toureng

89. www.isvolunteers.org

90. cedarcreek.umn.edu/about

91. www.attenboroughnaturecentre.co.uk/

92. www.mvotma.gub.uy/component/k2/

item/10010680-area-de-manejo-de-habitats-y-o-

especies-esteros-y-algarrobales-del-rio-uruguay-

rio-negro-proyecto-de-ingreso

93. www.segera.com/

94. tahinz.com/our-story/

95. www.wolwedans.com/

96. www.wolwedans.org/

97. www.borana.co.ke/conservancy/

98. maasaimaraconservancies.co.ke/

99. cottars.com

100. www.seedballskenya.com/cottars-wildlife-con-

servation/4594243181

101. www.grootbos.com/en

102. www.fynbos.co.za/

103. caiman.com.br/en/ecological-refuge/

104. www.sospantanal.org.br/

105. cepeam.org.br/

106. www.arocha.org/en/

107. www.norfolkwildlifetrust.org.uk/wildlife-in-nor

folk/churchyards

108. www.caringforgodsacre.org.uk

109. www.jabalmoussa.org/

110. For example see: www.cali.gov.co/dagma/

publicaciones/131788/-sistema-municipal-de- areas-protegidas---simap/

111. www.yolombo-antioquia.gov.co/NuestraAl-

caldia/SaladePrensa/Paginas/SISTEMAS-LO-

CALES-DE-\%C3\%81REAS-PROTEGIDAS-SILAP. aspx

112. geo.sernanp.gob.pe/geoserver/principal.php

113. www.resnatur.org.co

114. www.fundacionpalmaritocasanare.org/

115. www.fundacionpalmaritocasanare.org/proyec-

to/caiman-llanero/ and www.iucn.org/sites/dev/

files/content/documents/palmaritoprivatepas.pdf

116. www.cbd.int/

117. sustainabledevelopment.un.org/

118. www.protectedplanet.net

119. English: wcmc.io/WDPA_Manual; Français:

wcmc.io/WDPA Manual FR ; Español: wcmc.io/

WDPA_Manual_ES; русском: wcmc.io/WDPA_Ma-

nual_RU; عىبرع: www.wcmc.io/WDPA_Ma-

nual_AR

120. protectedplanet.net/country/MX

121. www.environment.gov.au/land/nrs/science/

capad

122. www.landtrustalliance.org/

123. elcn.eu/elcn/summary

124. www.alca.org.au/

125. ampaperu.info/

126. See: fflorestal.sp.gov.br/programa-estadual-

de-apoio-as-reservas-particulares-do-patrimonio-

natural-completa-10-anos/ and frepesp.org.br/

representatividade-2/

127. www.landtrustalliance.org

128. www.landtrustaccreditation.org/index.php

129. reservasprivadas.org.ar

130. www.resnatur.org.co/sobre-resnatur/proyec-

tos-alianzas/proyecto-gef-g5/

131. www.landtrustaccreditation.org/

132. www.gstcouncil.org/gstc-criteria/gstc-destina-

tion-criteria

133. www.landconservationnetwork.org

134. www.lincolninst.edu

135. www.landscapesnamibia.org/sossusvlei-na-

mib/

136. www.lincolninst.edu/

137. www.thelongrun.org/

138. www.namibrand.org/

139. www.pfi.org.cn/en/board/

140. www.laparios.com/

141. www.bfn.de/en/activities/national-natural-heritage.html

142. www.nrt-kenya.org/

143. iucnuk.wordpress.com/projects/putting-na-

ture-on-the-map/

144. www.cbd.int/convention/articles. shtm-

I?a=cbd-02; Translations of the text are available in

Arabic, Chinese, English, French, Russian, Spanish

145. www.cbd.int/doc/c/9b1f/759a/dfcee171bd-

46b06cc91f6a0d/sbstta-22-I-02-en.pdf; other

language versions can be found at: https://www.

cbd.int/meetings/SBSTTA-22 


\section{Glossary}

\begin{abstract}
Additionality: the action of impacts that would not have occurred without an intervention (IUCN Definitions). When used in the context of privately protected areas, it refers to the actions of non-state actors complementing rather than completing state-run protected area systems (that is, governance by government).
\end{abstract}

\section{Appurtenant easement or easement appendant: a right} to use adjoining property that transfers with the land. The parcel of land that benefits from the easement is the dominant tenement. The servient tenement is the parcel of land that provides the easement. The appurtenant easement always transfers with the land unless the owner of the dominant tenement releases it. The land subject to the easement appurtenant is the servient estate, the land benefited the dominant estate. However, if the easement is held incident to ownership of some land, it is an easement appurtenant. Appurtenant easements are usually the only readily available legal tools for implementing easements for PPAs where civillaw systems prevail. Civil-law systems are more widespread than common-law systems which are found only in countries that are former English colonies or have been influenced by the Anglo-Saxon tradition.

Biological diversity/biodiversity: the variability among living organisms from all sources including, inter alia, terrestrial, marine and other aquatic ecosystems and the ecological complexes of which they are part; this includes diversity within species, between species and of ecosystems. ${ }^{144}$

Citizen science: the collection and analysis of data relating to the natural world by members of the general public, typically as part of a collaborative project with professional scientists (Ellwood et al., 2017).

Conservation easement: a deeded transfer of an interest in real property to a qualified charity that results in a tax deduction in exchange for the contribution. The purpose is to conserve or protect the land or its resources for future generations. However, the conservation easement allows owners to retain other private property rights and to live on and use their land. A conservation easement is legally binding. The easement creates a legally enforceable land preservation agreement between a landholder and a government agency. The restrictions of the easement run with the land. Conservation easements are binding on all future owners of the property. For the purposes of PPAs, conservation easement should be enabled by specific legislation as a type of easement in gross (see below) that transfers with the land, or created between two parcels of land through an appurtenant easement.
Covenant: an agreement, contract or written promise between two individuals that frequently constitutes a pledge to do or refrain from doing something. The individual making the promise or agreement is known as the covenantor, and the individual to whom such promise is made is called the covenantee. Covenants are really a type of contractual arrangement that, if validly reached, is enforceable by a court. They can be phrased so as to prohibit certain actions and in such cases, are sometimes called negative covenants. There are two major categories of covenants in the law governing real property transactions: covenants running with the land and covenants for title. A covenant is said to run with the land in the event that the covenant is annexed to the estate and cannot be separated from the land or the land transferred without it. Such a covenant exists if the original owner as well as each successive owner of the property is either subject to its burden or entitled to its benefit.

Easement in gross: an easement that benefits an individual and is not tied to the land. It is a personal right of its holder to a use of another person's land and that is not dependent on ownership of a dominant estate. An easement in gross does not transfer with the property when it is sold. Further the individual that benefits from the easement cannot transfer the easement. An easement in gross should be documented to protect both parties. Putting the easement agreement in writing and defining the extent and duration of the easement can help avoid any future misunderstandings. Utility companies often own easements in gross. For the purposes of PPAs, conservation easements in gross need to be specifically enabled by legislation as a special type of easement that transfers with the land when ownership changes.

Ecotourism: Responsible travel to natural areas that conserves the environment, sustains the well-being of the local people and involves interpretation and education (Leung et al., 2018).

Equitable benefits: refers to the ultimate impact of development efforts on both genders. It implies that the results should be equally accessed and utilised by men and women. Equality of opportunities does not, necessarily, imply that both genders enjoy the same benefits (IUCN Definitions).

Equity: seeks people's access to equal opportunities and the development of basic capacities; this means that the barriers hindering economic and political opportunities, as well as access to education and basic services, should be eliminated, so that the people (women and men of all ages, conditions and positions) may be able to enjoy such opportunities and benefit from them. It means justice; that is, giving each person or group what is rightfully theirs, recognising the specific conditions or characteristics of each person or human group 
(sex, gender, class, religion, age). It is the recognition of diversity, without giving reason for discrimination (IUCN Definitions).

Fee simple: absolute title to land, free of any conditions, limitations, restrictions or other claims against the title, which one can sell or pass to another by will or inheritance. A fee simple title has a virtually indefinite duration. It is also called fee simple absolute. Today, the law presumes an intention to grant an estate in fee simple unless an indication to impose conditions or limitations is clearly stated. It is the most common way real estate is owned in common law countries, and is the most complete ownership interest one can have in real property. Fee simple based independent initiatives in PPAs by themselves are usually non-third-party verifiable and thus their transparency of intent is not always self-evident. Best practices in this case should include the establishment of publicly verifiable conservation restrictions that run with the land, and long-term financial support mechanisms such as dedicated trust funds that provide for future stewardship costs.

Governance: in the context of protected areas, governance has been defined as: "the interactions among structures, processes and traditions that determine how power is exercised, how decisions are taken on issues of public concern, and how citizens or other stakeholders have their say" (Borrini-Feyerabend et al., 2013, p. 10). Governance arrangements are expressed through legal and policy frameworks, strategies and management plans; they include the organisational arrangements for following up on policies and plans and monitoring performance. Governance covers the rules of decision making, including who gets access to information and participates in the decision-making process, as well as the decisions themselves (Borrini-Feyerabend et al., 2004).

Governance authority: the institution, individual, indigenous peoples or communal group or other body acknowledged as having authority and responsibility for decision making and management of an area.

Governance type: governance types are defined on the basis of "who holds management authority and responsibility and can be held accountable" for a specific protected area (Borrini-Feyerabend, 2004).

Indigenous and community conserved areas (ICCAs): natural and/or modified ecosystems, containing significant biodiversity values, ecological benefits and cultural values, voluntarily conserved by indigenous peoples and local communities, both sedentary and mobile, through customary laws or other effective means.

Landholder: in the context of these guidelines we refer to landholders as the main governance bodies responsible for the PPA. As there are at present very few examples of PPAs in the marine biome, these guidelines predominately use this term to encompass all PPAs whatever biome or ecosystem (marine, terrestrial or freshwater) they occur in. We use the term 'landowner' when ownership is clearly relevant to the best practice being discussed.

Land trust: a permanent land conservation institution that aims to protect the lands and waters that define communities and enrich their quality of life. A land trust may accomplish this through establishing and monitoring permanent conservation easements, ensuring that the protections remain in place regardless of who may own the land in the future. A land trust works with landowners to protect the natural values of their property and ensure that the scenic beauty of the area will be maintained for future generations. The protected property may also be donated by landowners, or the trust may purchase the property.

Nature-based tourism: Forms of tourism that use natural resources in a wild or undeveloped form. Nature-based tourism is travel for the purpose of enjoying undeveloped natural areas or wildlife (Leung et al., 2018).

Nature conservation: in this context nature always refers to biodiversity, at genetic, species and ecosystem level, and often also refers to geodiversity, landform and broader natural values. In the context of protected areas, conservation refers to the in-situ maintenance of ecosystems and natural and semi-natural habitats and of viable populations of species in their natural surroundings and, in the case of domesticated or cultivated species, in the surroundings where they have developed their distinctive properties (Dudley, 2008).

Networks: are used in these guidelines to specifically discuss the many private conservation networks of PPA owners that have been set up around the world. Best practices for such networks are discussed in Part B, Section 8 of the guidelines and illustrated in Case Study 8 from Peru.

Rapid Ecological Assessment (REA): of a terrestrial area or region is a flexible, accelerated and targeted survey of vegetation types and species. REAs utilise a combination of remotely sensed imagery, reconnaissance overflights, field data collection, and spatial information visualisation to generate useful information for conservation planning at multiple scales (Sayre et al., 2000).

Revolving fund: a dedicated fund operated by an entity (typically a conservation organisation) for the purpose of purchasing private land and then re-selling it to conservationminded buyers, in the process adding an in-perpetuity protection agreement (e.g. conservation covenant or easement) to protect the conservation value of the property. Proceeds from land sales are used to replenish the fund, enabling continual reinvestment in land protection (see Hardy et al., 2018 a,b,c).

Rightsholders: in the context of protected areas, we refer to 'rightsholders' as actors socially endowed with legal or customary rights with respect to land, water and natural resources. 
Stakeholders: in the context of protected areas, we refer to 'stakeholders' as actors who possess direct or indirect interests and concerns about these areas, but do not necessarily enjoy a legally or socially recognised entitlement to them.

Traditional Ecological Knowledge: is a cumulative body of knowledge and beliefs, handed down through generations of cultural transmission, about the relationship of living beings (including humans) with one another and their environment. Further, TEK is an attribute of societies with historical continuity in resource use practices; by and large, these are non-industrial or less technologically advanced societies, many of them indigenous or tribal (International Development Research Centre, Canada).

Transfer of Development Rights (TDR): A zoning technique used to permanently protect natural and cultural resources including farmland by redirecting development that would otherwise occur on these lands to areas planned to accommodate growth and development. TDR programmes enable landowners to be financially compensated for choosing not to develop some or all of their lands. These landowners are given an option under municipal zoning to legally sever the 'development rights' from their land and sell these rights to another landowner for use at another location. The land from which the development rights have been severed is permanently protected through a conservation easement or other appropriate form of restrictive covenant, and the development value of the land where the transferred development rights are applied is enhanced by allowing for new or special uses, greater density or intensity, or other regulatory flexibility that zoning without the TDR option would not have permitted.

Usufruct: a right in a property owned by another, normally for a limited time or until death. It is the right to use the property, to enjoy the fruits and income of the property, to rent the property out and to collect the rents, all to the exclusion of the underlying owner. The usufructuary has the full right to use the property but cannot dispose of the property nor can it be destroyed. The extent of usufruct is defined by agreement and may be for a stated term, covering only certain stated properties, it could be set to terminate if certain conditions are met, such as marriage of a child or remarriage of a spouse, it can be granted to several people to share jointly, and it can be given to one person for a period of time and to another after some stated event occurs. Since usufructs do not run with the land, but refer only to the right to use and benefit from the property and have limited duration and scope, their use on PPAs should be considered as a transient protection tool, until a more robust and permanent legally binding tool can be implemented. 


\section{Appendix 1: PPAs and other effective area-based conservation measures}

Over the past decade, a new management designation for area-based conservation has emerged. The 2020 Aichi Biodiversity Target 11 from the CBD refers to "protected areas or other effective area-based conservation measures". IUCN has been centrally involved in defining other effective areabased conservation measures (OECMs). As recommended by the CBD in 2018, UNEP-WCMC will begin gathering data on OECMs and integrating them either into the WDPA or a parallel database. One result of this is that private conservation initiatives that meet the definition of an OECM but not a PPA will be eligible to be reported to UNEP-WCMC under the new OECM definition.

\section{What is an 'other effective area-based conservation measure'?}

An 'other effective area-based conservation measure' (OECM) is defined in the draft recommendation to the CBD's Conference of Parties as: "a geographically defined area other than a Protected Area, which is governed and managed in ways that achieve positive and sustained long-term outcomes for the in situ conservation of biodiversity, with associated ecosystem functions and services and where applicable, cultural, spiritual, socio-economic, and other locally relevant values". ${ }^{145}$

\section{Distinguishing PPAs from private OECMs}

The Futures of Privately Protected Areas report (Stolton et al., 2014) and subsequent published guidance from the WCPA PPA Specialist Group (Bingham et al., 2017) made it very clear that PPAs are areas that fit the IUCN protected area definition. A PPA cannot both be an OECM and PPA; if it meets the IUCN protected area definition, it is a protected area. While there are acknowledged issues with reporting of PPAs to national databases and the World Database on Protected Areas (Bingham et al., 2017), this does not impact on the classification of an area.

The draft OECM Guidelines (IUCN, 2018) suggest "The distinguishing criterion is that protected areas should have a primary conservation objective, whereas an OECM should deliver the effective in-situ conservation of biodiversity, regardless of its objectives." Some jurisdictions, including Australia and South Africa, have already determined the types of private land conservation agreements that would qualify as a PPA and OECM on private land categories (Mitchell et al., 2018).
Both private protected areas and private OECMs have potential to complement each other within landscapes and seascapes and to contribute meaningfully to the qualitative and quantitative aspects of Aichi Target 11. Furthermore, OECMs can act as stepping stones to securing PPAs (see Box 9).

\section{Box 9 \\ Moving from OECM to PPA: A South African example}

While there is a clear distinction between OECMs and PPAs, OECMs can be used as stepping stones towards PPA declaration. A private landowner in South Africa was interested in declaring his property, which included 1,900 ha of fragmented mist belt grassland in southern KwaZuluNatal, as a PPA under the biodiversity stewardship programme (see Case Study 10 from South Africa). However, he was hesitant of the government's ability to meet their obligations to support the PPA. Facilitated through BirdLife South Africa, he agreed to first sign a Biodiversity Agreement, which is a lower category under biodiversity stewardship and meets the description of an OECM. After two years, during which time the landowner developed a more secure relationship with the government and NGO partners, he felt comfortable to begin negotiating a nature reserve declaration with the government through BirdLife South Africa (Mitchell et al., 2018). 


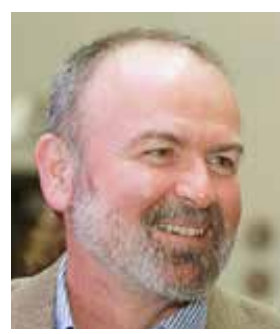

Brent A. Mitchell is Senior Vice President at the Quebec Labrador Foundation Atlantic Center for the Environment based in Massachusetts, USA. In his early career, he worked as a field biologist for America's oldest land trust, The Trustees of Reservations. Since joining QLF in 1987, he has promoted private approaches to nature stewardship through projects and exchanges in more than 50 countries. Brent chairs the Specialist Group on Privately Protected Areas and Nature Stewardship of IUCN's World Commission on Protected Areas. $\mathrm{He}$ is also a founding partner in the (US) National Park Service's Stewardship Institute.

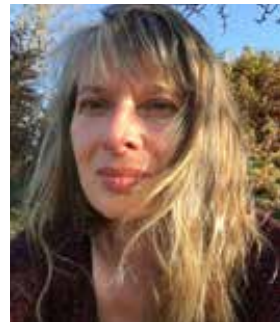

Sue Stolton set up Equilibrium Research with Nigel Dudley in 1991. Sue's interest in PPAs goes back over 20 years. In 1999, she co-edited with Nigel Dudley the book Partnerships for Protection which highlighted new strategies for planning and management of protected areas, stressing the need for protected area governance to encompass a far broader section of society. This was followed by a report on company PPAs for WWF. In 20132014, she led, with Kent Redford and Nigel Dudley, The Futures of Privately Protected Areas report which laid the foundations for these guidelines. Sue and Nigel hope one day to become owners/partners in a PPA, in the meantime they are actively involved in several of the PPAs which form the Dyfi Biosphere Reserve in mid-Wales, UK.

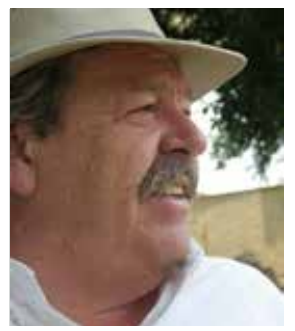

Juan Bezaury-Creel is the Mexico Country Representative and Director for External Affairs for The Nature Conservancy. Prior to joining the Conservancy, Bezaury has worked as country representative and Director of the World Wildlife Fund Mexico Program, as executive director of the Mexican non-profit Amigos de Sian Ka'an in Mexico's Caribbean Coast and with Mexican Government Agencies in charge of protected areas. A native Mexican and architect with a background in urban and regional planning, Bezaury is a member of the National Protected Area Council, the National Forest Commission Biodiversity Fund, the Technical Council of the Monarch Butterfly Fund and the Mesoamerican Reef Fund. He also sits on the board of various Mexican NGOs. Starting in 1974, Bezaury managed a small family PPA. He designed and implemented a transfer of development rights mechanism that limits development in the Sian Ka'an Biosphere Reserve coast and prohibits any development on the most biologically significant land parcels, while allowing the landowners to be compensated through selling their development rights. Further down the road, he collaborated with Mexico's legislators and environmental agencies on defining and establishing a certification process that recognises the value of private and community conservation efforts and has been directly involved in incorporating a sizable portion of Mexico's certified PPAs. He helped establish the Conservancy's Mexico Private Lands Conservation Initiative, together with local conservation partner NGOs, most of which now have developed significant private and social land conservation regional networks.

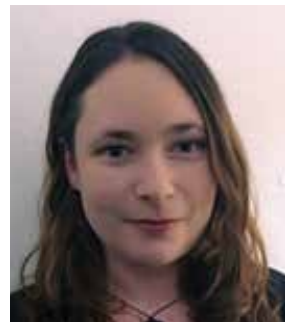

Heather C. Bingham is based at the UN Environment World Conservation Monitoring Centre (UNEP-WCMC), where she has worked on maintaining the World Database on Protected Areas (WDPA) for five years. Heather is responsible for coordinating UNEPWCMC's work on documenting protected areas under the governance of indigenous peoples, local communities and private actors. She has overseen the development of verification processes for data from non-government sources, and the redesign of the WDPA schema to better reflect the diversity of protected areas. These advances have enabled the WDPA to accommodate data directly from a broad range of governance actors, while safeguarding the quality and accuracy of the database. Heather has a Master's in Biology with Conservation and Biodiversity from the University of Sheffield.

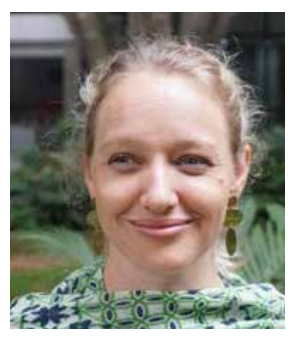

Tracey Cumming is a Technical Advisor with the United Nations Development Programme (UNDP) Biodiversity Finance Initiative (BIOFIN). Hailing from South Africa, Tracey has over fifteen years' experience in biodiversity policy and biodiversity finance, with particular experience in private and communal protected areas, incentives, and mainstreaming biodiversity into national development agenda. Tracey was the Biodiversity Stewardship Policy Advisor with SANBI for a number of years in South Africa, where she led the provision of technical, strategic and legal advice to the national Biodiversity Stewardship programme to national, provincial and NGO stakeholders, including creating a community of practice around biodiversity stewardship across the country. Tracey has an undergraduate degree in Economics and Environmental Science, and a Master's degree in Environmental Science. 


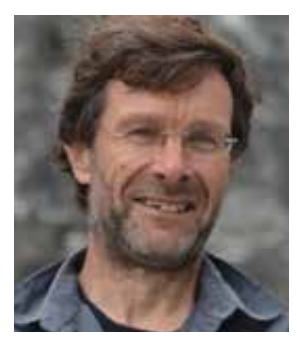

Nigel Dudley has been self-employed most of his professional life and has worked for many years in partnership with Sue Stolton in Equilibrium Research. In that time, he has collaborated with NGOs, UN agencies, international donors and governments in over 70 countries and has written many papers, reports and books. He was editor of Guidelines for Applying Protected Area Management Categories and a co-author of the IUCN best practice guidance on Governance of Protected Areas: From understanding to action, both of which considered issues relating to who is making decisions about protection. Nigel was also part of the team that put together The Futures of Privately Protected Areas report, which forms the background to the current guidelines and reflects a long time interest in private conservation initiatives as a site volunteer, NGO member and advocate. Nigel is an Adjunct Fellow at the University of Queensland and a member of the steering committee of the IUCN World Commission on Protected Areas.

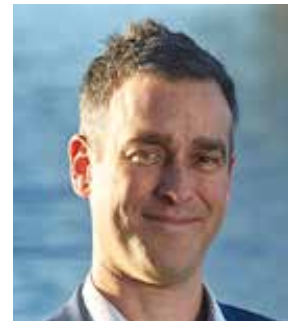

James A. Fitzsimons is Director of Conservation for The Nature Conservancy's Australia Program where he oversees the organisation's conservation planning, science, implementation and policy functions for that country. This includes major conservation programmes in the vast tropical savannas of northern Australia, the diverse central deserts, temperate estuaries of southern Australia, the wetlands and floodplains of the Murray-Darling Basin, and urban landscapes. He is an Adjunct Professor at Deakin University and publishes widely on practical conservation planning and protected area and conservation policy and legislation, and has co-edited four books (Innovation for 21st Century Conservation, Linking Australia's Landscapes, Valuing Nature: Protected Areas and Ecosystem Services and Big, Bold and Blue: Lessons from Australia's Marine Protected Areas). He regularly advises governments on protected area policy issues at state, national and international levels. Prior to joining The Nature Conservancy, he was a senior project officer with the Victorian Environmental Assessment Council developing recommendations for protected areas and public land use along Australia's largest river, the Murray. Prior to this, he was with the Victorian Department of Sustainability and Environment, where he worked on protected area and conservation policy issues, and was instrumental in selecting and purchasing endangered grasslands, grassy woodlands and wetlands for addition to the National Reserve System, significantly increasing the reservation of these ecosystems in south-eastern Australia. He owns, manages and conducts research on a 130 ha PPA containing a range of threatened ecosystems and species in south-eastern Australia.

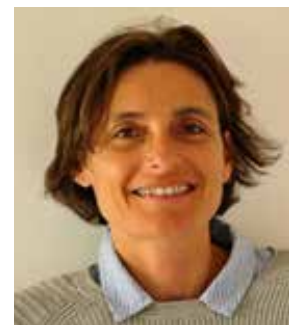

Delphine Malleret-King currently heads The Long Run, a UK based charitable membership organisation which supports a global network of tourism based PPAs, providing a platform for knowledge exchange and advocacy as well as a leading standard for PPAs, the Global Ecosphere Retreats ${ }^{\circledR}$ standard. Delphine studied Development Economics in France, and then carried out her postgraduate studies in marine conservation in the UK and Kenya. Based in Kenya, she has worked for more than 20 years at the interface of protected areas (government, community and PPAs) and communities as a free-lance consultant across Africa and beyond, focused on marine and terrestrial conservation, community engagement and socioeconomic impact monitoring for local, national and international organisations. Prior to joining the Long Run as head of technical assistance in 2014, she helped run the Laikipia Wildlife Forum (Kenya) for six years, bringing together community protected areas, PPAs and other land users under one vision of protecting the integrity of the Ewaso Ecosystem and supporting social and economic development. She relocated to the UK to take up her position as CEO of The Long Run in 2016. 


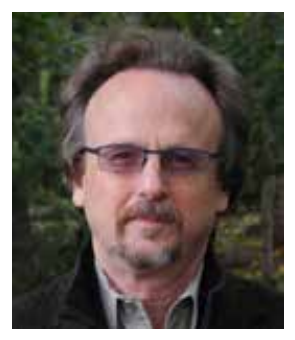

Kent H. Redford is Principal at Archipelago Consulting (archipelagoconsulting.com) established in 2012 and based in Portland, Maine, USA. Archipelago Consulting was designed to help individuals and organisations improve their practice of conservation and has worked with the Global Environment Facility, US National Park Service, Moore Foundation, MacArthur Foundation, Packard Foundation and the American Zoo and Aquarium Association amongst others. Prior to Archipelago Consulting, Kent spent 14 years at the Wildlife Conservation Society (WCS) in New York. Previously he spent five years as head of Science and Stewardship in The Nature Conservancy's Latin American Division where he was in charge of the Parks in Peril programme. He started his career with a decade on the faculty at University of Florida where he co-founded the Program for Studies in Tropical Conservation and the Tropical Conservation and Development Programs. He received his Ph.D. in Biology from Harvard University. Kent has worked on protected area issues throughout his career and was a co-author (with Sue Stolton and Nigel Dudley) of IUCN's 2014 The Futures of Privately Protected Areas. He currently serves as Chair of IUCN's Task Force on Synthetic Biology and Biodiversity Conservation.

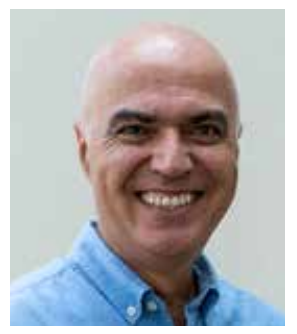

Pedro Solano is a specialist in environmental law with more than 30 years of working experience in conservation issues. During these years, he has developed expertise in different subjects related to natural protected areas, private and community based conservation strategies, ecotourism, climate change and environmental governance. Pedro has directly participated in the design and formulation of the Peruvian legal framework for the natural protected areas system and natural heritage regulations; and launched the Private and Community Based Conservation Initiative in 2005 to promote PPA design and management in Peru, generating an increase of PPAs from just 2 to nearly 250 today. $\mathrm{He}$ is frequently invited to give lectures and conferences and lead courses for national and international universities and agencies. He has published more than 10 books and hundreds of articles on subjects regarding natural heritage, protected areas, voluntary conservation, climate change and environmental law. He is member of both IUCN WCPA and the World Commission on Environmental Law, as well as the IUCN Specialist Group on PPAs. He is currently the Executive Director of the Peruvian Society for Environmental Law (SPDA), a leading organisation in Latin America founded in 1986 where he has worked since 1988. He is also a board member of the Amazon Conservation Association (ACA), the Amazon Basin Conservation Association (ACCA) and the Inter American Association for Environmental Defense (AIDA). 



\section{IUCN}

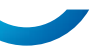

INTERNATIONAL UNION

FOR CONSERVATION OF NATURE

WORLD HEADQUARTERS

Rue Mauverney 28

1196 Gland, Switzerland

Tel: +41229990000

Fax: +41229990002

www.iucn.org

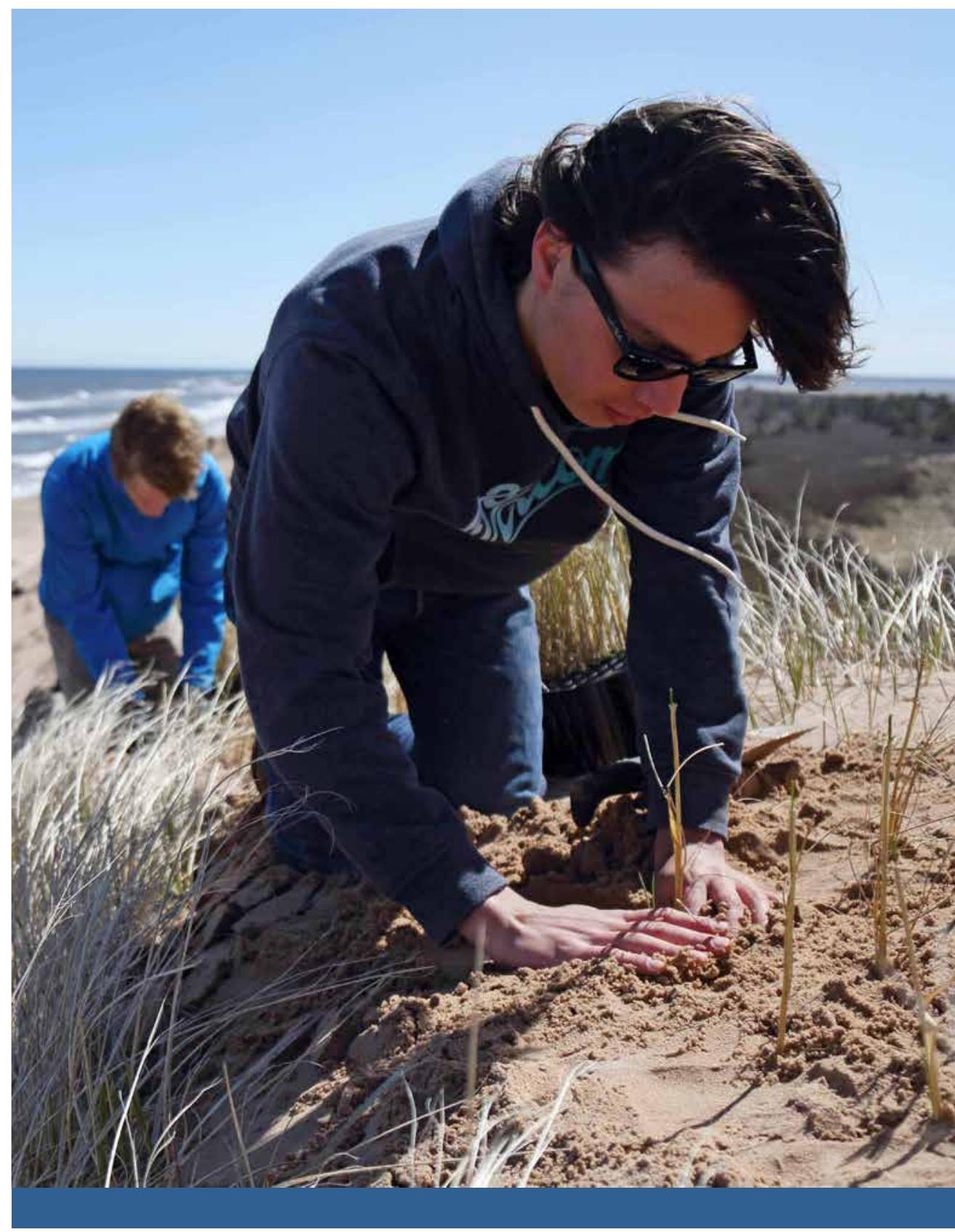

